\title{
Criteria for assessment of patient competence : a conceptual analysis from the legal, psychological and ethical perspectives
}

Citation for published version (APA):

Welie, S. P. K. (2008). Criteria for assessment of patient competence : a conceptual analysis from the legal, psychological and ethical perspectives. [Doctoral Thesis, Maastricht University]. Universiteit Maastricht. https://doi.org/10.26481/dis.20080905sw

Document status and date:

Published: 01/01/2008

DOI:

10.26481/dis.20080905sw

Document Version:

Publisher's PDF, also known as Version of record

Please check the document version of this publication:

- A submitted manuscript is the version of the article upon submission and before peer-review. There can be important differences between the submitted version and the official published version of record.

People interested in the research are advised to contact the author for the final version of the publication, or visit the DOI to the publisher's website.

- The final author version and the galley proof are versions of the publication after peer review.

- The final published version features the final layout of the paper including the volume, issue and page numbers.

Link to publication

\footnotetext{
General rights rights.

- You may freely distribute the URL identifying the publication in the public portal. please follow below link for the End User Agreement:

www.umlib.nl/taverne-license

Take down policy

If you believe that this document breaches copyright please contact us at:

repository@maastrichtuniversity.nl

providing details and we will investigate your claim.
}

Copyright and moral rights for the publications made accessible in the public portal are retained by the authors and/or other copyright owners and it is a condition of accessing publications that users recognise and abide by the legal requirements associated with these

- Users may download and print one copy of any publication from the public portal for the purpose of private study or research.

- You may not further distribute the material or use it for any profit-making activity or commercial gain

If the publication is distributed under the terms of Article $25 \mathrm{fa}$ of the Dutch Copyright Act, indicated by the "Taverne" license above, 
voor Tristan, Isabelle, Frédérique \& Emma 
Criteria for assessment of patient competence: a conceptual analysis from the legal, psychological and ethical perspectives

copyright (C) Welie, S.P.K. 2008

Eijsden, Limburg (NL)

ISBN: 9789090231280

NUR: 820

doctoral dissertation

Universiteit Maastricht, The Netherlands

keywords: health law, ethics, legal psychology, Dutch law, health care practice, human research, autonomy, beneficence, informed consent, decision-making, patient-provider relationship, professional standard, representation, patient competence, criteria, human information-processing, patient values, legitimate triggers for competence assessment, recognisable reasons, supportive situation

cover images: sequence from "Suske en Wiske: de Sputterende Spuiter" (Vandersteen, 1977, p. 1-2) reproduced with kind permission of Standaard Uitgeverij, Antwerpen, Belgium

printed by Fidlar Doubleday Inc.

Davenport, Iowa (USA) 
CRITERIA FOR ASSESSMENT OF PATIENT COMPETENCE

A Conceptual Analysis from the Legal, Psychological and Ethical Perspectives

\section{PROEFSCHRIFT}

ter verkrijging van de graad van doctor

aan de Universiteit Maastricht, op gezag van de Rector Magnificus, Prof.mr. G.P.M.F. Mols volgens het besluit van het College van Decanen, in het openbaar te verdedigen

op vrijdag 5 september 2008 om 12.00 uur

door

Sander Peter Karel Welie 
Promotores:

Prof. mr. F.C.B. van Wijmen

Prof. mr. J.C.J. Dute (Erasmus MC Rotterdam)

Prof. dr. G.A.M. Widdershoven

Beoordelingscommissie:

Prof. dr. G.M.W.R. de Wert (voorzitter)

Prof. dr. H.F.M. Crombag

Prof. mr.dr. P.C. Ippel (Roosevelt Academy)

Prof. mr.dr. J. Legemaate (Vrije Universiteit)

Prof. dr. F.R.J. Verhey

Het aan dit proefschrift ten grondslag liggende onderzoek is mede gefinancierd door de Nederlandse Organisatie voor Wetenschappelijk Onderzoek (NWO projectnummer: 41509116). 


\section{PREFACE}

The research which resulted in the present dissertation, started with a project funded by the Netherlands Organisation for Scientific Research (NWO; project number: 41509116).

It was carried out at the department of health law of the University of Maastricht, and the dissertation was completed at the department of health care ethics and philosophy of the same university, both of which departments have meanwhile merged into the department of metamedica (Faculty of Health, Medicine and Life Sciences). In the course of the research, former and present staff members, whose collegiality has been much appreciated, contributed in diverse manners to the process, not in the last place by providing pleasant company.

Part of the research was performed within the BioMed I project "Decision Making and Impaired Capacity". In that framework, the co-ordinating Centre for Philosophy and Health Care (University of Wales) warmly welcomed the author for four weeks as a visiting professor in Swansea, United Kingdom.

The employees of a hospital ward for geriatric patients and a nursing home ward for psychogeriatric patients, where empirical research took place (cf. Chapter 3), are thanked for giving the author the opportunity to gain a perception of the way in which the concept of patient competence is dealt with -or, rather, does not play an important part- in daily health care practice.

The Dutch National Foundation of Patient Advocates in Mental Health Care, the author's current employer, kindly allowed a two-week study leave in order to make the manuscript ready for being printed. The author greatly acknowledges Standaard Uitgeverij for its permission to reproduce a sequence from "Suske en Wiske" on the cover. Lastly, Chapters 2 through 7 have been published previously in the following journals and books (see below for bibliographic information). The author wishes to express his gratitude for the permission granted by the publishers of these journals and books to reprint these publications in this volume in slightly modified format and, in case of Chapter 6, English translation.

Chapter 2: Welie, S. P. K., \& Berghmans, R. L. P. (2006). Inclusion of patients with severe mental illness in clinical trials: Issues and recommendations surrounding informed consent. CNS Drugs, 20(1), 67-83. 
Chapter 3: Welie, S. (2008). Patient incompetence in the practice of old age psychiatry: The significance of empirical research for the law. In G. Widdershoven, J. McMillan, T. Hope \& L. v.d. Scheer (Eds.), Empirical Ethics in Psychiatry (pp. 231-247). Oxford/New York: Oxford University Press.

Chapter 4: Welie, J. V. M., \& Welie, S. P. K. (2001). Patient decision making competence: Outlines of a conceptual analysis. Medicine, Health Care and Philosophy, 4(2), 127-138.

Chapter 5: Welie, S. P. K. (2001). Criteria for patient decision making (in)competence: A review of and commentary on some empirical approaches. Medicine, Health Care and Philosophy, 4(2), 139-151.

Chapter 6: Welie, S. P. K. (2002). Wilsbekwaamheid in de gezondheidszorg. In: P. J. van Koppen, D. J. Hessing, H. L. G. J. Merckelbach \& H. F. M. Crombag (Eds.), Het Recht van Binnen: psychologie van het recht (pp. 85-106). Deventer: Kluwer.

Chapter 7: Welie, S. P. K., Dute, J., Nys, H., \& Wijmen, F. C. B. van (2005). Patient incompetence and substitute decision-making: An analysis of the role of the health care professional in Dutch law. Health Policy, 73(1), 21-40.

Maastricht, Sunday 29 June 2008 


\section{TABLE OF CONTENTS}

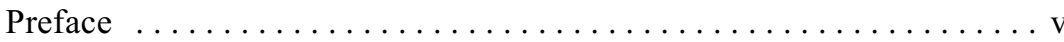

Table of Contents ....................... vii

1. Overview ..............................

S.P.K.Welie

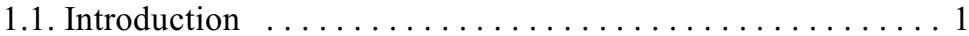

1.1.1. Initial sketch of the subject matter . . . . . . . . . 1

1.1.2. Lack of clear, unambiguous criteria ........... 1

1.1.3. Multi-disciplinary approach ............ 2

1.1.4. Outline of this dissertation ...............4

1.1.5. Starting-points: task-specificity and legal

consequences according to the Dutch Civil Code ... 4

1.1.6. Research questions . . . . . . . . . . . . . . . . 5

1.1.7. Methods ................... 8

1.1.8. Central thesis ..................8

1.1.9. Focus on the care context (as distinct from the research context) ................ 9

1.2. Structure of this overview $\ldots \ldots \ldots \ldots \ldots \ldots$

1.3. The background of two competing ethical principles . . . 10

1.3.1. Historical background . . . . . . . . . . . . 10

1.3.2. Beneficence . . . . . . . . . . . . . . . . . 11

1.3.3. Autonomy ...................... . . 12

1.3.4. Informed consent . . . . . . . . . . . . . . . 14

1.3.5. Relevance of patient competence as a function of the weight of autonomy . . . . . . . . . . . . . . 14

1.3.6. Three stipulative definitions . . . . . . . . . 15

1.3.7. Possible errors in competence assessment . . . . . . 15

1.4. Legal framework . . . . . . . . . . . . . . . . . 15

1.4.1. Legal regulations . . . . . . . . . . . . . . . . . . 15

1.4.2. Legal consequences of patient competence versus incompetence ................... 16

1.4.3. The odd exception of the (Dutch) Special Admissions into Psychiatric Hospitals Act . . . . . 17

1.5. Various criteria for assessment of patient competence . . . 18

1.5.1. Statutory definition of patient competence . . . . . . 18

1.5.2. Three kinds of standards discussed in the literature. . 18

1.6. Problems in competence assessment due to neglect of the concept's normative character . . . . . . . . . . . . 19 
1.6.1. Impediments to finding criteria . ............ 19

1.6.2. The underlying norm in competence assessment . . . 21

1.6.3. The need for an open norm .............. 22

1.7. Individuality and knowability of patient values ....... 22

1.7.1. Ontological and epistemological dimensions in relation to patients' values .............. 22

1.7.2. Implications for competence assessment . ....... 24

1.7.3. Catch-22 in competence assessment .......... 25

1.7.4. A practical solution .................. 26

1.8. Preconditions safeguarding the normative character of patient competence ...................... 27

1.8.1. Consensus about preconditions . . . . . . . 27

1.8.2. The assumption of competence . . . . . . . . 27

1.8.3. Task-specificity of competence ............. 29

1.8.4. The process character of competence .......... 29

1.8.5. Variability of the threshold of competence ....... 30

1.9. Process standards as the most suitable approach ...... 30

1.9.1. Process standards suit all preconditions ....... 30

1.9.2. The MacArthur approach ................ 31

1.10. Plea for a process standard called "recognisable reasons" . 32

1.10.1. The danger of quantitative test scores . . . . . . . 32

1.10.2. Recognisable reasons .................. 32

1.10.3. Relevance of the outcome of the decision ....... 33

1.11. Limited psychological validity of process standards .... 35

1.11.1. How do process standards relate to everyday choice behaviour? ................... 35

1.11.2. Unclarity of underlying values ........... 35

1.11.3. Inconsistency and unconsciousness of informationprocessing. ...................... 35

1.11.4. Being involved in the decision-making, is not identical to being competent to decide ........ 36

1.11.5. The importance of legitimate triggers for competence assessment and of due situational

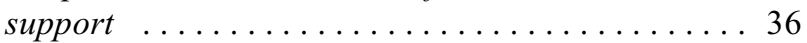

1.12. Patient competence as an ethical-anthropological notion . 38

1.12.1. An axiomatic aspect of patient competence ..... 38

1.12.2. The assumption of competence as a fiction of law . . 39

1.13. A closer look at the legal framework ............ 40

1.13.1. Legal grounds for sidestepping competence assessment .................... 40

1.13.2. Legitimate triggers for competence assessment . . . 40

1.13.3. "The complete picture" ............... 43

1.14. Conclusion ........................... 43 
2. Inclusion of patients with severe mental illness in clinical trials:

Issues and recommendations surrounding informed consent $\ldots 55$

S.P.K Welie \& Berghmans

2.1. Abstract ........................... 55

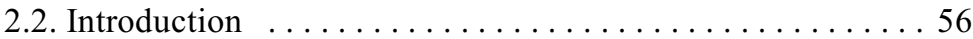

2.3. Historical Background to Ethics in Research ......... 57

2.4. Legal and Ethical Documents Developed to Govern Human Research . . . . . . . . . . . . . . . . . . . . . . . . 59

2.4.1. The Documents . . . . . . . . . . . . . . . . . . . . . . 59

2.4.2. Adherence to Norms ..................66 60

2.5. The Example of the Dutch Regulation of Human Research . 61

2.5.1. Outline of the Law . . . . . . . . . . . . . . . . 62

2.5.2. Substitute Consent ...................66 63

2.5.3. Therapeutic and Non-Therapeutic Research ...... 64

2.6. Comparison with Mechanisms of Informed Consent in

Other European Countries .................... 65

2.6.1. Belgium .........................6 65

2.6.2. France ..........................66 66

2.6.3. Germany .........................667 67

2.6.4. England and Wales ...................68 68

2.7. Therapeutic Misconception ................... 69

2.8. Mental Capacity . . . . . . . . . . . . . . . . . . . 70

2.8.1. Starting Points . . . . . . . . . . . . . 70

2.8.2. Criteria ......................... 71

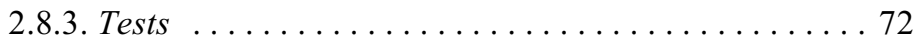

2.9. Discussion ......................... 72

2.9.1. Seeking a Balance .................... 73

2.9.2. Enhancing Mental Capacity ............... 74

2.10. Conclusion .......................... 75

2.11. Notes ............................... 76

3. Patient incompetence in the practice of old age psychiatry: The significance of empirical research for the law . . . . . . . . . 79 S.P.K. Welie

3.1. Abstract .............................. 79

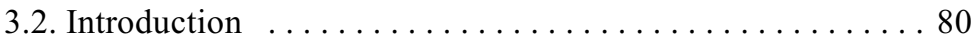

3.3. The relationship between empirical research and the law . 882

3.4. Patient competence in Dutch law ................. 84

3.5. Research into criteria of patient decision-making competence ......................... 86

3.6. Development of the research $\ldots \ldots \ldots \ldots \ldots \ldots . \ldots 87$ 
3.7. Results ... . . . . . . . . . . . . . . . . . . . . 89

3.8. Conclusion ......................... 92

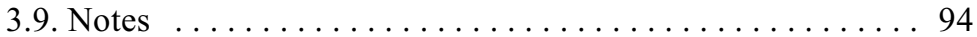

4. Patient decision-making competence: Outlines of a conceptual analysis ................................ 95 J.V.M. Welie \& S.P.K. Welie

4.1. Abstract ............................ 95

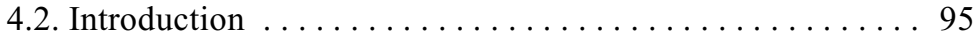

4.3. Towards a definition of competence ........... 97

4.4. Patient autonomy and decision-making competence ..... 99

4.5. The process of making decisions about one's own health(care) ........................ 102

4.6. Paternalism in competency determinations $\ldots \ldots \ldots \ldots 105$

4.7. The abilities involved in PDMC . . . . . . . . . . 107

4.8. Conclusions .......................... 111

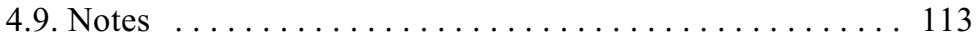

5. Criteria for patient decision-making (in)competence: A review of and commentary on some empirical approaches .......... 119 S.P.K. Welie

5.1. Abstract .............................. 119

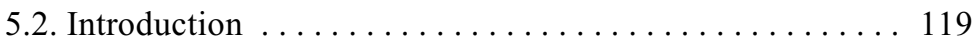

5.3. Four elements of competence .............. 123

5.4. Psychological (in)capacities underlying Patient DecisionMaking (In)competence: The negative approach ..... 124

5.5. Psychological (in)capacities underlying Patient DecisionMaking (In)competence: The positive approach . . . . 127

5.5.1. Tests of functional capacities . . . . . . . . . . 127

5.5.2. Tests of cognitive functioning . . . . . . . . . 128

5.5.3. Tests of specific PDMC issues ............ 129

5.6. Problems with PDMC assessment and initial sketch of possible solutions . . . . . . . . . . . . . . . 132

5.6.1. The concept of a supportive situation ......... 133

5.6.2. Emotions, and competence as a presumption or fiction of law ...................... 134

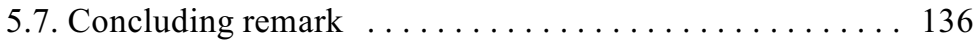

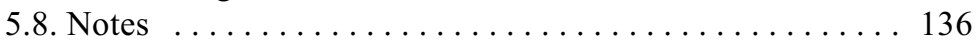

6. Patient competence in health care: Psychological considerations . . 143 S.P.K. Welie

6.1. Abstract ............................ 143

6.2. Introduction ......................... 144 
6.3. Legal consequences of competence versus incompetence . 145

6.4. Possible representatives . . . . . . . . . . . . . . . . . . . 146

6.5. Competence assessment in practice . . . . . . . . . . 147

6.6. The importance of criteria of competence . . . . . . . . 148

6.6.1. Social-psychological processes . . . . . . . . . . . . 149

6.6.2. The actor-observer divergence . . . . . . . . . . . 149

6.6.3. The self-serving bias . . . . . . . . . . . . . . . 149

6.6.4. Confirmation bias .................... 150

6.7. Criteria of competence .................... 151

6.7.1. The ability to determine one's will .......... 151

6.7.2. The ability to judge one's interests at hand reasonably ......................... 152

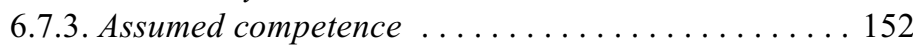

6.7.4. Decisional capacity .................... 153

6.7.5. Competence as "measured" by tests . ......... 154

6.8. Psychological critique of decisional capacity as criterion of competence . . . . . . . . . . . . . . . . . . 155

6.8.1. The conscious character of information-processing . 155

6.8.2. Consistency of information-processing . . . . . . 157

6.9. Emotionality as an alternative? . . . . . . . . . . . . 159

6.9.1. A functional analysis of emotions . . . . . . . . 160

6.9.2. Limitations . . . . . . . . . . . . . . . . . . . . . 160

6.10. Psychological critique of the use of test scores as a measure of competence ................... 162

6.10 .1 . The vignette method . ................. 162

6.10.2. Psychometric requirements .............. 164

6.11. The normative character of the concept of competence . 166

6.12. Conclusion ........................... 168

6.13. Recommended Literature . . . . . . . . . . . . . . . . 169

6.14. Notes . . . . . . . . . . . . . . . . . . . . . . . . . . . . . . . . . 169

7. Patient incompetence and substitute decision-making: An analysis of the role of the health care professional in Dutch law ...... 175 S.P.K. Welie, J. Dute, H. Nys \& F.C.B. van Wijmen

7.1. Abstract ............................. 175

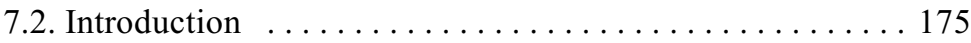

7.3. Legal concepts related to, but distinct from patient competence ............................. 179

7.3.1. Patient competence versus criminal responsibility . . 179

7.3.2. Patient competence versus legal capacity ........ 180

7.4. The basics of the Dutch model ................ 182

7.4.1. Explanation of the legal framework ......... 182

7.4.2. Representatives for the incompetent patient ..... 182 
7.4.3. Legal consequences of competence versus incompetence .................. 186

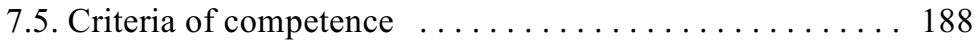

7.5.1. Statutory criteria of competence . . . . . . . . . . 188

7.5.2. Literature on criteria of patient competence . . . . . 189

7.5.3. On tests for competence assessment . . . . . . . . . 191

7.6. Preconditions of competence assessment . . . . . . . . . 192

7.7. Beyond the procedural role of the health care professional 195

7.7.1. Preparation of the decision by the health care professional .................... 195

7.7.2. Decision-making on behalf of the patient . . . . . . 197

7.7.3. Implementation of the decision . . . . . . . . . . . . 199

7.8. Discussion and conclusions . . . . . . . . . . . . . 201

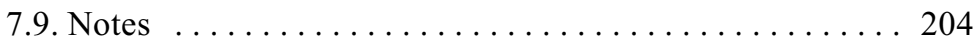

Bibliography ............................ 209

Author Index . . . . . . . . . . . . . . . . . . . . . . 243

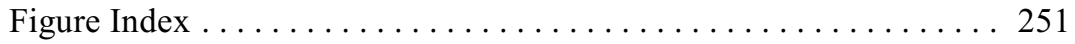

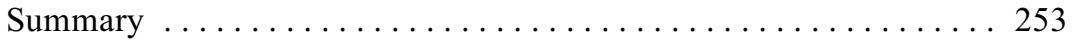

Abstract ................................ 259

Uittreksel .............................. 260

Dankwoord ........................... 261

Curriculum Vitae $\ldots \ldots \ldots \ldots \ldots \ldots \ldots \ldots$

Stellingen ............................ 265 


\title{
1. OVERVIEW
}

\author{
S.P.K.Welie
}

Zoals steeds is het in het recht zelden zwart-wit. (As always, it is seldom black-and-white in law.)

(Jörg \& Kelk, 1988, p. 144)

\subsection{INTRODUCTION \\ 1.1.1. Initial sketch of the subject matter}

For about three decades (cf. Roth, Meisel, \& Lidz, 1977), patient competence has been the subject of continuous discussion and academic research. The interest in this concept is explained by its pivotal place in statutory legal models of patient decision-making, which place is the result of the importance attached to the principle of respect for patient autonomy (or self-determination ${ }^{1}$ ) in health law and health care ethics. Especially -but not exclusively- in the fields of psychiatry, psychogeriatrics and care of the mentally retarded, doubts may arise among health care professionals and other persons involved as to the patient's decision-making competence. The consequences of competence assessment are potentially drastic, i.e. respecting the patients' decisions or overruling them. Therefore, a strong need for criteria is felt by those working in these fields, whether as health care professionals or as lawyers, ethicists or other relevant professionals. This felt need is understandable given the fact that statutory law defines patient competence in terms of an open norm. Criteria are hoped to provide the assessor of competence with the necessary guidance.

\subsubsection{Lack of clear, unambiguous criteria}

The legal, psychological and ethical literature, however, reveals a myriad of different, mutually incompatible definitions, approaches and criteria. Publications often end with the recommendation that more research ought to take place. The only topic of agreement among authors, really, is consensus about dissensus on criteria for assessment of patient competence. Formulating such criteria is apparently rather difficult. Empirical 
research has shown that in the practice of health care, explicit assessments of patient competence are hardly ever made; besides, the number of complaints by psychiatric patients on declarations of incompetence is negligible as compared to that number on compulsory interventions, and competence assessment has produced remarkably little case law.

On the one hand, these findings could mean that literature, health care practice and judicial procedures are just backward in relation to current state of the art legal regulation and ethical theory. On the other, they could also signify that the concept of competence is inherently problematic in nature from a theoretical viewpoint. Either way, a closer conceptual analysis of patient competence seems justified. Such an analysis is the subject of this dissertation.

\subsubsection{Multi-disciplinary approach}

For such an analysis to do justice to the issue, it must be multidisciplinary. After all, several academic perspectives are at the core of the subject, three of which will now be discussed. Omitting one of these three academic disciplines altogether would necessarily leave the analysis incomplete and ultimately useless. At the same time, it would obviously be beyond the scope of a dissertational research project to give an exhaustive treatment of these disciplines insofar as they relate to patient competence. Let us therefore explain not only why the three disciplines are relevant, but also what purposes they serve in this dissertation. Firstly, there is the law, which forms at least part of the reason why the concept of competence attracts so great a deal of interest. The law provides a rationale to the concept; moreover, it gives detailed legal consequences of competence versus incompetence, and a procedural context. In this dissertation, law, its primary discipline, is used for the initial definition of the concept of patient competence and for the statutory regulations that make up its context. The legal concept of competence functions as a starting-point throughout the dissertation. Unless stated otherwise, the Dutch legal system serves as the point of departure for our analysis. With regard to the present subject, the Civil $\operatorname{Code}^{2}$ constitutes the main source of regulation. The Civil Code contains the legal position of patients who receive voluntary care. In general, this dissertation does not pay any attention to the theme of third-parties' interests. In other words, it is herein assumed that the only interests involved in the decision-making, are those of the patient whose competence may have to be assessed. Furthermore, the legal position of 
minors is generally left aside, as are various exceptional situations, like time emergencies.

Secondly, a patient's competence or incompetence is connected to his $^{3}$ mental capacities, cognitive abilities, psychopathology, informationprocessing, preferential and decision-making behaviour, and deliberation and communication within the relationship with the health care professional and other persons possibly concerned, thus involving the domain of psychology, more in particular the fields of psychonomics, clinical psychology, psychodiagnostics, neuropsychology, personality theory and social psychology. In this dissertation, psychology is of help in listing relevant aspects of human cognition and in elaborating possible criteria of patient competence. Furthermore, it serves to make sure that the gap between normative criteria for competence assessment on the one hand and the psychological reality of human information-processing, decision-making and choice behaviour on the other is not too big. This discipline is also useful in pointing to the psychometric limitations of tests. Lastly, psychology prompts us to have a keen eye for the role of situational factors in competence assessment, including the behaviour of the one doing the assessment: like all human behaviour, patient behaviour during an assessment of competence is always the resultant of an interaction between personal factors and situational factors.

Thirdly, ethics can shed light on the subject. Among other things, it owes its relevance to the fact that a basic prerequisite of the law is that it be ethical. In addition, ethics, just as jurisprudence, legal theory and philosophy of law, systematically theorises concepts underlying the law, like human dignity, freedom, equality, justice, responsibility, reasonableness, respect, privacy, integrity, identity, interests, authenticity, personhood and conscience. In this dissertation, ethics provides a description of the underlying principles of beneficence and autonomy. It also helps us to bear in mind the normative character of the concept of competence. Most importantly, ethics is used because of two philosophical aspects of it, namely the methods of philosophical reflection and of logical analysis: the former method is used for making more explicit the meaning and the problematic aspects of legal concepts and rules, and for translating technical jargon to a "common sense" level in order to be able to relate the different disciplines to each other; the latter method is used for laying open the implications of the argument's various ingredients. 


\subsubsection{Outline of this dissertation}

The dissertation at hand consists of a collection of six papers, offering a closer, multi-disciplinary analysis of the concept of patient competence, supplemented by the present overview. On account of these papers' having been published as separate publications (see Preface - p. v), there is a certain overlap between the various chapters, notably when it comes to a description of preconditions of competence assessment and the legal consequences thereof.

This overview chapter is a "rational reconstruction" of its author's quest for -generally speaking- criteria for assessment of patient competence and -specifically speaking- answers to the research questions to be mentioned below. The word rational reconstruction is used to express that the chapter does not have the character of a factual report, chronologically describing all the activities undertaken by the researcher, but that it is a representation of the researcher's work attempting to expound the eventual argument in a comprehensible and convincing way (cf. Crombag, de Wijkerslooth, \& Cohen MJ, 1977, p. 14, 44).

\subsubsection{Starting-points: task-specificity and legal consequences according to the Dutch Civil Code}

During this quest for criteria, two basic starting-points have remained unchanged. The first starting-point, referred to as the task-specific conception of competence, means that competence assessment should not be conceived as an "all or nothing" judgment, implying that a patient is generally competent or generally incompetent, but that it should be conceived as a specific judgment of whether or not the patient is, right now, able to fulfil the concrete task that is facing him, e.g. choosing to accept or to refuse a certain health care intervention proposed to him by the professional. ${ }^{4}$

The legal consequences attached by the Dutch Civil Code to competence versus incompetence, form the second starting-point. Basically, these consequences are firstly that a free and informed choice of a competent patient is decisive, irrespective of its consequences, and secondly that someone else should make a substitute decision on behalf of an

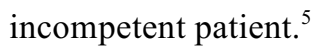




\subsubsection{Research questions}

The main question guiding the research for this dissertation, reads as follows:

\section{How ought patient competence to be assessed?}

In the course of the dissertation research, this leading research question has developed itself, in that several aspects thereof have demanded particular attention. It can therefore be divided into the following thirteen sub-questions, numbered "a" through "m".

The order in which the sub-questions are presented below, gives a rough outline of the overview which this first chapter will provide, although not all of the sub-questions are treated herein. More specifically, Chapter 1 does not go into sub-question " $\mathrm{k}$ ", on emotionality; ${ }^{6}$ however, attention is paid to this sub-question in Chapters 5 (sub-section 5.6.2) and 6 (section 6.9) of this volume. Indeed, immediately following each sub-question cross-references are listed to other chapters where that sub-question is addressed at greater length.

In addition, bibliographic references to other authors who have written about the particular sub-question, are included. The varying numbers of such bibliographic references are indicative of the relative amount of attention that each of these sub-questions has received in the literature so far.

-a What is the rationale of patient competence?

See Chapters 2 ((sub-)sections $2.3 \& 2.9 .1)$ and 4 of this volume for more information on this sub-question.

Cf. also: Faden, Beauchamp, \& King, 1986; Beauchamp, 1991; Elliott, 1991; Ogletree, 1995; Wettstein, 1995.

-b What is the relevance of patient competence?

See Chapters 3 (section 3.7) and 7 (sections $7.7 \& 7.8$ ).

Cf. also: President's Commission for the Study of Ethical Problems in Medicine and Biomedical and Behavioral Research, 1982; Law Commission, 1991; Law Commission, 1993a; Law Commission, 1993b; Law Commission, 1993c; Madigan, Checkland, \& Silberfeld, 1994; Law Commission, 
1995; Checkland \& Silberfeld, 1995; Checkland \& Silberfeld, 1996; Pepper-Smith, Harvey, \& Silberfeld, 1996; Schermer, 2001; Bielby, 2005; Stoppe \& European Dementia Consensus Network, 2008.

-c What legal consequences are at stake in competence assessment?

See Chapters 2 (sections $2.5 \& 2.6$ ), 6 (section 6.3) and 7 (subsection 7.4.3).

Cf. also: Gevers, 1987; Blankman, 1990; van Wijmen, 1990;

Legemaate, 1994; van Veen, 1998; Leenen \& Gevers, 2000.

-d With the help of what criteria can patient competence be assessed?

See Chapters 2 (sub-section 2.8.2), 5, 6 (section 6.7) and 7 (section 7.5).

Cf. also: Roth et al., 1977; Appelbaum, Mirkin, \& Bateman, 1981; Appelbaum \& Roth, 1981; Appelbaum \& Roth, 1982; Drane, 1984; Drane, 1985; Gutheil \& Bursztajn, 1986; van de Klippe, 1990; Legemaate, 1992; Berghmans, 1992; Ministerie van Justitie, 1994; White, 1994; Office of the Public Guardian and Trustee - Ontario Ministry of the Attorney General, 1996; Haekens, 1998; British Medical Association \& Law Society, 2004; Koninklijke Nederlandsche Maatschappij tot bevordering der Geneeskunst, 2004, p. 91-92, 99-101, 117 ff.; Hondius, Zuijderhoudt, \& Honig, 2005; Knuiman, Tholen, \& van Wijmen, 2006; Spanjaard, 2006, p. 2-3; NVVA beroepsvereniging van verpleeghuisartsen en sociaal geriaters, 2008; Hughes, 2008.

-e What are problems in competence assessment?

See Chapters 4 (sections 4.4, 4.5 \& 4.6), 5 (section 5.6), 6 ((sub-)sections 6.8, 6.9.2, 6.10\& 6.11) and 7 (section 7.7).

Cf. also: Freedman B, 1981; Culver \& Gert, 1990; Pincoffs, 1991.

-f What is the underlying norm in competence assessment? 
Cf.: Meisel, Roth, \& Lidz, 1977; President's Commission for the Study of Ethical Problems in Medicine and Biomedical and Behavioral Research, 1982, p. 27.

-g What preconditions should an assessment of competence meet?

See Chapters 2 (sub-section 2.8.1) and 7 (section 7.6).

Cf. also: Buchanan \& Brock, 1990; Weisstub, 1990;

Berghmans, 1992; Thomas Grisso \& Appelbaum, 1998.

-h Which of the available criteria for competence assessment best match(es) accepted preconditions?

-i Can patient competence be objectively measured by means of tests or test-like instruments?

See Chapters 2 (sub-section 2.8.3), 5 (sub-section 5.5.3), 6 (section 6.10) and 7 (sub-section 7.5.3).

Cf. also: Murphy \& Clare, 1995; Kapp \& Mossman, 1996; Glass, 1997; Grisso, Appelbaum, \& Hill-Fotouhi, 1997; Gouwenberg, Jonker, Smit, \& Schmand, 1997; Biesaart, Hubben, van Gemert, \& Oostra, 1997; Biesaart, Hubben, \& van Gemert, 2000; Vellinga, 2006.

-j How do the criteria of patient competence that best match accepted preconditions, relate to the psychological reality of human information-processing, decision-making and choice behaviour?

See Chapter 6 (section 6.8).

Cf. also: Berghmans, 2000; Leenen \& Gevers, 2000.

-k What role does emotionality play in patient competence?

See Chapters 5(sub-section 5.6.2) and 6 (section 6.9).

Cf. also: Bursztajn, Harding, Gutheil, \& Brodsky, 1991;

Silverman, 1997; Appelbaum, 1998; Charland, 1998a;

Charland, 1998b; Elliott, 1998; Charland, 1998c; Berghmans, 2000; Frijda, 2002. 
-1 How can the patient be supported when his competence is being assessed?

See Chapters 2 (sub-section 2.9.2), 5 (sub-section 5.6.1) and 6 (section 6.6).

$-\mathrm{m}$ When is an assessment of patient competence indicated?

See Chapter 3 (section 3.7).

Cf. also: Ministerie van Justitie, 1994; Schermer, 2001;

Koninklijke Nederlandsche Maatschappij tot bevordering der

Geneeskunst, 2004, p. 100-101, 117-118; Koninklijke

Notariële Beroepsorganisatie, 2006.

\subsubsection{Methods}

The methods used in this dissertation include the following: 1) literature study of legal, psychological and ethical sources; 2) qualitative empirical research, as described in Chapter 3 of this dissertation; and 3) multidisciplinary conceptual analysis, as exemplified earlier in the introduction.

\subsubsection{Central thesis}

The quest results -among other things- in a clarification of why it is so hard to formulate suitable criteria, which has to do with the normative character of the concept of patient competence; it also leads to a demarcation of the situations where an assessment of patient competence is appropriate and to assessment criteria that do justice to the character of the concept, called the recognisable reasons approach.

The central thesis of this dissertation is, thus, that procedural competence assessment, on the basis of explicit criteria, should be reserved for exceptional situations only. By "procedural competence assessment" is meant any assessment of patient competence with the goal of determining whether or not the decisional power in the matter in question has to be transferred to someone else, who can act as a representative of the patient. $^{7}$ 


\subsubsection{Focus on the care context (as distinct from the research context)}

Patient competence does not only play a role in decision-making on patient care, but also in decision-making on participation in scientific research. The research context is treated in the second chapter of this dissertation. The other publications -and the main body of the present overview- specifically address patient competence in the care context, notably care of voluntary patients. In what follows, an impression is given of the contents of the publications composing this dissertation, and their interrelationship is explained. How this will happen, can be read next.

\subsection{Structure of this overview}

In exposing the interrelationship between the above-mentioned publications, the present overview loosely follows the research questions outlined in the section entitled Introduction, as was said before. After going into the historical, ethical and legal background of the concept of patient competence (section $1.3^{8}$ ), the Dutch legal framework is treated, notably through a description of legal consequences according to the Civil Code (section $1.4^{9}$ ). We then give a brief survey of different criteria for the assessment of patient competence (section $1.5^{10}$ ), at which point it will turn out that generally accepted, concrete criteria of patient competence are not available.

That brings us to a critical examination of why competence assessment raises so many problems (section $1.6^{11}$ ), on the assumption that a clarification of the problematic nature of patient competence might be helpful in dealing sensibly with the concept. In this regard, we will point to the relation between the concepts of patient competence and patient autonomy, to a pick of different, disputable conceptions of autonomy held in the literature and to the individuality of patient values. Awareness of these features teaches us to have modest expectations with regard to the possibility of criteria of patient competence that are not only quite concrete, but also universally valid. Since it is argued that the main problem is neglect of the concept's normative nature, and that the subject of the patient constitutes the true norm in competence assessment, the patient and his values are made the subject of some reflection (section $1.7^{12}$ ). Competence assessment involves a circle, in that the assessment of competence requires knowledge of the patient's values, whereas knowledge of a patient's values presupposes confidence in the patient's competence. 
The first step on the way to tackling this conceptual problem is found in the presupposition that a patient's values are at least to some extent knowable for the assessor of competence. A further step towards practical solutions for the problems encountered in our quest for criteria of patient competence, concerns four preconditions of competence assessment, which preconditions attempt to safeguard the normative character of patient competence (section $1.8{ }^{13}$ ). A review of the available standards for competence assessment in light of these preconditions will show that so-called process (or evaluative) standards, focusing on the quality of the decision-making process by the patient, are the most defensible (section $1.9^{14}$ ). Subsequently, a specific elaboration thereof is proposed, namely the "recognisable reasons" criterion (section $1.10^{15}$ ). The recognisable reasons criterion prompts us to question its psychological validity, i.e. the degree to which it is representative of actual human choice behaviour and decision-making in real life (section $1.11^{16}$ ). We will see that the criterion has limited psychological validity due to the high demands on competence it entails. Ample application of it would lead to many false declarations of incompetence. Therefore, it is then asked whether patient competence ought not to be regarded more as an ethical-anthropological notion, than as a quality that is empirically testable in terms of criteria (section $1.12{ }^{17}$ ). Before concluding, we come back to the legal framework (section $1.13^{18}$ ), in an attempt to integrate the previous findings. This closer look will bring support for the central thesis of this dissertation: there are several legal reasons for evading a procedural assessment of patient competence and only a few legitimate triggers to resort to such an assessment.

\subsection{THE BACKGROUND OF TWO COMPETING ETHICAL PRINCIPLES}

\subsubsection{Historical background}

The rise of the concept of patient competence can be explained by developments in both scientific research and patient care. As to the former, the emphasis on the role of the prospective subject in decisionmaking about his participation in a research project is historically mainly a reaction to abuses in human experimentation, notably but not exclusively during the second World War (Leenen, Gevers, \& Biesaart, 2002, p. 240-246). Chapter 2 provides a further description of examples of unethical research studies and of the ethical and legal regulation they brought about. A basic rule in this regulation is that subjects can only be involved in research after they have competently and freely given their 
informed consent to participation (ten Have, ter Meulen, \& van Leeuwen, 2003, p. 92-93). ${ }^{19}$

In the context of patient care, the concept of patient competence has gained significance owing to the fact that the principle of beneficence has gradually had to tie for its guiding place in medical decision-making more and more with a competing principle, namely that of respect for patient autonomy or self-determination. The principle of respect for autonomy implies requirements not only for the one who has to facilitate and respect it, i.e. the health care professional, but also for the one who is supposed to practise it, i.e. the patient (Berghmans, 1992, p. 63-67).

Principles are characterised by the fact that they require interpretation in light of the concrete circumstances and by the fact that they will need to be weighed against other relevant principles, in attempts to find a legal answer to a legal problem (Scholten P \& Scholten GJ, 1974, p. 62-63, 125-126; Wiarda, 1988, p. 111; Franken, 1995, p. 100-101; Vranken, 1995 , p. 86-87, 89, 92). They do not lend themselves for simple, direct application to a case (cf. art. 6:2 \& 6:248 $\mathrm{j}^{\circ} 3: 12 \mathrm{BW}$ ). This section continues with an illumination of the two principles mentioned above. Also, attention is paid to the historical roots of the informed consent doctrine in the treatment domain, to the relevance of patient competence, to an ethical, a legal and a psychological definition of the concept and to possible errors in competence assessment.

\subsubsection{Beneficence}

The normative framework for the classical approach of patients in health care is provided for by the principle of beneficence. ${ }^{20}$ Beneficent behaviour "includes all forms of action intended to benefit other persons" (Beauchamp \& Childress, 1994, p. 260). Conceived as a principle, beneficence implies for the health care professional a duty to act in the interest of the patient. The principle can be related to the Corpus Hippocraticum, which is the first collection of writings in Western history dealing with medical professional conduct (Faden et al., 1986, p. 61; ten Have et al., 2003, p. 54). The Greek doctor Hippocrates of Cos, to whom the Corpus used to be attributed, lived in the fifth and fourth centuries B.C. (Armstrong, 1957/1977/1989, p. 19-20). He was an older contemporary of Plato, who referred to him as "the Asclepiad of Cos" in his dialogue Protagoras (Ashworth Underwood, 1991). A well-known part of the Corpus, the Hippocratic oath, contains the following passage: "I will use treatment to help the sick according to my ability and 
judgment [...]" (Beauchamp \& Childress, 1994, p. 189) or, in a different translation, "I will apply (medical) measures for the benefit of the sick according to my ability and judgment [...]" (Spicer, 1995).

Characteristically, someone other than the patient, namely the health care professional, decided what is best for the patient. As the power to decide rested with the health care professional -of old a physician-, it was deemed needless to inform the patient. Indeed, the Hippocratic tradition assumes that generally, the doctor had better not inform the patient about his condition and prognosis (Faden et al., 1986, p. 61). This information was supposed to be too burdensome for the patient, who, moreover, was considered incapable of comprehending it because of his illness and the connected suffering anyway. Even white lies were thought to be permissible, if they could benefit the patient, e.g. in giving him hope (Zwart, 1993, p. 46; Faden et al., 1986, p. 63).

Percival (1849, first edition 1803; Chapter II, par. 3, p. 48-49), whose work served as the basis for the first medical-ethical code of the American Medical Association (AMA) (version of 1847), hence argues that the professional ought ordinarily to refrain from informing the patient. In those exceptional cases where it is wise to inform the patient, Percival contends that the health care professional leave this task to someone else. A piece of the relevant provision from the AMA-code, almost a literal copy of Percival, reads as follows (American Medical Association, 1978; art. I-4, Chapter I, "Of the duties of physicians to their patients, and of the obligations of patients to their physicians", p. 1739): "A physician should not be forward to make gloomy prognostications [...]. [...] For, the physician should be the minister of hope and comfort to the sick; [...]. The life of a sick person can be shortened not only by the acts, but also by the words [...] of a physician."

\subsubsection{Autonomy}

After the Enlightenment of the eighteenth century and the nineteenthcentury liberalism, particularly as expressed by John Stuart Mill, in the second half of the twentieth century a different principle puts itself opposite the principle of beneficence in health law and bioethics, namely that of respect for patient self-determination or autonomy (Sluijters, 1985; Ippel, 1994, p. 35-37; van der Burg \& Oevermans, 1994; Engberts, 1997, p. 217-218 \& p. 251 ff.; Leenen \& Gevers, 2000, p. 33; Widdershoven GAM, 2000, p. 9-11, 21-22; Dute, 2000, p. 28-29; Leenen et al., 2002, p. 47; ten Have et al., 2003, p. 81; Legemaate, 2004; Hendriks, 2006, p. 5-7; van Wijmen, 2006, p. 8-9, 12, 39). The rise of this principle has 
not pushed aside the principle of beneficence. On the contrary, many variants of the latter can still be found in both legal (e.g. art. 4 Convention on Human Rights and Biomedicine, art. 7:401 jo $453 \mathrm{BW}$ ) and ethical (e.g. directives 2, 48-50, 56, 62-64, $104 \& 116-117$ plus explanatory remarks of the Charter for Health Care Workers by the Pontifical Council for Pastoral Assistance to Health Care Workers, 1995) contemporary documents.

In relation to individuals, the principle of respect for autonomy ${ }^{21}$ amounts to the idea that with regard to their own lives, people are entitled to choose themselves what norms and values they want to pursue, and that other persons have to defer to these choices, even when they diverge from the norms and values that prevail in a society (Musschenga, 1987, p. 112; Leenen \& Gevers, 2000, p. 32-41). ${ }^{22}$ Beauchamp and Childress define autonomy as "personal rule of the self that is free from both controlling interferences by others and from personal limitations that prevent meaningful choice [...]" (Beauchamp \& Childress, 1994, p. 121).

The key notions about autonomy have taken clear shape in the Age of Reason (ten Have et al., 2003, p. 81; Yeide, 1992, p. 269). Hegel goes back as far as the Reformation, as pronounced by Luther (1517), to trace the origins of the Enlightenment (Zwart, 1993, p. 63). Other authors even pin-point the Magna Charta, dating from 1215, as germinative factor for the principle of autonomy (Dupuis \& de Beaufort, 1988, p. 217-218; Olde Rikkert, Verweij, \& Hoefnagels, 1995, p. 155). John Stuart Mill has strongly influenced current opinion on autonomy. As opposed to the exponents of the Enlightenment, whose views stressed rationalism and emancipation, he concentrates his contemplations on human liberty, in particular liberty conceived as "freedom from coercion and interference by others in the life of the individual" (ten Have et al., 2003, p. 89-91). Mill is the philosopher of liberalism. Since in the liberalist conception of the principle of autonomy, the absence of something (namely undesired intrusion by others) is at the centre, Berlin in this matter uses the term negative freedom: "What is the area within which the subject [...] is or should be left to do or be what he is able to do or be, without interference by other persons?" (Berlin, 1969, p. 121-122). The negative conception of autonomy is related to the notion of privacy (Warren \& Brandeis, 1890; Faden et al., 1986, p. 39-41) and makes itself felt in American case law, ${ }^{23}$ where it is phrased as a "right to be let alone". Engelhardt reformulates this right as "the right to be left alone" (Engelhardt, 1986, p. 264 - italics added, SPKW). Critics, for their part, speak of "a right to rot" (Agich, 1993 in ten Have et al., 2003, p. 102). 


\subsubsection{Informed consent}

The informed consent doctrine gives a mechanism for decision-making that is attuned to the context of health care and in which the say of the patient is operationalised in concrete terms. Informed consent offers the patient the possibility to keep off unwanted medical interventions. According to this doctrine the health care professional needs the consent of the patient prior to her being allowed to carry out the intervention proposed by her. Patient consent is only valid if the professional has supplied the patient with enough information about the proposed intervention, and if the patient was free and competent in consenting. This specific doctrine has its origin particularly in two contexts: firstly, it was established in the context of medical scientific research (ten Have et al., 2003, p. 92) and secondly, it further emerged as a result of American case law. As for the latter context, it concerns judicial judgments in reply to claims of patients against physicians, notably in the area of surgery (President's Commission for the Study of Ethical Problems in Medicine and Biomedical and Behavioral Research, 1982, p. 15; Meisel et al., 1977, p. 285). The concept of "consent" already surfaces in the so-called Schloendorff-case ${ }^{24}$ from 1914 (Faden et al., 1986, p. 123; Dupuis \& de Beaufort, 1988, p. 218). Grisso and Appelbaum even point to an English case $^{25}$ from 1767 which ruled that consent is a necessary condition for legitimately undertaking a surgical operation (Grisso \& Appelbaum, 1998, p. 4). In 1957 the expression "informed consent" ${ }^{26}$ is first used, namely in the Salgo-case ${ }^{27}$ (Lidz, Appelbaum, \& Meisel, 1988, p. 1385; Zwart, 1993, p. 47). In the standard book by Faden and Beauchamp on the topic, King gives a survey of Anglo-American case law in which the doctrine has evolved (Faden et al., 1986, p. 114 ff.).

\subsubsection{Relevance of patient competence as a function of the weight of autonomy}

We have seen that the rise of the principle of respect for autonomy has put an end to the near monopoly of the principle of beneficence in health care. As a consequence, the patient is nowadays expected to play a more active role in the decision-making about his care. Patient competence is the aptitude for playing the role in question. ${ }^{28}$ It can be inferred that the relevance of this concept within the relationship between health care professional and patient increases, as in the circumstances of the case the principle of autonomy gains weight; after all, a larger place for patient autonomy entails expansion of the patient's responsibilities and accompanying tasks in his relationship with the health care professional. 
It goes without saying that, on the contrary, the more the principle of beneficence dominates the normative framework of this relationship, the more limited the relevance of patient competence is.

\subsubsection{Three stipulative definitions}

On the basis of the foregoing, three working definitions of patient competence, each from a distinct disciplinary perspective, come to the fore. From an ethical viewpoint, competence can be defined as the capacity for autonomous thought and action. Legally, the capacity to exercise rights, notably the right to give or withhold one's informed consent, defines competence. Capacity for choice, finally, constitutes a definition of competence from a psychological angle.

\subsubsection{Possible errors in competence assessment}

Two types of errors are at stake in assessments of patient competence. On the one hand, a competent patient might wrongly be deemed incompetent, resulting in an illegitimate infringement of his right to self-determination, in that others take over the decision-making on his behalf. On the other, a verdict of competence in relation to a patient who is really incompetent, would amount to abandoning someone in need of protection, in that he has to make decisions which he is not up to, thus risking to decide contrary to his interests and values.

\subsection{LEGAL FRAMEWORK}

\subsubsection{Legal regulations}

Several international legal documents refer to the concept of patient competence. A number of these documents are mentioned in Chapters 5 (section 5.2) and 7 (section 7.2) of this dissertation. The concept of competence features in many different ways in the legal framework. In correspondence with the different types of tasks involved in legal relationships and with the abilities and skills required for accomplishing those tasks, numerous legal provisions imply just as many distinct legal sorts of competence.

Some illustrative examples of such competences in Dutch law are the capacity to marry ${ }^{29}$ and the capacity to raise children or to have parental 
$a^{a c e s s}{ }^{30}$ in family and juvenile law, the capacity to make a will $l^{31}$ in law of succession, the capacity to draw up a declaration of self-binding, ${ }^{32}$ and the capacity to request euthanasia. ${ }^{33}$

We have already noticed that, in health law, patient competence generally pertains to the task of making a decision with respect to an intervention proposed by a health care professional, after having been informed adequately hereof. ${ }^{34}$

\subsubsection{Legal consequences of patient competence versus incompetence}

The legal consequences of patient competence in the context of informed consent according to Dutch law can be summarised as follows. ${ }^{35}$ If a patient is competent in relation to a certain decision, his choice of accepting or renouncing the intervention proposed by the professional, will eventually be of overriding importance. On condition that the patient has received proper information and no undue pressure has been exerted upon him, a competently made decision settles the matter. This goes for refusal of life-saving treatment as well. Culver and Gert refer to this aspect of patient competence when they discuss the commonly held legal adage that competent patients can never be legitimately subjected to compulsion for their sakes (Culver \& Gert, 1990, p. 619-621).

If a patient is incompetent in relation to a certain decision, the main legal consequence is that for that matter, this patient should be represented by someone who can decide on his behalf, usually a close family member. Like the patient, the representative has the right to give or withhold consent, on the understanding that the representative's right to refuse is not as absolute as that of the competent patient (cf. Gevers, 2004). In a lucid period preceding his incompetence, the patient may have written a so-called living will in relation to certain treatment questions. The living will contains the patient's health care related wishes with a view to possible future incompetence (Gevers, 2002). If such a document is indeed available, it is an important legal factor in deciding on the further course of treatment of this patient once he has become incompetent, both for the health care professional and for the representative. When a living will in which consent for a specific intervention has been refused, is present, valid and clear, it has to be respected and the intervention cannot take place (art. 7:450 section $3 \mathrm{BW}$ ).

By the way, a declaration of incompetence does not totally exclude the actual patient in question from the decision-making process. The incompetent patient too, has a legal role, in that the law instructs the 
representative to involve him in decision-making as much as possible (art. 7:465 section $5 \mathrm{j}^{\mathrm{o}} 1: 454$ section $1 \mathrm{j}^{\mathrm{o}} 1: 381$ section $4 \mathrm{BW}$ ). In addition to that, resistance by the incompetent patient to drastic interventions is generally to be respected, even when his representative has granted substitute consent (art. 7:465 section 6 BW). An exception to this "respect of resistance" rule occurs only when the intervention is necessary to prevent serious harm to the patient. What precedes, implies that patient incompetence is by no means a sufficient condition for ignoring the patient or for compulsory treatment. A further description of the legal consequences of patient incompetence along with possible representatives prescribed by the law, can be found in Chapter 7, notably in the decision tree (Fig. K) included in section 7.4 (p. 184-185).

\subsubsection{The odd exception of the (Dutch) Special Admissions into Psychiatric Hospitals Act}

One striking exception to the above-mentioned legal adage pertains to the (Dutch) Special Admissions into Psychiatric Hospitals Act (Wet Bopz) ${ }^{36}$ This statute mainly deals with the criteria and procedures for involuntarily committing -and possibly treating- patients whose psychiatric disorder makes them cause danger to themselves or to others. In this Act, incompetence does not act as a necessary condition for legitimate compulsion when only the patient's own interests are at stake. According to the Wet Bopz, danger, including danger to the patient himself, is a ground for overruling refusal of treatment by a competent patient, as it is for overruling a representative's substitute refusal and an incompetent patient's resistance (art. 38 section 5 third sentence \& art. $38 \mathrm{c}$ section $1 \mathrm{Wet}$ Bopz). ${ }^{37}$

However, a number of authors disagree with this peculiarity of the Wet Bopz (van de Klippe, 1997, p. 237-238; Dijkers \& Widdershoven TP, 2002, p. C1/Art. 38 - 992-998 (suppl. 2, januari 1996); Blankman, 2003, p. 93-94, 96-97, 100-101; Widdershoven TP, 2003, p. 38-39; Widdershoven TP, 2006). Moreover, even in the Wet Bopz the concept of competence does not let itself be stashed away. ${ }^{38}$ As far as this question is concerned, I will leave it at the observation that this aspect of the (Dutch) Special Admissions into Psychiatric Hospitals Act is in need of repair. ${ }^{39}$ Henceforth the argument is based upon the legal position of the patient according to the Civil Code, as therein the concept of patient competence gets the place that it deserves. 


\subsection{VARIOUS CRITERIA FOR ASSESSMENT OF PATIENT COMPETENCE}

\subsubsection{Statutory definition of patient competence}

A characteristic feature of the legal concept of patient competence is that assessment of competence takes place with the procedural goal of determining who should be invested with the power to decide in a certain matter. ${ }^{40}$ An answer to the question about a patient's competence settles whether or not the patient is to have this power.

The prevailing statutory definition of patient competence reads as follows: competent is the patient who can be deemed "able [...] to judge his interests at hand reasonably" (art. 7:465 sections $2 \& 3 \mathrm{BW}$ ). The main components of this definition, i.e. reasonable judgment and interests at hand, are open norms.

\subsubsection{Three kinds of standards discussed in the literature.}

In an attempt to provide more hold to those who have to assess patient competence, a diversity of definitions, criteria, standards, tests, conditions, procedures, guidelines, checklists, scales and approaches have been proposed and described in the literature. Figure F in Chapter 4 of this dissertation (p. 96) gives a sample thereof. If one thing is sure, it is that a generally agreed on standard for patient competence is lacking: "There is no international clinical, legal, philosophical, or ethical consensus about competence criteria or standards, and many are in use" (Wettstein, 1995, p.447; cf. also Schermer, 2001, p. 55).

To summarise the literature, three kinds of standards ought to be discussed (President's Commission for the Study of Ethical Problems in Medicine and Biomedical and Behavioral Research, 1982, p. 60-61; Berghmans, 1992, p. 299-302). Firstly, minimal (or preferential) standards only require from the patient that he express some choice. According to these standards, it does not matter what this choice amounts to, nor how the patient expresses it. As suggested by their name, minimal standards make low demands on patient competence then. Secondly, outcome (or consequential) standards hinge upon the contents of the patient's choice. If the assessor thinks that the patient's choice is foolish or irrational, or that it would lead to unacceptable consequences, the patient is supposed to be incompetent. When these standards are applied, the assessor's norms and values are crucial in competence assessment. 
Thirdly, in process (or evaluative) standards, the quality of the decisionmaking process in the patient establishes whether or not he can be regarded as competent. If this quality is sufficient for engendering the assessor's confidence that the resulting decision will reflect the patient's interests and values, the patient is competent. More information on definitions, criteria, standards, tests et cetera of patient competence is contained in Chapters 4-6

One more approach needs to be mentioned here, namely the sliding scale. This so-called scale is a combination of outcome and process standards. The sliding scale approach states that it depends upon the risk involved in a decision, which criteria are applicable for assessment of competence in relation to that decision (Drane, 1984, 1985). Briefly, low demands (i.e. awareness $\&$ assent) should be made on competence when decisions with little risk (e.g. consenting to life-saving treatment) are involved; in case of high risk decisions (e.g. refusing that same life-saving treatment or consenting to a risky experimental procedure), high demands (i.e. appreciation \& rationality) would be appropriate. Later, we will find out that the sliding scale approach conflicts with a precondition for competence assessment. ${ }^{41}$

\subsection{Problems in Competence assessment due to NEGLECT OF THE CONCEPT'S NORMATIVE CHARACTER}

\subsubsection{Impediments to finding criteria}

Apparently, patient competence is not amenable to an elaboration in terms of simple criteria. After more than 25 years of unfulfilled attempts to formulate such criteria, it seems more sensible to investigate the causes of the difficulty in achieving this goal, than to just persist in these attempts (cf. van Tongeren, 1991, p. 4-6). In my mind, neglect of the normative character of the concept of patient competence, both on the level of the underlying principle of autonomy and on the level of concrete criteria, forms the major explanation for the stubbornness of the subject matter. Specific reasons for this argument are expounded in Chapters 4 (section 4.5), 6 (section 6.11) and 7 (sub-section 7.7.2) of this dissertation.

In a discussion of patient competence, at least two legal principles are at stake. One is certainty of law, the other one patient autonomy. The principle of certainty of law means that legal norms and rules should be so clear that persons can know where they stand legally; we have already 
noted that the principle of autonomy explains the relevance of patient competence. Since the concept of patient competence is an element of legal regulation, the principle of certainty of law does pertain to it. In other words, patients are entitled to know how competence may be assessed. The same goes for health care professionals, now that the concept of patient competence determines their legal position too: after all, in case of competence, the professional has to abide by the patient's decisions; in case of incompetence, she should consult his representative. Attempts to operationalise patient competence in terms of concrete criteria, agree with the principle of certainty of law, in that they aim at clarifying how competence be assessed. These attempts try to enumerate and delineate observable cognitive abilities and information-processing behaviours which would define patient competence. It is my impression that in this search after criteria, too one-sided an emphasis has been put on certainty of law in the sense of "operationalisability", and that the underlying normative principle of respect for patient autonomy threatens to disappear from sight.

Several experts on the matter confirm the fact that patient competence is indeed a normative concept (e.g., Appelbaum \& Roth, 1982, p.951; Faden et al., 1986, p. 240; van de Klippe, 1990, p.131; Beauchamp, 1991, p. 53 \& 66; Legemaate, 1992, p.192; Berghmans, 1992, p. 382; van Delden, 1993, p.88; Checkland \& Silberfeld, 1996, p. 131; Vansweevelt, Swennen, Heerdt, Weyts, \& Jeger, 1998, p.542; Leenen \& Gevers, 2000, p.216-217; Koninklijke Nederlandsche Maatschappij tot bevordering der Geneeskunst, 2004, p.117). Let me illustrate this idea with the help of some quotations. Buchanan and Brock say that "the determination of competence is not simply an 'objective' factual determination based on some measurable property of an individual. Nor is its complexity simply psychological or more broadly empirical [...]" (Buchanan \& Brock, 1990, p. 17). Wettstein goes on to state that "competence determinations are $[. .$. value-laden judgments about the relative importance of autonomy and beneficence to the person, as assessed by the clinician or others" (Wettstein, 1995, p. 447).

Earlier, it was noted that from an ethical viewpoint, patient competence can be defined as the capacity for autonomous thought and action. ${ }^{42}$ Therefore, one might want to consult the underlying concept of autonomy in order to fathom the concept of competence. A short excursion through the literature, however, acquaints us with various conceptions of autonomy, such as autonomy conceived as "free action" (Miller, 1981; ten Have et al., 2003, p. 89 ff., p. 92; van Thiel \& van Delden, 1998, p. 15 ff.), autonomy conceived as informed choice or "effective deliberation" 
(Miller, 1981), autonomy conceived as personally principled decisionmaking (White, 1994, p. 13-16), autonomy conceived as "moral reflection" (Miller, 1981; Frankfurt, 1971; Dworkin, 1982, p.71; Dworkin, 1988, p.20,108), autonomy conceived as "authenticity" (Miller, 1981; van Thiel \& van Delden, 1998, p. 19 ff.), with a Kantian conception of autonomy (Yeide, 1992; ten Have et al., 2003, p. 87 ff., p. 92; van Thiel \& van Delden, 1998, p. 17 ff.) and with a notion of this concept inspired by an ethic of care (Tronto, 1993; Keller, 1997; van Thiel \& van Delden, 1998, p. 20 ff.; Haekens, 1998, p. 20; Schermer, 2001 , p. $25,157-159)$. The principle of autonomy turns out to be as elusive as its counterpart, the concept of competence (Faden et al., 1986, p. 237; Weisstub, 1990, p. 28; cf. Welie JVM, 1998, p. 60-72).

\subsubsection{The underlying norm in competence assessment}

What is the norm that it is really all about? It is my thesis that this norm is to be sought in the patient as subject. In a discussion of human rights and law in general, Scheltens states that the inherent dignity of human beings is the foundation of law (Scheltens, 1981, p. 21, 30, 36, 38, 47-50, 54; Scheltens, 1983/1988, p. 22, 60).$^{43}$ Exactly that which Scheltens says when discussing human rights and law in general, goes in health law for the patient as norm of competence and autonomy. We should not forget that self-determination for the patient within the relationship between health care professional and patient is meant to create room for the individuality of the patient.

Different persons may seek different values. What counts as an adequate decisional process or a competently made decision for one person, need not count as such for another person, even if all other things, like the task, the decision to be made, the condition that the patient is suffering from, the prognosis, the available medical options, the situation, the patient's mental state, the patient's knowledge of relevant facts, the consistency of the patient's decisional process etc., are equal. Hence, the concept of competence is not only task-specific and decision-relative ${ }^{44}$, but it is also person-relative and value-specific with that ${ }^{45}$ Legally valid criteria of patient competence must take into account this feature of the concept. ${ }^{46}$ In this context, it is interesting that in the field of mental health care, one argues for bringing up the patient's religion, philosophy of life or ideology during the intake interview, because of " $[t]$ he importance [thereof] for understanding the problems presented by the patient and for selecting the possible treatment options" (van Ree, 2004, p. 86; cf. also Berghmans, 1992, p. 384-387 and Franx, Stalmeier, \& Timmermans, 
2006, p. 639-642). ${ }^{47}$ By reason of the value-specific character of the concept of patient competence, the existence of valid criteria of patient competence that are both universal ${ }^{48}$ and concrete ${ }^{49}$, is a logical impossibility. Everyone who claims to have constructed such criteria, must therefore be wrong. When concrete criteria of patient competence are nevertheless indiscriminately applied to any patient, the law risks being perverted into its reverse: a straitjacket needlessly curtailing the freedom to live one's life at one's own discretion. ${ }^{50}$ Valid criteria either are universal and abstract, or they are concrete and limited in range to patients who share the same values.

\subsubsection{The need for an open norm}

A legal model intended to do justice to human dignity and to the individuality of patients, will not attempt fully to concretise criteria of patient competence; instead, it will deliberately safeguard the open character of these criteria, so that the assessor of competence has the opportunity to have her assessment resound with the individual norms, values, preferences, identity, lifestyle and life story of the patient in question (cf. Wiarda, 1988, p. 29, 34, 57-58; Bruggink, 1993; Loenen, 1996; Berghmans, 2000, p. 85 ff.). In this light, the statutory definition of patient competence is not at all bad: it is an open norm. ${ }^{51}$

Criteria of patient competence ought to refer the one who applies them, back to the concrete situation of the individual patient whose competence is being examined, and they require an answer to the normative question of what is "sufficient" against the background of that situation (Crombag et al., 1977, p. 119-120 \& 124-126).

\subsection{INDIVIDUALITY AND KNOW ABILITY OF PATIENT VALUES}

\subsubsection{Ontological and epistemological dimensions in relation to patients' values}

Now that the subject of the patient and his values prove to be essential when recognising the normative character of the concept of competence, it is time for some closer consideration of those values. What hypothetical assumptions can we formulate with respect to this topic? Two relevant dimensions in relation to patients' values should be made explicit (Welie JVM, 1998, p. 17-19, 59-61, 78-80, 88-89). ${ }^{52}$ Firstly, the ontological dimension concerns the question whether a patient's values are identical 
to or different from his fellow human beings' values. Secondly, the epistemological dimension regards the question whether or not a patient's values are knowable to other persons, notably to the health care professional who acts as an assessor of patient competence.

These dimensions have been represented as two axes in Figure A. That way, the figure's cells abstractly describe possible states of affairs in relation to patients' values. For clarity's sake, the figure employs a dichotomisation for each dimension. Of course, the discussion could be differentiated by employing gradual dimensions.

\begin{tabular}{|c|c|c|c|}
\hline & \multicolumn{3}{|c|}{ ontological dimension } \\
\hline \multirow{3}{*}{$\begin{array}{l}\text { epistemo- } \\
\text { logical } \\
\text { dimension }\end{array}$} & $\begin{array}{l}\text { the patient's } \\
\text { values are: }\end{array}$ & $\begin{array}{l}\text { identical to those } \\
\text { of other persons } \\
\text { ("objective") }\end{array}$ & $\begin{array}{l}\text { possibly different } \\
\text { from those of } \\
\text { other persons } \\
\text { ("subjective") }\end{array}$ \\
\hline & $\begin{array}{l}\text { knowable to } \\
\text { other persons } \\
\text { ("objective") }\end{array}$ & $\begin{array}{c}\text { decision-making } \\
\text { by the patient is } \\
\text { not necessary }\end{array}$ & $\begin{array}{c}\text { decision-making } \\
\text { by the patient is } \\
\text { not necessary }\end{array}$ \\
\hline & $\begin{array}{l}\text { unknowable to } \\
\text { other persons } \\
\text { ("subjective") }\end{array}$ & $\begin{array}{l}\text { assessment of } \\
\text { patient competence } \\
\text { is impossible }\end{array}$ & $\begin{array}{c}\text { assessment of } \\
\text { patient competence } \\
\text { is impossible }\end{array}$ \\
\hline
\end{tabular}

Figure A. Two relevant dimensions in relation to patients' values

It should be noted that the terms "objective" and "subjective" have a different meaning, depending upon which dimension they refer to. Objective in the ontological sense means that different people share the same values; subjective in the ontological sense means that different people hold their own individual values. Objective in the epistemological sense means that other people may have valid knowledge of the patient's values; subjective in the epistemological sense means that other people cannot have such knowledge. Objectivity (or subjectivity) in one sense of the term does not imply objectivity (or subjectivity) in the other sense of the term. 


\subsubsection{Implications for competence assessment}

The present figure yields four cells, which can be checked with a view to their implications for the possibility of competence assessment and the right distribution of decisional power over patient and health care professional.

Let us first examine the cell where a patient's values are identical to those of all other patients, and where these patient values are knowable to anyone besides. According to that cell, all patients really want similar treatment; furthermore, general knowledge of patients' treatment preferences can be attained. Under those circumstances, the health care professional could just as well decide on behalf of the patients on the basis of her knowledge of these preferences. In other words, if the present cell correctly describes the state of affairs in relation to patients' values, then the need for giving patients a voice in their relationship with the health care professional disappears conceptually, and with that the relevance of patient competence.

Next, the cell where patients' values are variable but still wholly knowable, more or less involves the same conclusion: patient participation in the decision-making is in principle redundant, now that the health care professional can calculate these values into the decision-making herself, provided of course that she has made the effort to learn them and to actually take them into account when deciding for the patient.

By the way, if we indeed assume the knowability of another man's values, it remains unanswered yet how actual knowledge of these values can be achieved. It seems likely that a health care professional can only succeed in getting to know her patients' values, when she expends the necessary time and energy therein, e.g. by wrapping herself up in each of her patients and their life stories and eventually by consulting their social systems (cf. Bijma \& Hutschemaekers, 2007). Contact with the patient appears to be necessary. The patient, then, does have a role in that he has to enable and/or facilitate this contact. However, this does not imply a part for the patient in the decision-making. ${ }^{53}$

In the cell where the patient's values are different from those of the health care professional and unknowable to her at that, an assessment of competence is not possible. Due to the person-relative character of patient competence, the patient's values make up the underlying norm in competence assessment. ${ }^{54}$ Without knowledge of the patient's values, one does not have the background information required to perform such an assessment. 
Lastly, in the cell where patient and health care professional have identical values, but these values are again unknowable to her, there are two possibilities. The health care professional could herself be incompetent, because she may not know her own values. Or the health care professional does know her own values, but she does not realise that they are shared by the patient. Either way, the professional again lacks the necessary evaluative base for accomplishing a competence assessment.

\subsubsection{Catch-22 in competence assessment}

Paradoxically, we find ourselves in the face of the following thorny conceptual choice: either, we assume that the patient's values are knowable to the professional, in which case there is no need to invest the patient with decisional power and hence no need to assess his competence to decide; or, we assume that the patient's values are unknowable, in which case it may be necessary to assess patient competence, while at the same time such an assessment is impossible to perform. This conceptual analysis lands us in a catch-22 situation. In order to be able to judge patient competence, you have to know the patient's values. In order to know the patient's values, you have to be able to judge patient competence. After all, the patient can only be considered a reliable source of his values in a certain matter, if he can be trusted to be competent in that matter.

The only escape from this catch concerns the patient who -after repeated attempts by the professional to explain the relevant information in a way adapted to the patient- still does not understand specific factual information that is crucial for the decision to be made. Such a patient is probably incompetent to make that decision. ${ }^{55}$ However, this is not the kind of patients that typically calls for criteria of competence. The hard cases arise when doubt exists as to the patient's appreciation of his situation. Since appreciating a situation is an evaluative activity, in which the patient's values are the decisive factor, we are back to the catch-22 circle.

The knotty situation under discussion is not linked with the question of who is to assess patient competence. Every assessor, whether she is a physician, a psychologist, a nurse, a social worker, a lawyer, an ethicist, a pastor or a spiritual counsellor, is confronted with the same problem. The same goes for family members and other possible representatives, who may have the advantage of having better insight into the patient's values, because they have usually known him for a longer time. In other words, 
the problem cannot be solved by changing the assessment procedure and routinely having a psychologist or a lawyer do the assessment instead of the health care professional, for example, although involvement of a trusted family member could help.

Abolition of the concept of patient competence does not solve the problem either. Doing away with this concept would lead to either deeming all patients competent, or deeming them all incompetent. This way of acting would inevitably have as an effect the incidence of many errors of type two and type one respectively. ${ }^{56}$

\subsubsection{A practical solution}

How can the problems pointed out above, be solved? Initially, the practical solution proposed by the author will presuppose that one can (and should) know a patient's values, at least to some extent, and, at the same time, that knowledge of a patient's values is not so evident as to render superfluous patient participation in the decision-making with a view to the contents of the decision. It might be asked what supports this aspect of the solution. The fact that it has an intuitive appeal, could be mentioned as a first reply to that question.

The second answer is that the discourse on patient competence -in addition to presupposing that different people may hold different values in their lives (inter-individual differences)- presupposes a certain degree of constancy and consistency, or at least coherence, between the values entertained by one person (intra-individual continuity) and the possibility for the patient to make known these values. Without the ideas of intraindividual continuity and knowability of patients' values, e.g., arbitray choices would not be amenable to critical scrutiny and living wills would be of no significance for the future. A patient's values have potential relevance for all of the decisions he has had to and may have to make; they can be regarded as a global component of patient competence. We can thus put forward the proposition that more can be learnt about a patient's current values by exploring and interpreting his past behaviour and actions.$^{57}$ The presupposition under discussion is also seconded by implicit assumptions in several statutory provisions of Dutch health law. ${ }^{58}$

Most importantly, this presupposition avoids falling into one of the extremes corresponding with the two rows in Fig. A. Please do mind, however, that it relinquishes conceptual clarity: other people are supposed both to know and not to know a patient's values. ${ }^{59}$ Nevertheless, paying the price of accepting some contradiction seems preferable to either 
cancelling the importance of patient decision-making authority, or giving up our quest for criteria for assessment of patient competence.

The solution is furthermore sought in those preconditions of competence assessment that meet with the agreement of most authors, which preconditions form the topic of the following section.

\subsection{Preconditions SAFEgUARding The nORMATIVE CHARACTER OF PATIENT COMPETENCE}

\subsubsection{Consensus about preconditions}

In spite of the dissension about criteria of patient competence, there is consensus about some starting-points for assessment of competence (cf. Buchanan \& Brock, 1990, p. 18 ff.; Grisso \& Appelbaum, 1998, p. 18 ff.). More in particular, these preconditions, four in number, intend to safeguard an assessment of competence's doing justice to the individuality of the patient in question. A review of the said preconditions may help us in further coming to grips with the concept of patient competence, in that they will enable us to test the tenability of the diverse criteria proposed in the literature.

Attention will now be paid to (1) the assumption of competence, (2) the task-specificity of competence, (3) the process character of competence and (4) the variability of the threshold of competence. A more extensive general discussion of these preconditions of competence assessment can be found in Chapter 7 (section 7.6) of this dissertation.

\subsubsection{The assumption of competence}

The first precondition concerns the assumption of competence (see, e.g., art. 1:1 section $1 \mathrm{BW}$; Nys, Welie SPK, Garanis-Papadatos, \& Ploumpidis, 2004, p. 331). It means that a patient ought to be regarded as competent, as long as the contrary has not been proven (Legemaate, 1992). In principle, this assumption applies to everybody: e.g., not only somatic patients, but also psychiatric patients, psychogeriatric patients, mentally retarded persons, compulsorily committed patients, persons for whom a protective judicial measure has been pronounced ${ }^{60}$, even patients who have been declared incompetent before, can appeal to the assumption. The assumption of competence is open to more than one interpretation. Six possible interpretations are distinguished here. 
In the first place, the assumption prescribes that a declaration of incompetence always requires proof on the basis of concrete facts, attuned to the individual case at hand. The assumption does not state how proof can be supplied, nor what standard is adequate.

In the second place, the assumption expresses the idea that there must be a legitimate trigger before a patient may be subjected to competence assessment. The following possible triggers are mentioned in the literature: refusal of treatment, decisions that seem to be contrary to the patient's interests, risky, strange or unusual choices, drastic decisions, evidence or suspicion of disfunctioning decisional abilities, psychiatric or neurologic conditions, mental retardation, and dementia (Ministerie van Justitie, 1994; Schermer, 2001). Together, these triggers cover so many situations, that they undermine the assumption of competence. A more restrictive approach would be appropriate. ${ }^{61}$

In the third place, the assumption implies that, in principle, the burden of proof rests with the one bringing forward incompetence (Weisstub, 1990; cf. art. 1:1 section $1 \&$ 3:34 section 1 BW; art. 177 (Dutch) Code of Civil Legal Procedure). Most probably, this will be the health care professional. ${ }^{62}$ However, the patient might also dispute the validity of a previous decision of his, by retrospectively arguing that he was incompetent at the time. And of course, a potential representative of the patient can advance patient incompetence too. ${ }^{63}$ By the way, the civil law provisions in question do not alter the fact that from the viewpoint of disciplinary law and law of complaint, a health care professional must be expected to be able to found her assessments of patient competence, whatever their outcome (i.e., patient incompetence or patient competence with regard to the decision at hand). In light of the above, one could wonder if a health care professional's declarations of competence need a less detailed foundation than her verdicts of incompetence.

In the fourth place, the assumption of competence can have the practical function of cutting the knot when doubts about the patient's competence persist, but unequivocal evidence of his incompetence is lacking. In that case the assumption tips the scales in favour of competence.

In the fifth place, the assumption has a symbolic meaning: it underlines the importance of human freedom in a legal formula and thus supports the principle of autonomy.

In the sixth place, the assumption of competence appears to have the potential function of a fiction of law. This means that under certain 
circumstances, a patient ought to be considered competent, even if there is proof to the contrary. Leenen and Gevers (2000) state that a person should only be declared incompetent, if "the consequences of [the patient's] inability are so serious that they warrant a declaration of incompetence". Apparently, it is conceivable that the consequences referred to do not justify such a declaration, in which case the patient passes for competent, although he may patently fail to meet specific criteria of competence. Chapters 5 (sub-section 5.6.2) and 6 (section 6.11) of this dissertation go further into this aspect of the assumption of competence. Also, this notion will be examined more closely in section 1.12 .

\subsubsection{Task-specificity of competence}

The second precondition regards the task-specific and decision-relative character of the concept of competence (see, e.g., President's Commission for the Study of Ethical Problems in Medicine and Biomedical and Behavioral Research, 1982, p. 55). ${ }^{64}$ It means that a patient's competence should be assessed in relation to the specific decisional task he faces. The result of this assessment cannot be transposed to other decisions, as these may invoke other cognitive abilities than the ones involved in the current decision. By implication, more complex decisions require more extensive information-processing abilities of the patient. A pathological disturbance affecting the patient's grasp of a certain topic, can be irrelevant for decisions in which that topic does not matter. This precondition also means that in patients with fluctuating mental conditions, the result of an assessment of competence is perishable.

\subsubsection{The process character of competence}

Thirdly, there is consensus about the process character of competence (see, e.g., Berghmans, 1992, p. 302 ff.; Donker, 1992; Gezondheidsraad, 2002). The decisive factor in competence assessment should not be the outcome of the decision-making, but the quality of the process that leads up to it. Otherwise, the risk of the assessor's imposing her professional or personal preferences on the patient would be too big.

Still, the reader ought to note that a focus on the quality of the decisional process does not totally exclude this risk, since an assessment of that quality, too, requires an evaluative judgment from some normative frame of reference. And does not the principle of autonomy entail that the 
patient should be allowed to determine himself not only what he will decide, but also how he will reach his decision?

\subsubsection{Variability of the threshold of competence}

Variability of the threshold of competence, the fourth precondition, implies that more drastic decisions legitimise higher thresholds of competence (see, e.g., section 4.7 of this volume - first published as Welie JVM \& Welie SPK, 2001b, p. 133, 135). From a logical viewpoint, the gravity of a decision depends upon what is at stake in the decision to be made, and not upon the eventual outcome of actual decision-making. If one is to avoid a bias on substantial grounds in competence assessment, the demands made on the quality of the decisional process in case of consent have to equal those in case of refusal when it concerns one and the same decisional task (e.g., whether or not to accept life-saving treatment).

\subsection{Process STANDARDS AS THE MOST SUITABLE APPROACH}

\subsubsection{Process standards suit all preconditions}

An appraisal of the different standards mentioned in the section entitled Various criteria for assessment of patient competence (section 1.5) in light of the aforesaid preconditions for competence assessment, notably the third one, induces us to defend a process standard. Both other kinds of standards, i.e. minimal standards and outcome standards, cannot be maintained because they are in conflict with the third precondition, concerning the process character of competence. Minimal standards do not pay any attention to the process leading up to the decision at all. Therefore, they are too permissive. They pass over the fact that specific choices may very well be incompetently made. Outcome standards focus exclusively on the outcome of the decision-making. Thus, they are too much open to paternalistic interpretation by the health care professional. By the way, the third precondition makes the sliding scale bite the dust too. The sliding scale really hinges upon the outcome of the decision, in that it may deem a patient competent or incompetent depending on whether he assents to or refuses to assent to one and the same intervention proposed by the health care professional.

Process standards, however, suit all preconditions. Since they focus on the quality of the decision-making process and hence on the patient's 
decisional abilities, these standards can be summarised in the term decisional capacity (Berghmans, 2000, p. 44 ff.).

\subsubsection{The MacArthur approach}

Obviously, process or evaluative standards lend themselves for more than one interpretation. The conceptual definition of qualities and abilities that are presupposed for adequate health care related decision-making, given in Chapter 4 of this dissertation, forms an example of a process standard. According to the definition at hand, competence is the ability to will a course of events that corresponds with one's personal values. In this definition, four elements define patient competence: cognitive content (knowledge of facts and personal values), manipulation of cognitive content (analysing, reasoning, prioritising, integrating etc.), freedom of will, and means of expression. A well-known variation on this definition is the one on which the research has been financed by the Research Network on Mental Health and the Law of the MacArthur Foundation. This, so-called MacArthur approach does not explicitly use the element freedom of will, but places other elements in the forefront instead. In this approach, consensus has emerged about four abilities that are required for patient competence; these abilities are "understanding information relevant to their condition and the recommended treatment, reasoning about the potential risks and benefits of their choices, appreciating the nature of their situation and the consequences of their choices, and expressing a choice" (Grisso et al., 1997, p. 1415).

In line with this approach, the research group in question has developed an instrument: the MacArthur Competence Assessment Tool-Treatment (MacCAT-T) (Grisso \& Appelbaum, 1998). This instrument has the format of a semi-structured interview about the actual decision a patient is facing, plus guidelines for the rating process. On the basis of the answers given by the patient, the user of the MacCAT-T can rate to what degree the patient possesses the required abilities. The scores range from 0 to 2 , where 0 stands for a response meeting "no" credit, 1 for a response meeting "partial" credit and 2 for a response meeting "full" credit. The ratings can be added to obtain a summary rating for each of the four abilities. 


\subsection{Plea FOR A PROCESS STANDARD CALLED "RECOGNISABLE REASONS"}

\subsubsection{The danger of quantitative test scores}

For clinical purposes, another interpretation of the process standards is preferable to the MacArthur approach as elaborated in the MacCAT-T, namely the "recognisable reasons" approach (Freedman B, 1981; Erde, 1991; White, 1994). The latter approach avoids the appearance of being an objective test. Although the authors of the MacCAT-T do stress that "the MacCAT-T does not provide scores that translate directly into determinations of legal competence or incompetence" (Grisso \& Appelbaum, 1998, p. 190), the risk is not imaginary that in the hassle of everyday care and under pressure of work, quantitative ratings like those yielded by the MacCAT-T, once they have been recorded in the patient's file, go lead a life of their very own, and that low scores will nevertheless be equated with incompetence.

In addition to that, the recognisable reasons approach better accommodates both the descriptive (how does the patient actually handle the information pertaining to the decision at hand?) and the normative (is his way of handling this information "good enough" to be deemed competent?) aspects of patient competence assessment. See below (p. 34) for a visualisation of these aspects, given in Figure B.

\subsubsection{Recognisable reasons}

The recognisable reasons approach is closely related to the definition of qualities and abilities relevant for patient competence that is given in Chapter 4 (section 4.7) of this dissertation. According to the recognisable reasons approach, a person is competent when he can give recognisable reasons for his decision. The term recognisable indicates that the assessor need not agree with the reasons given by the patient. For the patient to be regarded as competent, it is sufficient if the assessor understands -or should have understood- that the reasons stated by the patient are indeed paramount from the perspective of the patient's values and norms. The recognisable reasons approach seeks the norm that is needed for an assessment of competence, in the individual values and the person of the patient in question. As noted before, this approach presupposes that a patient's values are to some extent knowable for the assessor. ${ }^{65}$ It goes without saying that when it comes to the crunch, the reasons for a decision can only make sense insofar as they build on the right facts. 
Otherwise, finding someone competent would not warrant application of the consequences attached to patient competence by the law (notably respecting refusal of treatment that is necessary to prevent serious harm to the patient ${ }^{66}$ ). In other words, the recognisable reasons approach includes understanding of relevant information as a criterion of patient competence.

The descriptive aspect of patient competence assessment (see Fig. B) is accommodated by the recognisable reasons approach, because it sticks to the considerations that the patient himself advances to account for his decision. When, on the occasion of an assessment of competence, uncertainty arises as to the way in which the person handles relevant information, or as to the extent to which he is able to process this information, supplementary diagnostic research in that respect, e.g. in the form of neuropsychological assessment by means of a test battery adapted to the actual question, may naturally be indicated from a professional viewpoint, in order to map further this way of handling or this ability. To that end, the health care professional can consult specialised colleagues or refer the patient to them, if necessary.

The recognisable reasons approach also accommodates the normative aspect of competence assessment (see Fig. B) by putting at the centre of our attention the question of whether the patient's considerations can pass for valid reasons in the patient's own frame of reference.

To summarise the recognisable reasons approach, it firstly requires that the patient's choice derive from his reasons, as a valid conclusion follows from the premises. Secondly, it requires that the reasons put forward by the patient (as the "premises" of his choice) constitute both an adequate reproduction of relevant facts and a plausible representation of his pertinent values and norms (Pincoffs, 1991).

\subsubsection{Relevance of the outcome of the decision}

It can be asked if the recognisable reasons approach satisfies the third precondition, i.e. that the outcome of the decision-making ought not to be the decisive factor in competence assessment. We have to acknowledge that the outcome of the decision-making definitely plays a role in this approach. After all, the concept of recognisable reasons presupposes not only that the quality of the reasoning process is good, but also that the patient's reasons justify his decision. If someone displays all sorts of intelligible motives for proceeding with intervention $\mathrm{x}$, and yet he then 
decides to refrain from $x$, the assessor of competence will not feel confident about this patient's competence, even though his motives show him to have perfectly understood and appreciated his situation. In this case, an assessor would like to hear reasons why the person decides to

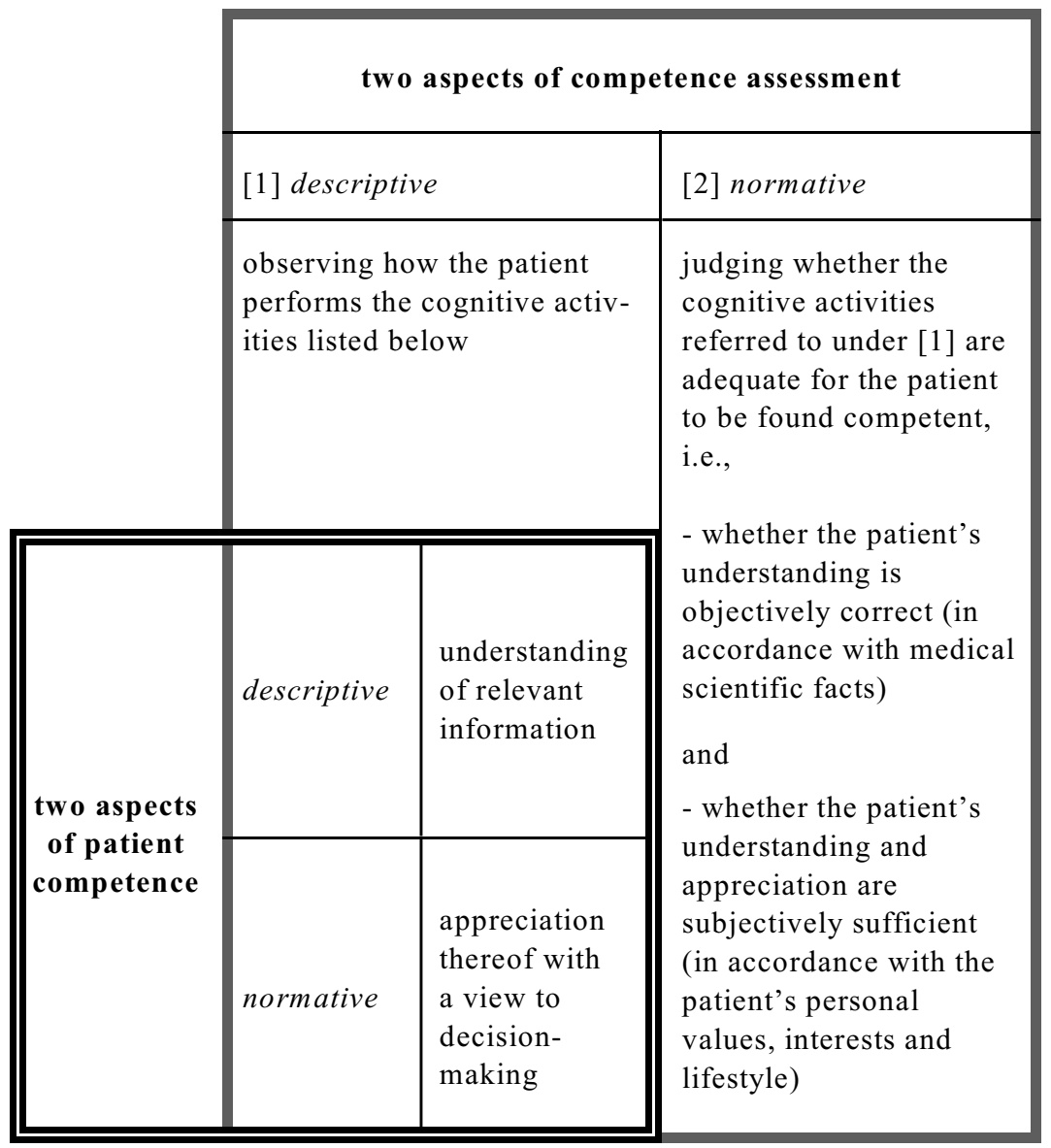

Figure B. Normative and descriptive aspects of patient competence and its assessment 
refrain from $\mathrm{x}$. For that, this person will have to come up with additional motives explaining his unexpected choice; furthermore, he will have to convince the assessor that the latter motives carry more weight for him than the former. Now that the recognisable reasons approach is not about an evaluation of the outcome of the decision in itself, but about the coherence between the patient's reasons and his eventual decision, the question posed at the beginning of this paragraph can be answered in the affirmative.

\subsection{LIMITED PSYCHOLOGICAL VALIDITY OF PROCESS STANDARDS}

\subsubsection{How do process standards relate to everyday choice behaviour?}

Upon the competence of patients, no higher demands ought to be made than are generally made upon people (Leenen \& Gevers, 2000, p. 35, 216 $\& 281)$. In light of this normative principle, it is interesting to ask how the criteria implied by the concept of decisional capacity -and those implied by the recognisable reasons approach, which forms a particular elaboration thereof- relate to the reality of everyday human informationprocessing, decision-making and choice behaviour. The concept of decisional capacity entails quite high demands on patient competence: it assumes conscious, consistent information-processing and relative clarity of underlying values.

\subsubsection{Unclarity of underlying values}

To begin with the latter, the tenability of the proposition that it is always clear what values a person pursues, is uncertain. For the person himself, too, these values are not given just like that. Rather, the patient, like all human beings, has to discover his own values through experience and in the interaction with other persons (Hermans, 1990, p. 11-23; Widdershoven GAM, 2000, p. 39-40; Hermans \& Kempen, 2002).

\subsubsection{Inconsistency and unconsciousness of information-processing.}

Moreover, much of normal human information-processing appears to be inconsistent and unconscious, actually (Freud, 1917; Piaget, 1973; Kihlstrom, 1987; Schacter, 1992; Reber, 1993; Wegner, 2002; Hassin, Uleman, \& Bargh, 2005). These psychological facts show us that the 
criteria involved in decisional capacity are at odds with the normative principle opening this section (see sub-section 1.11.1). Chapter 6 (section 6.8) of this dissertation hence argues that always asking of patients to meet the criteria in question, would far too often result in a conclusion of incompetence.

This even goes when attempts are made to enhance the patient's competence by improving the circumstances under which he has to make the decision (cf. also Grisso \& Appelbaum, 1998, p. 92 ff.). ${ }^{67}$ Thus, although from a legal and ethical perspective, process standards are the most suitable of the available standards for assessing patient competence, the psychological validity of process standards is questionable.

\subsubsection{Being involved in the decision-making, is not identical to being competent to decide}

The same kind of objections can be raised to the recognisable reasons approach. The assessor cannot look into the head of the patient. In order to be deemed competent, the patient himself must be able to give his reasons and to explain them in such a way that a competent health care professional can understand them, if the occasion arises for an explicit assessment of patient competence. This behaviour presupposes in the patient both a considerable amount of declarative knowledge of his own motives and reflection thereon.

When in the above-mentioned situation it is not so much the patient as it is the professional, who -on the basis of her familiarity with the patient and her interpretation of his actual, verbal or nonverbal behaviour- is able to formulate the "recognisable reasons" the patient may implicitly have, and to reconstruct his underlying values (or even to supplement the right relevant facts for decision-making), then, from a legal point of view, this is more a matter of involving an incompetent person in substitute decision-making, ${ }^{68}$ than a matter of having a competent patient make the decision. ${ }^{69}$ In sum, the recognisable reasons approach, too, makes rather high demands upon patient competence.

1.11.5. The importance of legitimate triggers for competence assessment and of due situational support

This means two things. Firstly, there have to be good reasons for proceeding to an assessment of patient competence. Secondly, if those 


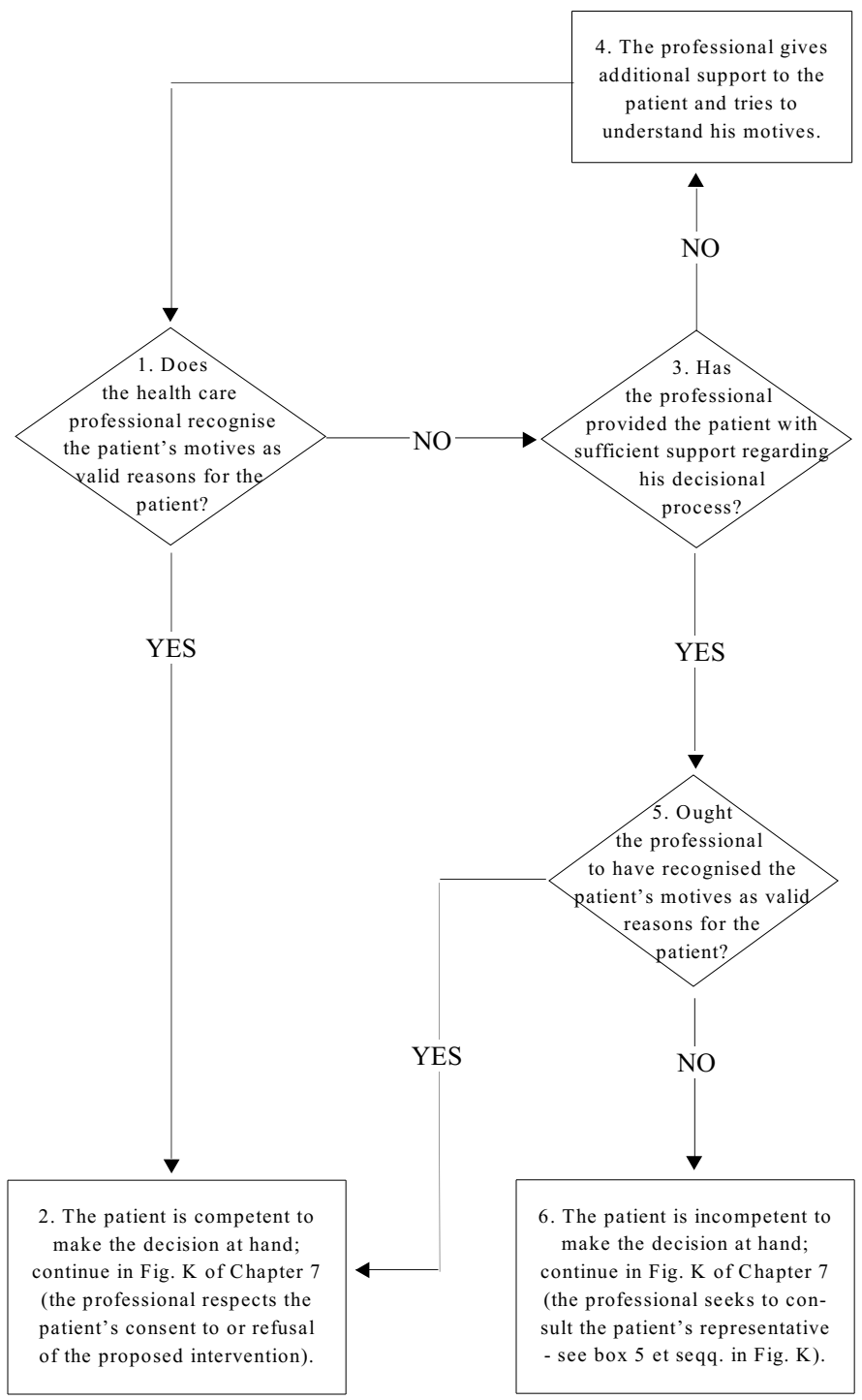

Figure C. Decision tree regarding the assessment of patient competence according to the recognisable reasons approach in combination with the notion of a supportive situation 
reasons indeed occur, every nerve should be strained to support the patient in his decisional process during the assessment. ${ }^{70}$ One has to avoid interpreting defective understanding or appreciation by the patient as incompetence, while the real cause is a lack of situational support. After all, for processing the information the patient is partly dependent on the situation in which he finds himself (cf. Lidz et al., 1983). This second matter has been visualised in Fig. C (see p. 37), which contains a decision tree regarding the assessment of patient competence according to the recognisable reasons approach in combination with the notion of a supportive situation.

\subsection{PATIENT COMPETENCE AS AN ETHICAL- ANTHROPOLOGICAL NOTION}

\subsubsection{An axiomatic aspect of patient competence}

The concept of patient competence turns out to raise innumerable problems: vagueness of legal definitions, a multitude of criteria, dissensus on the right approach, confusion of ideas due to different (implicit) presuppositions, contestability because of the concept's normative character, elusiveness of patient values, possible conflict with preconditions of competence assessment, unrealistically high demands on information-processing by patients (cf. Welie JVM \& Welie SPK, 2001a). As soon as one problem is recognised, its solution seems to imply new problems (cf. van Tongeren, 1991, p. 4-6). This circle can only be broken by conceiving patient competence as an ethical-anthropological notion. By "ethical-anthropological notion" I mean a normative (i.e., "ethical") view (i.e., "notion") of human beings (i.e., "anthropological") dictating that they deserve as much respect as possible. This view is an axiomatic postulate, rather than a notion that can be reduced to particular perceptible mental properties, qualities, capacities, traits or states (de Boer, 1980, p. 78-97; de Boer, 1983, p. 78-99; Berghmans, Welie SPK, \& Widdershoven GAM, 2004, p. 44-45). ${ }^{71}$

Adherence to this postulate means simply presuming competence in most cases, and generally not wanting to assess it. Furthermore, adherence entails a shift from a focus on formulating criteria by means of which competence could be assessed, to an obligation to strive for creating circumstances under which the patients' competence can safely be presumed. Only when legitimate triggers ${ }^{72}$ for assessment are present, is it no longer safe to presume competence, and do criteria of competence 
acquire relevance; in all other cases, these criteria are irrelevant (see lower left cell in Figure D on p. 39).

It is important to emphasise that adherence to the axiomatic postulate can result in assuming patients to be competent, where they would have been found incompetent had they been tested using criteria of competence.

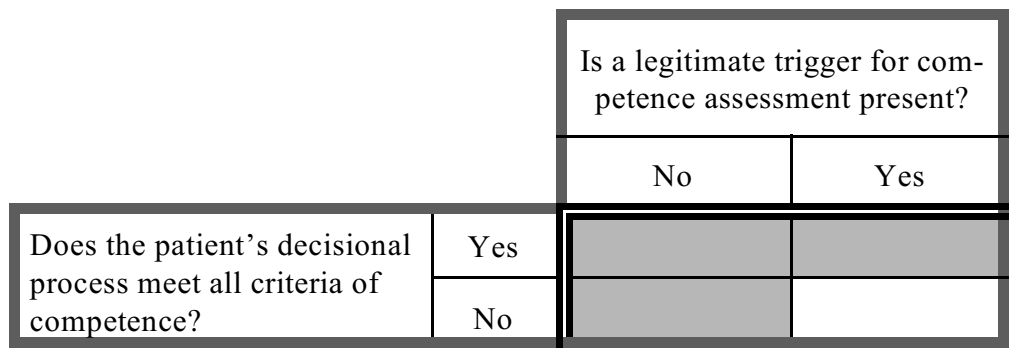

Figure D. The situations in which a patient must be treated as competent (grey cells)

These axiomatic figures of assumed qualities are not uncommon in law. One only has to think of many an example of basic legal values and principles that can be found in various declarations and treaties of human rights, such as human dignity, freedom and equality (cf. van Tongeren, 1991, p. 28). E.g., human beings are invested with dignity, not because they have certain properties, but "just" because they are human. ${ }^{73}$

\subsubsection{The assumption of competence as a fiction of law}

The fact that the ethical-anthropological notion of competence is not equivalent to competence as a testable quality, the former being broader than the latter (cf. Fig. D), is connected with the sixth aspect of the assumption of competence, i.e. its potential function of a fiction of law. ${ }^{74}$ The tenor of this ethical-anthropological notion can be so strong, that patients must possibly be assumed competent also when the quality of their decision-making process has not been examined separately from its outcome, or even when the quality of this process demonstrably falls short of certain agreed upon criteria. The sliding scale ${ }^{75}$ is really an example of the use of competence as a fiction: in many cases, namely always when the patient accepts unproblematic interventions or rejects problematic ones, it does not encompass a test of competence on the basis of his decisional process, but a substantial standard on the basis of the outcome of his decision; the patient's competence is then assumed, 
regardless of the degree to which his decisional process does or does not comply with the criteria.

In sum, the tenor of patient competence conceived as an ethicalanthropological notion, is that competence ought usually to be presumed, and that an explicit assessment of competence should be by-passed as much as possible. Is this permissible from a positive legal point of view?

\subsection{A CLOSER LOOK AT THE LEGAL FRAMEWORK}

\subsubsection{Legal grounds for sidestepping competence assessment}

The answer to the question just asked runs short but sweet: yes. More than that, not only can competence assessment frequently be sidestepped; it also has to be legally. Such an assessment should only take place exceptionally (cf. Leenen \& Gevers, 2000, p. 36-37 \& 217; Legemaate, 1994, p. 328-329). Several legal reasons can be put forward for this. Firstly, this is the essence of the assumption of competence. Secondly, there are various positive statutory grounds implying that assessment of competence is often unnecessary. ${ }^{76}$ These grounds are discussed in Chapter 3 of this dissertation. ${ }^{77}$ Mostly, the deeper cause is to be found in the fact that the health care professional is expected to act as the observer and keeper of the interests of her patient. Chapter 7, notably section 7.7, entitled Beyond the procedural role of the health care professional, treats numerous instances of this obligation. ${ }^{78}$

\subsubsection{Legitimate triggers for competence assessment}

Therefore, we propose an alternative decision tree, which precedes the one included in Chapter 7 (section 7.4). This alternative tree actually concerns what constitutes a legitimate trigger for explicit assessment of competence $^{79}$, with the attached legal consequences as described in the Dutch Civil Code. ${ }^{80}$

The alternative decision tree contains two triggers. The first trigger pertains to the situation in which the health care professional has reason to suspect that the patient's assent to the intervention proposed by her, goes against this patient's personal values.

This might be the case for patients who foster values that deviate from those which are common in society and expressed in her professional standard. ${ }^{81}$ One can think of a patient from a minority culture or with a 


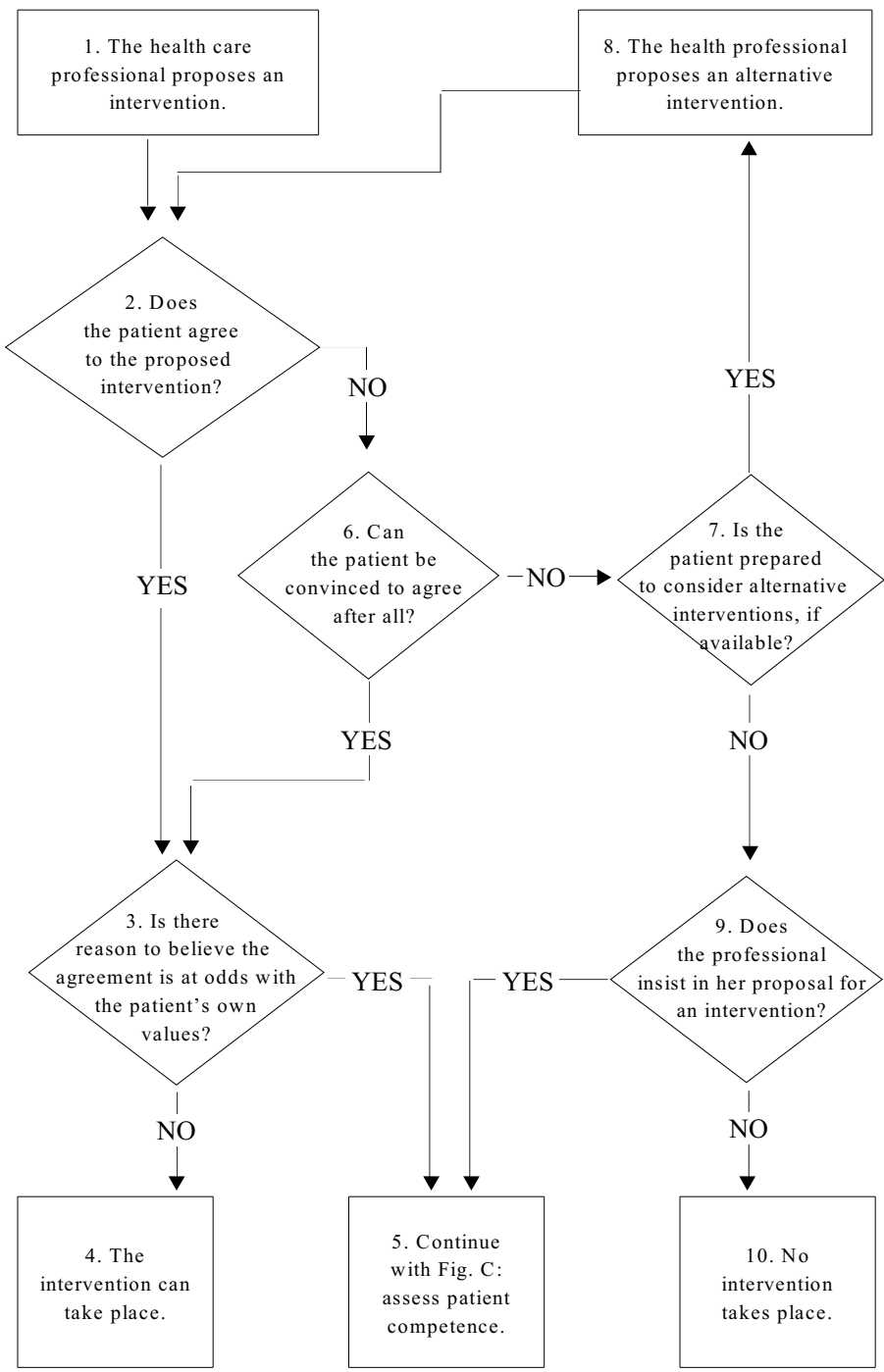

Figure E. Decision tree regarding legitimate triggers for competence assessment 
specific religious or ideological background. It could be objected that this example smacks of possible discrimination. However, there are reasons for employing it. In the case of a patient with a different cultural background, the professional cannot take for granted that the interventions proposed by her on the basis of her professional standard, match the patient's values, not even when he is assenting to the intervention. Furthermore, differences in cultural background between health care professional and patient may hamper effective communication, so that there is less cause for trusting the professional to be able to act as the observer and keeper of the interests of her patient. ${ }^{82}$ An explicit role may under these circumstances be indicated for the patient in decision-making, and an assessment of his competence with that.

The suspicion that the patient's assent goes against his own values, might also arise when the patient's actual assent runs counter to his stable previous behaviour, or when a trusted family member who accompanies the patient to surgery hours, shows amazement at the patient's assent. Then, again, the health care professional will want to make sure that this assent can really form the basis upon which to implement the intervention, in other words, that it forms a competently made, legally valid, informed consent.

The second trigger relates to the existence of lasting dissension between the professional and the patient as to the question of what is good care in the present situation. If repeated attempts to find an alternative option satisfactory to both the patient and the health care professional are unsuccessful, in which attempts the professional must have critically reexamined her own professional possibilities in order to optimally take into account the wishes and background of the patient, then the procedural solution consisting in an explicit assessment of competence seems unavoidable.

Figure E (p. 41) visualises these two triggers and their place in decisionmaking. The two respective triggers correspond with the two problems to the solution of which an assessment of patient competence aims at contributing. The first trigger (cf. boxes 2 , or $6, \rightarrow 3 \rightarrow 5$ in Fig. E) corresponds with doubts as to what constitutes good care for the patient in question, where "good" means not only within the professional standard but also in keeping with the patient's values. The second trigger (cf. boxes $6 \rightarrow 7 \rightarrow 9 \rightarrow 5$ in Fig. E) corresponds with the desire to prevent unjust use of any possible compulsion in implementing some specific care intervention. 


\subsection{3. "The complete picture"}

To get the complete picture, one should first enter Fig. E, then go on to Fig. C, if necessary, and finally, possibly consult Fig. K in Chapter 7 of this dissertation (p. 184). In this overview's section 1.3, entitled The background of two competing ethical principles, the times when health care professionals could paternalistically take over all decision-making for their patients, turned out to be definitively past. The overview's argument has hopefully shown that this does not mean that professionals have now become sheer "health care technicians", who do not and should not engage in judging their patients' interests but only follow consents or refusals with regard to medically indicated interventions. On the contrary, the patient's interests and values are an important beacon for professional action (cf. boxes $3 \& 8$ in Fig. E and boxes $1,4 \& 5$ in Fig. C). This state of affairs necessitates further reflection upon different possible models of the relationship between health care professional and patient (Szasz \& Hollender, 1956, p. 586-587; Faden et al., 1986, p. 62; Lidz et al., 1988; Moody, 1988; Ballard-Reisch, 1990; Agich, 1990; Berghmans, 1992, p. 24 ff.; Emanuel EJ \& Emanuel LL, 1992; Laín Entralgo, 1995; Bloom, 1995; Purtilo, 1995; Emanuel EJ \& Emanuel LL, 1996, p. 232; Morgan, 1997, p. 52; Bensing, 1998, p. 128).

\subsection{CONCLUSION}

From the legal, psychological and ethical perspectives likewise, it is more important to use best efforts to shape the interaction and consultation between health care professional, patient and other persons from the patient system possibly involved, in such a way that a health care option is found which is acceptable for everyone concerned, than it is to formulate concrete criteria of decision-making competence on the basis of which to deprive the patient of his power to decide. After all, that is what ready-made criteria will also have as an effect: where professionals will exercise some reserve when those criteria are lacking -to prevent arbitrary assessments-, the presence of such criteria would make it all too easy for them to pass judgment on patient competence, with a declaration of incompetence as possible outcome -albeit a "careful" or "accountable" declaration of incompetence-. Insofar as competence assessment is nonetheless necessary with a view to protecting the patient against unwanted, detrimental decisions, it is essential for the sake of clarity of the discussion and truthfulness to the underlying principles to use criteria that comply with the generally accepted starting-points. In this respect, recognisable reasons is the best approach. 


\subsection{Notes}

1. See note 21 on the etymology of the word autonomy.

2. In Dutch: "Burgerlijk Wetboek", abbreviated hereafter as "BW".

3. In order to enhance the readability of this overview chapter, masculine pronouns will be systematically used to refer to patients or their representatives, and feminine pronouns to refer to health care professionals.

4. Please note that the term patient incompetence (in American English usually called mental incapacity; "wilsonbekwaamheid" in Dutch) ought not to be confused with the term legal incapacity ("legal incompetence" in American English; "handelingsonbekwaamheid" in Dutch), the former referring to the actual inability to perform the decisional task at hand sufficiently, as assessed by the clinician e.g. (in Dutch law, it is mostly the health care professional that determines whether or not a patient treated by her is competent - (Slabbers, 2006, p. 145-147), and the latter to a formal legal category, namely the inability to perform independently non-annullable juridical acts, which inability results from statutory provision or judicial decision. Chapter 7 (sub-section 7.3.2) of this dissertation contains a more detailed account of the differences between these two concepts.

See also sub-section 1.8.3 of the current chapter for additional information about the task-specificity of competence.

5. See section 1.4 for a further description of legal consequences.

6. Where the other sub-questions are treated in this overview, is indicated by notes in section 1.2 .

7. Cf. note 40 .

8. Section 1.3 concerns sub-questions "a" (sub-sections 1.3.1-1.3.4, 1.3.6) and "b" (sub-sections 1.3.5, 1.3.7). In connection with sub-question "b", see also section 1.7.

9. Section 1.4 concerns sub-question "c".

10. Section 1.5 concerns sub-question " $d$ "; in connection with this subquestion, see also sections $1.9 \& 1.10$. 
11. Section 1.6 concerns sub-questions "e" (sub-section 1.6.1) and "f" (subsections 1.6.2-1.6.3). In connection with sub-question "e", see also sections $1.7 \& 1.11$. In connection with sub-question "f", see also section 1.12 .

12. Section 1.7 concerns sub-questions "e" and "b" (sub-section 1.7.2). In connection with sub-question "e", see also sections $1.6 \& 1.11$. In connection with sub-question "b", see also section 1.3.

13. Section 1.8 concerns sub-question "g".

14. Section 1.9 concerns sub-questions " $h$ " (sub-section 1.9.1), "d" (subsection 1.9.2) and " $i$ " (sub-section 1.9.2). In connection with subquestion "h", see also section 1.10. In connection with sub-question "d", see also sections $1.5 \& 1.10$. In connection with sub-question "i", see also section 1.10.

15. Section 1.10 concerns sub-questions "i" (sub-section 1.10.1), "d" (subsection 1.10.2) and "h" (sub-section 1.10.3). In connection with subquestion "i", see also section 1.9. In connection with sub-question "d", see also sections $1.5 \& 1.9$. In connection with sub-question " $h$ ", see also section 1.9 .

16. Section 1.11 concerns sub-questions " $j$ ", "e" and "l". In connection with sub-question "e", see also sections $1.6 \& 1.7$.

17. Section 1.12 concerns sub-questions "f" (sub-section 1.12.1) and "m". In connection with sub-question "f", see also section 1.6. In connection with sub-question "m", see also section 1.13 .

18. Section 1.13 concerns sub-question "m"; in connection with this subquestion, see also section 1.12.

19. By the way, although medical experiments form the historical cause for putting legal-ethical regulation of research on the agenda, protection of subjects is not only imperative in regard to medical research with patients, but also in regard to other scientific research using human subjects, e.g. psychological studies. Like medical research, undergoing psychological research can be drastic for the subject. Besides the risks and inconveniences associated with the research, this is due to a possible element of deception as to the object and design of the study (Welie SPK, Blomert, Merckelbach, \& de Vries, 2004). 
20. Etymologically, the term beneficence (beneficentia) is composed of two Latin words, namely the adverb bene (well, in a good manner) and the verb facěre (to make, to do).

21. The word autonomy is a compound of the Greek pronoun $\alpha$ v̇ $\tau$ ć / autos, meaning "self", and the Greek substantive vó meaning "that which is in habitual practice", "custom", "law". Hence,

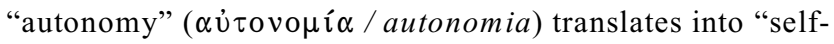
determination" or "independence". The term self-determination is common among lawyers, the term autonomy among ethicists. As can be expected on account of their etymological connection, both concepts have a substantial affinity too. Nevertheless, there are also important differences in meaning between these two concepts, though those who use the terms, do not always seem to be conscious of that. These differences in meaning relate to the differences that exist between law and ethics in general. This dissertation is not the place to go more deeply into this issue. For brevity's sake, henceforth the term autonomy will be mostly used, while not thus taking sides with either the ethicists or the lawyers.

22. Originally, the right to self-determination had respect to peoples as a whole, not to individual people. Cf. art. 1 section 1 first sentence of the International Covenant on Civil and Political Rights (1966) and art. 1 section 1 first sentence of the International Covenant on Economic, Social and Cultural Rights (1966), both of which state that "[a]11 peoples have the right of self-determination".

23. See Union Pacific Railway Company v. Botsford, 1891 (Justice Gray, citing Judge Cooley); Olmstead v. United States, 1928 (Justice Brandeis, dissenting).

24. Schloendorff v. Society of the New York Hospital, 1914 (Justice Cardozo).

25. Slater v. Baker and Stapleton, 1767.

26. Or "intelligent consent" (Faden et al., 1986, p. 125).

27. Salgo v. Leland Stanford Jr. University Board of Trustees, 1957.

28. Cf. the section entitled Introduction (in particular the first starting-point (i.e., task-specificity) in sub-section 1.1.5).

29. See art. 1:32 BW. 
30. See art. 1:266 \& 1:377a section 3 sub b BW.

31. See art. 4:942 ff. (old) / 4:55 ff.(new) BW.

Cf. also Koninklijke Notariële Beroepsorganisatie (2006).

32. See art. 34 a section $1 \& 34 \mathrm{p} \mathrm{j}^{\circ} 34 \mathrm{c}$ sub a Special Admissions into Psychiatric Hospitals Act. Please refer to sub-section 1.4.3 for more information about this statute.

33. See art. 2 sections 2-4 Termination of life on request and assisted suicide (review procedures) Act (in Dutch: "Wet Toetsing levensbeëindiging op verzoek en hulp bij zelfdoding").

34. See art. 7:465 $\mathrm{j}^{0}$ 7:448 \& 7:450 BW.

35. As stated before, the regulations comprised by the Dutch Civil Code make up the legal framework for the present analysis. See the section entitled Introduction (in particular the second starting-point in subsection 1.1.5).

36. In Dutch: "Wet Bijzondere opnemingen in psychiatrische ziekenhuizen", abbreviated hereafter as "W et Bopz".

37. As of $1^{\text {st }}$ June 2008, the Special Admissions into Psychiatric Hospitals Act has been changed (Wet van 25 februari 2008, Stb. 2008, 80). Before that date, art. $38 \mathrm{Wet} \mathrm{Bopz} \mathrm{pertained} \mathrm{to} \mathrm{all} \mathrm{three} \mathrm{sectors} \mathrm{covered}$ by this statute, i.e., psychiatric care, psychogeriatric care, and care for persons with mental retardation/intellectual disabilities. Now, art. 38 Wet Bopz regulates the two latter sectors only, whereas the sector of psychiatry is regulated by the newly added articles 38a-38c Wet Bopz.

38. Cf. art. 38 section 5 first and second sentence $\mathrm{j}^{\mathrm{o}}$ art. 38 section 2 second and third sentence $\mathrm{j}^{\mathrm{o}}$ art. 38 section 1 first sentence Wet Bopz; art. $38 \mathrm{~b}$ $\mathrm{j}^{\mathrm{o}}$ art. $38 \mathrm{a}$ section $4 \mathrm{j}^{\circ}$ art. $38 \mathrm{a}$ section $3 \mathrm{Wet}$ Bopz; art. $34 \mathrm{a}$ section $1 \&$ art. $34 \mathrm{p} \mathrm{j}^{\circ}$ art. $34 \mathrm{c}$ introduction and sub a Wet Bopz; art. 34o section 2 introduction and sub a Wet Bopz.

39. The committee that has conducted the third official evaluation of the Special Admissions into Psychiatric Hospitals Act, draws the same conclusion in its 2007 report (Derde evaluatiecommissie van de Wet Bopz, 2007, p. 93, 95, 99 \& 113), which conclusion has been adopted by the Dutch government (Kabinetsstandpunt, 2008, § 2.5). 
40. Competence assessment involves certain activities on the part of the health care professional in her interaction with the patient, like checking whether the patient has understood pertinent factual information and having the patient explain his motivation for a specific choice, depending upon the exact criteria one applies. It is possible that the same activities that are involved in competence assessment, are undertaken by the professional with some goal other than determining who should have decisional power. Examples of alternative goals might be searching treatment options that better suit the needs of the patient or finding ways to explain information to the patient that are adapted to his frame of reference and cognitive abilities. This theme is embroidered on in section 1.13. It is a question of semantics whether or not one would like to call these activities competence assessment. See also the central thesis of this dissertation in sub-section 1.1.8.

41. See sections $1.8 \& 1.9$; cf. also DeMarco, 2002.

42. See the ethical working definition of patient competence given in subsection 1.3.6.

43. Cf. e.g. the following quote: "Every single human being [...], by the mere fact of his existence $[\ldots]$, imposes a law on whole mankind $[\ldots]$ " ("Ieder mens legt [...] alleen al door het feit van zijn bestaan [...] aan het hele mensdom een wet op [...]”) (Scheltens, 1981, p. 49).

44. Cf. the words "at hand" in the statutory definition mentioned in subsection 1.5.1; see also (sub-)sections 1.1.5 and 1.8.

45. Cf. the evaluative phrase "reasonable judgment" in the statutory definition and the premise that patients can pursue individual, idiosyncratic values and norms - see section 1.3.

46. In abstracto, one general definition of competence may be suitable for patients with different values, e.g., being able to make a decision that is in accordance with one's own personal values. In concrete cases however, different mental operations are involved, depending on what values an individual patient pursues.

The choice between surgery and radiotherapy for a patient with laryngeal cancer can serve as an example. Suppose that surgery entails functional loss of one's voice and very good chances of survival, and that radiotherapy implies retention of the voice and a short life expectancy. Choosing the latter intervention might be a bit awkward for a woodcarver who suffers from this disease, but it could be perfectly understandable for an opera singer with the very same medical 
condition.

47. This plea contrasts sharply with the finding of Fiselier et al. (Fiselier, van der Waal, \& Spijker, 2006, p. 384) that when patients hold religious outlooks on life, this is by many psychiatrists considered a sign of pathology. The latter attitude is illustrated by the following quotation of one of the interviewed psychiatrists: "If I hear that someone is religious, I estimate his IQ about 20 points lower."

The plea also gains approval from various sides. According to General principle E in the American Psychological Association's Ethics code, respect for people's rights and dignity includes respect for differences based on religion (American Psychological Association, 2002a; however, cf. Ethical standards 3.01 \& 3.03 too). The American Psychological Association's so-called multicultural guidelines give a further elaboration (American Psychological Association, 2002b; see Guidelines \#2 \& \#5).

In the same vein, article 12 of the Universal Declaration on Bioethics and Human Rights states that " $[\mathrm{t}]$ he importance of cultural diversity and pluralism should be given due regard" (General Conference of UNESCO, 2005).

The Committee of Ministers of the Council of Europe recommends its member states to promote that health care providers acquire "cultural competence", i.e., "the ability to provide effective health care services taking into consideration the individual's [...] religious, spiritual and cultural beliefs" among other things (Committee of Ministers of the Council of Europe, 2006; see General consideration 1 in the Appendix to Recommendation $\operatorname{Rec}(2006) 18)$.

For a historical excursion into Roman times, see Mendelson (2007) on philosophical orientation as factor in decision-making.

48. The term "universal" meaning that they are applicable to all possible patients.

49. The term "concrete" meaning that their application in a specific case directly leads to a conclusion of competence or incompetence.

50. Cf. the remarks on paternalism in criteria of patient decision-making competence in Chapter 4 (section 4.5 ) of this dissertation.

51. See section 1.5 of this chapter.

52. Cf. Chapter 4 (section 4.5) of this dissertation. 
53. See Chapter 7 (section 7.8) of this dissertation.

54. Cf. the value-specificity of patient competence, mentioned in the previous section (sub-section 1.6.2).

55. By the way, even the patient who does not understand "crucial" information, might still be competent, namely when his values and interests deviate so much from what the professional believes to be his values and interests, that the information which the professional thinks is crucial for the decision, is really not at all crucial or even relevant; cf. Fig. B (see section 1.10).

56. See sub-section 1.3.7.

57. All the same, even within one individual person, the existence of conflicting values and the possibility of gradual or sudden development -and hence, change- of values have to be acknowledged (see Chapter 6 of this dissertation, section 6.8).

58. See Chapter 7 of this dissertation.

59. From the perspective of the health care professional -as the regular assessor of patient competence-, this presupposition amounts to a situation in which -on the one hand-she is expected not to interfere in the patient's "personal business" (in order to avoid unwanted paternalism) and -on the other hand- such interference is required for being able to accomplish competence assessment (with a view to the necessary personal background information for this assessment). This problem might very well be an additional explanation of the empirical finding, described in Chapter 3 of this dissertation, that health care professionals do not usually engage in explicit assessment of competence.

60. Think of measures like "curatele" or "mentorschap"; cf. Chapter 7 (subsection 7.3.2) of this dissertation.

61. See below, in section 1.13 .

62. Cf. art. 7:454 section $1 \mathrm{j}^{\circ}$ art. 7:465 sections $2 \& 3 \mathrm{BW}$; art. 56 section 2 sub a j ${ }^{\circ}$ art. 38 section 2 second sentence $\&$ art. 38 a section 4 first sentence Wet Bopz.

63. See Rb. Arnhem 20 juli 2005, BJ 2005, 40 m. nt. Welie SPK, p. 245. 
64. See also section 1.1 (sub-section 1.1.5).

65. See section 1.7 .

66. See section 1.4.

67. Cf. Chapters 2 (sub-section 2.9.2) \& 5 (sub-section 5.6.1) of this dissertation.

68. Cf. art. 7:448 section 1 second sentence \& art. 7:465 section $5 \mathrm{j}^{\circ} 1: 454$ section $1 \mathrm{j}^{\mathrm{o}} 1: 381$ section $4 \mathrm{BW}$.

69. See section 1.4.

70. Cf. the second principle of the English Mental Capacity Act 2005: "A person is not to be treated as unable to make a decision unless all practicable steps to help him to do so have been taken without success" (http://www.opsi.gov.uk/acts/acts2005/20050009.htm).

71. In his exposition on the foundations of a critical psychology, de Boer (1983) distinguishes five "postulates of dialogue", i.e., intentionality, integrity (composed of truthfulness \& reliability), rationality, unicity and authenticity.

72. See also sub-section 1.13.2.

73. To name just two examples, the preamble of the Treaty establishing a Constitution for Europe (Rome, 2004), which treaty has not come into force (see below), speaks of "the inviolable and inalienable rights of the human person".

Additionally, the preamble of the Charter of fundamental rights of the European Union (Nice, 2000; Strasbourg, 2007), which was to form part II of the European constitutional treaty, mentions "the indivisible, universal value[...] of human dignity".

By the way, the aforesaid Treaty establishing a Constitution for Europe has never been implemented. Here is why. It was signed in Rome by representatives of the 27 member states of the European Union on the $29^{\text {th }}$ of October 2004 . Then most member states ratified it; however, the rejection in referenda by France and the Netherlands in 2005 caused postponement of the ratification process.

After a period of reflection, the European Council meeting in June 2007 decided to start negotiations on a Reform Treaty as its replacement. This treaty, which does not amend the formulation quoted from the 
preamble, was signed in Lisbon on the $13^{\text {th }}$ of December 2007 (Treaty of Lisbon amending the Treaty on European Union and the Treaty establishing the European Community, 2007). The ratification process of the Treaty of Lisbon is now taking place in the member states. As of $13^{\text {th }}$ June 2008 , the treaty has been ratified by 18 member states; Ireland voted against the treaty in a referendum on the $12^{\text {th }}$ of June 2008 .

74. See sub-section 1.8.2.

75. See section 1.5 .

76. One ground relating to the "respect of resistance" rule -see section 1.4 (sub-section 1.4.2)-, another one relating to shared decision-making by patient and possible representative, i.e. a course of action in which together they make decisions that are endorsed by both of them, without explicit assessment of the patient's competence in the matter at hand - the so-called "dual strategy" (cf. Schermer, 2001, p. 149-151).

77. See particularly section 3.7 .

78. Similar conclusions are drawn by Touwen in her dissertation on substitute decision-making for incompetent patients in nursing home medicine, where she writes that in the relationship between physician and representative, it is the physician's responsibility to guard the interests of the patient (Touwen, 2008; see p. 291-292 \& 299-302).

79. Cf. the second aspect of the assumption of competence in sub-section 1.8.2.

80. See section 1.4 .

81. For all practical purposes, the situation where the professional does not have a clue what values her patient fosters, should be considered equivalent to a suspicion of deviant values, with regard to this first trigger.

82. Multicultural Guideline \#1 of the American Psychological Association states that "[p]sychologists are encouraged to recognize that, as cultural beings, they may hold attitudes and beliefs that can detrimentally influence their perceptions of and interactions with individuals who are ethnically [...] different from themselves", where ethnicity is defined in terms of "one's culture of origin" (American Psychological Association, 2002b).

Sometimes, "communication problems" can be taken very literally. 
Therefore, Strategy 3 in Recommendation No. Rec(2006)18 of the Committee of Ministers of the Council of Europe concerns the removal of language barriers (Committee of Ministers of the Council of Europe, 2006). 


\title{
2. INCLUSION OF PATIENTS WITH SEVERE MENTAL ILLNESS IN CLINICAL TRIALS: ISSUES AND RECOMMENDATIONS SURROUNDING INFORMED CONSENT
}

\author{
S.P.K Welie \& Berghmans
}

\subsection{ABSTRACT}

Modern medicine would be unthinkable without the possibility of administering pharmaceuticals and other evidence-based interventions. The development of these interventions requires scientific research, ultimately with human subjects. This venture raises ethical, legal and human rights issues, which are addressed in numerous national and international declarations and regulations. In these documents, special attention is usually directed towards research involving vulnerable groups, such as children, pregnant women, unemployed persons, refugees, patients with psychiatric disorders, dementia or mental retardation, and those who are dying.

In relation to patients with psychiatric disorders, two important and mutually connected ethical questions can be posed. Firstly, is research with persons who have severe psychiatric illnesses permissible? And, secondly, how can the mental capacity of prospective research subjects be assessed? We investigate these questions using the Dutch legal system as an example.

Regarding the first question, the Dutch Medical-Scientific Research on Human Subjects Act (1998) presents a detailed regulation that is in line with relevant international documents, such as the Convention on Human Rights and Biomedicine (1997). In the Dutch statute, the possibilities for research involving subjects who lack mental capacity are limited, but not completely excluded. Under certain conditions, two types of research are exempted from the general prohibition of research with such subjects that is included in article 4 of the statute. These two types are (i) therapeutic research and (ii) non-therapeutic research that could not take place without the participation of subjects from the category to which the mentally incapacitated person belongs. The conditions pertain to ethical and scientific review, insurance, written proxy consent and respect for resistance by the subject. An extra condition for the permissibility of non- 
therapeutic research is that the risks for the prospective subject are negligible and the burdens minimal. Although the Dutch regulation obviously does not solve all problems, it is relatively clear when compared with the situation in other European countries, such as Belgium, France, Germany, and England and Wales.

Regarding the second question, two basic factors need to be considered when defining 'mental capacity'. These relate to the assumption of competence and to the task-specificity of capacity. The crucial issue in assessing mental capacity is not whether a psychiatric diagnosis is present, but whether the patient has the mental abilities required to make the decision at hand in a meaningful way. In establishing an appropriate standard for capacity assessment, several interests have to be weighed. The ethical demands of protection of subjects and stimulation of scientific research may be balanced by attempting to enhance patients' mental capacity. The procedure of 'experienced consent' seems promising in this regard, although this approach entails its own ethical problems.

\subsection{INTRODUCTION}

Modern medicine would be unthinkable without the possibility of administering pharmaceuticals and other evidence-based interventions. The development of these interventions requires scientific research, ultimately with human subjects. This venture raises ethical, legal and human rights issues, which are addressed in numerous national and international declarations and regulations (Capron, 1999). In these documents, special attention is usually directed towards research involving vulnerable groups, such as children, pregnant women, unemployed persons, refugees, patients with psychiatric disorders, dementia and mental retardation, and those who are dying (Dresser, 1999). Such groups are considered 'vulnerable' because, as a result of their medical condition or specific status, they may be restricted in their freedom to decide whether or not to participate in research.

This review focuses on the ethics of including patients with severe mental illness, such as schizophrenia or major depression, in research; however, many of the issues discussed are also relevant to patients with impaired cognition or learning disabilities.

In relation to patients with psychiatric disorders, two important ethical questions can be posed (Eckstein, 2003; Roberts LW \& Roberts B, 1999).

Firstly, is research involving persons who have a severe psychiatric illness permissible? It will be shown that, from a legal and ethical viewpoint, the answer to this question is primarily determined by the 
persons' mental capacity (Carpenter et al., 2000). Having mental capacity is not equivalent to not having a specific psychiatric diagnosis, and vice versa (Berghmans, 2001). In determining a person's mental capacity, what is crucial is whether the person has the mental abilities to perform the decisional task at hand. A particular psychiatric diagnosis may leave intact the required abilities, whereas, by contrast, the relevant abilities of a person who does not have a psychiatric illness may be adversely affected by numerous factors such as young age, intellectual development, fatigue, intense emotion or general anaesthesia. Therefore, the second question is - how can the mental capacity of prospective research subjects be assessed?

These two questions will be explored by discussing five topics: (i) the historical and conceptual background to the questions posed above, using examples of unethical research studies that have triggered ethical debate and legal regulation, and paying attention to the principle of respect for individual autonomy; (ii) legal and ethical documents developed to govern human research; (iii) the Dutch regulation regarding research, to serve as a model for evaluating the types of clinical research that are permissible in patients with psychiatric illnesses; (iv) a comparison of this regulation with those from four other European countries); (v) the phenomenon of 'therapeutic misconception'; and (vi) approaches to defining mental capacity.

\subsection{Historical Background to Ethics in Research}

The history of unethical involvement of human subjects in research has been extensively documented (Annas \& Grodin, 1992; Jones, 1993; McNeill, 1993; Pappworth, 1967; Weyers, 2003). In what follows, some of the major events are outlined.

The experiments that took place in Nazi Germany during World War II were important stimuli for the regulation of human research. In these experiments, prisoners in concentration camps were used as subjects (Weyers, 2003). The researchers involved were later judged by the Nuremberg tribunal (Annas \& Grodin, 1992), and the tribunal's verdict, issued in 1947, outlined the conditions under which research with human subjects is permissible, conditions that later became known as the Nuremberg Code (see sub-section 2.4.1) (Burt, 1996; Katz J, 1993; Nuremberg Military Tribunals, 1947). Among these conditions are the requirements that the prospective subject be informed about the intended research and that the subject be allowed to decide freely whether or not to participate (principle 1). 
Germany was not the only place where unethical research took place during World War II - it also happened in Japan (Morimura \& Shimozato, 1983; Whymant, 1983). This is less well known because of a deal brokered after the war between Japanese scientists and the US government, which was very interested in the results of the research. In the Japanese research, prisoners of war were subjected to various interventions, such as injection with pestilence, cholera, typhoid or other bacteria; freezing of the extremities; systematic deprivation or starvation; infection with syphilis; protracted exposure to x-rays; and vivisection. These types of studies were aimed particularly at developing methods for biological warfare (Bergkamp, 1988; Weyers, 2003; Whymant, 1983). The conditions of the deal were that the results of the Japanese experiments would be put at the disposal of the US government, in exchange for immunity from criminal prosecution for the scientists involved. Obviously, this was kept strictly secret, as, at the same time, German scientists and physicians were standing trial in Nuremberg for their misdeeds (Bergkamp, 1988).

Unfortunately, the end of World War II did not see an end to unethical research, as was highlighted in a famous article by Beecher (Beecher, 1966). This article gives an account of 22 unethical studies, which were only a subset of 50 easily found unethical studies. One example that is relevant to this present review is the Willowbrook experiment, so called after the institution where it was conducted. In this experiment, started in 1955, institutionalised patients (children with mental retardation) were consciously infected with hepatitis by the investigators. The aim of the study was to determine the period of infectivity of the virus. It is not clear whether the parents of the subjects were appropriately informed about the risks of participation.

Another example concerns human radiation experiments conducted in the US between 1944 and 1974 (Mastroianni \& Kahn, 1996). A characteristic of many of the 4000 experiments performed between these dates was that the informed consent of patients or healthy subjects was lacking or questionable. In a number of cases, children, prisoners and mentally handicapped individuals participated in the research (Advisory Committee on Human Radiation Experiments, 1995). In 1998, the American National Bioethics Advisory Commission explicitly addressed the rights and welfare of research subjects with psychiatric illnesses and made many recommendations for change, including increasing independent assessment of the capacity to give informed consent for research involving more than minimal risks (Charney, Nemeroff, Lewis, et al., 2002; National Bioethics Advisory Commission, 1998). 
The above-mentioned examples flagrantly conflict with the principle of respect for an individual's autonomy. Since in human research, the subjects' well-being, health and sometimes even life are at stake, this principle dictates that the subjects them-selves should have the final say on their participation. In practice, the principle is operationalised in terms of free and informed consent, i.e. that inclusion in a study is generally only acceptable after the subject has been informed about all relevant aspects of the study and has voluntarily decided to participate. Mental capacity is a necessary condition for the legal validity of informed consent (Faden et al., 1986).

\subsection{Legal and Ethical Documents Developed to Govern Human RESEARCH}

In order to provide an ethical framework for the conduct of human research, a number of legal and ethical documents have been developed. In discussing documents such as these, a distinction can be made between the norms contained in these documents and the degree to which researchers and other persons involved actually adhere to those norms.

\subsubsection{The Documents}

The Nuremberg Code is generally regarded as the first international code of conduct for medical researchers (Nuremberg Military Tribunals, 1947). However, it was not the first code for researchers as such. Indeed, the experiments that took place during World War II are particularly outrageous when it is considered that some 40 years earlier (in 1900) the government of Prussia (at that time, part of Germany) had issued a ministerial directive in which informed consent of subjects was prescribed as a requirement for the permissibility of research (McNeill, 1993; Jochen Vollmann \& Winau, 1996; Weyers, 2003). Although developed to help prevent unethical research, the Nuremberg Code was associated with a major problem - physicians and researchers did not generally feel appealed to by the code, considering it to be a document that applied to Nazi criminals only. The introduction of the Declaration of Helsinki addressed this problem. This document was laid down by the World Medical Association in 1964 and has since been amended several times, most recently in 2000 (Carpenter, Appelbaum, \& Levine, 2003; World Medical Association, 1964 (as most recently amended in 2000)). The Declaration provides ethical principles for medical research involving human subjects (see particularly provisions $24,25 \& 26$ ). The 
fact that it has been articulated by a global organisation of physicians engenders the hope that it can enjoy the agreement of physicianresearchers. Another important document is the Universal Declaration of Human Rights, proclaimed by the General Assembly of the United Nations in 1948 (General Assembly of the United Nations, 1948). This Declaration contains provisions on human dignity, liberty and privacy, but does not specifically refer to human research. In contrast, the International Covenant on Civil and Political Rights (1966) does mention research and consent. Article 7 of this treaty reads as follows: "No one shall be subjected to torture or to cruel, inhuman or degrading treatment or punishment. In particular, no one shall be subjected without his free consent to medical or scientific experimentation" (italics added). In relation to patients with psychiatric disorders, the second sentence of the article gives rise to the question of whether such patients are able to lend valid consent, and - if not - whether their consent can be substituted by the decision of a representative.

The above outline of regulations is not exhaustive. ${ }^{1}$ Moreover, the list is still growing; for example, the United Nations Educational, Scientific and Cultural Organization (UNESCO) is in the process of developing a Declaration on Universal Norms on Bioethics, which may address the field of research involving human subjects (UNESCO, 2004, 2005). ${ }^{2}$ In addition to these international regulations, in many jurisdictions rules regarding the conduct of research with humans have been laid down in the law, and mechanisms of independent ethical review of research protocols (institutional review boards, research ethics committees) have been developed (Evans D \& Evans M, 1996).

\subsubsection{Adherence to Norms}

If the history of legal and ethical documents teaches us one thing, it is that formulating commendable principles is not in itself sufficient to warrant actual compliance with these principles. On the contrary, the direct effects on researchers seem to be rather limited. The Declaration of Helsinki is exemplary in this respect. For instance, article II.3 on placebo controls, added in 1996 ("every patient - including those of a control group, if any - should be assured of the best proven diagnostic and therapeutic method"; see the present paragraphs 30 and 29), has been largely ignored (Carpenter et al., 2003). How far researchers adhere to ethical and legal norms, in particular with regard to informed consent, is difficult to assess on the basis of research reports and scientific publications. However, a recent review of a sample of reports of trials 
including patients with Alzheimer's disease published in 62 journals (125 articles published between January 1992 and December 1998) showed that neither institutional review board review nor informed consent was mentioned in $28 \%$ of the studies. In $48 \%$, there was no mention of subject involvement in the consent process or of any potential subjects refusing to participate or withdrawing from the study (Stocking, Hougham, Baron, $\&$ Sachs, 2004).

The primary concern of researchers is obtaining research results. In addition, researchers do not always have a good understanding of the rationale of legal and ethical documents. A promising method of ensuring that intended norms are adhered to is to incorporate them into the goals that researchers are interested in, such as funding for research, publication of research results in scientific journals and/or drug licensing (Nicholson, 2003). In that way, adherence to ethical norms is instrumental in reaching the desired goals. An example of this approach is provided by the Vancouver Group, an international committee of medical journal editors (International Committee of Medical Journal Editors, 2004 (October)). The uniform requirements for manuscripts submitted to the journals of this group demand that authors indicate - in the methods and/or results section - how the researchers dealt with ethical standards. Among other things, authors have to describe whether the procedures followed were in accordance with the Declaration of Helsinki.

In research with vulnerable groups who may have questionable mental capacity, transparency of the research process would be promoted by requiring that any published report of the research include a description of the method and criteria used for the assessment of capacity. This is currently not a standard requirement, as even the Vancouver Group only requires that "[w]hen informed consent has been obtained it should be indicated in the published article" (see II.E.1. of the requirements) (International Committee of Medical Journal Editors, 2004 (October)).

\subsection{The Example of the Dutch Regulation of Human RESEARCH}

The Medical-Scientific Research on Human Subjects Act (1998) is a Dutch statute that presents a detailed regulation of research with human participants. ${ }^{3}$ This statute is in line with relevant international documents, such as the European Convention on Human Rights and Biomedicine (1997), and it is currently being amended with a view to the implementation of the European Union directive entitled Good Clinical Practice (2001). ${ }^{4}$ Therefore, the Dutch regulation can serve as a model 
for evaluating what types of clinical research are permissible in patients with a psychiatric illness. However, as will be shown, the statute can be critically questioned, thus illustrating the problems and complexities to which such a regulation may give rise. It should be noted that the Medical-Scientific Research on Human Subjects Act only regulates research as part of which participants are subjected to certain interventions or are required to behave in a certain manner. Other regulations deal with research that uses data or tissue which has been collected previously, e.g. during the course of regular patient care (Contract of medical treatment Act, 1994; Federatie van Medisch Wetenschappelijke Verenigingen, 2001/2002; Federatie van Medisch Wetenschappelijke Verenigingen \& Raad voor Gezondheidsonderzoek, 2003/2004; Personal Data Protection Act, 2000; SociaalWetenschappelijke Raad, 2003).

\subsubsection{Outline of the Law}

The Act contains several general legal obligations, which apply to both research with mentally capacitated subjects and research with mentally incapacitated subjects. These obligations include scientific and ethical review by an officially recognised, independent body; appropriate insurance against potential damage consisting in the death of or bodily injury to subjects arising from their participation in the research project; and written informed consent by prospective participants.

Regarding subjects with a psychiatric illness, the statute includes a specific prohibition on research with subjects who lack mental capability (article 4). However, this prohibition is immediately followed by two exceptions. These relate firstly to so-called 'therapeutic' research and secondly to 'non-therapeutic' research that could not take place without the participation of subjects from the category to which the mentally incapacitated person belongs (the latter being so-called 'group-bound' research). Research is considered 'therapeutic' if it may confer direct benefit to the subject, and 'non-therapeutic' if no such benefit is to be expected. An example of the former is a trial in which the effects of two antidepressants are compared in patients with major depression; in addition to generating scientific insights, in such research the subjects may benefit therapeutically from participation. An example of nontherapeutic research is positron emission tomography (PET) measurements of brain glucose metabolism and blood flow in patients with major depressive disorder, the aim of which is solely to generate patho-physiological knowledge about brain function in this state. 
One extra condition pertains to non-therapeutic, group-bound research: its risks for the prospective subject should be negligible and its burdens minimal. In light of this extra condition, medication discontinuation and symptom provocation studies, which are much debated in the literature, may be problematic (Berghmans, 1999; Carpenter, Schooler, \& Kane, 1997; Eckstein, 2003; Shamoo \& Keay, 1996). The proposed article $13 \mathrm{f}$ entails additional provisions on pharmaceutical research with adults who lack mental capacity, including the obligation to explicitly define the risks and burdens for subjects and to continually monitor these risks and burdens during the course of the research. ${ }^{5}$

\subsubsection{Substitute Consent}

Obviously, when a researcher would like to involve a mentally incapacitated person in a research project, somebody else needs to provide consent on behalf of the subject (Kim, Appelbaum, Jeste, \& Olin, 2004; Sunderland \& Dukoff, 1999). According to Dutch law, possible representatives for adults who lack mental capacity can be recruited from different categories: (i) legal representatives (curator or mentor), who have been assigned as a guardian by a judge; (ii) attorneysin-fact, who have been authorised by the patient previously, when he/she still had mental capacity; and (iii) spouses or other life partners. For elderly patients, the Dutch government has stated that the circle of possible representatives should be broadened to encompass close family members, notably brothers, sisters and children (Ministerie van Volksgezondheid, Welzijn en Sport, 2002; Staatssecretaris van Volksgezondheid, Welzijn en Sport, 2004). Those who are soliciting proxy consent have to be aware of problems in representation, such as a conflict of interests between the patient and his representative, or proxy 'incompetence'.

The Dutch Act does not mention the use of an 'advance directive'. This legal instrument is usually defended in the context of medical treatment. In an advance directive, a patient may indicate his/her treatment preferences in case he/she becomes mentally incapacitated. From a theoretical perspective, there is no reason why the use of an advance directive should not also be explored in decision-making on research participation (Lötjönen, 2003); e.g., somebody who is well-disposed towards research may decide to ensure that he/she will be available for certain kinds of research even if he/she develops a disease that takes away mental capacity (Berghmans, 1998; Bravo, Dubois, \& Pâquet, 2003). Such a written statement explicating how the person feels about research might later function as a ground for including the person in a project. 
A research advance directive may be helpful in therapeutic or nontherapeutic research involving minimal burdens and risks to the participating subject (Backlar, 1998; R. Dresser, 2000; Keyserlingk, Glass, Kogan, \& Gauthier, 1995). Morally and legally more complicated is the issue of involving incapacitated patients in non-therapeutic research with more than minimal bur dens and risks on the basis of a research advance directive (Berghmans, 1998). Certainly, such a directive could help in reconstructing the mentally incapable patient's presumptive will, which should be guiding substitute decision-making anyway. A special provision of the Act instructs researchers to release from the study any mentally incapacitated person who resists the interventions to which he/she is subjected as part of the study. This provision is aimed at protecting the subject from forced submission to research interventions. In other words, resistance by the incapacitated subject deserves more respect than substitute consent by a representative. The effect of this provision is that the issue of mental capacity is not relevant when dealing with subjects who refuse to participate: when mentally capable, they have the right to withhold consent or to withdraw from the study; when mentally incapable, they are under cover of the provision in question. Hence, these subjects should not be involved in the research project (see also recommendations 7 and 9 of the National Bioethics Advisory Commission, 1998). In practice, many human research boards and investigators will not include a subject who is unwilling to sign the consent form along with his/her legal guardian.

\subsubsection{Therapeutic and Non-Therapeutic Research}

Concerning the legal distinction between therapeutic and non-therapeutic research, the law assumes that subjects could personally benefit from participation in therapeutic research, and that this is not the case for nontherapeutic research. However, the validity of this distinction is questionable (Levine, 1986). For example, a therapeutic research study may prove that the experimental intervention is ineffective, in which case undergoing the experimental condition would not be beneficial to the subjects. Conversely, a non-therapeutic study may be associated with benefits for the subjects, such as more attention from healthcare workers. In addition, in a clinical trial, one component (the experimental treatment) may have potential benefit, but other components may not (e.g. pharmaceutical intervention combined with an imaging procedure). Furthermore, in placebo-controlled phase III studies, subjects in the control (i.e. placebo) group will not receive any treatment at all. The latter problem might be solved by observing ethical principle 29 from the 
Declaration of Helsinki, which lays down that in research testing new medical methods, members of the control group should receive current best treatment rather than placebo (Lavori \& Sugarman, 2000). For a more detailed discussion of these issues, readers are referred to an article by Carpenter et al. (2003) on recent developments with regard to the Declaration of Helsinki.

The amended version of article 3 of the Dutch statute states that, in general, research is only ethically acceptable if the risks and burdens for the subject are expected to be proportional to the interest of the subject and of other present or future patients. Since research is not primarily about promoting individual subjects' interests but about gaining scientific knowledge, it is doubtful whether research can ever meet this requirement. ${ }^{6}$ Regarding group-bound research, the imperative of proportionality means that even the slightest risk or discomfort for subjects would imply inadmissibility of the research if not compensated for by some expected advantage for the subjects. Thus, the legal notion of group-bound research seems to encompass a therapeutic dimension as well.

\subsection{COMPARISON With MECHANiSMS OF INFORMED Consent in Other European Countries}

The organisation of legal representation for prospective research subjects who are deemed to be mentally incapable is generally left to national jurisdictions (see article 1, second sentence of the Convention on Human Rights and Biomedicine). The legal frameworks of four other European countries are reviewed in sub-section 2.6.1 to 2.6.4 to demonstrate the diverse ways that have been developed in dealing with the regulation of research involving those with a psychiatric illness (European Commission, 2004).

\subsubsection{Belgium}

In Belgium, there is no specific statutory legislation on human experimentation. The Code of Medical Deontology of the Belgian National Council of the Order of Physicians devotes articles 89 to 94 (inclusive) to general rules about this topic (Nationale Raad van de Orde van Geneesheren, 2003). An advice by the Belgian Consultative Committee on Bioethics, expanding on a previous advice, tackled the question of whether patients with a serious form of Alzheimer's disease can be subjected, under very strict conditions, to non-therapeutic 
experiments that involve only minimal risk and burden for the patient (Raadgevend Comité voor Bio-Ethiek, 2001a, 2001b). The Committee's reasoning can be analogously applied to patients with other severe psychiatric illness. Firstly, the Committee under-lined the desirability of regulation by a basic law. From a material viewpoint, the advice proposes that subjects with dementia/psychiatric illness who have mental capacity should be allowed to participate in non-therapeutic research under the same conditions as mentally capacitated subjects who do not have psychiatric illness/dementia. According to the proposal, consent should be obtained from the subject and from the legal guardian ('wettelijke voogd') if the subject has one; in this respect, the proposal deviates from the Dutch model, in which consent of the mentally capacitated subject would be sufficient in this case. Furthermore, the members of the Committee agreed that experiments involving persons who lack mental capacity can be justified under certain circumstances when participation is ex-pected to be of substantial direct benefit to the subject; in other words, when the research is therapeutic in nature. There is disagreement among the members of the Committee about non-therapeutic research with subjects who are mentally incapable, notably concerning the permissibility of more than minimal risk and the possible role of representatives and advance directives. Some members argue for the involvement of subjects lacking mental capacity in non-therapeutic research under stringent conditions on the basis of substitute consent by a representative, preferably supported by an advance directive. Other members argue that non-therapeutic research should only take place on the basis of an explicit advance directive. Still others argue that nontherapeutic research with incapacitated persons ought always to be prohibited, even if the person in question has an advance directive stating his willingness to participate in such research.

\subsubsection{France}

French law is generally characterised by the fact that it does not recognise the notion of factual mental incapacity: for a person to be treated as incapable, a declaration of incapacity by a court is required (Jansen S, 1999, 2000). The result of such a judicial measure is that the legal authority to give or withhold consent in a valid way is taken away from the person in question, even if he or she is actually capable of making a specific decision. With a view to the latter situation, paragraph 1 of principle 23 of recommendation no. R (99) 4 of the Committee of Ministers of the Council of Europe (1999a, 1999b) to Member States on Principles concerning the Legal Protection of Incapable Adults, a 
recommendation adopted by France, prescribes that in addition to consent by the substitute decision maker provided for by law, the consent of the person in question ought to be sought once it is established that he/she has sufficient mental capacity for giving or withholding such consent. The French Act on the Protection of Persons Undergoing Biomedical Research ('Loi relative à la protection des personnes qui se prêtent à des recherches biomédicales') designates a competent authority and a legal guardian as potential substitute decision makers for adults who are incapacitated and who have been placed under guardianship (Lötjönen, 2003). In emergency situations, a family member of the subject can also provide substitute consent for research procedures that are aimed at improving the quality of emergency care. In the absence of family members, a physician can do this. It is unclear whether anyone has the authority to decide on behalf of a person who is mentally unable to give or refuse consent, but for whom the court has not applied the measure of guardianship, when there is no emergency. To address this legal hiatus, the French National Consultative Bioethics Committee for Health and Life Sciences has suggested that at admittance to the hospital patients be given the opportunity to assign a 'representative', 'agent' or 'spokesperson' for themselves (Comité Consultatif National d'Ethique pour les sciences de la vie et de la santé, 1998). However, this suggestion does not answer the question of whether these representatives can only act in a consultative capacity or whether they are also empowered to participate in decision-making on behalf of the patient.

\subsubsection{Germany}

As in Belgium, German law has no statute dealing specifically with informed consent and medical research (Vollmann, 2002). The German Drug Act ('Arzneimittelgesetz') and the Act on Medical Products ('Medizinproduktegesetz') regulate these topics for human participants in trials with drugs or medical products, respectively. Furthermore, these topics are addressed by judgments of the Federal High/Supreme Court ('Bundesgerichtshof') and by professional law of the Federal Chamber of Physicians('Bundesärztekammer'). In 1997, the Central Ethics Commission at this Chamber delivered a statement on the protection of patients who are mentally incapable in medical research (Zentrale Ethikkommission bei der Bundesärztekammer, 1997). With a view to involvement of incapacitated subjects in research, this statement defends conditions that are similar to those contained in the Dutch Medical Research involving Human Subjects Act. Substitute decision-making for those subjects is taken over by legal guardians ('Betreuer'; $§ 1896 \mathrm{ff}$. 
German Civil Code/'Bürgerliches Gesetzbuch') and advance directives (Nys et al., 2004). The fear of repetition of the research abuses that occurred during the Nazi regimen has stirred up a controversial public debate in Germany on the issue of non-therapeutic research involving patients with a psychiatric illness (Helmchen, 2000). As a result, Germany has not ratified, nor even signed, the Convention on Human Rights and Biomedicine (see article 17).

\subsubsection{England and Wales}

The legal situation in England and Wales is complicated by two factors (British Medical Association \& Law Society, 2004; Lötjönen, 2003). ${ }^{7}$ Firstly, English law contains no definition of legal guardians for healthcare purposes; moreover, relatives are not in a position to give valid consent on behalf of the patient/subject. Secondly, the general criterion for substitute decision-making is the 'best interests' standard (see principle 43 of the code Good Medical Practice; General Medical Council, 1995). Interpreting this standard so broadly as to encompass inclusion in research procedures, as is commonly done, is problematic from a semantic point of view, since these procedures aim primarily at accumulating medical knowledge for scientific purposes. In a 1991 report (see sections 6.2.2 and 6.3.4 of the report), the Medical Research Council pled in favour of a role for relatives, friends or "person[s] acceptable to the [research ethics committee]" who are not directly involved in the research, in providing substitute consent (Medical Research Council, 1991 (reprinted 1993)). This 'ethical' solution was at odds with the law at the time - which was acknowledged by the Medical Research Council, thus necessitating legal reform.

In the meantime, an extensive consultational process has taken place on the topic of mental incapacity (Law Commission, 1991, 1993a, 1993b, 1993c, 1995; Lord Chancellor's Department, 1997, 1999). The obligation to implement the European Union directive Good Clinical Practice (2001) has provided an extra stimulus for a review of the relevant law. In 2004, two new regulations were introduced, one being a statutory instrument, namely "The Medicines for Human Use (Clinical Trials) Regulations 2004", and the other being a legal bill, namely the Mental Capacity Bill (Department for Constitutional Affairs, 2004 (June)). ${ }^{8}$ The Medicines for Human Use (Clinical Trials) Regulations 2004 deal with research on medicines using human subjects. Three sections of the Regulations specifically relate to incapacity in adults: Schedule 1, Part 1, paragraph 1(5); Schedule 1, Part 1, paragraph 2; and Schedule 1, Part 5 "Conditions and principles which apply in relation to an incapacitated adult". The 
Mental Capacity Bill also contains provisions on research (i.e. $30 \mathrm{ff}$.), but it is not applicable to clinical trials (30(3) $\left.\mathrm{j}^{\mathrm{o}} 30(5)\right)$.

Both The Medicines for Human Use (Clinical Trials) Regulations 2004 and the Mental Capacity Bill introduce a wide circle of possible representatives for prospective adult research subjects who are mentally unable to give informed consent. The former regulation defines as a representative any person who is suitable for this task given his/her personal relationship with the incapacitated subject, or - if such person is not available or not willing to act as a substitute decision maker - an independent professional, e.g. the doctor primarily responsible for the healthcare provided to the adult in question, or a chaplain or social worker trained and nominated by the relevant healthcare provider. The Mental Capacity Bill contains comparable provisions (32(2), 32(3)). In both regulations, an advance refusal by the presently incapacitated subject must be respected. However, in the Mental Capacity Bill, a representative's refusal to consent to therapeutic research can be overruled with the approval of a court. ${ }^{9}$ The British Medical Association and The Law Society offer practical guidance on issues related to capacity to consent to research (British Medical Association \& Law Society, 2004).

\subsection{Therapeutic MisconCEPtion}

An important factor that may undermine the mor al and legal validity of informed consent in research is the so-called 'therapeutic misconception' (Appelbaum, Roth, \& Lidz, 1982). This occurs when a research subject fails to appreciate the distinction between the imperatives of clinical research and those of ordinary treatment, and, there-fore, inaccurately attributes therapeutic intent to re-search procedures (Lidz \& Appelbaum, 2002). This leads them to believe that there will be some personal health benefit from participating in research. The occurrence of this misconception among potential subjects is not surprising, given the fact that even the legal distinctions between experimental treatment, therapeutic re-search and non-therapeutic research are fraught with ambiguities. The therapeutic misconception may lead to an underestimation of or disregard for the potential risks and disadvantages associated with the research procedures (Lidz, Appelbaum, Grisso, \& Renaud, 2004). Despite efforts to establish clear boundaries between clinical care and research through informed consent, subjects often maintain a therapeutic misconception (Appelbaum, Roth, Lidz, Benson, $\&$ Winslade, 1987). The therapeutic misconception does not only occur in patients with psychiatric disorders (Lidz \& Appelbaum, 2002). It has 
also been described in trials of anti-cancer agents, particularly with regard to non-therapeutic phase I studies involving patients whose treatment options are exhausted (Daugherty et al., 1995; Weinfurt, Sulmasy, Schulman, \& Meropol, 2003). Issues related to the therapeutic misconception can also arise in clinical practice, in that patients attribute larger than actual benefits to a particular treatment.

\subsection{Mental CAPACiTy}

According to the Dutch model, the permissibility of research with patients who have a psychiatric illness depends upon the mental capacity of the patients. If these patients are mentally capable, re-search with them is allowable under the same conditions as research with other subject groups. If the patients lack mental capacity, only limited forms of research can legitimately take place. This raises the issue of how to assess the mental capacity of prospective subjects (DeRenzo, Conley, \& Love, 1998; Gunn, Wong, Clare, \& Holland, 2000; Gunn, Wong, Clare, \& Holland, 1999).

\subsubsection{Starting Points}

Two starting points should guide any assessment of mental capacity. The first is the assumption of competence (Weisstub, 1990, p. 6, 19). This assumption implies that any adult person ought to be considered as having mental capacity, unless the contrary can be proven. The assumption applies to patients with psychiatric disorders in the same way as it does to other persons, which means that psychiatric illness is no ground for inferring mental incapacity. Hence, in principle, patients with a mental illness are eligible to be research subjects. However, given the difference between the goals of research and therapy (particularly in regard to non-therapeutic research, which involves no benefits to the subject), it can be argued that the assumption of competence in vulnerable groups of subjects should be qualified (Berghmans, 1995). This would imply an obligation to assess explicitly mental capacity in all nontherapeutic trials involving subjects with psychiatric illnesses (Olde Rikkert et al., 1995).

The second starting point is that mental capacity should not be viewed in a categorical or formal sense; instead, it ought to be conceptualised as task specific and decision relative (Grisso \& Appelbaum, 1998, p. 18 ff.; President's Commission for the Study of Ethical Problems in Medicine and Biomedical and Behavioral Research, 1982, p. 55; Weisstub, 1990, 
p. 6-7; section 5.2 of this volume - first published as Welie SPK, 2001a, p. 140). Incapacity cannot be derived from the fact that a person belongs to a certain diagnostic group or has a special legal status, such as contractual incapacity. Rather, in judging capacity, the assessor must examine whether the prospective subject actually has the mental abilities that are required to perform the task at hand, i.e. making a decision about research participation. Having a psychiatric diagnosis, lacking contractual capacity or even being involuntarily committed does not preclude the possibility of having these abilities. This starting point also entails that a person may have capacity in relation to a certain decision but not in relation to another decision, e.g. one that is more complex.

\subsubsection{Criteria}

Be that as it may, it is still unclear what task is implied for the prospective subject in handling in-formed consent. Because of this, diverse criteria for mental capacity have been suggested in the literature (Glass, 1997). According to one approach, the 'task at hand' is regarded as the making of any decision. If the patient is able to express a choice, he/she has capacity, regardless of the content of the decision. The underlying conception of the principle of autonomy is one of respect for spontaneous behaviour and preferences. In this approach, no attention is paid to the extent to which the behaviour and preferences reflect comprehension of the situation in which the subject finds him- or herself. As a result, this approach is generally considered too liberal and insufficiently protective. In another approach, the 'task at hand' is conceived as making a rational decision. The corresponding criterion of mental capacity is the ability to make a good decision. This criterion hinges upon an evaluation of the outcome of the decision. However, the outcome of a decision is not only determined by a person's mental abilities, but also by this person's values and lifestyle. Capacity assessment on the basis of the outcome of a decision runs the risk of ignoring or even condemning the subject's personal values. Therefore, this approach is in conflict with autonomy and too protective. A third approach, that attempts to avoid the disadvantages of the previously described approaches, focuses on the quality of the decision-making process that led the prospective subject to his/her decision. The underlying concept of autonomy is one of well considered decisionmaking. There is emerging consensus that capacity be operationalised as decisional capacity, which is the ability to make an informed decision. 


\subsubsection{Tests}

Those who have to assess mental capacity, feel a need for tests to help them judge relevant abilities, and even to promote certainty of law. This has resulted in the development and publication of various psychometric instruments (Vellinga, Smit, van Leeuwen, van Tilburg, \& Cees Jonker, 2004). A well documented example is the MacArthur Competence Assessment Tool-Treatment (MacCAT-T) (Grisso \& Appelbaum, 1998). Derived from this instrument is the MacArthur Competence Assessment Tool for Clinical Research (MacCAT-CR) (Appelbaum \& Grisso, 2001). In the MacArthur approach, four abilities together define decisional capacity. These concern the ability to (i) understand relevant information; (ii) reason about the risks and benefits of potential options; (iii) appreciate the nature of one's situation and the consequences of one's choices; and (iv) express a choice. As to the latter ability, the difference between this and the first approach mentioned in sub-section 2.8.2 is that none of these abilities is in itself sufficient; instead, all are necessary for capacity. In addition to insight into the prospective subject's mental abilities, one also needs a defined standard to reach a judgment on capacity: whether or not somebody has capacity, depends upon whether or not his/her mental abilities meet the standard in question. The standard determines what information is essential in light of the decision to be made; it also determines to what degree the subject has to present understanding, reasoning and appreciation. Setting the right standard is a normative issue that cannot be decided by test instruments themselves.

\subsection{DisCUSSION}

Defining mental capacity as decisional capacity, as currently tends to be done, implies a high standard for capacity. In everyday life, decisions are not always based on conscious and deliberate information processing, not even important decisions like accepting a job, buying a house, marrying, having children, or deciding whether or not to receive a lifesaving treatment. It could analogously be argued that the standard of capacity should be lowered with regard to decisions about whether or not to participate in scientific research. However, if this were the case, it would not be possible to be certain that subjects who had agreed to participate in research really knew what they had assented to. In the context of research, high standards for capacity seem justified by the fact that research is not primarily in the interest of the subject. Besides, the information about research and research protocols may be more abstract 
- and hence more difficult to understand - than information about receiving care, for example.

When discussing the permissibility of research with patients who have a psychiatric illness, respect for autonomy and due protection of those who lack autonomy are not the only interests at stake. There is also the interest of encouraging scientific research in order to secure better evidence-based care for (future) patients (see Guideline 12 - plus Commentary - of the International Ethical Guidelines for Biomedical Research Involving Human Subjects; Council for International Organizations of Medical Sciences, 2002). In addition, the interest of trust in the scientific community is at stake (Michels, 2004).

\subsubsection{Seeking a Balance}

If the focus of legislation is on the interest of patient protection, a high standard of capacity has to be used. In this way, it is possible to be confident that mentally capable psychiatric patients who agree to participate in research truly understand what they are doing. However, a high standard of capacity might mean that too few patients meet the standard; thus, cutting off the possibility of conducting sound research. There is the danger of a vicious circle here: the limited availability of effective treatment options for patients with psychiatric illnesses results in a group of patients who have severe illnesses; severe psychiatric illness may remove patients' mental capacity; the desire to protect vulnerable patients has the effect of preventing these patients from taking part in scientific research; and this in turn limits the production of scientific knowledge and prolongs the deficiency of effective treatment options.

Thus, an absolute emphasis on the protection of prospective subjects would eventually be counterproductive. An emphasis on the interest of scientific progress would result in the use of a low standard of capacity, resulting in there being plenty of patients who qualify as having capacity and, for that reason, being involved in research projects without the restricting conditions pertaining to mental incapacity. This approach would leave open the possibility of abuse of vulnerable patient groups, as exemplified in the examples outlined in section 2.3.

A so-called sliding scale approach to the assessment of mental capacity would be a different way of dealing with this issue (Buchanan \& Brock, 1989). Briefly stated, this approach would imply a high standard for mental capacity in the case of research with high risk/burdens and low or absent possible benefits for the subject, and a lower standard in the reverse case. This approach, however, is not without its critics (Bergh- 
mans, 2001; Culver \& Gert, 1990). As a sliding scale approach connects the assessment of mental capacity to the level of risk involved in a particular decision, it would imply that a person can be considered competent or incompetent depending on the consequences of his/her decision.

\subsubsection{Enhancing Mental Capacity}

Obviously, a conflict exists between the protection of subjects and scientific progress (Jonas, 1989). The dilemma could be resolved by maintaining high standards for capacity on the one hand and finding a way to enhance patients' capacity on the other. Thus, the necessary protection of patients could be realised and, at the same time, researchers would be able to recruit enough subjects for inclusion as participants in their research studies. The enhancement of patients' capacity is a reasonable aim, given that the constituent mental abilities are not static. Different strategies to enhance subjects' capacity and to improve the consent process in research have been or are being explored (DeRenzo et al., 1998; Flory \& Emanuel EJ, 2004; Wendler, 2004). In this context, the notion of 'experienced consent' is noteworthy (Olde Rikkert, van den Bercken, ten Have, \& Hoefnagels, 1997). The aim of this approach is the enhancement of capacity by providing subjects with the opportunity to experience what the research is about in a tryout period. The idea is that research experience is a useful addition to verbal information in educating patients about the implications of research participation. As such, experienced consent is an enrichment of the informed consent procedure.

Olde Rikkert and colleagues (1997) have conducted empirical research into this notion. The aim of the research was to determine the effects of research experience on the capacity to consent. The research was conducted in a geriatric population and had the following design. Patients participated in a try-out of a week. Cognitive scores were obtained before and after the try-out and were then compared. These cognitive scores pertained to the comprehension of six basic categories of essential information, i.e. purposes of the research; departure from ordinary medical practice; risks; inconveniences and tasks; benefits; and the subjects' rights. The results of the study were that, among other things, the comprehension scores showed a statistically significant in-crease over time.

However, two criticisms can be made of this study. Firstly, no control group was involved and, therefore, the increase in comprehension scores 
may not have been the result of undergoing the try-out. The increase could be attributed to the passage of time, or, alternatively, to the fact that subjects were given verbal information about the research project twice, namely before and after participation in the try-out.

Secondly, and more fundamentally, one might wonder if subjects who do not have the capacity to consent to participation in a research project, have the capacity to consent to participate in a try-out of that project. Evidently, there is the danger of getting into a catch-22 situation: valid consent for subject participation in research is needed; mental capacity is a necessary condition for the validity of consent; the aim of the experienced consent procedure is to improve the mental capacity of subjects who currently lack this capacity, by putting them through a tryout; for participation in the try-out, valid consent is needed; however, mental capacity is a necessary condition for the validity of consent. Besides having a representative provide proxy consent, the only way of escaping this situation is to suppose that the standard for capacity to consent to participate in the try-out is lower than the standard for capacity to consent to participate in the whole study. The fact that participation in a try-out may be less drastic than participation in a whole project supports this supposition. However, the fact that understanding the rationale of participation in the try-out is even more complicated than understanding the implications of participating in the research itself, undermines it. Therefore, the supposition is open to discussion.

\subsection{CONCLUSION}

Research with subjects who have a psychiatric illness raises legal and ethical issues. An important issue is the involvement of those patients who lack decisional capacity and the connected issue of capacity assessment in the context of research. In order to improve practice, we suggest a number of recommendations to researchers in mental health.

Firstly, it is essential that researchers are sensitive to the issue of mental capacity and its assessment in the context of research with patients who have psychiatric illnesses. Although there is a general assumption of competence, in the context of re-search it is important to not presume too easily that subjects from vulnerable patient groups have capacity to consent to participation. This is particularly the case when research involves no or only remote benefits for the subject. Secondly, researchers should be sensitive to the therapeutic misconception. Subjects should be made aware of the fact that a clinical researcher is not - or at least not exclusively - dedicated to the patient/ 
subject's best interests (Warner, Roberts LW, \& Nguyen, 2003). Subjects need to be educated not only about how treatment and research differ, but also about why they do (Lidz \& Appelbaum, 2002). This alerting process should be as much a part of the consent disclosure in a research project, as an explanation of the nature, purpose, overall risks, burdens and possible benefits, alternatives, and other information required. Lastly, in order to promote transparency and public accountability, research publications ought to include a legal and ethical paragraph in which the informed consent process and the assessment of mental capacity (if applicable) is described, as well as the issue of risks and burdens for participants. Research with vulnerable patients generates public concern. Transparency and accountability are essential both for the research community to retain the trust of the public and for the protection of research subjects and for the progress of science.

\subsection{Notes}

1. Cf. the Additional Protocol to the Convention for the Protection of Human Rights and Dignity of the Human Being with regard to the Application of Biology and Medicine, on Biomedical Research, 2004; Committee of Ministers of the Council of Europe, 1999b, 2004; Convention for the protection of Human Rights and dignity of the human being with regard to the application of Biology and Medicine (Convention on Human Rights and Biomedicine), 1997, cf. Chapter V on scientific research ( $\mathrm{j}^{\circ}$ art. $5 \& 6$ ); Convention of 13 January 2000 on the International Protection of Adults; Council for International Organizations of Medical Sciences, 2002, see particularly guidelines 9, 13 \& 15; European Union, 2001; International Conference on Harmonisation of technical requirements for registration of pharmaceuticals for human use, 1996, see particularly provisions 4.8.5, 4.8.7, 4.8.8, 4.8.12 \& 4.8.14 $\mathrm{j}^{\circ} 4.8 .13$; Treaty establishing a Constitution for Europe, 2004; World Health Organization: European Region, 2005; World Health Organization: Regional Office for Europe, 1994.

2. After the present paper had been accepted for publication (i.e., 7 February 2005), the declaration referred to was adopted by acclamation on 19 October 2005 by the $33^{\text {rd }}$ session of the General Conference of UNESCO as the Universal Declaration on Bioethics and Human Rights (General Conference of UNESCO, 2005). See article 7 on norms relating to research involving persons without the capacity to consent (www.unesco.org/shs/bioethics). 
3. See http://www.ccmo-online.nl/main.asp?pid=21 for an unofficial full text translation of this statute in English.

4. After the present paper had been accepted for publication, the amendment referred to was enacted (d.d. 24 November 2005) and came into force (d.d. 1 March 2006).

5. In the meantime, this article (13f) has become part of the Medical-Scientific Research on Human Subjects Act. Cf. note 4.

6. See also art. $13 \mathrm{f}$ introduction sub $\mathrm{d} \&$ sub e.

7. This description of the state of affairs in England and Wales has by now gotten out of date; see note 8 .

8. After the present paper had been accepted for publication, the bill referred to received Royal Assent on 7 April 2005, thus becoming the Mental Capacity Act 2005. It came fully into effect on $1^{\text {st }}$ October 2007 (see http://www.dca.gov.uk/menincap/legis.htm, http://www.justice.gov.uk/publications/mentalcapacity.htm and http://www.publicguardian.gov.uk/mca/mca.htm).

9. The provision concerned has finally been cancelled in the Mental Capacity Act. 


\title{
3. PATIENT INCOMPETENCE IN THE PRACTICE OF OLD AGE PSYCHIATRY: THE SIGNIFICANCE OF EMPIRICAL RESEARCH FOR THE LAW
}

\author{
S.P.K. Welie
}

\subsection{ABSTRACT}

The purpose of this chapter is to introduce and discuss a heuristic method for using the results of empirical research within a normative legal framework. An elaboration is given of one variant of this method, which I call systematic (or methodical) apology. It consists of a critical reexamination of generally recognised sources of law on the basis of specific research questions derived from empirical results; and it aims at a differentiation of current legal views in the light of actual practice. In explaining the method, a qualitative empirical study into assessment of patient competence in Dutch geriatric care settings serves as a caseexample. The data-gathering techniques used for the empirical study were non-participant observation of, and semi-structured interviews with, health care professionals. The empirical results prompted a shift in the research questions. It was found that health care professionals generally do not solve decisional dilemmas through competence assessment. Application of the method of "systematic apology" generated a number of innovative legal arguments limiting the scope of the procedural approach that is implied by competence assessment. It is argued that the method of "systematic apology" offers a way of integrating empirical research in the normative study of law, while at the same time doing justice to the epistemological distinction between empirical facts and legal norms. This method can make a difference for practice by enabling a better tuning of the legal model to health care practice, without either indiscriminately adopting the health care professionals' habits and attitudes, or imposing a legal way of thinking on health care professionals. The method can help bridge the gap between legal theory and health care practice. 


\subsection{INTRODUCTION}

Over the last decade an increasing amount of empirical research has been carried out within a legal framework. This is in contrast with traditional methods of academic legal research, which were confined to the study of jurisprudential literature and the close analytical reading of legal regulations and case law. Empirical studies relating to legal questions, concepts, or mechanisms were considered to be outside the field of legal research, instead belonging to fields of scientific research such as: technical research (e.g. error margins in the measurement of speed transgression; Muijlwijk, 1996; Hofstee, 1996); jurimetrics (e.g. the prediction of judicial decisions on the basis of empirical facts of the case; Combrink-Kuiters, 2000); sociology or psychology of law; forensic psychiatry; or criminology.

An important stimulus for this recent trend towards empirical legal research is the attempt to improve the quality of legal regulation by empirically evaluating the effects of regulation on practice (Winter, 1997). In the field of health law several evaluation reports on Dutch statutes containing patient rights have been published. In some cases the obligation to evaluate is included in a statute (Hendriks, 2000, p. 87-88). An example of this can be found in the Special Admissions into Psychiatric Hospitals Act, which regulates involuntary commitment to, and treatment in, mental institutions. Article (art.) 71 of this statute prescribes a periodic evaluation of the Act. It reads as follows: "In agreement with Our Minister of Justice, Our Minister [of Welfare, Health and Cultural Affairs] shall, within three years of the date [of entering into force] and subsequently every five years, send the States General [the parliament of the Netherlands] a report on the way in which the law has been applied."

The methods used in empirical evaluative research of statutes generally take the form of postal surveys among those whom the statute concerns (e.g. health care professionals, patients) and semi-structured interviews, possibly complemented by panel or expert meetings (e.g. Dute, 2000, p. 6). From the data a multitude of tables with percentages are generated. The aim of this type of research is formulated in quite diverse ways. It may be to assess whether the goals of the statute are realised in practice, or whether the legislation has any undesired side effects (ZorgOnderzoek Nederland, 2001, p. 9). This approach involves a test of actual practice by the statutory standards and hence presupposes that these standards are clear. In the case of statutes where these standards have not been laid down unambiguously, the aim of evaluative research is different. In this 
case the aim may rather have the character of contributing to the continuous process of interaction between all the interested parties with a view to finding a shared interpretative framework (Olsthoorn-Heim, 2003, p. 16).

In all these types of empirical evaluative research of health law statutes it is primarily the statutes that are under investigation, and not health care practice itself. This kind of research raises the question of how an observed discrepancy between legal requirements and actual practice ought to be interpreted. Such a discrepancy could be taken as evidence that practice is "wrong", because it does not comply with legal requirements; but an alternative interpretation is that the statute is "defective" because it does not do justice to the dynamics of actual practice. Given this double-edged nature of evaluative research one would expect the methodology to pay attention to the possible different interpretations of empirical data within a normative legal context. The methodological accounts of this research, however, do not bring up this theme. In the reports of the three official evaluations of the Special Admissions into Psychiatric Hospitals Act, for example, there is no reflection on the problem of facts versus norms (Evaluatiecommissie Wet Bijzondere Opnemingen in Psychiatrische Ziekenhuizen, 1995, p. 11; Evaluatiecommissie Wet Bijzondere opnemingen in psychiatrische ziekenhuizen, 1996, p. 116 ff.; Begeleidingscommissie evaluatie Wet Bopz, 2002, p. 15, 18-21, 48-53; Derde evaluatiecommissie van de Wet Bopz, 2007, p. 12, 25-31, 34, 106). In a review of five years of empirical evaluative research of statutes, it is stated that this type of research is essentially a critical examination of the assumptions underlying a statute (Olsthoorn-Heim, 2003, p. 18). Whether the assumptions referred to are descriptive or normative ones, is unfortunately not specified.

The problem of the normative significance of empirical descriptive data is not only relevant to the evaluative research of statutes, but also to any kind of empirical study in which the research question addresses legal concepts. Empirical studies yield a description of what the research subjects actually do and think, whereas the law is about how people should behave. This problem is the subject of this chapter. A research study into the criteria for assessing patient decision-making competence, carried out by the author, will serve as a case example. In this study, empirical research was undertaken in the practice of old age psychiatry in order to clarify the meaning of the legal concept of competence and, if possible, to specify criteria in terms of which the abstract legal concept can be operationalised. 
In this chapter I will first explore the relationship between empirical research and the law. Several positions which can be taken on this relationship will be touched on. I will then describe a study into criteria of competence. After an explanation of the Dutch legal background of patient competence, and the design of the study, I will show how the research question developed during the course of the study. As a consequence of the methodological position taken, the development of the research question resulted in a view on the scope of criteria of competence that is somewhat original, and in an elaboration of legal notions and provisions to which other authors have paid little systematic attention. The chapter ends with a discussion of the value of empirical research in health law.

\subsection{THE RELATIONSHIP BETWEEN EMPIRICAL RESEARCH AND THE LAW}

It has been argued above that empirical research that relates to legal concepts raises the question: what is the normative significance of its results. This is a feature shared by both ethical and legal empirical research, as both types of empirical study aim to make prescriptive inferences from a description of actual practice. This question of the normative significance is especially important for the law, since the incorporation of an element or rule within a legal model implies the possibility that its observance is compulsory. There are, therefore, certain formal safeguards that have to be met before a proposition or an argument may be called legal. These safeguards amount to the requirement that the proposition in question must be reducible to a generally recognised source of law, which has been referred to as a "formal source of law" (Walker, 1980, p. 1156 ff.; Komen, 1988, p. 24 ff.; Black et al., 1990, p. 1395; Franken et al., 1995, p. 95, 98). There is a limited array of formal sources of law. In the Dutch legal system the most important of these are treaties, the constitution, codes or statutes, case law, and jurisprudence.

I will discuss three different positions that can be taken in relation to the question of what is the normative significance of empirical data in the context of health law research. The first position is that the results of empirical research are not relevant for the legal model in a normative sense. This position rests on the argument that the legal model is on the normative level ("what ought to be done") whereas the results are on the descriptive level ("what is done"), and that these two levels are strictly separate. Conflating these levels amounts to a violation of Hume's law ${ }^{1}$ (Singer, 1991, p. 505; Mackie, 1967, p. 178; MacNabb, 1967, p. 86). 
According to this position the only thing to be learned from empirical legal research is whether or not actual practice complies with the law. Law itself does not benefit from this kind of research, nor is it harmed by it: it is not affected by descriptive results. Empirical research can be used to monitor the degree to which subjects are adhering to legal norms, to trace factors that determine the behaviour concerned, and to assess the possible need to take measures to implement or enforce the law. It has no other value.

The second position depends on the view that actual practice and the law are conceptually connected. This position can be supported on both formal and substantial grounds. The formal grounds are related to the frequent occurrence of open norms in health law, such as the professional standard, "due professional care" (art. 7:453 (Dutch) Civil Code), reasonableness, harm, and "interests at hand" (art. 7:465 Civil Code). The use of open norms by the legislator implies that the interpretation and elaboration of these norms is left to health care practitioners, besides others, such as lawyers, ethicists, scholars and judges. Thus, the actual views and customs of practitioners, like self-regulation by the profession, obtain the authority of a source of law. Through the open norm, the legislator delegates the legal competence of operationalising the statutory norm to the persons who are dealing with it in practice.

The substantial grounds amount to the idea that the legislator and practitioners are motivated by the same concerns for the patients' wellbeing and autonomy. Insofar as practitioners act in accordance with the rationale of the law, there is no difference between their considerations and legal considerations. Good practical reasons, therefore, can have a rightful place in a legal argument and they can complement the statutory framework.

The third position that can be taken on the normative significance of empirical data agrees with the first position in insisting on a clear distinction between facts and norms, but, in contrast with the first position and in line with the second position, maintains that descriptive results are relevant for the legal model. To that end, empirical results should be used as part of a heuristic method. This method requires that for each salient empirical result, the researcher critically investigates the associated legal norms. Depending on the "valence" of the initial evaluation of the results, i.e. negative (the research subjects' behaviour is experienced as unexpectedly "disobedient") or positive (the research subjects' behaviour is experienced as unexpectedly "obedient"), this critical investigation will take the form of an attempt either to justify, or to denounce, the observed behaviour. 
This method could be called "systematic (or methodical) apology" or "systematic (or methodical) accusation" respectively. ${ }^{2}$ When the empirical research produces results that seem in conflict with the legal model, the researcher ought to ask himself whether it is nevertheless possible to defend the results from a legal point of view; when the researcher finds results that appear to conform to the legal model, he should ask himself whether it is nevertheless possible legally to condemn those results. These questions provide a perspective from which prevailing conceptions of the law can be criticised by re-examining the generally recognised sources of law. Legal elements or arguments may be found that would not have been discovered without the data from the empirical study. The method under discussion is called "heuristic" because it enables us to ask questions that could serve to find out relevant elements or arguments, but that do not offer a guarantee of doing so (see Oxford English Dictionary Online, 1989).

According to this third position, the confrontation of legal notions with actual practice may serve as a stimulus to gain a deepened, more critical understanding of the legal model. This position can, therefore, be characterised as a hermeneutic approach (Widdershoven GAM, 1987, p. $88,102 \mathrm{ff}$.). It goes without saying that the confrontation of actual practice with legal notions may also be instructive for practitioners insofar as their actions and reasons truly fail in light of the law.

\subsection{Patient COMpetence in Dutch LaW}

The Dutch Civil Code has a detailed regulation of the legal consequences of patient decision-making competence. Broadly speaking, the legal consequence is that a competent patient's decisions, in response to the interventions proposed by the health care professional, ought to be respected, even if this means renouncing life saving treatment or other interventions that are deemed necessary from a medical point of view. The legal consequence of incompetence is that a representative has to decide on behalf of, and in the interests of, the incompetent patient. The representative may be a person who has been officially appointed by a judge ("legal representative"); or, more commonly, either "attorneys in fact" (i.e. persons authorised by the patient when still competent), or partners and close family members.

The consequences attached by the law to competence versus incompetence, are potentially far-reaching. It is important, therefore, to know when a patient is competent and when he is incompetent. However, 
in this regard, the Civil Code does not offer much help. It gives only an open norm as definition for competence. According to this definition, a patient is competent if he is able to judge his interests at hand reasonably (art. 7:465 Civil Code). Because of the use of several abstract notions, such as interests and reasonableness, the definition is amenable to varied interpretations. Therefore, lawyers, clinicians and researchers aim at formulating criteria that can serve as an operationalisation of the statutory definition.

The establishment of concrete criteria for determining patient competence would enable an algorithm to be developed for dealing with informed consent. Such an algorithm would combine the criteria for competence assessment with the above-mentioned statutory legal consequences attached to whether a patient is competent or incompetent. This algorithm would be procedural in nature, because it is primarily oriented towards the question "who decides on care" and not towards the substantial question "what is good care".

Although at present no generally accepted criteria of competence exist in the Dutch system, there is consensus about two aspects of competence assessment. First, Dutch law agrees that the assessment of patient competence is mainly the responsibility of the attendant health care professional (Ministerie van Justitie, 1994; Hubben, 2000, p. 134; subsection 7.3.2 of this volume - first published as Welie SPK et al., 2005, p. 25). The professional has to do this, regardless of the patient's formal legal status, in the process of determining whether an informed consent or refusal by his patient is valid. For patients with a legal representative, the latter person may also be involved in the assessment. If the attendant health care professional wishes, he can consult specialists on the matter, e.g. psychiatrists or psychologists. As a last resort, the issue can be brought before the court.

Second, according to current opinion, patient competence is a taskspecific concept. (President's Commission, 1982, p. 55; Buchanan \& Brock, 1990, p. 18 ff.; Weisstub, 1990, p. 6-7; Beauchamp, 1991; Legemaate, 1994; White, 1994, p. 44 ff.; Wettstein, 1995; Gert et al., 1997, p. 132; Grisso \& Appelbaum, 1998, p. $21 \mathrm{ff}$; Chapter 4 of this volume - first published as Welie JVM \& Welie SPK, 2001b). The patient is competent if he has the abilities required for the task in hand (e.g. making a decision about the intervention proposed by the health care professional), and he is incompetent if he does not have these abilities. This means that the assessment of competence is specific to the decision in question. The result of the assessment does not pertain to other decisions as these may require other mental abilities. Neither does the result of an assessment 
prevail beyond the moment of assessment, since the patient's mental abilities may fluctuate, recover or deteriorate in the course of time.

\subsection{RESEARCH INTO CRITERIA OF PATIENT DECISION-MAKING COMPETENCE}

In Dutch law the assessment of patient competence is generally left to health care professionals. In this section I will describe an empirical research study that I have carried out that explores the ways in which health care professionals deal with this issue of patient competence in practice. The goal of the research was to learn something from actual practice in order to elaborate the law with regard to the assessment of patient competence. In order to take practice seriously and to be capable of adjusting the research methods if the preliminary results gave reason to do so, a flexible design was needed. It was decided to adopt qualitative methods as these give the opportunity to reformulate the research question in the course of the investigation (cf. "open and emerging design"; Creswell, 2003, p. 106-107). The research focused on the field of old age psychiatric care, in particular care for patients with early dementia. This focus was chosen because it was expected that the question of whether or not patients are able to make decisions for themselves, would be regularly under discussion among the health care professionals, albeit not necessarily in terms of patient decision-making competence.

My purpose in conducting the empirical research was not to judge the behaviour of the practitioners on the wards under investigation, but to develop the legal model further. Indeed, since the law does not provide clear and unambiguous standards for judging the way in which the practitioners reach specific verdicts of competence, it is not possible to make such a judgment. The research, therefore, started from the second of the three positions outlined above: it was assumed that practical routines and reasons displayed by health care professionals could supplement the legal model. The original research question was: how do health care professionals assess their patients' decision-making competence? The starting-point was the task-specific conception of patient competence.

The research was carried out on two wards for geriatric and psychogeriatric patients in a hospital and a nursing home respectively. The techniques used to collect the data were non-participant observation of, and semi-structured interviews with, health care professionals. During the observation the researcher's role was limited to overt attendance of 
diverse activities and consultations of the health care professionals, but did not include becoming involved in patient care nor active interference with the health care professionals' behaviour (cf. box 1 in Schwartz H \& Jacobs, 1979, p. 57). The observation in the hospital took place over nine weeks; the observation in the nursing home took place over seven weeks. A longer period of observation had originally been anticipated; however, this period was shortened in the light of the results. Ten interviews were conducted, of which nine were individual interviews and one was a group interview with four health care professionals. Those interviewed were physicians, a psychologist, nurses, nurse's aides and managers.

The researcher spent whole days on the wards thus gaining insight into the daily routines. He attended the following activities: initial discussions, for example in the outpatient clinic, with patients about management; admissions; provision of information to patients, representatives and/or family members; multi-disciplinary case conferences; staff meetings; discussions of the treatment or care plan; rounds; handovers between shifts; daily care; doctor consultations; therapeutic activities; recreation for patients; informal moments with health care professionals (e.g., meals); consultations of psychologists, medical specialists, lawyers and members of regional indication-committees for care allocation; and the discharge of patients from the institution.

\subsection{DeVELOPMENT OF THE RESEARCH}

The initial phase of the research showed, unexpectedly, that the issue of patient decision-making competence was not a topic of debate or discussion at all among the observed health care professionals. Health care professionals never explicitly asked themselves, or discussed with each other, whether or not a patient was able to take a specific decision. In the exceptional cases when mention was made of competence, the professionals referred either to the competence to manage financial affairs (which was outside the scope of the research), or they used competence as a rhetorical label to describe a patient who assented to the proposed clinical management in order to lend weight to a decision that had in effect been already taken by people other than the patient. One hypothesis to account for this result is that health care professionals had not had sufficient time to become familiar with the concept of competence, since the relevant provisions in the Civil Code had only entered into force a short time before the empirical study took place (cf. Evaluatiecommissie Wet Bijzondere opnemingen in psychiatrische ziekenhuizen, 1996, p. 116-117). This hypothesis is unconvincing, however, because the 
provisions in the Civil Code were largely codificative in nature: patients enjoyed the right to informed consent long before the codification of this right. Hence, the law has required health care professionals to judge their patients' competence to exercise this right for a longer time.

In the light of these results the research question was adapted and changed to the following two questions: (1) do health care professionals discuss their patients' decision-making competence; and (2), if not, why not? Further observations confirmed the previous finding that competence is very rarely discussed by health care professionals. In the interviews, some health care professionals denied this result, others confirmed it. The former claimed that the assessment of competence was, indeed, undertaken by practitioners. But on more detailed inquiry it turned out that they meant something different from the legal concept. For example, several interviewees, when claiming that they assessed competence, meant that they considered respect for patient autonomy an important principle. But appreciating the significance of autonomy is not the same thing as assessing competence. Indeed, in many cases, an assessment of competence might have shed doubt on the patient's ability to take an autonomous decision. One interviewee, in claiming to assess competence, had the global process of diagnosing and getting to know the patient in mind. This process takes place immediately after the patient's admission. Knowledge of the patient's condition and person may be necessary for a judgment of competence, but it is not sufficient. Furthermore, a proposed management plan is not normally formulated at this initial stage; so a context for competence assessment is lacking. Some interviewees meant by "assessing competence" that they attempted to take into account the patient's wishes when making decisions for the patient. Although this activity may be commendable, it is not equivalent to judging competence: it implies that the patient is assumed to be incompetent, since competent patients decide for themselves. Besides, incompetence does not mean that a patient's wishes could be disregarded. ${ }^{3}$ In summary, those health care professionals interviewed who denied the results of the observational study, had in mind something other than the legal concept of competence, i.e. the task-specific assessment of a patient's mental abilities to decide whether or not to consent to the intervention under consideration.

Some of the health care professionals interviewed agreed that patient competence was not widely assessed or discussed. The reasons given in justification were generally in conflict with the legal model. The most frequently given justification was that patients lack medical education, thus making informed consent unfeasible. This argument however ignores the legal and ethical requirement for the practitioner to provide the patient 
with the necessary information and to explain such information to him; hence, there is no need for the patient to know all relevant medical facts in advance.

The purpose of the research had not been to judge the practitioners on the wards under investigation. Their reasons for acting in a certain way, however, had to be evaluated vis-à-vis their compatibility with the basic assumptions of the law and the rationale of statutory law; otherwise they cannot be used for elaborating the statutory framework. After it had turned out that competence was rarely an issue among health care professionals and that the reasons stated as a justification for this were untenable, the third position (see above) was taken with regard to the relationship between empirical research and the law (systematic apology). This led to a more differentiated legal approach, as is exemplified in the next section.

\subsection{RESULTS}

The empirical results, outlined above, led to further analysis of the literature from a specific perspective. The following questions directed this analysis: are there any legal reasons for refraining from assessment of patient competence; and, if so, what are these reasons? This analysis showed that the generally recognised sources of law do indeed contain several legal arguments for not engaging in competence assessment under certain circumstances. These arguments will now be briefly discussed.

A first argument relates to article 7:466 section 2 Civil Code, which states that patient consent may be presumed to have been given if the intervention in question is not drastic in nature. In all cases where this provision applies, the health care professional does not have to solicit consent. Since patient competence is the competence to give or withhold consent, there is no need, under these circumstances, to assess competence. The expression "intervention [...not] of a drastic nature" is a statutory term in Dutch law. It relates to the inconvenience, burden, risks and suffering to the patient which are a result of the intervention or treatment. Examples of drastic interventions include surgical operations, Electro-Convulsive Therapy and medication that has serious side-effects. ${ }^{4}$

The second argument pertains to the presumption of competence (Hipshman, 1987; van de Klippe, 1990; van Wijmen, 1990; Weisstub, 1990, p. 6, 19; Ministerie van Justitie, 1994, p. 8; Legemaate, 1994; White, 1994, p. 3ff.; Madigan et al., 1994; Law Commission, 1995, p. 32 \& 223; 
Leenen \& Gevers, 2000; Koninklijke Nederlandsche Maatschappij tot bevordering der Geneeskunst, 2004, p. 92, 95, 100, 116; cf. art. 1:1 section 1 Civil Code). This presumption states that each patient, regardless of his psychiatric diagnosis or legal status, must be assumed to be competent, as long as proof to the contrary has not been provided. The presumption shows that there is generally no reason for competence assessment: health care professionals can just presume patients to be competent.

Similar arguments can be made with regard to the view that the patient's competence may not be called into question unless there is a legitimate trigger for doing so (Ministerie van Justitie, 1994, p. 8; Legemaate, 1994, p. 328; Koninklijke Nederlandsche Maatschappij tot bevordering der Geneeskunst, 2004, p. 100-101, 117), and the view that a patient can be justifiably declared incompetent only if the disadvantages of such a pronouncement (e.g. humiliation or stigmatisation of the patient, infringement of privacy, or possible subjection to coercion) are outweighed by its advantages (assistance of a representative, possibility of beneficent intervention) (van de Klippe, 1990, p. 131, 135; Legemaate, 1994, p. 328-329; Leenen \& Gevers, 2000, p. 216). In other words, when no legitimate trigger is present or when the consequences of declaring the patient incompetent are not preferable to the consequences of declaring him competent, a declaration of incompetence is unacceptable, even if the patient clearly does not have the mental abilities required to take the decision under consideration.

Another related argument, bears on the plea for a sliding scale approach (Drane, 1985; Ministerie van Justitie, 1994, p. 11; Legemaate, 1994, p. 330). A sliding scale approach "requires an increasingly more stringent standard [of competence] as the consequences of the patient's decision embody more risk" (Drane, 1984, p. 925). Among other things, this means that low demands are to be made on the competence of a patient who accepts regular medical treatment: for such a patient to be deemed competent, according to the sliding scale, it is sufficient if his awareness is not diminished and if he has the ability to express assent, either explicitly or implicitly, to the treatment suggested by the health care professional. These criteria require so little from the patient that establishing whether a patient meets them, is hardly a question of assessing competence. For unproblematic decisions, a patient's competence does not matter, really, on account of this "sliding scale approach" (cf. Koninklijke Nederlandsche Maatschappij tot bevordering der Geneeskunst, 2004, p. 101; Leenen \& Gevers, 2000, p. 216; Chapter 7 of this volume - first published as Welie SPK et al., 2005). 
A further argument for why assessing competence may be irrelevant, regards shared decision-making by health care professional, patient and family member(s). Patients are often accompanied by one or more close relatives when attending appointments for consultation with the doctor, especially in the face of major decisions (cf. Schermer, 2001, p. 149-151, on "the dual strategy"). If the health care professional succeeds in reaching agreement with both patient and family member on what medical course of action to pursue, it follows from article 7:465 sections $2 \& 3$ Civil Code that competence assessment is irrelevant. This is because close relatives are potential representatives. Provided that all parties have been well informed and that no undue pressure has been exerted, the health care professional can be assured of having obtained valid consent in this situation: if the patient is competent, then the patient's agreement provides valid consent; if the patient is incompetent, then the family member's consent is legally valid.

Finally, article 7:465 section 6 Civil Code states that resistance of an incompetent patient against drastic interventions that are not necessary to avoid serious harm for the patient, ought to be respected by the health care professional (cf. Law Commission, 1995, p. 60 ff. \& 224). ${ }^{5}$ In all situations, therefore, where a patient objects to such an intervention, whether the patient is competent or not, the health care professional should desist from implementing the intervention. Once again competence assessment is of no legal significance, at least not in answering the question whether coercion can be used. The expression "serious harm" like "intervention [...not] of a drastic nature" is a statutory term in Dutch law. An operation for a minor condition (such as a hernia repair, under some circumstances) might count as a drastic intervention that is not necessary to avoid serious harm.

It is of course true that concepts like "drastic intervention", "legitimate trigger", "unproblematic decision", and "serious harm", are open to various interpretations (Sluijters \& Biesaart, 2005; Tweede Kamer der Staten-Generaal, 1993/94). But whatever dispute may arise in that regard, it is also clear that all of the above arguments limit the scope of the procedural approach implied by competence assessment. To put it briefly, a patient's competence (or lack of it) is legally decisive only in situations that fulfil two cumulative conditions (both are necessary): 1) a patient persists in not complying with a drastic intervention which is necessary to avoid serious harm, or with a non-drastic intervention which is necessary to avoid serious harm or needed to bring about a substantial improvement in the patient's condition; and 2) the family member(s) or representative agree(s) with the health care professional that the intervention should take 
place. This second condition is explained by the fact that the relatives' disagreeing with doctors constitutes potential substitute refusal in case of a patient resisting the proposed intervention. ${ }^{6}$

The arguments that I have put forward thus qualify the prevailing legal opinion that assessment of patient competence is pivotal in medical decision-making and that criteria of competence should be applicable to all imaginable situations. This is an important qualification because it demonstrates that in many cases health care professionals can dedicate themselves to a discussion of what is good care for a specific patient, and to attempts at persuading the patient of the value of what they sincerely believe to be good care, without needing to assess competence. For those cases in which competence assessment plays a key role in decisionmaking, insight into the applicable circumstances can direct academics and practitioners in formulating valid and useful criteria of patient competence.

In summary, the use of the heuristic method of systematic apology, involving collecting empirical data, has facilitated systematic reflection on a number of elements in the legal model, the implications of which have not been previously thought through. Empirical methods can constitute a useful supplement to the more traditional methods of legal research, in particular in helping to avoid a one-sided emphasis on leading theoretical notions.

\subsection{Conclusion}

In this chapter I have argued that the empirical study of how health practitioners behave can play an important part in enhancing legal analysis. I have illustrated my argument through describing an empirical study that I carried out in the area of the assessment of patient competence to consent to treatment. The aims and design of the study were the result of initial legal analysis. But the aims changed in the light of the results of the first part of the study, and the results overall then elicited further legal analysis. I distinguished three different approaches to the relationships between legal analysis and empirical research. The approach that developed from the empirical study, I have called "systematic apology".

A crucial phase in systematic apology is the critical re-examination of generally recognised sources of law. The sources of law cover a broad domain, including not only positive statutory law, but also legal doctrine 
and juridical principles, among other things. This has the advantage of offering plenty of legal material to tap. Law has a history of more than four thousand years (Cuneiform Law, 2004), in which an abundance of concepts and arguments can be found.

A disadvantage, however, of this is that the demarcation of which legal elements can reasonably be seen as applicable to a specific context, is vague. When studying the legal literature, for example, there are no objective criteria for ascertaining which authors are authoritative, nor even for ascertaining whether authors should be classified as contributing to legal doctrine or as formulating ethical theories.

Systematic apology is a heuristic method for articulating legal arguments in defence of some of the practitioners' behaviour. It requires the researcher to be prepared to re-examine critically the sources of law in the light of empirical results that at first sight suggest that practitioners do not act in accordance with legal concepts or rules.

The method under discussion is not only a way of differentiating legal views among health lawyers and as such an academic instrument to develop the domain of health law; it is also interesting for clinicians because it gives them a lego-political voice, not in the sense of defending any behaviour a health care professional might display, but in the sense of translating practical rationality and rational practices into legal terms. The implications for clinical practitioners of using the empirical method of systematic apology are very different from those of Evidence Based Medicine. In the latter, reportedly ineffective health care interventions are ruled out as options for the practitioner. Thus the practitioners' discretionary power is reduced. In the former, the practitioners' power is enhanced by having their input inform the legal discourse.

A practical advantage of the use of systematic apology as a means of developing the legal model, is that health care professionals will identify more easily with the ensuing development of the legal model. This should help such professionals to be more sensitive to, and better able to deal with, legal aspects of their relationship with patients and their representatives. Since health care professionals can directly contribute to a realisation of patient rights through their day-to-day contacts with patients, this sensitivity would be a move in the right direction of improving patient's rights. In that way, the juridificative, bureaucratic tendency to formulate ever more legal regulations and procedures with ever less "healthy" effect in professional care for patients, can be counterbalanced. 


\subsection{Notes}

1. See Hume. (1739/1740). A treatise of human nature, book III, part I, section I.

2. Alluding to Descartes' systematic/methodical doubt.

3. Cf. art. 7:465 section 5 second sentence Civil Code. See also principle 9 of Recommendation No. R (99) 4 of the Committee of Ministers of the Council of Europe to Member States on Principles concerning the Legal Protection of Incapable Adults (Strasbourg, 1999).

4. Thanks to Dr. B. Pinckers for supplying examples.

5. Cf. also art. 5 (c) European Union directive Good Clinical Practice (Directive 2001/20/EC, Official Journal L 121).

6. The situation in which a family member is not available, is left aside, as is the possibility for the practitioner to overrule representatives because of the latter's doing a bad job (art. 7:465 section $4 \mathrm{j}^{\circ}$ section 5 Civil Code); cf. Welie SPK, 2005, p. 255-256. 


\title{
4. PATIENT DECISION-MAKING COMPETENCE: OUTLINES OF A CONCEPTUAL ANALYSIS
}

\author{
J.V.M. Welie \& S.P.K. Welie
}

\subsection{ABSTRACT}

In order to protect patients against medical paternalism, patients have been granted the right to respect of their autonomy. This right is operationalised first and foremost through the phenomenon of informed consent. If the patient withholds consent, medical treatment, including life-saving treatment, may not be provided. However, there is one proviso: The patient must be competent to realise his autonomy and reach a decision about his own care that reflects that autonomy. Since one of the most important patient rights hinges on the patient's competence, it is crucially important that patient decision-making incompetence is clearly defined and can be diagnosed with the greatest possible degree of sensitivity and, even more important, specificity. Unfortunately, the reality is quite different. There is little consensus in the scientific literature and even less among clinicians and in the law as to what competence exactly means, let alone how it can be diagnosed reliably. And yet, patients are deemed incompetent on a daily basis, losing the right to respect of their autonomy. In this chapter, we set out to fill that hiatus by beginning at the very beginning, the literal meaning of the term competence. We suggest a generic definition of competence and derive four necessary conditions of competence. We then transpose this definition to the health care context and discuss patient decision-making competence.

\subsection{INTRODUCTION}

The issue of a patient's decision-making competence (PDMC) is complex, complicated, and, worst of all, highly controversial. It is directly tied to contemporary debates about patient autonomy versus provider beneficence; manifold methodically diverse disciplines can and should concern themselves with the issue; and there is no way to evade the volatile debate on the proper relationship between socio-political 
ideology, psychiatry, and state power. Yet it is also clear that the issue of PDMC cannot simply be dismissed as irrelevant for everyday clinical practice. Although many times ethical dilemmas are incorrectly labelled as PDMC-type problems (notably dilemmas concerning the utility or futility of medical treatment), PDMC-type problems do arise in clinical practice frequently.

Besides evading the topic of PDMC altogether, one might try to evade the substantial issues it involves by reverting to a purely procedural strategy. That is, instead of wondering what it means to be competent, what it means to be able to make decisions that foster one's own health, the PDMC analysis is limited to such questions as "Who has the right to judge PDMC," and "How is PDMC to be established." We believe that such questions, notwithstanding their importance, should be postponed until the essence of PDMC has become clear. For reasons of clinical urgency, care providers may have no choice but to limit themselves to such procedural questions. But it should always be remembered that such

\section{Some Definitions of Competence}

Competency is "the capacity to make an explicit, reasoned, and intentional choice among alternative courses of action." Pellegrino \& Thomasma: For the Patient's Good, 1988, p. 149.

Competency is "the exercise of practical skills that meet (and are evaluated according to) some norm" and "that maintain or further the individual's own preferences and goals in life." Pepper-Smith, Harvey \& Silberfeld, 1996, p.137.

"Competence...is a particular person's capacity to perform a particular decision-making task at a particular time and under specified conditions." Buchanan \& Brock, Deciding for Others, 1990, p. 18.

"Competence refers either to an individual's capacities (a descriptive definition) or to whether that individual's particular capacities are sufficient to render legal decision-making authority to him or her (a threshold definition)." Wettstein, in the Encyclopedia of Bioethics, 1995, p. 446-447.

"Competence, in making medical decisions, is the ability to make a rational decision." Gert, Culver \& Clouser: Bioethics-A Return to Fundamentals, 1997, p. 137.

"Competence is used to denote the eligibility to assume responsibility for decision making that affects one's own welfare.” May, 1998, p. 250. 
questions can only be properly answered after the more substantial issues have been settled - explicitly or implicitly.

Unfortunately, the literature on PDMC provides a rather opaque mixture of approaches, conditions, criteria, procedures, tests and even definitions (see Figure F). Some authors take their starting point in decision-making models developed in formal logic, others borrow from psychiatric notions and vocabulary. ${ }^{1}$ Some take a practical approach, others a theoretical. Some define competence, others incompetence, and the reader is left wondering whether their definitions may be reversed. Often it remains unclear whether conditions are meant to be necessary or sufficient.

In one point, however, the literature does agree: In most publications it is stressed that clear and generally accepted standards or guidelines for competence are lacking. In this chapter, we set out to fill that gap. We intend to do so by beginning at the very beginning: the literal significance of the term competence. Next, we suggest a generic definition of competence and derive four necessary conditions of competence. Finally, we transpose this definition and the four ensuing criteria to the health care context, more specifically, the issue of patients' decision-making.

Evidently, this chapter does not provide a comprehensive analysis of PDMC. Our goal is, in fact, very modest. We merely provide an analysis of the concept of PDMC and sketch its attributes. It is only when such foundations are laid that we can begin to determine the mental abilities underlying competence and the clinical tests that can reliably diagnose mental deficiencies rendering patients incompetent.

\subsection{Towards a definition of competence}

It is always illuminative to start a systematic analysis with an etymological exercise. In Latin, the word competens means "coming together at one point" or "fitting together," and (hence) "being fit for the purpose." When contending that $\mathrm{X}$ is competent to do $Y$, it seems we are simply saying that $\mathrm{X}$ has the ability to do $Y$, is qualified to do $Y^{2}$

Obviously, matters are not that simple. But before leaving the etymological level, we want to emphasise that the kind of ability or quality denoted by the term competence apparently presumes a "coming together" (com-petence) of certain qualities. We invoke the term when a particular task requires the person to be "duly qualified" (Webster 
Dictionary, 1983) and, hence, has all of the abilities it takes to get the job done. A competent person can be trusted to do the job well. Clearly, then, a judgment of competence requires that four conditions are met:

1. The kind of task to be fulfilled is known. In most instances, different tasks will require different skills, and hence competence in one area need not imply competence in another.

2. It is known what it means to fulfill such a job well. To be competent does not imply that one can do a perfect job or even an excellent job. But one must be able to obtain sufficient results (given the circumstances) for the outcome to be considered "a job done well." In other words, competence is a "threshold concept." Hence, neither the person presumably competent to fulfill the job, nor those judging his/her competence, need to know what would qualify as a perfect outcome. But we still need to be able to differentiate between "pass" and "fail" in this particular area.

3. The abilities or qualities required to do the job well are known. A verdict of competence does not merely describe a person's past performance. Generally we do not expect someone to first complete the job before we call him/her competent to do so. Rather, we trust (s)he is going to do the job sufficiently well, given certain abilities and qualities. Hence, we also need to know what kind of abilities and qualities it takes for someone to do the job well.

4. It is known whether the person charged with the job has the required qualities or abilities. We must have information on him/her that is independent of our seeing him/her do the particular job right here and now. It may be that we have seen him/her successfully complete similar jobs in the past. More often, we trust a person to be competent because we know (s)he has been trained or taught to do such jobs and/or has gained experience in this area.

Knowing that a person is able to make sound decisions does not guarantee (s)he is actually going to apply those abilities. A person may simply refuse to behave competently. Such recalcitrance, stubbornness, inconsistency, laziness, or erraticness constitutes a critical problem for the theoretician of competence, and particularly of patient decisionmaking competence. What if a competent patient "chooses" not to decide competently? Is individual freedom of choice the most important human value, even if such freedom entails outcomes that are maleficent for the patient on all other accounts? Moreover, what kind of choices would qualify as free choices? Would the decision to do exactly the opposite of what just about everyone, including the patient, takes to be the most 
beneficial course of action, qualify as a free choice? Can the decision to decide incompetently itself be a competent decision?

Notwithstanding the theoretical validity of these questions, we should not lose sight of the fact that the patient's right to respect for his/her autonomous decisions and the entailed debate about PDMC, historically is not rooted in an existentialist or liberal ethics that assigns freedom ultimate value. The societal acknowledgment of this and similar patient rights has grown out of the discovery of a series of flagrant abuses by physicians of their patients' trust in them. Given the ever present danger of such abuse of power - not in the least because many of the physicians involved in these immoral experiments and treatments did not agree they were acting immorally or even violating patients' interests -, patients have been granted the right to informed consent. Patients, rather than their care providers, are assumed to be the best judges of their own health related interests. ${ }^{5}$ Hence, each individual patient has been granted the right to rank-order all possible interests and values entailed in certain proposed medical treatments that (s)he will (or will not) agree to undergo. In this light, it would be inconsistent to force freedom onto patients as the ultimate value to be cherished above and beyond all other possible values and interests.

It is doubtful, moreover, that the clinician will frequently face patients who apparently are competent, but refuse to behave competently in their decision-making. It is quite inconsistent to first entrust oneself knowingly and willingly to a care provider in order to be healed, and then refuse willingly and knowingly to work towards a beneficial treatment plan. Moreover, if some patients would behave in this manner, it is quite unlikely that they would behave like this consistently. By giving it some time, the care provider may find the patient more "amenable" after all. In the framework of this chapter, we will simply assume that the competent but erratic patient will, in due time, revert to a proper analysis of the problem at hand and adopt a sensible decision-making strategy, notably if so requested by a caring and trusted health care provider.

\subsection{Patient AUtonomy AND DeCision-MAKing COMPETENCE}

Now that we have outlined the conditions of any kind of "competence," we can turn to the field of health care. What do we mean when we deem a patient competent or incompetent? It is generally argued that competence, 
when applied to patients, is a necessary condition of the patient's right to respect of her autonomy. ${ }^{6}$ That is to say, the autonomy or selfdetermination of patients must be respected by health care providers, but only if patients are competent to determine their own health care. It is only if patients' decisions are the result of their own will, rather than someone else's will (be that an external or internal "other" will), that they can properly be called autonomous, rather than heteronomous.

Another way of making this point is in terms of responsibility. It is generally believed that patients, and not the state or the medical community, carry final responsibility for their own health care (or at least the acceptance or refusal thereof). If a patient refuses much needed medical care, no one but the patient is responsible for that decision. ${ }^{7}$ Patients have a right to be left alone. But we can only hold persons responsible if they could have made a different decision, if they were free and able to reach a different decision. Competence is the patient's ability to make a choice about the various medical interventions offered to her by the care giver, and to bear accountability for that choice.

May (1998) has argued that this competence does not entail a specific task, but is in fact global. According to May, there is no significant difference between a patient refusing an operation advised by her surgeon that may save her bowel from becoming necrotic, or the same person refusing an investment recommended by her financial advisor that may keep her business from going bankrupt. The refusal of the investment may be utterly stupid, but it was still "her decision," an autonomous decision that must be respected. Many people invest without really knowing what they are doing, they risk and gamble, acting on sudden urges and poorly researched inklings. Nevertheless, these investments reflect autonomous decisions. Following May, the refusal of the abdominal operation likewise can be an autonomous decision, even if it was an utterly stupid decision, based on a momentary opinion or passing desire. ${ }^{8}$

We are not convinced that the decision to refuse an intestinal operation is fully analogous to the refusal of the financial investment, not even if considered under the aspect of autonomy only. Unlike clients, patients are vulnerable, which is why medicine is a true profession, committed to protecting patients, but financial management is not. ${ }^{9}$

However, the more important observation is that patients generally do not appreciate physicians' respecting their autonomy because of a desire to be "left alone." It is not the formal freedom advocated by libertarian 
philosophers they are seeking. Most patients do not want their physicians to simply leave them alone with the final decision. They do not insist on consent prior to treatment because it is their body that will be manipulated, their privacy that will be invaded. Rather, most patients visit a physician because they are in need of help. They desire to be cared for. They seek health care that will benefit them and to that avail they submit themselves to the judgment of medical experts. Truly beneficial health care, however, is always tailored to the unique needs of each individual patient, consistent with the unique personality and identity of each individual patient, his or her life story, expectations and plans. The patient cannot do without the medical expert, but the latter cannot do without the former either if she is to offer truly beneficial health care. The respect patients are seeking is not a respect of formal autonomy, but respect of autonomy as personal uniqueness.

In this perspective, patient consent is much more than a token of the patient's agreement, a free decision on par with the decision to buy more Microsoft stock. Rather, the patient's consent constitutes the final confirmation by the patient that the treatment proposed is the outcome of a joint diagnostic, prognostic and therapeutic dialogue between patient and physician. This, in turn, provides the necessary warrant to the physician that his/her interventions are, indeed, beneficial. For the physician, unlike the financial manager, is bound by an ethical duty to provide only those medical interventions that are truly beneficent.

We thus find that patients' autonomy must be respected by physicians because patient autonomy is a necessary condition for the determination of beneficial care. Indeed, it is generally agreed nowadays that patients, not physicians, are the best judges of what is objectively in their own medical interest. Making such decisions is seldom easy, neither for caregivers nor for patients. But patients are most likely to arrive at the most accurate decision.

Thus, the peculiarity of medical (as opposed to, say, economic) decisions, is primarily due to the (partial) unknowability for third persons (such as physicians) of an individual patient's personal health related interests. In this regard, health related interests are similar to love related interests. It is (nowadays generally thought to be) impossible to decide for another person what spouse will best match him/her. Likewise, it is impossible to decide for another person what kind of medical treatment will be in his/her best health related interests. Unlike purely material interests such as stock options or even environmental safety, love and health are too 
personal to be perceived and too individual to be expressed and measured in commonly applicable terms or units.

Health care providers cannot assess individual patients' health related interests, certainly not without the involvement of a competent patient $\mathrm{him} /$ herself - if health care providers could, there would be no (or less of a) need to grant patients decision-making authority. Presumably patients can do so, or at least are much better at it than clinicians, provided they are competent to do so. Once again, respect for a patient's autonomy is conditional on the patient's ability to actually realise his or her autonomy. But the task at hand has changed. It is no longer a simple matter of choice and accountability. It is no longer global but quite specific. The task at hand involves decision-making; more specifically, deciding about one's own health needs and the medical care that is likely to be beneficial.

We emphasise once more that the task involved is one of making decisions about one's health care such that one is likely going to be benefited by that health care. PDMC is the ability to fulfill this task. That does not mean, however, that the patient must actually fulfill this task and decide in favour of health care that is likely to be beneficial. A patient is competent if he could have reached such a decision; not if he actually does. For example, a seriously ill Jehovah's Witness patient might, without much consideration, refuse outright all treatment options because they all involve administering blood products. From a medical perspective, this refusal evidently is not beneficial to the patient. Nevertheless, the patient would be competent if he could have reached another decision, i.e., if he has the ability to reach decisions in favour of health care that is likely to be beneficial. This ability might be evidenced from past decisions regarding treatments that did not involve blood products. What we need to know, then, is what kind of patient decisionmaking process is likely to yield decisions that accurately reflect a patient's own medical interests.

\subsection{THE PROCESS OF MAKING DECISIONS ABOUT ONE'S OWN HEALTH(CARE)}

Competence to perform a particular task does not hinge on a person's actually accomplishing that task. Whether a particular patient has the qualities and abilities to make satisfactory health care related decisions ought to be assessed independently of the particular decision (s)he is actually making. Instead, it is the process leading up to that decision, that should concern us. 
The clinical reality frequently digresses from this maxim. Most patients who agree with proposed interventions are presumed competent by their doctor, simply because they agree with him or her. Rarely will a physician proclaim: "This patient agreed with my treatment plan; she must be incompetent!" The reverse is much more likely: "This patient rejected my (scientifically sound and artful) treatment plan; I wonder whether he is really competent."

It shall be clear that this (all too common) line of thinking is at odds with both the historical and philosophical underpinnings of the concept of patient autonomy and PDMC. In years past physicians would commonly override any decision on the patient's part that was at odds with their medical convictions; after all, the physician's highest and overriding duty was to act for the benefit of the patient (as interpreted by the physician). In response to such medical paternalism patients were granted the right to respect of their autonomy. Nowadays, the same kinds of decisions by patients may end up overridden on the same paternalistic grounds, but via the backdoor of incompetence.

In order to be true to history as well as philosophically sound, it is important that PDMC is determined without relying on the patient's actual decisions. Instead, the focus should be on the quality of the decision-making process. That is not to say that a quality assessment of patients' health care related decision-making can be based solely on the formal aspects of that decision-making process. Any good decisionmaking process is only good because and to the extent that it actually yields good decisions. Good decisions concerning health care are presumably those that actually foster patients' health and medical wellbeing. Hence, we need to know what these interests are in order to determine what qualifies as a good decision, such that we can determine what kind of process leads up to such a decision and, hence, qualifies as a good process. But this invokes a circle: In order to learn about a patient's interests, we examine the decision-making process; but in order to examine the decision-making process, we need to know what is in his interest.

We can only "circumvent" this circle by acknowledging that, explicitly or implicitly, a substantial judgment about what qualifies as good health care is always being presumed in PDMC debates and assessments. We thus run into a paradox, or at least a paradoxical situation. On the one hand, patients' health care related interests are thought to be so personal that outsiders such as caregivers are unable to adequately assess them. On 
the other hand, the same outsiders presumably are able to judge patients' decision-making competence although such assessments require insight into patients' health care related interests. Granted, providers' knowledge of patients' interests is generic in nature, whereas patients are presumably able to gauge their personal and (in part) peculiar interests. Nevertheless, providers' generic knowledge is still considered a sufficiently accurate reflection of individual patients' interests to justify PDMC judgments by the providers.

This paradox cannot be eliminated but should not be ignored either. Rather, in the process of establishing criteria of PDMC, an attempt should be made to explicate any substantial (as opposed to merely formal) criteria. Justice is served better by publicly avowed paternalism than by an untenable vow of moral neutrality.

We have seen that it is not possible to construct minimum standards of PDMC in a morally neutral manner, based solely on some kind of formal logic of decision-making. Substantial value judgments about patients' health care interests are involved necessarily. There is, however, an additional problem. It is not possible either - not in this chapter but, most likely, neither in any larger framework - to develop a theory about patients' health care interests that will meet general consensus (on which basis we could then go on to develop PDMC standards). After all, the whole debate on PDMC has emerged from the recognition that health care related interests are too personal to be adequately addressed in a generic medical theory.

Instead, we - like just about everybody else involved in the debate on and practice of PDMC assessments - take for granted certain conventional beliefs about patients' health care interests as they currently and commonly guide health care practices. These beliefs range from rather generic ideas that health, pain-freeness, and functional ability are goods, whereas handicaps, illnesses, and death are to be prevented, to the more specific conviction that "well-ness" is the reflection of a person's state of adequate order and adaptation, physically, mentally, and socially. That is to say, a person is "healthy" or "wholesome" when his or her state of being is "in order" as opposed to "disordered," structured by a certain "logos" rather than the result of "chaos." The impact of these conventional convictions will become more evident in the final part of this chapter, where it is simply assumed that competently made health care decisions are "informed," "reasonable," "balanced" - all characteristics of an "orderly," "logical" way of being - and specific 
patient decision-making abilities and qualities are deduced from these characteristics.

\subsection{PATERNALISM IN COMPETENCY DETERMINATIONS}

Even though the whole construct - starting with the principle of patient autonomy, operationalised in the patient's right to informed consent, and topped with the notion of PDMC - had one purpose and one purpose only: to curb medical paternalism, we have found that some degree of paternalism is inevitable. Firstly, a patient is only competent to reach decisions about her own health care if those decisions will result in health care that actually benefits her; but the definition of benefit necessarily supersedes the subjective views of the patient and relies, at least in part, on the views of health care professionals. Secondly, in the absence of a generally agreed-upon theory of health care benefits, the views of individual clinicians inevitably will affect their assessment of patient's decision-making competence.

Even if some degree of paternalism is inevitable, we should strive to prevent paternalistic and potentially biased assessments as much as possible. One way to do so is to always keep in mind that patients have the right to be considered competent until proven otherwise. That maxim holds true at the bedside when assessing a particular patient's (in)competence. The clinician should not ask whether mental exams can show the patient to be competent, but whether they show the patient to be incompetent. Since PDMC is a threshold concept, a patient's decisions may only be overridden if they are the result of a decision-making process that evidently fails to meet certain minimum standards (and, hence, no longer warrants decisions that adequately reflect the patient's interests). Conversely, any decision-making process that does meet those minimum standards, regardless of the outcome, should be respected. ${ }^{10}$

Technically, this means that the tests to determine a patient's decisionmaking incompetence should have the highest possible specificity. The level of specificity (preventing false positives) is more important from an ethical standpoint than the level of sensitivity (preventing false negatives). ${ }^{11}$ It is morally preferable that some patients are treated as competent when, in fact, they are incompetent, than that some patients are treated as incompetent when, in fact, they are competent. The duty not to harm (in this case, not to violate a patient's freedom of choice) overrides 
the duty to do good (i.e., to heal), notably in the area of medicine and health care.

The clinical-ethical maxim that patients are competent until proven incompetent should also hold true in the research domain when we try to determine the validity of a test for decision-making abilities and qualities generally required to make a competent decision. ${ }^{12}$ That determination will require an empirical comparison between incompetent and competent patients. When dividing our research subjects into these two categories, we would have to decide which subjects belong in what group. But on what grounds? If we fill our group of incompetent subjects with patients who have already been found incompetent by their clinicians, we risk inheriting the paternalistic biases that often motivate clinical determinations of incompetence. For example, it rarely happens that a patient's (in)competence is examined when and because she quietly consented to treatment; that usually only happens when she refuses interventions proposed by the physician. Or consider the example of informing patients. The Dutch study on "Medical Decisions Concerning the End of Life" shows that $56 \%$ of hospital patients were deemed incompetent to engage in a discussion on Do-Not-Resuscitate (DNR) orders (van der Maas et al., 1991). This number is remarkably high. If we assume that DNR discussions do not require a higher level of competence than most other medical decisions, more than half of the hospitalised patients would be incompetent to engage in any patient related decisions. Moreover, according to this study this percentage is exactly the same for patients in nursing clinics which serve many more patients percentagewise with dementia and other mental deficiencies.

Since questions about competence generally are raised only when patients refuse the treatment, not when they quietly consent, chances are that the pool of patients presently labelled incompetent was held to a more demanding standard of competence than those who are presently labelled competent. Had the more demanding standard been applied across the board to both consenting and refusing patients, the distribution would have turned out quite different and many more patients would be labelled incompetent. Conversely, if the standard to which consenting patients are typically held would be applied across the board, many patients presently labelled as incompetent would have to be relabelled as competent.

Granted, if we apply the latter rather than the former standard, we may end up with an incompetence test that sets the threshold for competence too low. But then again, it is ethically "safer" to deem too many than too few patients competent. 
It should be pointed out that the above mentioned clinical-ethical maxim constitutes an important limit to any listing of decision-making standards and entailed PDMC criteria. Since any patient who cannot be determined incompetent shall be assumed competent, it only makes sense to list PDMC criteria that can be operationalised and tested reliably. For example, if we were to contend that a good decision-making process is one that accounts for the patient's authentic values, but we do not really know how a patient would achieve such a decision and, hence, what qualities and abilities are required to make such a decision, let alone how these are to be tested, there is no point in listing authenticity among the minimum criteria of PDMC.

\subsection{The ABiLities INVOLVED IN PDMC}

We have tried to clarify (1) the kind of task to be fulfilled: to make a sound decision about one's own health care. We have discussed (2) what it means to fulfill this task well and emphasised the importance of giving patients the benefit of the doubt, treating them as competent until proven incompetent. We can now move to (3) a discussion of the abilities or qualities that are required to do the job well. What abilities and qualities are required to make satisfactory decisions about one's health?

As mentioned earlier, a non-paternalistic approach would require a generally agreed-upon substantive theory about the benefits of health care. In the absence of such a theory, we submit - as a hypothesis not to be evidenced in the context of this chapter, but one that is consistent with and/or overlaps taxonomies developed elsewhere (see e.g., Buchanan and Brock, 1990; Pepper-Smith et al., 1996) - that a patient's decisionmaking about his or her own health care relies on at least four qualities and abilities: (i) the ability to absorb, comprehend and retain knowledge or, more broadly, cognitive content; (ii) the ability to manipulate cognitive content critically; (iii) freedom of will; and (iv) the ability to express oneself.

(i.) The importance of this first factor, absorbing, comprehending and retaining knowledge, immediately follows from the fact that the decisionmaking process implies an estimation of probable outcomes and an evaluation of these outcomes. The estimation of outcomes is based on a patient's acquired knowledge of relevant facts. If this knowledge base is seriously flawed, the resulting decisions are likely to be flawed too (in the sense of not representing a patient's health related interests). Such a 
flawed knowledge base may be the result of care providers' withholding relevant information, in which case a verdict of patient decision-making incompetence would simply be void. As the concept of "informed consent" expresses, it is the care provider's obligation to supply the patient with correct, complete, and relevant factual information on the diagnosis, prognosis, therapeutic alternatives, and likely medical benefits and burdens of those alternatives. ${ }^{13}$

Alternatively, patients may refuse to even consider the supplied information, for example by refusing to carefully read the informed consent form. In doing so, the patient disqualifies himself as a competent decision maker and the patient's consent is void. ${ }^{14}$

But a flawed knowledge base may also result from a patient's mental inability to absorb, comprehend or retain the supplied data, in which case a verdict of incompetence would be justified. How much information must be supplied in any given case and how well a patient must be able to comprehend it, will be proportional to the gravity of the decision at hand. ${ }^{15}$

In determining a patient's ability to comprehend the supplied data, caregivers must be cautious not to consider any denial or divergent interpretation of these data as a lack of comprehension on the patient's part. All "data," even scientifically validated, quantitative data, presume a particular epistemological and moral frame of reference. Side-effects of medical interventions are only "side"-effects if one underwrites the presumed medical goal of the intervention - which the patient may not. Physiological normalcy may not concur with what the patient takes to be normal. And the tendency of patients to adopt a qualitative stance as opposed to the more quantitative stance of medical science and practice should not be dismissed as a bias on the patients' part; the quantitative stance of medical science may well be the biased stance. In sum, patients should not be forced - on penalty of being found incompetent - into adopting a medical-scientific base of knowledge as the only correct base.

Evaluating expected outcomes is a more complicated process than estimating probable outcomes in that it involves both "passive" knowledge and the ability to actively manipulate and balance a range of data so as to reach an evaluation. We will return to this active ability hereunder. Evaluation of the expected outcomes requires an explication of the values that are implied by the supplied "factual" data as well as the values cherished by the patient himself. Hence, the patient must comprehend both facts and values. For a competence determination, not 
the particular content of the values pursued by the patient is relevant, but the patient's awareness of these values. After all, the principle of respect for a patient's autonomy prescribes that a patient should be free to pursue whatever values (s)he embraces. The demand for knowledge of one's values lacks moral substance and, hence, is compatible with this principle.

(ii.) Manipulation of knowledge or, more broadly, cognitive content constitutes the second factor that determines patients' decision-making. Cognitive content may include intellectual as well as emotional information. Manipulation of this content is related to the ability to critically analyse the available information and to maintain a certain degree of logic and consistency. It involves the planning of the future in view of the past, and the balancing of short term and long term effects. Other aspects of manipulation are combining, weighing, prioritising, and integrating information. Finally, the competent decision maker should be able to correct mistakes. The fact that somebody starts his decisionmaking process from incorrect facts should not automatically imply his incompetence; the person's ability to adjust his own assumptions on the basis of new information must be decisive.

Once again, it should be emphasised that a patient's apparent "failure" to adjust assumptions on the basis of supplied new data does not necessarily reflect decision-making incompetence on the part of the patient. The patient may have good reasons (in his epistemological and moral frame of reference) to deny the corrective power of the supplied new data. The crucial determinant is the degree of the patient's "reasonability" in manipulating cognitive content: the ability to clarify a decision by means of reasons. Cognitive manipulations as described above (analysis, planning, prioritising, correction, etc.) are essentially "reasonable" in nature. ${ }^{16}$ If a patient cannot give reasons, (s)he may be presumed not to have any reasons and, hence, have failed to adequately manipulate the cognitive content.

Granted, patients may not be willing to share their reasons with the care provider. Consequently, much of the patient's cognitive manipulations will remain hidden to the outsider. The right to be treated as a competent patient, able to make autonomous decisions, therefore may square with the right to respect of one's privacy. However, this kind of a dilemma is not uncommon in clinical medicine. Physicians are often faced with patients who withhold sensitive information that is necessary to make a proper diagnosis and/or to determine the optimal course of action (e.g., 
alcohol and drug use, sexual practices, compliance with prescribed therapies). Patients will only reveal such sensitive information if they trust their physician. Physicians hence must take great care to assure their patients that they are bound by a professional duty - the single most important professional duty - to maintain confidentiality. Without threatening the patient, again on penalty of finding him incompetent, into releasing such private information, the attending physician must share her own dilemma with the distrusting patient and express her own uneasiness about the patient's decision, a decision the reasons of which she cannot comprehend. If no adequate level of trust can be established, the attending physician may have to refer the patient to another care provider.

Though the formerly described unsurpassable lack of trust poses a difficult problem if it arises in the process of determining competence, it is probably quite rare. Of greater magnitude are the difficulties that will necessarily arise in the operationalisation and measurement of "reasonability" once we grant the possibility of significantly different yet coexisting epistemological and moral frameworks. This fundamental problem is but one more representation of the paradox (described in section 4.5) that is inherent in the very concept of PDMC. Hence, we will not be able to "solve" it. Still, we have to guard cautiously against (unintentionally) imposing a particular such framework onto the patient lest we violate his or her autonomy.

(iii.) The third element, freedom of will, parallels the concept of responsibility in criminal law. In the context of PDMC, freedom of will pertains to the ability to choose any option available once elements (i) and (ii) have been fulfilled. If somebody knows his situation and the different courses of action open to him, evaluates decision $x$ negatively as compared to decision $y$, yet seems unable to chose $y$ over $x$, he has no or insufficient freedom of will.

A lack or insufficiency of freedom of will may be caused by "internal" disorders such as a depression, addiction or phobia. ${ }^{17}$ But "external" forces may also infringe on a patient's decision-making competence when such compulsion does, in effect, curtail the patient's internal decisionmaking abilities. A patient who accepts continued dialysis because his children are living off his pension may be unaware of that subtle compulsion and, hence, be incompetent to make autonomous, to-berespected and abided decisions. On the other hand, he may be well aware of his family's "parasitic" behaviour and able to explain to the care provider that he would have opted for another course of action if it were not for this "compelling factor." In the first instance, the patient's 
decision clearly is not a to-be-respected autonomous decision. His freedom of will is reduced by the family's subtle coercion. But if the patient appears to voluntarily accept his family's "parasitism," as in the second scenario, his decision may be autonomous even though it violates his own medical best interests. For the patient, other (i.e., family related) interests apparently outweigh his medical interests. Indeed, in that case one can no longer consider the family's behaviour "parasitic" in the original sense of that term and, hence, a form of external "force" that restricts the patient's freedom of will.

(iv.) The fourth element, means of expression, pertains to the ability to express a decision in a way comprehensible to one's caregivers. Not only should the patient be able to express his final decision, he should also be able to testify that his decision is based on sufficient and relevant knowledge of facts and values, the result of adequate manipulation of cognitive content, and voluntary. In other words, the fourth element contains the ability to account for one's decision in terms of the process which resulted in the decision. ${ }^{18}$

The degree to which a patient must be able to express himself is proportionate to the gravity and complexity of the decision at hand. While a simple nod of the head may suffice to consent to auscultation, generally it will not when the decision concerns a uterus extirpation. In situations where a patient is physically unable to speak or write, it may be necessary to reconstruct a debate and suggest to the patient possible lines of reasoning which the patient can confirm or deny by nodding or shaking his head. However, in case of unsurmountable doubt - a locked-in syndrome being the ultimate such instance - a patient may justifiably be considered incompetent. In such instances chances are greater that one will foster the patient's interest via substituted decision-making than by following the ambiguous expressions of the patient.

\subsection{CONCLUSIONS}

The history of medicine, health care and biomedical research is marked by silence, disregard of patients' wishes, and at times coercion. In order to protect patients against medical paternalism, patients have been granted the right to respect of their autonomy. First explored in the late 19 th and early 20 th century, by the end of the second millennium patient autonomy had become an undisputed staple of all codes of ethics in health care and a legally protected and enforceable right. This right is 
operationalised first and foremost through the phenomenon of informed consent. If the patient withholds consent, medical treatment, including life-saving treatment, may not be provided.

However, there is one proviso: The patient must be competent to realise his autonomy and reach a decision about his own care that reflects that autonomy. Since this most important of patient rights hinges on the patient's competence, it is crucially important that patient decisionmaking incompetence is clearly defined and can be diagnosed with the greatest possible degree of sensitivity and, even more important, specificity. Unfortunately, the reality is quite different. There is little consensus in the scientific literature and even less among clinicians and in the law as to what patient decision-making competence exactly means, let alone how it can be diagnosed reliably. And yet, patients are deemed incompetent on a daily basis, losing the right to respect of their autonomy.

In this chapter we have tried to analyse the concept of patient decisionmaking (in)competence. This analysis leads us to a fourfold conclusion:

a. Competence to make decisions about one's own health care (and to make such decisions better than one's health care providers) entails the capacity to gauge one's own health related interests and to make a decision in favour of interventions that are likely to foster those interests.

b. Whether the patient's decisions actually foster his/her health related interests is not decisive, because competence entails a capacity to decide rather than the act of deciding.

c. Competence to decide about one's own health care entails at least four more specific abilities: (i) The ability to acquire and retain cognitive content; (ii) the ability to manipulate cognitive content critically; (iii) freedom of will; and (iv) the ability to express oneself.

d. When assessing those four abilities with diagnostic tests, the largest possible degree of sensitivity and, even more important, specificity must be strived for to prevent competent patients from being treated as incompetent and losing the pivotal right to respect of their autonomy. ${ }^{19}$

How these abilities can be diagnosed clinically is a topic that exceeds the purposes of this chapter. The interested reader be referred to the next chapter in this volume, in which one of us takes the analysis further into the clinical domain by discussing empirical research into criteria and tests for assessing PDMC (Chapter 5 - first published as Welie SPK, 2001a). We close with an important reminder: The decision of a competent 
patient is not necessarily a good decision (and, hence, may have to be overridden after all); and the decision of an incompetent is not necessarily a bad decision (and, hence, may have to be realised after all).

\subsection{Notes}

1. Much of the Dutch literature only addresses the legal consequences of incompetence. The meaning of the concept is taken for granted. When definitions or criteria are given, they are adopted from legal abstract formulations or are alternative readings of those formulations. Only two articles explicitly have criteria for (in)competence as their primary subject. However one of these (Legemaate, 1992) only repeats the approaches mentioned in the other one (van de Klippe, 1990). The latter, moreover, appears to be based on American literature, part of which is being discussed in the next chapter in this volume (see, e.g., Appelbaum and Grisso, 1988; Appelbaum and Roth, 1981; Appelbaum and Roth, 1982; Roth et al., 1977).

2. See also Beauchamp, 1991, p. 50.

3. It may be objected that the expression "She's a competent surgeon" does not merely connote that she is able to "pass" the surgeon's board exam, but rather that she is quite good a surgeon. However, in this case "competent" is used as an evaluative attribute of the surgeon as surgeon. When saying that "He is competent to perform surgeries," the term does not evaluate the quality of this surgeon's surgeries, but the mere ability of that person to perform surgeries, that is, to pass the surgeon's board exam. In it in this latter sense that the term "patient decision-making competence" is used.

4. See also Checkland and Silberfeld, 1995.

5. The assumption that patients are the best judges of their own health care related interests and, hence, of the health care they ought to undergo, is very prevalent among patients, clinicians, bioethicists and certainly among health lawyers. Many statutes and court verdicts hence have been founded on this assumption, including bills and verdicts on PDMC. For the purposes of this chapter, we too accept this assumption, but only for the purposes of this article chapter. A critical analysis of this assumption can be found in Welie JVM (1998). 
6. We reserve the term Patient Decision-Making Incompetence for those instances in which a patient's liberty is curtailed because of a defective decision-making process by that person and in which this curtailment is justified by that person's own interests, and not (or not only) by the interests of specific third persons or of society in general. This does not mean that the term incompetence is only employed in the abovementioned sense. For example, the label incompetence may be used by authoritative institutions to deal with persons who show asocial or antisocial behaviour under a medical system when the criminal system does not offer any sanctions to this behaviour. Nor do we contend that no other instances exist in which somebody's liberty can justifiably be curtailed (e.g., to protect other people against physical aggression by that person). However, such phenomena surpass the scope of this chapter.

7. There may be some exceptional situations in which third persons or institutions do carry responsibility for the patient's decisions even if the patient is competent. This may be the case if the patient is also a parent of minor children and the refusal of life-sustaining medical treatment would result in harm to those children. In such instances, a refusal of treatment by a competent patient may demand respect from the perspective of patient autonomy, but be overruled nevertheless by the State because of the superseding interests of the minor children. The same is true for soldiers; at least under American military law, soldiers relinquish (some of) their patient rights when they enter the military and are required to accept treatment prescribed by the physician, even if the soldier is competent to reach autonomous decisions. These examples underscore Gert, Culver and Clouser's thesis that competency may not be a sufficient condition for granting a patient's refusal of treatment (1997, Chapter 10). Beneficent paternalism, overriding a competent patient's refusal of treatment, may be justified or even morally required in such instances.

In this chapter we do not address the issue of hard paternalism, i.e., overruling a competent patient's explicit decision. However, in view of medicine's paternalist history, we would urge great caution. As Marta reminds us: "Patients retain agency and authorship of their lives whether or not they are deemed competent to do so by others, and whether or not they are fully autonomous." This is because it is the patients themselves, "whether competent or incompetent, autonomous or nonautonomous, primarily rational or nonrational, ... [who] live with, bear the consequences of, whatever actions they take or are taken for them" (Marta, 1998, p. 365). There is, therefore, some wisdom in the Dutch distinction between forced care and forced medical treatment. A patient can be forcefully admitted (i.e., committed) to a health care 
institution; however, being committed does not necessarily mean being incompetent. Indeed, the committed patient retains his or her right to refuse medical treatment.

8. May (1998) does grant the possibility that there may be other reasons to override the refusal of the surgery that might not apply to financial investments. But such reasons should not be confounded with the assessment of the patient's competence to reach an autonomous decision. Note that the example of the investment is May's own, but he is not specific about the kind of medical intervention this would parallel. The analogous example of the abdominal surgery is ours.

9. It shall be clear that the distinction sketched is prescriptive, not necessarily descriptive. Many financial managers operate as though they were professionals (in the sense described), whereas many physicians do not fulfill their professional obligations. As one of us has argued, when medicine caters to the optional wishes of patients and becomes a provider of elective services, it no longer qualifies as a true profession (Welie JVM, 1999).

10. Such decisions should be respected, though not necessarily acted upon. Health care professionals may refuse to fulfill a competent patient's autonomous wishes if such wishes are clearly incompatible with the consensus-based standards of professional health care practice or if the practitioner has serious conscientious objections against fulfilling the patient's wishes.

11. Once again, we emphasise that patient's incompetence rather than patient competence should be tested. This implies that a positive outcome is an outcome of incompetence and a negative outcome an outcome of competence. Perfect specificity (no false positives) means that all patients deemed incompetent on the basis of a test-score (the positives), are indeed incompetent so that no competent person is unjustly deemed incompetent.

12. It should be pointed out that the attempt to design an incompetence test is itself a dubious endeavour. If, as we have argued, competence is task-specific, as well as specific to the individual patient in his/her situation, it becomes impossible to find a sample of like patients large enough to undertake such statistical research. How are we to find 200 "Dax Cowarts," i.e., males between 20 and 25 years of age who used to fly fighter jet pilots and compete in rodeos, but have suffered 3 rd degree burns over $60 \%$ of their body, have lost both eyes and virtually 
all of their fingers, have "lived" in an I.C.U. for the past six months and now need to decide about reconstructive hand surgery? The more prudent approach, therefore, would be to ideally determine the abilities required to make a competent decision, and only develop empirical tests for each of these specific abilities.

13. In other words, the care provider is morally required given his/her duty to beneficence - to foster conditions under which the patient is more likely to be competent to make decisions. Providing relevant information is a generally agreed-upon example, as is waiting until the patient has regained consciousness, is less depressed, or no longer in pain. Even patients with mild dementia have good and bad days and consent should be sought on their good days, since they are more likely to be competent at that time.

But these examples raise a new ethical question. There are many conditions that potentially hinder competent decision-making. For example, patient and doctor may speak different languages. While it is reasonable to expect a large hospital in the US to have Spanish speaking translators on staff, it would not be reasonable to expect a small Finnish hospital to have a Portugese translator on staff. Being provided with information, even in one's native tongue, does not mean understanding it. Some patients have had too little basic education to even comprehend information that is explained in laymen's terms. How much should the physician do to re-educate the patient so that conditions become optimal for a competent decision? To many patients, the mere fact of being in a hospital is a very disquieting condition. Out of awe for the expertise or fear of authority, many a patient turns into a non-assertive "child." Does the hospital have an obligation to create a home-like environment for patients? How far does the care provider's obligation go to create optimal conditions for competent decisionmaking?

14. At least from an ethical point of view. From a legal point of view, the patient may not be able to argue successfully that he was incompetent to provide consent. Similarly, one cannot successfully plead guilty to drinking while driving, and at the same time claim that the resulting pedestrian's death was nonvoluntary (being the result of the blood alcohol instead).

15. In both scenarios - the patient who refuses to absorb the information and the patient who is mentally incapable of absorbing the information - the patient is incompetent to make decisions about her own health care and any consent she may give to proposed interventions is invalid. Consequently, the proposed medical intervention may not be initiated. 
However, the two scenarios differ in what should happen next. Whereas the care provider is morally obligated (out of his or her duty to beneficence) to seek an alternative source of consent for the second patient, that obligation to beneficence ceases as a result of (or at least is significantly limited by) the first patient's voluntary opposition to the care process. The first scenario is analogous to that of a patient who cannot cut back on his alcohol consumption prior to a liver transplantation. Such a patient disqualifies himself for the transplantation because he is apparently unable to complete the necessary post-surgical treatment plan (which includes a particular diet). For all practical purposes, it is irrelevant whether a patient is unable to do so because he is addicted to alcohol, or simply unwilling to even try reduce his alcohol intake. Likewise the patient who refuses to read the consent form, disabling her ability to absorb and comprehend the necessary information, for all practical purposes is incompetent to consent to the proposed treatment. We thus digress from Faden and Beauchamp (Faden and Beauchamp, 1986, Chapter 8) who list comprehension and voluntariness as conditions of a valid consent separate from the condition of competence.

16. We opt for the term "reasonable" as opposed to "rational" (as preferred by Gert, Culver and Clouser, 1997). Although "reasonable" is etymologically rooted in the Latin term "rational," the latter term has more philosophical "baggage" than we wish to take along (such as the distinction between rationalism and empiricism, or between rationalism and intuitionism).

17. Culver and Gert (1990) seem to exclude such reductions in the patient's freedom of will from the determination of competence. Hence, the patient in their example (p. 627) who knows electroconvulsive therapy will be a truly beneficial treatment for him with very few side-effects but just cannot bring himself to consent out of an irrational fear for ECT, is competent according to Culver and Gert, whereas such a patient would be incompetent under our definition. In a later work, Gert, Culver and Clouser suggest a different definition of competence: the ability to make rational decisions (1997, p. 137). Since the phobic refusal of the ECT is irrational, the patient is incompetent after all.

18. Pomerantz and de Nesnera (1991), seconded by Marta (1998), suggest that a patient may be competent and her decision reasonable, even if it all makes sense to the patient only, but not to the care providers. We don't think this is a sensible expansion of the idea of PDMC. Not only is it epistemologically questionable whether the term "reasonable" or 
"rational" has any meaning outside of an intersubjective context; PDMC is itself anchored in the intersubjectiveness of the caregiverpatient relationship. It is towards the caregiver that the patient can claim a right to respect of her autonomy; it is for the sake of optimal patient care that the caregiver must assess the patient's competence.

19. This is not to say that sensitivity is unimportant. Although historically the risk of both weak and strong paternalism has proven to be real, and the need for specificity is therefore urgent, we may also end up harming patients if we find them competent when they are, in fact, incompetent. As the time available to physicians for in-depth conversations with their patients becomes ever shorter and the pressure to proceed expeditiously ever greater, there is the risk that we abandon patients to difficult decisions, decisions they are not competent to make. 


\title{
5. CRITERIA FOR PATIENT DECISION-MAKING (IN)COMPETENCE: A REVIEW OF AND \\ COMMENTARY ON SOME EMPIRICAL APPROACHES
}

\author{
S.P.K. Welie
}

\subsection{ABSTRACT}

The principle of autonomy presupposes Patient Decision-Making Competence (PDMC). For a few decades a considerable amount of empirical research has been done into PDMC. In this contribution that research is explored. After a short exposition on four qualities involved in PDMC, different approaches to assess PDMC are distinguished, namely a negative and a positive one. In the negative approach the focus is on identifying psychopathologic conditions that impair sound decisionmaking; the positive one attempts to assess whether a patient actually has the required abilities and qualities. Characteristic of the latter approach is the use of (or development of) test-like instruments for PDMC assessment. Some of these tests are discussed and commented on. Although they may be useful in investigating aspects of PDMC, none of the described approaches and tests offers a reliable and valid method for PDMC assessment. In response to a potential misuse of tests, the concept of a "supportive situation" is briefly introduced in order to draw attention to the risk of prematurely deeming patients incompetent on the basis of low test scores, whereas their insufficient performance may be (partly) attributable to a lack of situational support. Also, the need for and possibility of an emotionalist concept of PDMC are suggested, as an alternative to the more common rationalist one. In this regard, the legitimacy of competence being conceived as a presumption or fiction of law, deserves further investigation.

\subsection{INTRODUCTION}

Mr. X has been living for more than fifteen years in a psychiatric hospital. Mr. X suffers from a syndrome described as paranoid schizophrenia. He has hallucinations, confusion and impaired speech. During his stay at the hospital Mr. X turns out to have a swollen 
lymph gland in his neck. From a puncture it appears that the swelling can indicate a malignant form of cancer. The chances of malignity are about 50 percent. Mr. X refuses to consent to any form of investigation into the nature of the swelling in his neck. As reason for this, he states that the swelling is his "health-knobble" and that removal of this knobble would harm his physical condition. Mr. X says that he has his doubts about the benevolence of his health care professionals' intentions: they might want to render him infertile. He also contends that going through with the intended medical interventions against his will, would wreck all confidence that he still has in psychiatric treatment.

Then Mr. X gets a severe pneumonia. His physician urges him to take antibiotics. To the physician's surprise, Mr. X agrees to his advice and is prepared to follow the course of prescribed treatment. ${ }^{1}$

In the case described above, the physician might want to investigate Mr. $X$ 's Patient Decision-Making Competence (PDMC). PDMC is an important concept in that it aims at distributing decisional power in health care matters without referring to what substantially constitutes a good decision. A good deal of attention is paid to PDMC both in health care ethics and in health law. One can find expositions on the subject in handbooks on medical ethics (e.g. Beauchamp and Childress, 1994, p. 132; ten Have et al., 1998, p. 110). The pivotal role of PDMC is also recognised in international legal documents, like the Declaration on the Promotion of Patients' Rights in Europe (World Health Organisation, 1994, see e.g. 2.4, 3.3, 3.4, 3.5, 3.7, and 3.10) and the 1997 Convention on Human Rights and Biomedicine of the Council of Europe (articles 5, 6,17 , and 20).

During the past few decades, lots of empirical research has been done into PDMC (for a review, see Appelbaum and Grisso, 1995). Like the theoretical literature, this research is characterised by the varying research questions and designs that have been used. Some examples can give an impression of the big variety of research questions and designs.

In one type of research, the number of PDMC issues in psychiatric consultations is quantitatively and diagnostically explored (Ruskin, 1985; Golinger and Fedoroff, 1989; McKegney et al., 1992). According to the setting, the percentage ranges from 3 to $25 \%$.

A second way of research entails the description of specific populations in terms of PDMC. Examples of this kind are the research by Stanley B et al. into geriatric patients (1984), the research of Grisso and Appelbaum 
(1995b) and Melamed et al. (1999) into psychiatric patients, and that of Appelbaum and Grisso into medically ill patients (1997). Cournos, in her review (1993), compares psychiatric patients with medical patients on the topic of PDMC. A recurring result is that medically ill patients may have problems with patient decision-making too.

Thirdly, researchers attempt to construct empirical models of patient decision-making. These models have different conceptual foundations. Some use traditional variables like psychiatric condition, intelligence and medication compliance (Rosenfeld and Turkheimer, 1995). Others take their concepts and vocabulary from neurology, cognitive psychology and neuropsychology (Alexander, 1988; Marson et al., 1996; Marson et al., 1997b; Freedman M et al., 1991).

A type of research that has gained much following, consists in the development of measuring instruments for the assessment of PDMC (Grisso et al., 1995a; Grisso et al., 1997; Tomoda et al., 1997;

Gouwenberg et al., 1997; Biesaart et al., 2000). Reading of this literature reveals a myriad of testlike ${ }^{2}$ instruments, e.g. the UTD (Understanding Treatment Disclosures), the POD (Perceptions of Disorder), the TRAT (Thinking Rationally About Treatment), the MacCAT-T (MacArthur Competence Assessment Tool-Treatment), the SICIATRI (Structured Interview for Competency Incompetency Assessment Testing and Ranking Inventory), the CQ (Competency Questionnaire), the MOC (Measure of Competency to Render Informed Treatment Decision), MUD (Measuring Understanding of Disclosure), and the DCCL (Disclosure Consent Check List), to name but a few.

In the fifth place, one can find comparison of different methods to assess PDMC (Rutman and Silberfeld, 1992; Cohen MJ et al., 1993; Bean et al., 1996; Marson et al., 1997a). The methods compared include clinical versus test evaluations, and routine physician judgments versus structured clinical interviews.

There is also empirical research into "external" influences on patients' performance in PDMC investigations. Fitten and Waite examined the influence of medical illness and hospitalisation (1990a). Wenger and colleagues have studied the impact of the moment on which PDMC investigation takes place in relation to the moment of hospitalisation (1994a). Tymchuk and others found influences of the format of the informed consent information (1988).

Yet another kind of research is directed at factors influencing health care professionals' estimation of patient competence; Mangone et al. (1993) 
found a possible source of contamination in that feelings of burden among health care professionals may lead to an underestimation of patients' functional competence.

Lastly, the consequences of PDMC on the further course of treatment form the subject of empirical research. For example, Hanson et al. (1994) showed that for incompetent patients decisions to withhold life-sustaining treatment are made more often than for competent patients; this relationship even held when the data were controlled for differences in severity of illness, diagnosis and other relevant variables.

In the former chapter in this volume (Chapter 4 - first published as Welie JVM \& Welie SPK, 2001b) we have tried to give a systematic exposition on the concept of competence. According to our outline given there, competence is a task-specific concept, ${ }^{3}$ and four elements of competence should be distinguished. ${ }^{4}$ We have seen (at the end of section 4.6 on Paternalism in competency determinations) that it is important that the qualities and abilities defining PDMC have sufficient empirical content, i.e. that they can be operationalised and tested reliably. Otherwise, those in charge of judging PDMC do not have a solid basis for deviating from the assumption of competence. Therefore in this chapter we will subject some empirical research on PDMC to closer consideration.

First our outline about elements of competence will be summarised. Then we will discuss some empirical research into the subject on the basis of published research literature. The discussion will be limited to that research literature that addresses the question how PDMC should be assessed, particularly that literature that provides test-like approaches to the assessment of PDMC. In our discussion we will attempt to classify the different approaches in an orderly way, to illustrate them with examples and to supply them with some critical comments. It is expressly not our intention to give a full overview of all the literature and all the tests available. ${ }^{5}$ Two approaches to the assessment of PDMC will be distinguished, a negative and a positive approach. The first consists of checking whether the patient shows any psychopathologic conditions that preclude competent decision-making. This approach is "negative" in that it checks for conditions which indicate the absence of PDMC. Any person who does not suffer from any such psychopathologic conditions will be assumed to be competent. The second, positive approach, purports to measure directly whether a patient possesses the abilities and qualities implied in patient decision-making. Both approaches shall be discussed in more detail. Lastly some suggestions are made on how to handle problems with PDMC assessment. 


\subsection{Four ELEMENTS OF COMPETENCE}

In the former chapter in this volume, it was proposed that four qualities are involved in PDMC, namely cognitive content, manipulation of cognitive content, freedom of will, and the ability to express oneself.

Cognitive content owes its relevance to the fact that it forms the base of the patient's decisional process. It refers to the state of being informed about the facts according to the informed consent doctrine; besides - as cognitive content does not only relate to knowledge of facts, but also to (knowledge of) beliefs and values -, this quality provides the subjective normative dimension on the basis of which an individual patient can evaluate the different options. In other words, cognitive content enables the patient to form an image of the available courses of action and their consequences as well as to appreciate these. This knowledge base may be impaired because of both "internal" and "external" factors. In this chapter, we are only concerned with the first, since the second - caused, for example, by a physician's failure to inform the patient - does not render the patient incompetent, but the assessment of the patient's (in)competence invalid.

Manipulation of cognitive content, the second quality determining patients' decision-making, involves the ability of the patient to use the available information in such a way as to reach a conclusion in a specific health care related situation that calls for a decision, a conclusion that is consistent with the patient's cognitive content and that implies the patient's preference about what ought to be done. Manipulation of cognitive content includes all kinds of cognitive activities, such as analysing information, integrating different pieces of information, reasoning, planning, weighing different options and prioritising. Also, the ability to correct mistakes can be mentioned as relevant in this regard. A patient's starting from incorrect facts and hence reaching conclusions that are not in line with the facts of the situation, does not imply incompetence. To settle that matter, one ought to check whether the patient is able to adjust the starting assumptions if provided the correct information. Also, making a mistake in reasoning does not justify a verdict of incompetence; after all, to err is human. More important is whether the patient can critically reconsider his reasoning with the help of others.

Freedom of will is the third element constituting PDMC. It is the ability to select whatever option the patient wants most, i.e. that option of the ones available that matches most closely the patient's values. If there's 
only one option on hand, it relates to the choice to undergo or not to undergo that option. Freedom of will is not a freedom to present arbitrary behaviour. If the elements (i) and (ii) have not been met, there seems to be no sensible role for freedom of will. Once somebody understands his health care related situation and has reasoned about and evaluated the different courses of action, freedom of will means that he or she is indeed able to make that decision that came out as the best one in the preceding decisional process. White refers to this element as what she calls the capacity to resolve situations (1994, p. 53). A lack or insufficiency of freedom of will may be caused by "external" forces (such as children putting pressure on their parents) or "internal" disorders (such as a depression or addiction). In this chapter, we are once again concerned with the latter only. ${ }^{6}$

The fourth quality involved in patient decision-making is means of expression. This element relates to the ability to clarify to somebody else, mostly the patient's health care professional, what the patient's choice amounts to. This clarification includes both the concrete choice that the patient made, and the reasons motivating that choice. Ideally, to meet this fourth quality the patient ought to be able to show that he fulfills the first three qualities. This quality is called the capacity to recount one's decision-making process to others by White (p. 53). In the aforementioned article, we have pointed out that there may be a tension between the principle of autonomy and that of privacy in regard to manipulation of cognitive content. This applies to means of expression too. Also, it is clear that some "didactic" abilities may be needed here, that are not necessary for the decision-making per se.

\subsection{Psychological (in)Capacities underlying Patient Decision-Making (In)COMPETEnCE: The negative}

\section{APPROACH}

We have seen that - with a view to the actual assessment of competence a negative and a positive approach can be distinguished. ${ }^{7}$ In the negative approach it is investigated whether the patient has any condition that impairs decision-making. Illustrative for the negative approach is the exposition by Appelbaum and Roth. In their 1982 publication, these authors outline psychiatric aspects relevant to PDMC. ${ }^{8,9}$ They distinguish several standards of competence, each of which can be related to the qualities involved in PDMC mentioned above. ${ }^{10}$ 
The first quality, cognitive content, is approximately parallelled by the standards "factual understanding of the issues" and "appreciation of the nature of the situation". A large number of conditions, e.g. mental retardation, brain damage and denial, may obstruct compliance with these standards. Some of these conditions are listed in Figure G.

The second quality, manipulation of cognitive content, resembles Appel-

- Lack of intelligence

- Mental retardation

- Dementia

- Defective language skills

- Impaired recall and memory

- Brain damage

- Acute toxic states

- Denial

- Psychotic distortion, projection or nihilism

Figure G. Psychiatric conditions obstructing cognitive content baum and Roth's standard of "rational manipulation of information". In their article, they describe various relevant psychiatric aspects (listed in Fig. H) threatening compliance with this standard, like delusions, anxiety and depression.

Appelbaum and Roth do not provide a standard that matches our third quality, freedom of will. However, in their discussion of the standard "rational manipulation of information", they mention some aspects that interfere with - what they call - the voluntariness of the decision ( $\mathrm{p}$. 954). They list the three conditions listed in Figure I. While Appelbaum and Roth do not further specify the first of these three conditions, dependency may take many forms and concern both people and products, notably alcohol and other drugs.

The ability to express oneself, the fourth quality in our model, corresponds closely with Appelbaum and Roth's standard of "evidencing a choice". They consider the following conditions to undermine this standard (Fig. J).

- Delusions

- Hallucinations

- Loosening of associations or other severe thought disorder

- Extreme phobia or panic

- Anxiety

- Euphoria

- Depression

- Anger

- Agitation

- Obsessive preoccupation

Figure H. Psychiatric conditions obstructing manipulation of cognitive content

In the above mentioned enumerations of relevant psychiatric aspects, almost the whole range of possible psychopathologic conditions passes in review. Furthermore, not listed are certain conditions that affect all four 
qualities, notably decreased awareness, somnolence, and unconsciousness. This approach would turn any psychiatric patient into an incompetent patient. But this is clearly incorrect. Whereas all of these conditions might be associated with impaired PDMC, they are not necessarily so. The negative approach suffers from a serious lack of specificity because it does not specify the exact relationship between these conditions on the one hand and PDMC on the other. ${ }^{11}$

This shortcoming appears clearly if we try to apply this approach to the case of Mr. X, described above. ${ }^{12}$ As Mr. X suffers from confusion and hallucinations, his cognitive content and his manipulation of it might be impaired. However, we do not know whether this is indeed the case. Why does Mr. X accept the proposed antibiotics treatment? Does he perhaps think that his physician is trying to heal their relationship by offering him fertility enhancing medication? Or do his delusions not pertain to this matter? In order to judge PDMC we ought to know whether these conditions interfere with the decisional process regarding the antibiotics course, and - if they do - how they do so. Of course we may have some common sense ideas about how these questions should be answered and what more information should be gathered from Mr. X. But the point is that these problem solving strategies are not included in the negative approach itself. Hence, whether one judges this approach to be satisfactory or not, depends upon how much confidence one has that the assessor will fairly supplement this approach with his own views, experience and empathy towards the patient.

- Excessive dependency

- Passivity

- Unwarranted trust of the patient towards the caregiver seeking consent or towards other parties that may be affected by the eventual decision

Figure I. Psychiatric conditions obstructing freedom of will
- Mutism

- Catatonia

- Mania

- Word salad

- Marked ambivalence like in schizophrenia

Figure J. Psychiatric conditions obstructing ability to express oneself 


\subsection{Psychological (in)Capacities underlying Patient DECISION-MAKING (IN)COMPETENCE: THE POSITIVE AP- PROACH}

Rather than determining who is not competent, one may try to test whether a patient functions sufficiently well to make his own health care related decisions. We call this the positive approach. As mentioned earlier ${ }^{13}$, our discussion of such tests is not intended to be exhaustive. In connection with empirical research, more tests have been developed. Overviews thereof are given by Murphy and Clare (1995), by Kapp and Mossman (1996), by Glass (1997) and by Kitamura et al. (1998).

If one were to follow the positive approach in the case of Mr. X, he would have to undergo another procedure to resolve the matter, i.e. he would have to cooperate with the administration of the test. It is not inconceivable that the problem that originally gives rise to the desire to assess PDMC (e.g. refusal of care that the physician considers to be necessary), repeats itself in the attempt to solve it, in that the patient refuses to undergo the test procedure. In that case the problem is only moved, not solved. ${ }^{14}$ In the case of Mr. X however, the physician will probably not raise questions about his patient's competence, because $\mathrm{Mr}$. $\mathrm{X}$ assents to a treatment that his physician deems advisable. ${ }^{15}$ This indicates that it is not only important which criteria one applies when judging PDMC, but also at what occasions one wants to (or should) judge PDMC at all.

In the empirical literature about patient competence one can find tests belonging to one of three groups. These groups relate to (1) "functional" capacities, (2) "cognitive" functioning and (3) specific PDMC issues, and will now be treated successively.

\subsubsection{Tests of functional capacities}

The first group consists of tests that estimate a patient's level of functional independence. Examples of tests from this group are Katz's Activities of Daily Living (1963), Lawton and Brody's Instrumental Activities of Daily Living (1969), and Winograd's Self-Care Scale (1984). These tests focus on behaviours like going to toilet, bathing, dressing, feeding, and ambulation. In other words, they concern physical activities, rather than mental decision-making processes. ${ }^{16}$ This focus makes these scales unfit as tests of PDMC. ${ }^{17}$ The unsuitability of these 
tests of functional independence as screening instruments for PDMC also appears from the low correlation coefficients between these tests and other more PDMC-specific empirical measures of competence (see Winograd, 1984; Fitten et al., 1990b).

\subsubsection{Tests of cognitive functioning}

The second group contains tests that measure aspects of cognitive functioning. Folstein et al.'s Mini-Mental State (1975) and Pfeiffer's Short Portable Mental Status Questionnaire (1975) are examples of such tests. Among the abilities covered by these instruments are orientation, recent memory, long-term memory, attention, ability to name and capacity for serial calculation. The relation between these cognitive functions on the one hand and the qualities involved in PDMC (notably cognitive content and manipulation of cognitive content) on the other hand seems evident. But again, the correlations between these tests and tests that more directly measure PDMC, and hence the relationship between cognitive abilities and PDMC, are not clear. This is evidenced by the diversity of relationships suggested by results of empirical research.

Thus, Winograd (1984) suggests that possession of the cognitive abilities constitutes a sufficient, but not a necessary condition of PDMC. In other words, the presence of these cognitive abilities would guarantee PDMC; absence of these abilities would not imply incompetence: there are other ways to be competent in patient decision-making. However, research by Fitten and colleagues yields opposite results (1990b). Their data suggest that cognitive abilities form a necessary, but not a sufficient condition of PDMC. In other words, being competent in patient decision-making would require at least - but not only - having cognitive abilities. Still another relationship follows from data found by Janofsky's research team (1992). In their study a high score on a measure of cognitive abilities predicts competence in patient decision-making. A low score on this measure predicts incompetence. An intermediate score is associated both with competence in some persons and with incompetence in others.

The unclarity is evidenced as well by the diverging correlation coefficients researchers have found between cognitive tests and measures of PDMC. Winograd (1984) finds a low correlation, whereas Diamond and colleagues (1989) find a high correlation and Fitten's team (1990b) a moderate correlation. At best, these tests of cognitive functioning pertain to component capacities involved in the four qualities of PDMC, but they cannot simply be looked upon as tests of PDMC. 


\subsubsection{Tests of specific PDMC issues}

Tests of the third group specifically address the issue of PDMC. One of these tests is the Mental Competence Scale (MCS), developed by Winograd (1984). The MCS intends to measure the ability to respond sensibly to interview questions and the ability to judge the environment. It consists of a clinical evaluation of a semi-structured interview. Administration of the interview ranges from half an hour to two hours. The interview's questions relate to seven areas, namely demography, health status, activities, community life, staff relationship, institutional living, and life perspectives. Based on the patient's responses to the interview-questions, the interviewer evaluates the patient clinically by rating him on a four point scale in six categories. These categories are (1) consciousness, (2) orientation, (3) attention, (4) idea association, (5) thought quality and (6) affect. For each patient the scores on the different categories can be averaged, resulting in one composite mental competence score, ranging from 1.0 (excellent) to 4.0 (severely impaired).

Use of the MCS can increase insight into the patient's mental functioning and may thus contribute positively to PDMC assessment, not in the last place because administration of the scale obliges the user to a more or less intensive conversation with the patient. At the same time, we should observe that the final composite score in itself provides little - if any hold, since it can represent totally different distributions of scores on the aforesaid categories; e.g., a particular low composite score may be the consequence of inadequate attention, but the exact same score can signify poor thought quality just as well. The implications of differential performance on these categories for PDMC might be quite diverse. Besides, the MCS seems to pass over the task-specific character of PDMC, as the actual decision at hand is not mentioned among the areas to which the interview questions relate.

Another test belonging to the third group is the Decision-Making Capacity Assessment (DMCA) by Fitten and colleagues (1990b). The DMCA uses three vignettes. Each succeeding vignette describes a more complex hypothetical treatment situation. The first one concerns prescription of a hypnotic; the second one involves a diagnostic procedure called thoracocentesis; and the third one deals with the choice of cardiopulmonary resuscitation. These vignettes must be read to the patient twice. Thereupon a series of questions is to be asked in order to test the level of recall and understanding of the facts and issues involved in the vignettes. Also, the patient's ability to come to a decision and the 
ability to give reasons for the decision are tested with the questions "As the patient, would you take this medicine or not?" and "Can you tell me why?" respectively. Regarding this last question, it is only checked whether the patient's decision is derived from the facts as he or she understands them; the quality of the argumentation and the rationality per $s e$ of the response are not considered in the rating. The patient's answers to these questions yield a score ranging from 0 (no vignette passed) to 3 (all vignettes passed). Because of the hierarchical nature of the vignettes, it is hypothesised that a patient who passes a certain vignette, will also pass the easier vignettes.

One strong side of the DMCA is its attempt to take the patient's frame of reference as starting-point for evaluating PDMC: the reasonableness of the patient's decisions is viewed as a function of their deducibility from the facts as understood by the patient. ${ }^{18}$ Another advantage of the DMCA is that the one assessing PDMC by means of the DMCA does not have to judge the substantial merits of the actual decision at hand: the only thing that matters is the patient's performance on the three hypothetical vignettes. Thus the risk of paternalistic interpretation of the patient's interests in the decision at hand is diminished. ${ }^{19}$ However, this advantage can also be looked upon as a disadvantage: the organisation of the DMCA with the help of hypothetical vignettes makes it potentially irrelevant for the specific decision at hand. The specific condition of the patient may very well affect his performance on the vignettes, but leave intact his competence to decide the issue he finds himself faced with in reality (or vice versa). In principle, this criticism applies not only to the DMCA, but to all tests that use vignettes. The importance of this criticism depends upon the possibility to arrange all possible decisions upon one single dimension of gravity and complexity. If that were indeed possible, a positive score on hypothetical decision $p$ would justify a conclusion of competence in relation to all decisions "easier" than decision $p$ and a negative score on decision $q$ would justify a conclusion of incompetence in relation to all decisions "harder" than decision $q$. In view of the qualitatively different interests and values that patients pursue and moreover - given the fact that the gravity of a decision and its complexity are wholly different concepts (or at least not identical concepts), ${ }^{20}$ the existence of such a dimension is highly doubtful.

The Hopkins Competence Assessment Test (HCAT) of Janofsky and colleagues (1992) also intends to measure more directly PDMC. As distinct from the DMCA, which concentrates on medical issues of different complexity, the HCAT focuses on the legal aspects of the relationship between patient and caregiver. It consists of a to-be-read 
essay and a questionnaire for determining to what degree a patient understands this short essay. Administration of the HCAT takes ten minutes on the average. The essay describes the informed consent doctrine and the concept of durable power of attorney. Three versions of the essay are available. Each version has a different level of readability. First the relatively most difficult version of the essay (thirteenth grade reading level) is read to the patient. If the patient does not score sufficiently, the person administrating the HCAT should proceed with an easier version, and so on, until a maximal score is obtained. Possible scores on the HCAT range from 0 to 10 .

An advantage of the HCAT is that it accommodates the patient (and his "partial autonomy") by prescribing to proceed to an easier reading level version if the patient does not make the harder version, thus maximising the degree of involvement of marginally competent persons. A disadvantage of the HCAT is its orientation to legal matters. Competence according to the HCAT is competence in understanding the juridical conception of the care relationship, whereas competence according to our analysis of PDMC is competence to gauge personal health related interests and to decide accordingly. In other words, in the HCAT a fundamentally different task is assumed as the central starting-point.

An advantage of the MCS, the DMCA and the HCAT is that they result in a gradual score. This enables the person judging PDMC to adjust the threshold of competence according to the gravity of the decision at hand. An ambivalent feature of these tests, in particular of the DMCA and the HCAT, is their standardisation. From a psychometric viewpoint, standardisation obviously is an advantage. It enhances the reliability of the instruments. From the perspective of the principle of respect for autonomy, however, standardisation is a disadvantage. It may lead to neglect on behalf of the caregiver of the individual needs of a specific patient. There is the real danger that the power to decide is granted to a representative, once the patient does not obtain a sufficient score on one of these instruments, whereas such a patient might have been perfectly able to decide himself, had the caregiver made some extra effort by taking into account the specific circumstances of this patient (and, for example, adjusted his explanation of the relevant information to the experience of the patient). 


\subsection{Problems With PDMC ASSESSMENT AND INITIAL SKETCH OF POSSIBLE SOLUTIONS}

We have explored several approaches and tests proposed in empirical literature on competence and we have seen that they are very different in nature. The discussed methods have in common that the assessor should "know what she or he's doing". As for the negative approach, insight is required into the relationship between psychopathology on the one hand and PDMC on the other. Professional use of the tests (making up the positive approach) demands an evaluation of the measured constructs' relevance for the actual decision at hand. For all approaches goes that it ought to be known whether a judgment of PDMC is indicated at all (and if indeed, when).

If one is to avoid that these tests are going to lead their own lives in practice apart from the goal for which they have been constructed, it is essential that the person in charge of PDMC assessment have a clear understanding of the rationale of the concept of PDMC, and that this person understand what the contribution of each specific test could be in assessing PDMC. This admonition is not superfluous, as the background of the concept is mainly ethical and legal in nature, whereas the assessment will often be carried out by health care professionals, who have a limited education in these disciplines. The danger is not imaginary that health care professionals conceive the concept of PDMC as a "Fremdkörper" 21 in their business. That being true, uncertainty about the nature of the concept might evoke defensive use of tests, in which the mere application of the test and the resulting score are supposed to settle the question of whether or not a patient is competent. Another factor contributing to the risk that tests may be (unconsciously or consciously) misused, is the seemingly objective nature of test scores. This pseudoobjectivity may conceal from those not familiar with the construction of tests, the substantial assumptions and evaluations that preceded the quantification.

Two issues related to the use of tests in the assessment of PDMC deserve further attention. One has to do with - what I will call - the requirement of a "supportive situation". The other issue concerns the role of emotions in PDMC. Before concluding, both issues will be briefly explained. 


\subsubsection{The concept of a supportive situation}

The first issue, also touched upon in the last section of the previous paragraph ${ }^{22}$ is the temptation ${ }^{23}$ to consider a patient incompetent once he scores insufficiently on a test. To do that would be ignoring the fact that test behaviour - like any behaviour - is the resultant of interaction between personal and situational ${ }^{24}$ variables. If one yields to this temptation, one fails to do what should be done, i.e. investigating whether the poor performance can be attributed to situational circumstances (e.g. poor explanation of the relevant information by the health care professional) and investigating whether something can be done to make involvement of the patient in the decision-making meaningful again (e.g. giving a clearer explanation of this information in a way that is adjusted to the specific strengths and weaknesses of the individual patient). ${ }^{25}$

Ideally, a negative test score should not be used to sidetrack the patient, but to obtain clues how to help the patient make the decision himself. In this view, decisional power may be transferred from the patient to his representative on the basis of an insufficient test score only then, if it has been assured that optimal help has been given to the patient in the decision-making process, or - to use a different formulation to express the same idea - if the presence of a supportive situation has been guaranteed. In other words, the presence of a supportive situation is a necessary condition for using negative scores to pass decisional power from patients to representatives.

The help implied in a supportive situation may concern any of the four qualities that are involved in PDMC according to our previous analysis. For example, the health care professional could support the patient with respect to manipulation of cognitive content by explaining the significance of the probabilities associated with side-effects or by correcting logical reasoning errors; he could also help a suggestible patient with respect to freedom of will by presenting the alternative options in such a way that this patient is not unduly influenced by his suggestions.

Of course, it remains to be examined what counts as a supportive situation for a specific patient, and also how much may be asked from a health care professional in this regard. Here, there are at least three problems - not unrelated to each other.

Firstly, there is the practical economic limitation that health care professionals do not have disposal of the resources to engage themselves 
endlessly with one patient. Secondly, there is the psychological proviso that not every health care professional is capable of getting to know just any patient well. The psychological relation between them determines how much information a particular health care professional can gather about the characteristics of a certain individual patient. Lack of empathic or communicative skills, or a misfit between the personalities of professional and patient could be psychological barriers to sufficient personal understanding. ${ }^{26}$ Thirdly, there is the ethical objection that at a certain point "helping" the patient to make his own decision may turn into substitute decision-making by the health care professional for the patient. ${ }^{27}$ For example, the attempt to simplify the information to a patient that has difficulty in understanding it, may well amount to deciding that certain complicated aspects of the treatment are not important for this patient. According to the informed consent model, such a decision ought to be taken by the patient or by a proxy of the patient, but not by the health care professional.

All of these problems may be dealt with by involving a family member casu quo representative in the attempts to "help" the patient.

\subsubsection{Emotions, and competence as a presumption or fiction of law}

The second issue concerns the fact that PDMC assessment that focuses specifically on the actual task, i.e. the concrete decision at hand, tends to imply high, rationalist requirements for patients: the patient has to - as it were - demonstrate that his decision has come about in a careful way and that it fits into his preferences and values. This problem is inherent in the situation where somebody else than the patient tests through a conversation with the patient whether the latter has completed certain "steps" (or carried out certain cognitive operations) in taking the decision. Such a situation presupposes that the patient can clarify these steps/operations to the other person and hence that the patient is consciously aware of all these facets of his decisional process. The ensuing model of rational, conscious decision-making is not representative for the way people generally reach decisions. In general, decisions are to a large degree motivated by emotional or intuitive factors, that are not - or at least not totally - conscious to the one taking the decision.

If we want to do justice to the everyday reality of decision-making, there should be room for an "emotionalist" concept of PDMC. ${ }^{28}$ From a theoretical perspective, it is not strange to relate emotions to PDMC; 
since the eighties of the last century psychologists have argued that emotions are "rational", functional facilities, in that they are specific cognitive processes that inform us about the meaning of an event in light of the wants and aims of the one experiencing them. ${ }^{29}$ Such an emotionalist concept of PDMC is meant as an alternative to the aforementioned rationalist concept; it does not intend to add extra, affective requirements to PDMC.

An objection to an emotionalist concept of PDMC is that it makes PDMC by definition hard to investigate, if not unassessable. Of course, one could try to weigh the "integrity", "soundness" or "validity" of the emotions motivating a choice by analysing them with the patient. But this kind of scrutiny would take us back to the rational domain and thus to the rationalist concept of PDMC. The question whether an emotionalist concept of PDMC can be acceptable and - if so - in which cases, needs further research. ${ }^{30}$

In any event, it should be noted that from a legal point of view we can defend that PDMC need not always be assessed, and hence need not always be assessable. For that purpose, we have to interpret the assumption of competence as a presumption or fiction of law. ${ }^{31}$ This means that in certain cases or classes of cases it is assumed to be irrefutably true that a patient is competent, although there are no actual data available about the patient's competence, or even that it is assumed to be irrefutably true that a patient is competent, when the patient is actually known to be incompetent according to some accepted definition. In other words, in those cases, the patient's actual competence or incompetence is irrelevant. Acceptance of this interpretation of the assumption of competence implies admitting that incompetence cannot bear the weight that is put upon it: ${ }^{32}$ not all decisional dilemmas in health care for individual patients can be solved through this concept.

Usually, the objective of a presumption or fiction of law is to extend the scope of a protective procedure. In my proposal, however, it amounts to reducing the scope of procedures aiming at the protection of incompetent patients: in cases where the presumption or fiction of law would apply, its legal consequences are firstly that there is no duty for the professional to consult to a representative nor to solicit a proxy decision, and secondly that the patient's wishes decide in a legally valid way whether or not a proposed health care intervention shall take place.

Obviously, there needs to be a justification for the use of the assumption of competence as a presumption or fiction of law. This justification could 
consist in other interests' or principles' prevailing above the interests and principles associated with PDMC assessment. Further elaboration of possibilities for such a justification is beyond the scope of this chapter. In any case, the suggested presumption or fiction of law has the advantage of allowing the normative considerations that now implicitly influence PDMC assessments, ${ }^{33}$ to be brought up for explicit discussion (and for criticism with that). After all, the legitimacy of a fiction is reasoned out on material grounds ("is it acceptable/desirable that the patient's wishes are acted upon?") and not on procedural grounds ("has the patient enough decision-making capacity to grant him decisional power?"). If this line of argumentation is carried on, I expect patient autonomy to get stronger in the end.

\subsection{CONCLUDING REMARK}

To conclude, it is welcome that the empirical basis for PDMC judgments is being strengthened. With an eye to the principle of autonomy, such a basis is helpful in preventing arbitrary judgments. However, the empirical orientation should not degenerate into the illusory pursuit of developing instruments that would enable "algorithmic" measurement of competence. This endeavour would misunderstand the normative nature of the concept of PDMC. Moreover, it would endanger an important goal of the informed consent doctrine: the notion of such an instrument would take away the need for a conversation with the patient in order to discover which course of action suits most to the personal preferences and values of each individual patient. Thus, the responsibility of the health care professional would be eroded in an essential regard.

\subsection{Notes}

1. This case is an adapted version of a lawsuit that was actually settled by a court in the Netherlands (President Arr.-Rechtbank Assen, 7 oktober 1992).

2. The term "test-like instrument" is preferable to the term "test", because it is not always clear to what extent these instruments meet the psychometric criteria applicable for tests (standardisation, instructions for administration, guarantee of user's competence to use test, reliability and validation, interpretation against explicit norms; cf. Groth-Marnat, 1990, p. 8). For convenience's sake, the terms will be used interchangeably in the rest of this chapter. 
3. See section 4.3 of this volume.

4. See section 4.7 of this volume.

5. References to articles in which the literature is reviewed in a more exhaustive way, are included in section 5.5.

6. One could ask oneself what is the case if somebody with a high suggestibility "succumbs" to an advice given by somebody else, an advice which is - in itself - not intrusive or pushy: the person follows the advice, not because he agrees to it substantially, but because he cannot run counter to it. Supposing that the element freedom of will is not met, is this due to external or internal circumstances then? Actually, an external factor, i.e. the advice by somebody else, initiates the process that leads to the automatic choice. The patient might have come up with his own decision, had the other person refrained from his advice. But the fact that the patient reacts to the advice in the way he does, is connected to an internal factor, i.e. his high suggestibility. We probably tend to ascribe the lack of freedom of will in this case to internal factors, if "a normal person" would not have reacted to the advice by succumbing to it. Although this is not the place to treat the philosophical question of what is internal versus external to a person in his interactions with other persons, we like to point out that this distinction apparently depends upon what we consider a normal thing to do in given circumstances. In other words, the distinction between internal and external connects to the definitions of normalcy and abnormalcy. Analogous questions can be asked in relation to the other elements.

7. See the Introduction of this chapter (section 5.2).

8. Although this chapter is a literature review and hence does not directly report empirical research, it contains an outline of psychopathologic phenomena that impair subjects' performance and therefore has enough empirical substance to be included in this discussion.

9. In their article, the subject is competence to make decision to participate in research, whereas in our analysis patient care decisions form the context. However, both concepts of competence are similar in nature. One could contend that in relation to research decisions the threshold of PDMC should be set higher than in relation to care decisions (because in the first category of decisions other interests than the patient's own are directly involved) (cf. Drane, 1984, 1985). Others may argue that even concerning research decisions the threshold might 
be low, if there is a ponderous policy interest in promoting the kind of research in question (cf. Appelbaum and Roth, 1982, p. 956). Whatever position one takes with respect to the threshold, it doesn't alter the fact that the psychological capacities underlying PDMC are identical in both contexts.

10. The four "commonly used" standards discussed by Appelbaum and Roth (1982, p. 951) are "evidencing choice", "factual understanding of the issues", "rational manipulation of information" and "appreciation of the nature of the situation" successively. It should be noted that in their overview these standards are meant as alternative ways to determine competence. In other words, a patient is competent if she meets standard one; or, a patient is competent if she meets standard two, et cetera. The question is then which standard ought to be used under what circumstances. The authors devote the latter part of their article to this question (see p. 956 "Choosing the Standard"). In our outline, however, the four qualities involved in PDMC function as cumulative conditions of competence: each quality is necessary (and together they are sufficient); hence, as soon as a patient does not satisfy one of the required qualities, she is incompetent (even if she does meet all other ones).

11. Another criticism of this approach is that all the disputes and uncertainties that are inherent to psychopathologic diagnosis because of the different schools and orientations in this discipline (cf. American Psychiatric Association, 1994, p. xv), make themselves felt in the assessment of PDMC.

12. See the Introduction of this chapter (section 5.2).

13. See at the end of the Introduction of this chapter (section 5.2).

14. This dilemma is discussed by Wenger and Halpern (1994b).

15. This circumstance (patient assent to treatment proposed by health care professional) does not always justify passing over the issue of PDMC. Not only can incompetence be a ground for overruling refusal by a patient, it can also lead to the annulment of a patient's assent (e.g. by a proxy). In the latter case, the professional that has acted on the basis of the patient's assent, would turn out to have acted without valid consent. Accepting any assent merely because it is in line with the professional's proposal, is contrary to the rationale of granting decisional power to the patient. That rationale amounts to securing that the professional's proposal is checked from the perspective of the patient's personal 
preferences and values. Observation of agreement between the professional's proposal and the patient's reaction to it does not guarantee that this check has taken place.

16. One could object that the distinction between physical activities and mental decision-making processes is not plausible, as the latter allegedly underlie the former. E.g., deficits in frontal lobe information processing function associated with planning might lead to impaired functional independence (Lezak, 1995, pp. 650, 653-654). However, that's not what we mean with decision-making here. If we use that term in the context of PDMC, we refer to conscious efforts at resolving the mental task of determining what course of action should be taken, irrespective of the actual implementation thereof.

17. This is not to say that functional incompetence is wholly irrelevant to PDMC. E.g., if a functionally incompetent person has to make a decision in which functional competence is a relevant consideration (for example about living on his own), this person's unawareness of his functional incompetence might lead to his being considered incompetent to decide the matter. However, decisive for a judgment of PDMC then is not his functional incompetence per se, but his (lack of) insight into his functional incompetence.

18. It is the question whether taking the patient's frame of reference just like that as starting-point is really possible (from an epistemological point of view) and desirable (from an ethical point of view). With regard to the first question, interpretation of the patient's utterances by the assessor unavoidably plays a part; further treatment of this question would be getting too far off the subject. Furthermore - concerning the second question -, logical deductibility of conclusions proves nothing about the plausibility of the premises (cf. Freedman on two ways of failing to produce recognisable reasons - Freedman B, 1981, p. 64). Imagine a psychotic patient: his decision can follow from his ideas in a perfectly logical way, whereas these ideas are still apertly incorrect according to common sense. It is therefore unlikely that any representation of affairs ought to be accepted. This implies that some judgment of the patient's frame of reference is necessary.

19. We should note that, in order to evaluate the performance of the patient on the vignettes, the patient's interests in the corresponding hypothetical situations still need to be assumed to a certain extent: as explained in the previous note, some judgment on the patient's frame of reference by the assessor is necessary; hence, the risk of paternalism is really not avoided, but only moved from the actual decision to the 
hypothetical decisions in the vignettes.

20. Cf. Culver and Gert, 1990, p. 627 and similarly Freedman B, 1981, p. 67.

21. The German word Fremdkörper literally means "foreign body"; meant here is an outsider concept that does not fit easily into the conceptual world proper to the own professional practice.

22. See at the end of sub-section 5.5.3.

23. The word temptation is intentionally used, because the seemingly objective way that a test offers to settle the difficult problem of PDMC, is attractive to somebody who does not know how to deal with the problem.

24. By situation, I mean all variables that are external to the patient, hence also the behaviour of the health care professional.

25. Consistent with this line of reasoning is the HCAT's previously noted prescription of switching over to an easier version when the patient first fails the test. For such a course of action a distinction is needed between "essential" constituents of the decisional task (i.e. the issues the patient really has to decide himself) and "accidental" constituents thereof. An example of the latter would be the level of readability of the HCAT essays.

26. Here not only psychological, but also professional/technical restrictions come into play. Take a health care professional treating a patient with a somatic disorder. If this patient also suffers from an inconspicuous mental or sensory condition that asks for a special form of communication, but if that condition falls outside the domain of his specialty, the professional might not recognise the condition and hence fail to take adequate measures. A surgeon treating a mentally retarded patient, but overlooking the patient's mild deafness could be an example.

27. In terms of note 25 , this is the case as soon as the health care professional is not only modifying accidental constituents, but also essential constituents of the decisional task.

28. Cf. Berghmans, 2000, p. 87.

29. Cf. Frijda, 1993, p. 137. 
30. For a discussion of the (positive) role of emotions in ethical decisionmaking and PDMC, see Callahan, 1988; Charland, 1998; Appelbaum, 1998.

31. Cf. Black et al., 1990, pp. 623, 894.

32. To use the words of Pincoffs $(1991$, p. 87) in a slightly different context (and to answer at the same time the (rhetorical) question he raises).

33. Madigan et al. (1994, p. 150) acknowledge that in the practice of PDMC assessment, judgments - h.l. evaluation of the conclusiveness of evidence - are actually adjusted in reaction to the acceptability of the results as experienced by the assessors: whether or not they could "live with" the results determines how they handle the evidence. 


\title{
6. PATIENT COMPETENCE IN HEALTH CARE: PSYCHOLOGICAL CONSIDERATIONS
}

\author{
S.P.K. Welie
}

Deux excès: exclure la raison, n'admettre que la raison. Blaise Pascal, $1670^{1}$

\subsection{Abstract}

Statutory regulations of patient rights using the informed consent model, hinge upon the concept of patient competence. This concept used to be defined as the ability to determine one's own will. Nowadays, the usual criteria operationalise patient competence as decisional capacity, notably in terms of understanding and appreciating the information relevant for the decision at hand. Conscious information-processing and consistency are thought to be necessary elements. Criteria ought to be such that patients generally meet them. In spite of its theoretical importance, actual health care practice and judicial practice seem remarkably little engaged in assessing patient competence. An examination of the usual criteria of competence from a psychological point of view by means of some examples of empirical studies, shows that they are problematic, because unconscious information-processing and inconsistency are regular features of everyday decision-making. Regarding the tendency to develop tests or testlike instruments for "measuring" competence, it can be argued that the psychometric requirements of tests make these instruments unsuitable as operationalisation of patient competence. Therefore, tests can at best have the descriptive function of contributing to the assessor's insight into the patient's cognitive abilities. Those having to assess competence in practice need to have clear and fair criteria for competence assessment. Otherwise, competence assessment might be invalidated by irrelevant biases and considerations. We conclude that a normative discussion should take place about when it is appropriate to make high demands on patient competence in the manner of decisional capacity, and about what the basis is for acting upon a patient's choice in scenarios where no (or lower) demands are made upon patient competence. Such a discussion implies a (re)construction of patients' values. In a pluralist, democratic society, this discussion ought to take place explicitly. 


\subsection{INTRODUCTION}

During the last decade or so, several statutes with implications for health care have been enacted in the Netherlands, such as the Special Admissions into Psychiatric Hospitals Act (1992), the Mentorship for Majors Act ${ }^{2}$ (1994), the Contract of Medical Treatment Act ${ }^{3}$ (1994), the Organ Donation Act (1996), the Medical-Scientific Research on Human Subjects Act (1998) and the Euthanasia Act (2001). These statutes strengthen the legal position of the patient. Most of them use the informed consent model, which means briefly that a health care professional has the duty of informing the patient about proposed interventions and that interventions are not to take place without the patient's consent (Dupuis \& de Beaufort, 1988, p. 219). This model bears not only upon therapeutic interventions, but e.g. also upon diagnostic ones or upon those that are part of scientific research. The aim of informed consent is to enhance the autonomy of the patient (Beauchamp \& Childress, 1994, p. 120; Leenen \& Gevers, 2000, p. 32; Roscam Abbing, 1994, p. 6; Sluijters, 1985, p. 16; Widdershoven GAM, 2000, p. 21).

The aspiration of assigning patients authority over medical interventions, raises the question whether they are actually able to exercise this authority in a meaningful way. This question concerns the patient's competence. ${ }^{5}$ The case below illustrates this private law concept.

Mrs. A is a 72-year-old woman. ${ }^{6}$ She and her six cats live in the mansion where she also spent her youth. The house, which used to be luxurious, is now filthy and Mrs. A heats the living room with a $\log$ fire. Some acquaintances who worry about Mrs. A because of the wintery temperatures, offer her their help. However, she refuses to accept any help, with the exception of food, for which she insists to pay. The acquaintances have noticed that Mrs. A's feet are blackloom, blistered and bleeding. Therefore, they call in the police, who organise an involuntary commitment to the hospital. Earlier, a physician on duty in that same hospital had seen Mrs. A and described her as a strong-willed individual, who is mentally competent for her age. During the commitment, the diagnosis of gangrene is made. The attendant surgeon states that without amputation Mrs. A has a 5\%-10\% chance to live, and a 50\% chance with this operation. He advises amputation of both lower legs. Mrs. A determinately refuses to give her consent for this procedure. The surgeon thereupon calls into question Mrs. A's competence. 
This case gives a good picture of the situation in which a judgment of competence may be relevant. A patient (in casu Mrs. A) has come into contact with health care (admission to hospital). The health care professional (surgeon) determines on the basis of his professional standard what intervention is medically indicated (amputation) and offers this intervention to the patient. The offer is accompanied by the necessary information (explanation of chances of survival). An intervention can only legitimately take place after the health care professional has received permission. It is up to the patient to give or withhold consent. In this case the patient refuses. The health care professional wonders whether that decision is legally valid. And if it were not, he has to know who can decide on behalf of the patient. Patient competence is the crucial factor in answering these questions.

\subsection{LEGAL CONSEQUENCES OF COMPETENCE VERSUS INCOMPETENCE}

The law attaches certain consequences to the classification as competent or incompetent ${ }^{7}$ (Welie SPK, 2001b). In case of a competent patient, the health care professional has to fulfil his duty of informing and obtaining consent to the patient himself. In case of an incompetent patient, he has to turn to a representative of the patient for that purpose (art. 7:465 BW). From the patient's perspective, the legal consequence of competence is that the patient can exercise his rights himself, whereas incompetence entails that somebody else should do this for him. Usually the health care professional is in charge of judging his patient's competence.

The competent patient decides about his own health care. This means that an intervention for which a competent patient has withheld or withdrawn consent, cannot (or no longer) take place, regardless of the consequences. The interventions which a competent patient has the right to refrain from, include life-saving treatment.

If a patient is incompetent, his representative ought to decide on his behalf. According to current doctrine, a representative should be guided by the subjective interests of the patient. Thus he can counterbalance the health care professionals' tendency to be guided by what is medically -or otherwise- possible, and to overlook considerations which have their ground in the patient's values and convictions about life (Dupuis, 1994, p. 41; Tijmstra, 1987). When such a representative refuses to give substitute consent, the intended intervention in principle must not take place. But even when the representative does grant consent, it is not yet certain that the intervention can indeed be performed. 
This firstly depends on the patient's behaviour. In case the patient does not resist the intervention, it can be applied all right. However, in case the patient resists, it further depends upon the intervention's necessity for preventing "serious harm" to the patient (art. 7:465 section $6 \mathrm{BW}$ ). If the intervention is necessary in the aforesaid sense, it can legitimately take place; the patient can then be subjected to lawful coercion. If not, the patient's resistance ought to be respected and the intervention discontinued. It is important to note that under the latter circumstances the incompetent patient's utterances have priority over those of his representative. The terms "serious harm" can be interpreted as unacceptable damage to well-being or health, or as danger of life or death, like Mrs. A's case.

By the way, the issue of a patient's competence is not only relevant in refusal of consent cases. Also when the patient accepts treatment, the health care professional needs to know whether the patient can be regarded as competent. That is because an incompetent patient's assent does not serve as valid consent. From a legal point of view, acting on invalid consent is equivalent to acting without consent. A health care professional who does so, runs the risk of legal liability within the framework of complaint procedures ${ }^{8}$, as much as in disciplinary jurisdiction, civil suit or criminal prosecution. After all, it is quite possible that the representative of an assenting but incompetent patient withholds consent on good grounds - or would have withheld such consent, had he been consulted.

\subsection{Possible RePresentatives}

Dutch law provides for various categories of possible representatives. Characteristic of all of these categories is that they belong to the patient system instead of the health care system. The following categories are listed: (1) legal representative, (2) attorney-in-fact, (3) spouse or other life partner and (4) close family member (parent, child, brother or sister of the patient).

This order also forms a hierarchy. After establishing the patient's incompetence, the health care professional should first address a legal representative. If the patient does not have a legal representative, the health care professional will have to consult an attorney-in-fact. If such a person is not available either (or does not want to represent the patient), it is the turn of the third category, and so on. 
Categories (1) and (2) require a brief elucidation. In this context, by legal representative the law understands a curator or mentor. A curator is appointed by a judge in the course of placement under "curatele", which is a protective court measure for adults who are unable to observe their interests properly. An adult person is assigned a mentor when the judge pronounces a mentorship for him. This measure is comparable to curatele, but has legal consequences that are less far-reaching than those of curatele; furthermore, mentorship is specifically aimed at the protection of non-financial interests. If there is a legal representative for a patient, this representative has a say in assessing competence alongside the health care professional (Jansen S, 1999, p. 31). It shall be clear that in such a situation, conflicts regarding competence assessment may arise between professional and representative.

The attorney-in-fact is somebody who has been authorised in writing as a proxy decision-maker by the patient himself while still competent to do so. This authorisation only takes effect once the patient has been found incompetent.

\subsection{Competence ASSESSMENT IN PRACTICE}

We have seen that assessments of competence may have drastic consequences. Given the doubts one can have in relation to patients' competence -notably in specific care sectors ${ }^{9}$-, combined with the drastic consequences of competence assessment, one would expect there to be frequent discussion on the occasion of such assessments, as well as clear criteria for assessing competence. Neither turns out to be the case. Neither in health care practice, nor in the administration of justice, patient competence is regularly a topic of dispute. Factual information on this can be found in the annual reports of the Dutch National Foundation of Patient Advocates in Mental Health Care. The statistics of this foundation give insight into the questions and complaints of psychiatric patients who call in a patient advocate. Of 23161 questions and complaints which were recorded in the year 2003, only eight related to a declaration of incompetence (Stichting Patiëntenvertrouwenspersoon Geestelijke gezondheidszorg, 2004a). ${ }^{10}$ Many years (up to 2002 inclusive), not a single complaint about competence assessment was brought before a complaint committee with the help of a patient advocate (Stichting Patiëntenvertrouwenspersoon Geestelijke gezondheidszorg, 2003). In 2003, for the first time complaints before a complaint committee dealt with this assessment; but it still concerned only three out of 339 filed complaints (Stichting Patiëntenvertrouwenspersoon Geestelijke gezondheidszorg, 2004b). ${ }^{11}$ Evaluative research of the Mentorship for 
Majors Act has shown that even judges are not very knowledgeable about the regulations on with patient competence (Oomens, van Zutphen, Blankman, \& Beijers, 1998, p. 68).

As for criteria for competence assessment, after 25 years of research the achieved progress comes down to the recommendation to "stimulate research into a conceptual clarification of incompetence and into developing guidelines for the operationalisation and practical application of criteria of incompetence [...]" (Begeleidingscommissie evaluatie Wet Bopz, 2002, p. 10). ${ }^{12}$

This state of affairs justifies the question whether something is fundamentally wrong with the concept of competence. Why should a health care professional (or a judge) take it upon himself to pass such a judgment on the patient? Either clinical (and legal) practice is right in not mentioning competence; in that case the legal model discussed before is but an empty doctrine. Or the law does make sense; but then the silence in practice is problematic. Abolishing the concept of competence gives no solace. On the contrary, it would generate insurmountable problems. Abolition takes away the possibility of distinguishing between patients in this regard and results in putting all patients in the same box. If all patients are simply assumed to be competent, patients in genuine need of help might unjustly be abandoned; conversely, patients' liberty rights would likely be paternalistically infringed upon, if they are all assumed incompetent.

Perhaps difficulties in operationalising competence into concrete terms, are the cause that this concept is not much alive in practice. In this chapter, I give the law the benefit of the doubt and go to look for criteria of competence.

\subsection{THE IMPORTANCE OF CRITERIA OF COMPETENCE}

Assessors may be able to judge intuitively a patient's competence. In that case we could do without criteria of competence. And in the same time, the silence in practice would be explained: assessing competence is so easy that no words have to be wasted on that topic. However, this point of view is untenable. It ignores the fact that assessors themselves express a need for criteria (Gouwenberg et al., 1997, p. 54). Also, it fails to appreciate that without criteria assessors run the risk of passing judgment on improper grounds. 


\subsubsection{Social-psychological processes}

The need for clear guidelines is all the stronger for health care professionals, because they are themselves directly involved in the treatment of the patient. Without enough to hold on to, there is every chance that in their assessment of competence they will be guided by their own interests, consciously or -more probably- unconsciously. Since the health care professional who assesses competence, is part of the situation in which the issue of competence arises, he is under the influence of social-psychological attributional processes. Relevant examples of such processes, which may reinforce each other, are the actor-observer divergence (also called the fundamental attribution error) and the self-serving bias.

\subsubsection{The actor-observer divergence}

The actor-observer divergence refers to the discrepancy that exists between the way in which people interpret their own conduct and the way in which other people evaluate that exact same behaviour (Brown, 1986, p. 169). Actors tend to attribute their conduct mainly to external, situational factors, whereas observers are inclined to explain other people's behaviour in terms of causes that are situated within the actor. If we now regard the patient as the actor and the health care professional as the observer, it will be clear that the health care professional will consider the patient's behaviour mostly as a function of personal characteristics of the patient. For example, when the patient does not understand information, the health care professional will be tempted to ascribe this to insufficient comprehension on the part of the patient, and will not be quick to seek an external cause as explanation, such as the complexity of the information or a defective explication of it. Health care professionals can easily take inadequate behaviour by patients as proof of the latter's deficient personal capacities.

\subsubsection{The self-serving bias}

The second attributional process, the self-serving bias, concerns "a tendency for actors to take credit for successes and to disclaim responsibility for failures" (Brown, 1986, p. 162). In order to understand its relevance in the present context, we have to look at the health care professional as the actor (e.g., in discharging his task of informing the patient of possible interventions). Like the previous one, this bias carries 
the risk that the health care professional will be blind to his own contributions to the relationship between himself and the patient when something goes wrong in that relationship; instead, he will "blame" the patient.

Both processes increase the chances that patients are erroneously deemed incompetent. These processes can be corrected by using criteria in which relevant considerations are made explicit, rather than relying on the alleged intuitive assessment capabilities of the health care professional.

\subsubsection{Confirmation bias}

In exceptional cases, i.e., when it comes to a legal action, the judge has to evaluate a patient's competence. He has more distance to the situation than the health care professional. Therefore, he is less susceptible to the above-mentioned forms of bias. However, a judge who assesses patient competence, is amenable to errors in reasoning too. So criteria that can compensate for these errors, may prove helpful to judges as well. An example of such reasoning errors is the tendency to give more weight to information that confirms some supposition, than to information that counters this supposition (confirmation bias). A judge who has to pronounce sentence in a legal dispute about patient competence, has already been put on a certain track by the presentation of the question. There is doubt about the patient's competence; otherwise legal proceedings would not have been started. Under those circumstances, clues suggesting incompetence are readily found and believed. ${ }^{13}$

As a matter of fact, unless they are part of an algorithm -which is highly unlikely-, criteria will not exclude all interpretative activity by the assessor. Within the margins left open by the criteria, deviant behaviour can be labelled as incompetence from the very start (Rosenhan, 1973). The context (e.g., a psychiatric ward or a previous finding of incompetence) then makes an assessor construe ambiguous information in a one-sided manner. Such stigmatisation should be avoided by actively searching for alternative readings. 


\subsection{CRiteria of COMPETENCE}

\subsubsection{The ability to determine one's will}

Traditionally, somebody is competent if he is able to determine his own will. This formulation could be found for example in the original version of the Dutch Special Admissions into Psychiatric Hospitals Act. ${ }^{14}$ In law, the concept of will is well-established. Article 3:33 BW defines a juridical act as "a will to produce juridical effects, which will has manifested itself by a declaration" (italics added -SPKW). ${ }^{15}$

This concept of will is connected to classical psychological views of Plato and Aristotle about the will as one of several (three and five, respectively) faculties of the soul (Fraenkel, 1919, p. 74; Plato, 1962, p. 160 ff. \& p. 481 ff.; Störig, 1986, p. 153; van Veldhuijsen, 2001, p. 10). ${ }^{16}$ These views have been elaborated in the so-called systematic philosophy of mind, the precursor of modern psychology (Peters \& Mace, 1967, p. 1 ff.). They resound in the once authoritative standard books by the German psychologist Lersch (Lersch, 1938, p. 189-190 \& 213; Lersch, 1956, p. 438-439). In these books various definitions are given of the will ("der Wille") and of the activity of willing ("das Wollen"). According to Lersch, the will is a mental ego-function in which a human person experiences his autonomy. In psychiatry, similar ideas prevailed (Hengeveld, 2001, 2002).

The concept of will hardly plays a role in contemporary scientific psychology. The indexes of an arbitrary choice of commonly used academic handbooks on psychology do not feature the entries "will", "free will" or "volition" (Atkinson, Hilgard, \& Smith, 2000; Bernstein, Clarke-Stewart, Roy, \& Wickens, 1997; Carlson, Buskist, \& Martin, 2000; Gleitman, Fridlund, \& Reisberg, 1999). At best someone's will is inferred from his doings: "he is doing it, hence he apparently wills it". Such an indirect conception of will does not add anything to the analysis, obviously. Even worse, in a discussion of patient competence this conception is plainly problematic. After all, the patients involved usually do something (e.g., they refuse a treatment intervention), but other persons doubt whether the patients' actual behaviour corresponds with what they "really want". Crombag appropriately warns that the wilfulness of a behaviour does not refer to a descriptive aspect of that behaviour, but to an appraisal of it (Crombag, 1981, p. 22 ff.). 


\subsubsection{The ability to judge one's interests at hand reasonably}

That is why in 1995 a new statutory criterion was introduced into Dutch law, which defines a competent patient as someone who can be deemed "capable of judging his interests at hand reasonably" (art. 7:465 section 3 BW). Simultaneously with the introduction of this provision, the formulation in the Special Admissions into Psychiatric Hospitals Act was adapted. ${ }^{17}$ It catches the eye that the new statutory criterion has the character of an open norm, that is, a norm with an abstract character of which the component terms require further interpretation with a view to applying and attuning them to a concrete situation. ${ }^{18}$ The phrase "reasonable judgment" admits of more than one interpretation; moreover, it is open to discussion exactly what interests are at stake. The intention of the words "at hand" is clear: they give expression to the task-specific nature of competence. That is to say, an assessment of competence does not pertain to a general status of the patient, but relates exclusively to the question whether or not the patient can make the actual decision in a meaningful way. Therefore, a patient's competence has to be reassessed for each new decision. It even has to be reassessed as time passes. This is because the mental capacities underlying competence may fluctuate in time, both in a negative and in a positive direction.

The tenor of this new criterion is that a patient's competence is not determined by the content of his decision (e.g., refusal of life-saving treatment), but by the way in which he reaches the decision (Dillmann \& Legemaate, 1992, p. 828; van de Klippe, 1990, p. 124 ff.; Ministerie van Justitie, 1994, p. 9). If a decision is based upon a reasonable judgment of the interests involved, it is okay, regardless of the outcome of the decision. The criterion draws attention to the quality of the decisionmaking process.

\subsubsection{Assumed competence}

The statutory open norm provides health care professionals with limited support. The so-called assumption of competence ${ }^{19}$ can help health care professionals in their assessment of patient competence: a patient should always be considered as competent, until "in an individual case, on account of the concrete circumstances" the opposite has been firmly established (Legemaate, 1994, p. 328). In the first place, this means that one needs a good reason, before one can turn to the assessment of a patient's competence. Secondly, the assumption of competence implies that incompetence may not be assumed, but must be "proven" (van de Klippe, 1990, p. 124). 
By postulating the presence of a legitimate trigger as a necessary condition for an assessment of competence by means of criteria, the assumption of competence restricts the scope of possible criteria and with that the scope of the concept of competence embodied in these criteria. Besides, the assumption serves as a rule of thumb for all those cases in which incompetence cannot be demonstrated. In default of proof to the contrary, the patient ought then to be held to be competent. Thus in this (negative) way, the assumption can help the assessor reach a verdict. However, when an assessment of patient competence is indicated, the assumption does not supply us with any (positive) criterion. Leenen contends that no higher demands should be made upon the competence of patients than are generally made upon people (Leenen \& Gevers, 2000, p. 216). This suggestion will play a part in the psychological critique of the prevalent approach. ${ }^{20}$

\subsubsection{Decisional capacity}

In order to get better grip on the open statutory norm for patient competence, the literature attempts to formulate more concrete criteria. The prevalent approach is to operationalise competence as "decisional capacity" (Dillmann \& Legemaate, 1992, p. 828; Koninklijke Nederlandsche Maatschappij tot bevordering der Geneeskunst, 2004, p. 92, 99-101, 117 ff.; Ministerie van Justitie, 1994, p. 9 \& 11; Chapter 4 (section 4.7) in this volume - first published as Welie JVM \& Welie SPK, 2001b, p. 133 ff.; van Wijmen, 1996b, p. A3.1.14-20 ff.). Although there is no consensus as to the exact elaboration of this concept, according to the respective authors it denotes that the decisional process of patients has to meet requirements of conscious and rational information-processing. Thus the conception of competence as decisional capacity fits in with the informed consent doctrine. ${ }^{21}$ In a way, patient competence becomes the mirror image or complement of the health care professional's obligation to provide information. ${ }^{22}$

An enumeration by White illustrates the prevalent approach (White, 1994, p. 154). She asserts that a patient is competent when he is able to receive relevant information, to recognise this information, to remember information, to relate situations to himself, to reason about alternative options, to rank alternatives, to select an option, to resign himself to this resolution, and to explain by way of recognisable reasons how he came to his decision. We should note that the latter ability implies that a competent patient be conscious of the information-processing which precedes the decision and that he have declarative knowledge about this. 
"Adequately competent persons are able to recount [to others] the process by which they arrived at their decisions", says White (1994, p. 181).

The prevalent approach can be summarised in two "steps": to be regarded as competent in a certain matter, the patient should firstly have the ability to comprehend information that is relevant for the decision at hand ("understand"), and secondly the ability to place this information against the background of his personal values and convictions ("appreciate") (Culver \& Gert, 1990, p. 621 \& 627; Gert, Culver, \& Clouser, 1997, p. 132). Consistency is taken as a kind of minimum requirement (Legemaate, 1994, p. 330; Ministerie van Justitie, 1994, p. 13).

\subsubsection{Competence as "measured" by tests}

In the attempt to establish objective standards for competence, the test approach is gaining more and more popularity. This approach matches the plea for actuarial methods (Dawes, Faust, \& Meehl, 1989; Groth-Marnat, 1990, p. 24). Actuarial methods are diagnostic or prognostic methods that are founded on quantitative empirical relationships and of which the interpretation is automated. With the assistance of actuarial methods it is possible to use more systematically than in clinical judgment the available empirical knowledge. In addition, these methods preclude subjective bias and arbitrary associations of the assessor in the interpretation of data. Proponents are working on the construction of tests that aim at measuring in a reliable and valid way the psychological abilities constituting decisional capacity.

Examples of such tests are the MacCAT-T (MacArthur Competence Assessment 1-Treatment) and the SICIATRI (Structured Interview for Competency Incompetency Assessment Testing and Ranking Inventory) (Grisso \& Appelbaum, 1998; Grisso et al., 1997; Kitamura et al., 1998, p. 233; Tomoda et al., 1997). In the Netherlands too, research has been conducted into usable tests for specific patient groups, such as psychogeriatric patients or persons with mental retardation/intellectual disabilities (Biesaart \& Hubben, 1999; Biesaart et al., 2000; Biesaart et al., 1997; Gouwenberg et al., 1997; Schmand, Gouwenberg, Smit, \& Jonker, 1999; Vellinga, Smit, van Leeuwen, van Tilburg, \& Jonker, 2002; Vellinga et al., 2004). 


\subsection{PSYCHOLOGICAL CRITIQUE OF DECISIONAL CAPACITY AS CRITERION OF COMPETENCE}

The year 2000 saw the evaluation of the legislation concerning the contract of medical treatment (Dute et al., 2000). The report in question shows that the "translation" of medical knowledge into information that is intelligible for patients, presents problems. Different factors (which tend to defy manipulation, to say the least), like age, educational level, sex, diagnosis, prognosis and communicative style of the patient, influence the patient's ability to absorb and digest the information. Moreover, patients appear to have difficulty remembering information (Dute et al., 2000, p. $60 \& 66)$.

The results of the evaluative study give the impression that there is something wrong with patients' processing of information. The source of this problem may be the health care professionals: they might fail in their task of giving information and explaining it properly. However, one could just as well put forward the hypothesis that decisional capacity is too demanding as criterion of patient competence. Does academic psychology offer any evidence to support this hypothesis? In order to answer this question, two elements of the prevalent approach will now be examined: (1) the conscious character of information-processing, and (2) its consistency.

\subsubsection{The conscious character of information-processing}

Unconscious motivation of behaviour and choices is normal. Hence, information-processing partly takes place in an unconscious manner. ${ }^{23}$ Especially the appreciative aspect of information-processing is likely to be mediated by such unconscious processes. But neuropsychological and psychophysiological research reveals that the processing of factual (as distinguished from appreciative) information also proceeds to a large extent unconsciously (Damasio AR, 1994, 1995).

A study by Bechara and colleagues exemplifies this (Bechara, Damasio H, Tranel, \& Damasio AR, 1997). This study dealt with "normal" subjects and subjects with prefrontal cortical damage. Both groups of subjects were confronted with the same gambling task: they had to choose from different decks of cards; playing from some decks would lead to an overall gain, playing from other decks to an overall loss. This task was devised to simulate real-life decision-making. To a certain degree, it is comparable with the kinds of decisions that patients are faced 
with in health care. After all, diagnostic and prognostic information is always probabilistic (the diagnosis has some chance of being correct, the therapy has some chance of being effective, there is some chance for side effects to occur). ${ }^{24}$ The study showed that normal subjects -as opposed to those with brain damage- already started choosing from the advantageous decks before they realised the nature of the game, i.e., before they could explain it to the experimenter. ${ }^{25}$

Bechara and colleagues gather from this that overt knowledge is normally based on unconscious (or preconscious) cognitive mechanisms of selection. These mechanisms precede conscious awareness. ${ }^{26}$ Apparently, there are cases in which conscious awareness is not necessary for taking effective decisions. In those cases, experience unconsciously plays a functional role in processing factual information. ${ }^{27}$

In this regard, Damasio states: "Not all actions commanded by a brain are caused by deliberation. On the contrary, it is a fair assumption that most so-called brain-caused actions [...] are not deliberated at all" (Damasio AR, 1995, p. 89). One can sense what is the right thing to do in a given situation without conscious reasoning. Damasio's quotation of the seventeenth-century French mathematician and philosopher Blaise Pascal is significant: "[T] he heart has reasons that reason does not know at all" (Damasio AR, 1995, p. 200; Pascal, 1924, p. 164, pensée no 277).

If it is normal that decision-making is (wholly or partly) unconscious and if it is at the same time true that no higher demands should be made upon the competence of patients than are generally made upon people, then the requirement of conscious information-processing, which is included in the prevalent approach, is too stern. Demanding that a patient give a conscious account of his entire decision-making process, asks too much of patients: even though the patient may not (yet) be able to do this, he possibly takes rational decisions nevertheless. The prevalent approach focuses disproportionately on the way in which a decision actually comes about (the heuristics of the decision). It is more plausible to seek criteria of competence on the level of the reasons a person can give for his decision (the legitimation of the decision). ${ }^{28}$ A patient who has understandable, respectable reasons for his decision, ought to be deemed competent, even if he does not know how he actually reached this decision. By the way, this somewhat milder criterion still does not accommodate persons who already feel what should be done, but are not yet able to indicate why. 


\subsubsection{Consistency of information-processing}

What about the second element of the prevalent approach, i.e. consistency? Before inspecting whether academic psychology sheds any light on this issue, we have to realise that people are able to reconsider their mistakes, that they can change their minds, that their values may suddenly shift because of concrete life events or may evolve gradually over time. Also, it is quite conceivable that at one and the same moment, a person pursues values which contradict each other, yielding incompatible preferences. For example, somebody who suffers from a life-threatening disease, may have positive plans for his life on the one hand, and hence a desire to live; on the other hand, the side effects of life-saving treatment may be so onerous for this patient, that he is not prepared to take them into the bargain and that he therefore refrains from (further) treatment. In this example, there is an incoherence between the desire to live and the final decision. Such incoherence does not by definition imply patient incompetence. After all, the art of decision-making entails the ability to cut the knot of conflicting values in all conscience. In short, a certain degree of "changeability" does not automatically disqualify someone as a sensible human being.

Consistency can mean several things. Advocates of consistency as minimum requirement for competence, do not usually define exactly what they understand by it. Inconsistency may relate to the commission of logical errors, but also to taking contradictory decisions. Both types of inconsistency will be discussed.

Research has shown that logical fallacies are widespread in human reasoning. An investigation by Wason had the following design (Wason, 1966). Subjects were presented with three things: a proposition, a number of cards and an instruction. The proposition read as follows: "If a card has a vowel on one side, it has an even number on the other side". The cards were sitting flat on the table, with only one side visible to the subject. All cards had a letter on one side and a number on the other. The instruction was to test the truth of the proposition and to flip no cards but those that are relevant for the test.

From a logical perspective, subjects should only turn over two sorts of cards, namely those which have a vowel on the visible side, and those with an odd number on the visible side. By turning over a card with a vowel, it can be tested whether the above proposition is correct; by turning over a card with an odd number, the proposition can be refuted (that is, when the other side is found to have a vowel). 
Wason's subjects indeed tended to flip the cards with a vowel. However, beside that, subjects made two kinds of errors. In the first place, a lot of subjects turned over cards with an even number. Probably, this action is prompted by the idea that if a vowel implies an even number, an even number must imply a vowel (and a consonant an odd number). But this interpretation is inconsistent with the proposition. The proposition merely pertains to vowels, and it does not preclude that consonants have an even number on the other side. In the second place, most subjects do not turn over cards with an odd number, although this would be functional in testing the proposition. In sum, subjects do show behaviour that is inconsistent with the instruction, and they omit behaviour that is consistent with it.

If the reader finds it pretty hard to grasp the results of Wason's investigation and still considers himself to be competent, this is a first indication that the requirement of consistency as criterion of competence is too demanding. Tversky and Kahneman's research provides yet further evidence for this message (Tversky \& Kahneman, 1981). It involves inconsistency in the sense of taking contradictory decisions. In this research, a problem was put before subjects, plus two possible solutions, from which one had to be chosen. The solutions were characterised by the fact that in one option it was certain which advantages and disadvantages would occur (1), whereas in the other option there were probabilities for these events to happen (2). Furthermore Tversky and Kahneman employed two different ways of conveying exactly the same information: a "positive" (a) and a "negative" (b) one. Of two groups ${ }^{29}$ of respondents, one got the positive and the other one the negative version.

One example of such a problem is fighting a deadly disease. Subjects had to choose from two alternative programmes to combat the disease. In the positive version, the choice was as follows:

Which programme would you favour, programme X or programme $Y$ ?

If programme $\mathrm{X}$ is adopted, one third of the population will be saved (1a);

If programme $\mathrm{Y}$ is adopted, there is a $33 \%$ chance that the whole population will be saved and a $67 \%$ chance that nobody of the population will be saved (2a).

The negative version ran as follows:

If programme $\mathrm{X}$ is adopted, two thirds of the population will die (1b); 
If programme $\mathrm{Y}$ is adopted, there is a $33 \%$ chance that nobody of the population will die and a $67 \%$ chance that the whole population will die (2b).

Significant differences were found between the choosing behaviour of the two groups. The group that got the positive version, had a strong preference for programme X, which offers certainty (1a). The other group, however, systematically preferred programme $\mathrm{Y}$, the "chance programme" (2b). Apparently, it is not only of importance to decisionmaking what substance the information has, but also how this information is presented or "framed", to use Tversky and Kahneman's terminology: the same dilemma is dealt with differently, depending upon the way in which it is formulated. This result is particularly relevant for the health care setting, where it is the health care professional who has to decide both what information to communicate and how to do so.

Interestingly, Tversky and Kahneman also observed these "reversals of preference" in physicians and university faculty, of whom especially the latter are supposed to be paragons of rationality. When even healthy intellectuals show inconsistent behaviour in a hypothetical decision, what are we to expect of an "average" patient who is faced with an acute medical decision about his illness (cf. Leenen \& Gevers, 2000, p. 312)? All in all, inconsistency proves to be a normal phenomenon in human inference. The second element of the prevalent approach, consistency, therefore cannot serve as a general criterion of competence either. Wagenaar and Crombag (2002) give a systematic account of errors in reasoning in a judicial context (cf. Nisbett \& Ross, 1980). ${ }^{30}$ It concerns "errors, which fairly prudent and careful people will make unwittingly and in good faith. When alerted to these errors, they will frankly confess and resolve not to commit them anymore; however, they will often lapse into these same mistakes again anyway" (Wagenaar \& Crombag, 2002, p. 838). If such reasoning errors are relevant for an assessment of competence, the criterion ought not to be committing these errors in itself, but the (in)ability to acknowledge and repair them.

\subsection{EMOTIONALITY AS AN ALTERNATIVE?}

Human rationality is limited and defective (Simon, 1983, p. 17 \& 34). Does emotionality outperform decisional capacity as a criterion of competence? We have already seen that Bechara's and Damasio's studies suggest that people automatically feel what is the best course of action in a given situation. Accepting emotionality as criterion of competence 
would mean that a patient who feels a certain preference in favour or against a proposed intervention, is ipso facto competent and should therefore have his preference honoured without further reflection or discussion: I feel, ergo I am competent.

Frijda gives impetus to this idea by calling emotions rational: "Someone's emotions can contain a real, objective appraisal of the state of affairs and therefore be named rational, they may have originated from consistent reasoning and judgment, and good reasons can possibly be advanced for justifying their occurrence. Moreover, emotions-in-general are to be regarded as rational psychical systems, in the sense that they enable the organism to adjust adequately its comings and goings to the promotion of its interests activated by the external world" (Frijda, 1993, p. 141-142). This line of thought is elaborated by various authors in reference to the context under discussion, namely health care decision-making and patient competence (Berghmans, 2000, p. 87 ff.; Charland, 1998a, 1998b; Frijda, 2002; sub-section 5.6.2 in this volume - first published as Welie SPK, $2001 \mathrm{a}$, p. 146 ff.).

\subsubsection{A functional analysis of emotions}

The proposal to use emotionality as alternative criterion of competence, is based on a functional analysis of emotions (Frijda, 1993, p. 136 ff. \& 64 ff.): because of the way in which they come about, emotions represent interests of the person who is feeling them. If a decision or choice relies on the right emotions, we know that the interests represented by these emotions have been calculated into that decision. Frijda thus refers to emotions as "servers of interests" (Frijda, 1993, p. 59).

What has been said now in terms of interests, could also be formulated in terms of values. Damasio describes emotions as "a system for automated qualification of predictions, which acts, whether you want it or not, to evaluate the extremely diverse scenarios of the anticipated future before you" (Damasio AR, 1995, p. 164; italics added -SPKW). That is exactly what is at stake. If it is true that following the emotional preferences of the patient guarantees proper observation of his interests and values, emotionality would be a fitting criterion of competence. ${ }^{31}$

\subsubsection{Limitations}

Unfortunately, conceiving competence as emotionality entails its own problems. These can be subdivided into three kinds. In the first place, a valid emotion usually pertains to a limited array of interests only (e.g., 
direct, short-term interests) ${ }^{32}$ (Frijda, 1993, p. $147 \&$ 153). Not all interests of the individual are necessarily represented in his emotions. This means that acting upon a valid emotion does not warrant that all relevant interests of the person in question are looked after.

Even if in a given situation only short-term interests play a role (and the previous objection is therefore not applicable), a second problem occurs: an emotion may not be valid (Frijda, 1993, p. 65). The interests involved are possibly misrepresented in the activated emotions. Like the intellect, emotional life is fallible. There are dysfunctional emotions, which are generated in an inaccurate, pathological way. Evidence for this view can be found in the existence of mood disorders, which used to be called emotional and affective disorders (Davison \& Neale, 1990, p. 129 \& 220). Examples hereof are anxiety disorders, depressions and bipolar conditions (American Psychiatric Association, 1994, p. 393, 320 \& 328).

Thirdly, emotions often arise in a spontaneous, unconscious, automatic way. Hence, we tend to trust them blindly. But in light of the former two problems, that would be unacceptable. Additionally, an assessment of competence legally must satisfy certain procedural requirements of carefulness: the question whether or not a patient is competent, should be open to verifiable scrutiny. ${ }^{33}$ However, if emotions are to be trusted blindly, they defy such scrutiny. Even the existence of the emotion (or the fact that it is being felt) can hardly be demonstrated.

One might object that in a legal proceeding, the scope and validity of emotions could be more or less objectified by means of further reflection upon these emotions. Although this objection is in itself correct, it cannot save emotionality as criterion of competence: after all, with such reflection we fall back on a rationalist model.

In a discussion of competence, emotionality is certainly a relevant concept. Emotions can help both the person who feels them and other persons involved, in discovering the former's interests and values. ${ }^{34} \mathrm{But}$ the limitations of emotionality as discussed render it unsuitable as a legally conclusive criterion of competence. The fact that a patient feels a preference (or dislike) for a proposed intervention, does not guarantee that this patient is competent and that his preference (or aversion) would have to be followed without further question. 


\subsection{PSyCHOLOGICAL CRITIQUE OF THE USE OF TEST SCORES AS A MEASURE OF COMPETENCE}

In the discussion of the prevalent approach, we made mention of the tendency to develop tests for "measuring" competence. Adherents of this idea expect such tests to provide an objective basis for determining who should hold the power to decide, the patient or someone else (Kapp \& Mossman, 1996). One such test is the vignette method that has been constructed by Gouwenberg and colleagues after the example of American researchers (Fitten, Lusky, \& Hamann, 1990; Gouwenberg et al., 1997; Marson, Ingram, Cody, \& Harrell, 1995). This method will now be discussed in some more detail. After that, we will go into the relationship between psychometric requirements and assessing competence more in general.

\subsubsection{The vignette method}

The above-mentioned vignette method is intended for competence assessment in elderly demented patients. Vignettes are descriptions of hypothetical situations in health care which call for a decision. The method contains two vignettes about treatment matters. The first vignette concerns the choice between physiotherapy or surgery for a broken hip, the second one the choice between treatment or no treatment of pneumonia with antibiotics in a patient with incurable cancer. Each vignette is accompanied by a questionnaire. The questions included therein relate to four categories: (1) understanding of the information presented, (2) weighing of advantages and disadvantages, (3) motivation, and (4) foreseeing the consequences of a decision.

Use of the test entails the following procedure. A vignette is read to the patient (if necessary, twice). Next, the test user administers the accompanying questionnaire and scores the answers as correct or incorrect. ${ }^{35}$ Finally a competence score is calculated by adding up the total number of correct answers. For the vignette about the broken hip, which has ten accompanying questions, this procedure yields a score ranging between 0 and 10 .

During the method's construction, its content-related validity ${ }^{36}$ has been judged by a multi-disciplinary panel of 154 experts, consisting of lawyers, ethicists, psychologists, general practitioners, psychiatrists, geriatricians, nursing home doctors, nurses and representatives of organised interest groups for the elderly. The questions that were judged 
of importance by most panel members, involve understanding ("Could you tell briefly what this is about?") and motivation ("Why do you opt in favour of surgery/physiotherapy?").

For further validation ${ }^{37}$ of the test, fieldwork has taken place with 240 respondents, specifically 120 elderly persons with ${ }^{38}$ and 120 without cognitive impairments. The degree of dementia, respondents' cognitive capacities, and a physician's assessment of their competence, served as additional criteria. In order to enable comparison of competence scores with the physician's assessment, the former were dichotomised into "competent" and "incompetent". For this purpose, a cut-off score was used that was based on a predetermined percentile in the group of elderly without dementia. ${ }^{39}$ The results of the fieldwork showed somewhat of a relationship between the method's competence scores and the additional criteria.

Some critical remarks can be formulated with respect to the foregoing test construction. Firstly, the relevance of the vignettes at hand is questionable in light of the task-specific nature of competence. A high or a low score on these vignettes is not necessarily indicative of the person's abilities to deal with the health care decisions he is actually faced with in real life. Strictly speaking, the present test only gauges the capability to make hypothetical decisions about the matters covered by the vignettes. In the second place, the fact that individual patients have personal values and convictions, thwarts the use of a uniform classification for scoring the answers of all patients as correct/incorrect. This is particularly true of the categories 2 (weighing) and 3 (motivation). And yet this method seems to use such uniform classification.

Thirdly, the final competence score is not very informative. From this score, it cannot be deduced anymore which questions cause difficulty for the patient-respondent, neither where his strong points are. For instance, a person who has trouble with understanding but not with motivation, can get the same score as a person for whom the reverse is true. ${ }^{40}$

Furthermore, the percentile chosen for dichotomising, is rather arbitrary. Why would precisely $95 \%$ of non-demented persons be competent and $5 \%$ of that group incompetent? This criticism is less grave, as the chosen boundary could be adjusted in the event of further construction.

Also, it is the question to what extent a physician's assessment is a good criterion for validation, since these assessments come about on obscure grounds. More than that, now that it has not been specified in relation to what decision respondents' competence has been judged by the physicians ${ }^{41}$ meaningful assessment of competence is out of the question. ${ }^{42}$ 
Finally, dementia and cognitive impairment (i.e., two of the three additional criteria used in validating the test) are not equivalent to incompetence. There is little consensus about criteria for competence assessment; but if there is one thing that most authors agree on, it is that being a patient -even having a mental disorder- does not imply incompetence (Legemaate, 1994, p. 328; Ministerie van Justitie, 1994, p. 8; van Wijmen, 1996b, p. A3.1.11). ${ }^{43}$ Therefore, the relationship which was found between the method's competence scores and these additional criteria, is not really relevant.

\subsubsection{Psychometric requirements}

Without taking the discussion of this specific test any further, I think that, in general, it is inappropriate to intend for tests the function of measuring competence. Exactly those characteristics that make a measuring procedure deserve the name "test", are problematic in light of the quality to be measured here. Let me explain this.

A test is a method for establishing whether -and to what degree- a certain characteristic or quality is present. To be a genuine test, this objective must be realised in a systematic and replicable way. That is why a successful test is a measuring instrument.

The field of psychometrics is devoted to tests aiming at "psychological" properties of persons (traits, states, behaviours, inclinations, abilities, attitudes, dispositions). ${ }^{44}$ Administration of such tests elicits test behaviour from the persons being tested. These concrete behaviours of test subjects are supposed to be informative of the properties to be measured.

The systematic nature of a psychological test allows it to acquire added value $^{45}$ in three respects, i.e., through (1) reliability, (2) standardisation of normative comparison scores and (3) validity. ${ }^{46}$

Reliability means that using the same test with the same person always yields the same score (provided that the psychological property to be measured has not changed, e.g. as a consequence of the person's having been subjected to the test). Since test behaviour -like any form of human behaviour- is the resultant of the interaction between the person and the situation, situational differences -including differences between test raters- must not distort the measuring results on repeated test occasions. Therefore the situation (and with that the influence of the situation) has to be controlled. In jargon this is called standardisation of the test administration. In an ideal test, standardisation is realised by completely 
fixing the way in which the test ought to be presented to the subject, as well as all other features of the test situation. Thus, the situation can be kept identical at each administration of the test.

This first aspect of the systematics of tests is dubious when judging patient competence. Autonomy implies that in principle decisional power belongs to the patient. The circumstances under which the patient has to make the decision, should be attuned as much as possible to the strengths and weaknesses of the individual patient, so as to maximise patient autonomy (Legemaate, 1992, p. 191). Hence, what is required from a psychometric point of view, i.e., standardisation of test administration, is inadmissible from the viewpoint of autonomy. Conversely, what is required from the viewpoint of autonomy, i.e., taking into consideration the personal characteristics of the one whose competence is being judged, is undesirable from a psychometric point of view. Thus, standardisation of test administration by definition renders a test unsuitable for "measuring" patient competence in an ethical and legal context.

Standardisation of normative comparison scores means that a test score can be quantitatively compared with available test scores of other individuals. Thanks to this type of standardisation, it can be determined for example to what degree the test score of an individual deviates from the average score of a certain population, or how many people from some specific reference group perform better (or worse) than the individual concerned.

However, the individual differences into which standardisation of normative comparison scores gives insight, are not particularly interesting within the framework of a judgment of competence. Scores that deviate from what is "normal", do not imply incompetence. The point of autonomy is precisely to create room for diversity and to legitimise deviations from the norm. Only in an abstract sense there is a general norm that all patients have to comply with in order to be deemed competent. ${ }^{47}$ Yet the concepts used as elements in the various definitions of competence, are variable ${ }^{48}$ : their content changes, depending on the decision to be made and on the values and convictions of the patient whom the decision concerns. "The average patient" does not matter in this regard. Imposing upon a patient what "the average patient" does, would amount to prescribing a Procrustean bed.

The validity of a test pertains to the correspondence between what the test actually measures, and what it purports to measure. A test's validity can be examined by correlating the test scores to other measures of the same variable. Supra it has become clear that such measures are not at our disposal in relation to patient competence: a univocal empirical criterion 
for validation is lacking. Therefore the validity of a test for competence remains uncertain.

In closing this topic, the problem with the idea of a test for patient competence, is that such a test either does not measure competence, or is no test. Tests do not take into account individual, idiosyncratic circumstances, whereas that is exactly what competence is about (cf. Groth-Marnat, 1990, p. 24-25). This does not alter the fact that test data may have supplementary value within a more encompassing assessment of patient competence. Rather than as a measure of competence, those data should then be regarded as a measure of the patient's cognitive functions. Knowledge of these functions can help in judging competence, but it can also give clues for finding an approach of the patient which is better adapted to his strong and weak points.

Moreover, the assessor who intends to use test scores, ought not to forget that such scores only reveal a picture of the patient's cognitive abilities at a given moment in time. Fluctuating mental conditions may necessitate repeated administration of the test, for the only mental state that is of importance with a view to judging competence, is the one in which the patient finds himself when the decision regarding his health care actually has to be made.

Also, the user of tests should keep in mind that insight into the cognitive abilities of the patient as provided by descriptive test results, does not entail a norm that the patient has to fulfil in order to be granted the right to decide. Only if the test scores on relevant abilities are so extremely high or low that it is absolutely clear whether or not the patient in question is competent, can such a normative conclusion be drawn. Patients with severe mental retardation or advanced-stage dementia could serve as examples. For such cases, however, tests are not needed at all. ${ }^{49}$

\subsection{THE NORMATIVE CHARACTER OF THE CONCEPT OF COMPETENCE}

The widespread interest in all kinds of cognitive (rational and emotional) abilities and hence psychology is understandable. It is based in hopes that psychology might offer the kind of neutral, descriptive operationalisation of competence that enables us smoothly to cut the knot in decisional dilemmas and to determine in a procedural way who has the final say in a decision. These hopes are vain in the sense that they ignore the normative character of the concept of competence (Beauchamp, 1991, p. 53 \& 66; Buchanan \& Brock, 1990, p. 17 \& 47; Checkland \& Silberfeld, 1996, p. 131; Legemaate, 1992, p. 192). An assessment of competence constitutes 
a legal and hence normative judgment. Such a judgment implies both establishing facts and weighing these in light of the normative context. Competence assessment does deal with the question whether -and to what degree- certain abilities are factually present, but it also involves the question whether the abilities present meet the relevant norm. This norm is not a constant factor, but varies with the situation.

If we regard decisional capacity as a configuration of factual abilities, the preceding discussion gives rise to several possibilities. Of course it is possible that criteria in the manner of decisional capacity also comprise the applicable norm for competence. A patient can then actually satisfy this norm or fail to do so (and hence be deemed competent or incompetent, respectively).

But it is also possible that an individual patient is quite decisionally capable all right and that he is nevertheless not awarded decisional authority. In that case, the applicable norm apparently entails even higher demands than criteria in the manner of decisional capacity, or it requires qualifications of a totally different nature.$^{50}$ This may be the case for decisions which are very drastic for the patient (Buchanan \& Brock, 1990, p. 51 ff.; Culver \& Gert, 1990, p. 623 ff. \& 639; Leenen \& Gevers, 2000, p. 307, 313, $343 \&$ 349; Legemaate, 1994, p. 330), or for issues with important social implications (Freedman B, 1981, p. 61 ff.). An example of the former category is the decision on the subject of euthanasia. An extra condition for the validity of this decision is the ability to reach "a voluntary and carefully considered request". ${ }^{51}$

Professional soldiers who refuse to undergo medical treatment in times of war, thereby endangering their availability, could constitute an example of the latter category.

And finally it is possible that a patient is not decisionally capable, but still allowed to "decide" the matter. His wishes may then, for instance, be acted upon, because there is nothing at stake for the patient; in other words, the norm does not make demands upon the patient's abilities, because the decision does not have any consequences worthy of mention. Imagine a demented elderly person on a psychogeriatric ward who has drunk enough in the course of that day and who now declines a cup of coffee offered to him by the nurse during the evening round. Or, alternatively, the wishes of the patient may be followed notwithstanding doubts about his competence, because the disadvantages of competence assessment (violation of privacy, breach of confidence, humiliation, risk of stigmatisation) do not outweigh possible advantages (cf. the principle of proportionality; Algra, Gokkel, \& Klijn, 2001). Or, the wishes of the 
decisionally incapable patient are honoured, because they are socially unproblematic or even useful (Drane, 1984, 1985; Faden et al., 1986, p. $283 \& 290 \mathrm{ff}$.). Complying with a patient who assents to a routine curative treatment intervention, has public benefit in that healthy citizens are better able to make their contribution to society and cost less to it. When these are the real reasons for carrying out a patient's wish, the quality of the decisional process that led the patient up to formulating his choice, (or the lack thereof) does not matter. From a legal perspective, it is then advisable instead to employ an irrefutable legal presumption of competence. Application of such a presumption makes immediately clear that facts relating to competence are not relevant. Furthermore one thus avoids the suggestion that dubbing a patient competent would always guarantee that the interests of this patient and his autonomy are of overriding importance in a decision.

\subsection{CONCLUSION}

Decisional capacity is a meaningful criterion of competence, which nonetheless cannot have universal applicability due to the fact that it generally requires too much from patients. For the same reason, an informed consent model building on decisional capacity as criterion of competence, can only have a limited scope (Sprung \& Winick, 1989, p. 1351). Tests and test scores can at best have an auxiliary function in enhancing knowledge of the patient's cognitive abilities, but they can never replace an assessment of competence.

A normative discussion should take place as to the question in what scenarios the operationalisation of competence as decisional capacity is fair and in what scenarios it is not (Pincoffs, 1991, p. 80). ${ }^{52}$ Such a discussion will produce scenarios (or classes of scenarios) in which this operationalisation must be abandoned and a less demanding conceptualisation of competence must be adopted. ${ }^{53}$ New questions then arise. Firstly, one should ask oneself what the justification is for going by the choice of the patient in applying or desisting from a medical intervention in these scenarios. ${ }^{54}$ The concept of emotionality may play a role in providing a justification, but an appeal to it is not sufficient to this end. Secondly, it should be asked whether there could be a justification for passing over the choice of the patient or even using compulsion in these scenarios.

In discussing all these questions, substantial considerations regarding the interests of the patient (and possibly the interests of third parties or society as a whole ${ }^{55}$ ) will emerge. This means that other persons than the 
patient, namely those who participate in the discussion ${ }^{56}$, make a (re)construction of the values and convictions of the patient. In a pluralist, democratic society this is a delicate affair. Therefore, such a (re)construction ought to take place explicitly (Vanderpool, 1991, p. 199 ff.).

\subsection{RECOMMENDED LITERATURE}

Culver, C.M., \& Gert, B. (1990). The inadequacy of incompetence. Milbank Quarterly, 68(4), 619-643.

Frijda, N.H. (1986). The emotions. Cambridge/Paris: Cambridge University Press/Editions de la Maison des Sciences de l'Homme. Wason, P.C. (1966). Reasoning. In B.M. Foss (Ed.), New Horizons in Psychology (Vol. 1, pp. 135-151). Harmondsworth, England: Penguin Books.

\subsection{Notes}

1. Pascal (1924, p.159 - pensée $\left.n^{\circ} 253\right)$.

2. See the articles 1:450-462 of the Dutch Civil Code (Burgerlijk W etboek/BW).

3. See articles 7:446-468 BW.

4. Its full title is "Termination of life on request and assisted suicide (review procedures) Act”.

5. Not to be confused with their legal capacity (art. $3: 32 \mathrm{j}^{\mathrm{o}}$ art. 1:234 \& $381 \mathrm{BW}$ ) or de facto capacity (art. 3:34 BW). Cf. (Brahn \& Reehuis, 1993, p. 212, 215, 237).

6. This case actually took place in the United States of America, where it was eventually heard before the Supreme Court. See (Abernethy, 1984).

7. I confine the discussion to an outline of the general rules. No attention is paid to exceptions concerning minority (art. 7:450 section $2 \mathrm{j}^{\circ} 465$ section $1 \mathrm{BW}$ ), living wills (art. 7:450 section $3 \mathrm{BW}$ ), the health care professionals' and representatives' own (professional) responsibility toward the patient (art. 7:453, 465 sections $4 \& 5 \mathrm{BW}$ ), and situations of time emergency (art. 7:466 section $1 \mathrm{BW}$ ). 
8. Cf. the Right of Complaint for Clients in the Care Sector Act (1995).

9. Care for children/adolescents, persons with mental retardation/intellectual disabilities, psychiatric patients, elderly patients or demented persons.

10. For the years 1999, 2000, 2001 and 2002, these statistics are 15320 and two, 15111 and six, 16569 and twelve, and 20084 and twelve, respectively.

11. See http://www.pvp.nl/html/jaarcijfers.htm for more recent statistics (in Dutch only).

12. Cf. (Roth et al., 1977); see also (Kabinetsstandpunt, 2004).

13. Cf. (Crombag, van Koppen, \& Wagenaar, 1994, p. 52) for a criminal law context.

14. Art. 38 section 2 second sentence Special Admissions into Psychiatric Hospitals Act.

15. Cf. (Haanappel \& Mackaay, 1990) who translate the Dutch word "wil" as "intention".

16. See Plato's Politeia ( $\S 436 \mathrm{a}$ ff.) and Phaedrus ( $\S 246 a-247 \mathrm{c}$ ); see Aristotle's De Anima ( $\S 414 a 29-415 a 13)$.

17. The statutory criterion of competence has not been made uniform throughout all legislation; the old formulation (or variants thereof) can still be found in the articles 1:32, 35 section 2, 88 section 5,165 section $3 \& 268$ section 2 sub c BW, in art. 40 section 6 Special Admissions into Psychiatric Hospitals Act, and -remarkably- in the very recently added articles $34 \mathrm{a}$ section $1 \& 34 \mathrm{p}$ section 1 of the Special Admissions into Psychiatric Hospitals Act and in art. 2 section 2 of the fairly recent Euthanasia Act.

18. Cf. Loenen (1996, p. 125 ff.).

19. Cf. art. 1:1 section $1 \mathrm{BW}$.

20. In this approach, competence is operationalised as decisional capacity (see below). 
21. Cf. art. $7: 448 \mathrm{BW}$.

22. Cf. the title of (van Wijmen, 1996a).

23. Cf. (Freud, 1917).

24. There is also a difference: in health care decisions, these chances are specified beforehand by the health care professional, whereas in the gambling task, the subjects have to experience the chances of loss and gain during the course of their participation.

25. Cf. (Reber, 1993). Bechara et al. also find that even after they have discovered the nature of the game and know the correct strategy, the subjects with brain damage fail to utilise this knowledge and continue choosing from the disadvantageous decks. In other words, in this case intellectual understanding of the game without well functioning connected neuropsychological emotional mechanisms, is worthless on the behavioural level. When we link this finding to the discussion of criteria for competence assessment, the conclusion would be that decisional capacity as criterion of competence requires rather too little from patients: in addition to insight into the situation, the patient also needs the right emotional abilities (to mobilise his insight in an effective way).

26. Cf. Kunst-Wilson \& Zajonc (1980); Zajonc (1980, 1984).

27. See also Crombag (2002).

28. Cf. the concept of recognisable reasons, as developed by (Freedman B, 1981, p. 64 ff.) and by (Erde, 1991, p. 241-243).

29. Tversky and Kahneman do not mention that subjects had been allocated to the two groups randomly. I assume this is the case and that the influence of possible group differences can be ruled out; otherwise the results cannot be ascribed with certainty to the experimental conditions.

30. In relation to patient competence, reasoning errors matter in two respects. Firstly, errors can be made by patients in deciding on their health care (see directly above). Then the question is whether these errors signal incompetence or are just a regular, neutralisable feature of human cognition. Secondly, health care professionals (or eventually judges) can commit errors in judging a patient's competence (see above under section 6.6, entitled The importance of criteria of competence). Then the question is how these errors can be optimally counteracted 
through their professional standards.

31. Cf. the phrase "judging his interests at hand reasonably" in the current statutory definition.

32. Damasio contends that the so-called "secondary" emotions can also cover long-term interests (Damasio AR, 1995, p. 134 \& 175).

33. See principles $12.1 \& 16$ from Recommendation No. R (99) 4 of the Committee of Ministers of the Council of Europe to Member States on Principles Concerning the Legal protection of incapable adults; cf. also the Anglo-American concept of "due process of law" (Black, Nolan, \& Nolan-Haley, 1990; Walker, 1980), the principle of certainty of law, and the (judicial/professional) duty to motivate a verdict.

34. See principle 9.1 from the above-mentioned Recommendation No. $\mathrm{R}$ (99) 4 of the Committee of Ministers of the Council of Europe.

35. Gouwenberg and colleagues do not explain what counts as correct and what as incorrect.

36. Content-related validity pertains to the test items' representativeness of the quality that the test pretends to measure (Groth-Marnat, 1990, p. 1516). See below for a short explanation of the concept of validity in relation to tests.

37. It concerns concurrent validity.

38. Among whom there were 64 with dementia.

39. I.e., the fifth percentile.

40. In case of a high composite competence score, the patient might still be incompetent, that is, if he scores insufficiently on the necessary understanding of information (category 1) but has high scores on the categories that build on his misunderstanding. In case of a low competence score, it is relevant to know where the difficulties arise, for it is the health care professional's duty to support the patient as much as possible in exercising his autonomy. This support possibly takes the form of compensating for specific unfavourable conditions (see subsections $1.11 .5,2.9 .2,5.6 .1$ and 6.10 .2 of this dissertation).

41. See Gouwenberg et al. (1997, p. 28-29). 
42. Cf. once again the task-specific nature of competence.

43. Conversely, the absence of disease is no guarantee either that the person involved is competent.

44. Given the limited scope of this chapter, we can only offer a schematic description of some basic psychometric concepts. The interested reader be referred to the literature mentioned in note 46 .

45. As compared to just any assessment procedure.

46. Cf. Drenth \& Sijtsma, 1990, p. 82, 85, 95, 173; Evers et al., 1988, p. 11, 31, 51; Evers, van Vliet-Mulder, \& ten Laak, 1996, p. 5; Groth-Marnat, 1990, p. 8; ten Laak \& Bergsma, 1995, p. 97; de Zeeuw, 1995, p. 22, 27, 33; de Zeeuw, 1996, p. 31 \& 46.

See also Harré \& Lamb, 1983, p. 632-633; Lezak, 1995, p. 140; Reber, 1995, p. 498-500, 658-659, 749-750, 790-792, 831-834.

47. Like, being capable of judging his interests at hand reasonably, having decisional capacity, or understanding and appreciating relevant information. See the section entitled Criteria of competence (6.7).

48. E.g. "reasonable judgment", "interests" and "relevant information"; cf. note 47 .

49. In these cases a test would have no incremental validity. Cf. GrothMarnat (1990, p. 20) and Nelson, Fogel, \& Faust (1986, p. 81).

50. Insofar as these qualifications serve other interests than those of the individual patient, it is clearer to make explicit that the applicable norm is not (or not only) comprised by patient autonomy, and that a patient might be competent to decide on his own interests but that his wishes may still be disregarded with a view to those other interests.

51. Art. 2 section 1 sub a Euthanasia Act.

52. With "scenarios" I do not mean a distinction between people or sorts of patients, but a distinction between types of decisions or situations.

53. Cf. also sub-sections $1.11 .5 \& 1.13 .2$ of this dissertation.

54. Cf. also sections $7.7 \& 7.8$ of this dissertation. 
55. In which case the considerations also concern the relevance of the interests of the patient.

56. E.g., -on the microlevel- the health care professional or a representative, -on the mesolevel- organisations for health care, patients' associations or the judiciary, -on the macrolevel- policymakers and administrators, scholars and scientists or the legislature. 


\section{PATIENT INCOMPETENCE AND SUBSTITUTE DECISION-MAKING: AN ANALYSIS OF THE ROLE OF THE HEALTH CARE PROFESSIONAL IN DUTCH LAW}

S.P.K. Welie, J. Dute, H. Nys \& F.C.B. van Wijmen

\subsection{ABSTRACT}

In any jurisdiction that takes patient autonomy and patient rights seriously, patient competence is a pivotal concept. Competence, which should be distinguished from criminal responsibility and legal capacity, can be defined as the ability to exercise rights, more in particular the ability to exercise one's right to give or refuse informed consent. It depends upon a patient's competence whether or not this patient has the final say in a health care decision and whether or not the patient can legitimately be subjected to compulsory interventions in that context. These possibly far reaching consequences explain why competence is the topic of a growing amount of legal regulation and why policy attempts are made at operationalising the concept in workable criteria. Although agreed upon criteria for competence do not exist, there is consensus about some preconditions of competence assessment. Two kinds of models of substitute decision-making for incompetent patients are available, i.e. best interests models and representational models. The Dutch Contract of medical treatment Act is treated as an example of the latter. It is shown that in the Dutch model, health care professionals are not at the mercy of patient representatives. On the contrary, health care professionals are supposed to judge their patients' subjective interests and may eventually overrule the representatives. A public debate ought to take place about the basis for this authority.

\subsection{INTRODUCTION}

During the past decade, the amount of statutory law protecting patient rights has strongly increased in The Netherlands. Examples of statutes which have been enacted in that period, are the Special Admissions into Psychiatric Hospitals Act (1992), ${ }^{1}$ the Contract of medical treatment Act (1994) (an addition to the Dutch Civil Code $=$ Burgerlijk Wetboek $=$ 
BW), ${ }^{2}$ the Organ donation Act (1996), ${ }^{3}$ the Medical-scientific research on human subjects Act (1998), ${ }^{4}$ and the Euthanasia Act (2001). ${ }^{5}$ That development raises the question whether patients are always able to exercise these rights in a meaningful way. This question is discussed in terms of competence and incompetence. Competence is a well-known legal institution, both within and outside the area of health law. ${ }^{6}$ It relates to the ability to accomplish a task and to the corresponding authority to perform that task. Persons are in principle assumed to be competent. If it can be demonstrated that a person is not competent regarding a specific task, certain legal consequences may occur. Competence, as it is used in the context of health care and patient decision-making, applies particularly to the right to give or refuse informed consent. The exercise of this right entails possibly far reaching consequences, such as discontinuing or refraining from life-saving treatment, substitute decision-making or forced treatment.

Obviously, the concept of competence does not only feature in Dutch law. In other countries, particularly the United States of America, Canada, England, Wales and Scotland, it has been a topic of considerable discussion as well, e.g. in the course of legislative processes (Department for Constitutional Affairs, 2003; Law Commission, 1995; Lord Chancellor's Department, 1999; Office of the Public Guardian and Trustee - Ontario Ministry of the Attorney General, 1996; President's Commission for the Study of Ethical Problems in Medicine and Biomedical and Behavioral Research, 1982; Scottish Executive, 2001; Weisstub, 1990). Competence is a key concept in several international regulations, such as the Declaration on the Promotion of Patients' Rights in Europe (Amsterdam, 1994), the European Convention on Human Rights and Biomedicine (Oviedo, 1997), Recommendation No. R (99) 4 of the Committee of Ministers of the Council of Europe to Member States on Principles Concerning the Legal protection of incapable adults (Strasbourg, 1999), and the Convention on the International Protection of Adults (2000). The latter Convention contains private international law and shows that Dutch law can be applicable outside The Netherlands too. In a time where patients become increasingly mobile and make use of health care services across the borders of their own country, this is not unimportant (Nys, 2000).

In short, competence is a crucial notion in any jurisdiction that takes patient rights seriously. As soon as patients are granted rights, it can be asked whether they are able to exercise these rights themselves and, if not, who is going to do this on their behalf. In this regard, there are two kinds of models, i.e. best interests models and representational models, the meaning of which will be explained shortly in more detail. It hardly 
requires any explanation that the background of competence and informed consent is constituted by the principle of individual selfdetermination, also referred to as the principle of respect for autonomy (Beauchamp \& Childress, 1994; Feinberg, 1986). This principle can be related to several international human rights and other legal documents, e.g. art. 8 of the European Convention for the Protection of Human Rights and Fundamental Freedoms (Rome, 1950) on respect for private life. In health care, the patient's life, health and well-being are at stake. Possible interventions affect the patient's own body and person. So it is the patient who should be primarily responsible for deciding in these matters.

Patient competence has a pivotal place in the legal framework, in that it determines who can exercise a patient's right to informed consent. If the patient is competent, he $\mathrm{e}^{7}$ himself can decide in a legally valid and binding way to give consent to the proposed intervention, or to refuse giving such consent. If the patient is incompetent, somebody else has to decide on his behalf. As noted previously, two different types of models exist as to the question who is the appropriate person to do this. In one kind of models, the best interests models, the attendant health care professional is regarded as such. In these models, the health care professional has the task of finally deciding for her ${ }^{8}$ incompetent patients. This type of model is opted for in England and France (Grubb, 1998). The other kind of models, the representational models, hold a representative responsible for this task. According to the prevailing opinion, the representative may not be the same person as the patient's health care professional (van Wijmen, 1990, p. 42). Usually it is someone close to the patient, e.g. his partner or a close family member. In representational models, the health care professional normally has to abide by the representative's decisions. Countries such as The Netherlands, Germany and Belgium, have representational models of decision-making for incompetent patients. ${ }^{9}$ The idea of representational models is that in patient decision-making, a line can be drawn between "objective factors" on the one hand and "subjective factors" on the other (van Veen, 1998, p. 50). The objective factors relate to general knowledge that a health care professional can learn during her education, e.g. how to take an anamnesis, how to do a physical examination, how to read laboratory results, how to reach a careful differential diagnosis, how to select effective treatment interventions on the basis thereof, how to explain medical technical information in lay terms, how to keep a good patient file. These factors are called objective, because it ought not to matter which professional is involved: every professional should come to the same conclusions, given that they have the same professional background and that they are dealing with one and the same patient. In this regard, the professional would be 
exchangeable. The subjective factors, on the other hand, relate to the personal meaning that these objective factors have in the life of the individual patient involved, e.g. how bad it is to suffer from a condition, how the condition interferes with the patient's activities, how treatment impacts upon his daily life experience, how burdening certain side effects are. These subjective factors depend upon what could be called patient specific characteristics, i.e., the patient's personal beliefs, convictions, norms, values, goals, interests, plans, preferences, experiences, emotions, identity, social relations, life story, lifestyle, etc.. With a view to decisionmaking, the patient is not interchangeable here, not even if we are talking about patients with strictly the same medical condition. On the contrary, the patient is all that matters in this regard. In representational models, the following division of labour is given: the objective factors are clearly the domain of the health care professional, whereas the subjective factors are the patient's domain, unless the patient is incompetent; in that case, the latter factors become the domain of a representative.

In the present exposition, we will criticise the idea that in representational models, the health care professional can confine herself to assessing the abovementioned objective factors and otherwise following the decisions taken by the patient or his representative. The Dutch model will be used as an example of a representational model. We will show that in this model the health care professional is supposed to evaluate to a certain extent the above-mentioned subjective factors. In sum, it will be demonstrated that under some circumstances the health care professional is legally expected to act as a substitute decision-maker for the patient. It should be noted that we use the term "competence" to denote the normative judgment implying that the actual abilities of a patient are sufficient to accomplish a specific decision-making task (and incompetence to denote such inability). In using that term, we do not mean the related concept of criminal responsibility. Nor do we mean any formal legal category that might apply to a person. ${ }^{10}$ These related concepts will be the first topic under discussion in what follows. Then, the basics of the Dutch model will be reviewed. After this, the subject of criteria of competence will be discussed. In the next section, four preconditions of competence assessment are examined. We go on to analyse the role of the health care professional in the Dutch model. A discussion and some conclusions will end the exposition.

This chapter does not specifically address end of life issues. The legal position of minors is left aside too. Instead, the general decision-making model concerning the health care of adult patients is the central theme. 


\subsection{LEGAL CONCEPTS RELATED TO, BUT DISTINCT FROM PATIENT COMPETENCE}

Patient competence is conceptually related to other legal concepts, such as criminal responsibility and legal capacity. However, the context, elaboration and legal consequences associated with these other concepts are very different from those associated with patient competence. To clarify the topic of this chapter, these other concepts and the distinction between them and patient competence will be discussed here.

\subsubsection{Patient competence versus criminal responsibility}

Competence is to be distinguished from the related concept of criminal responsibility. From a theoretical perspective, both concepts have to do with the question whether a person can be held responsible for his behaviour in light of that person's mental capacities. Patient competence features in the context of health law and health care. The question of criminal responsibility however, is raised in the context of criminal law, where a person has already committed a criminal act, as opposed to a person who may be dangerous as a result of a psychiatric disorder but who has not - or not yet - done any harm. In the criminal law context, a court has to judge whether the committed act can be imputed to the offender. The assessor of criminal responsibility therefore has to reconstruct in retrospect the mental state of the perpetrator at the time of the offence, whereas patient competence ought to be judged on the basis of the actual mental capacities of the patient, in light of the care decision that still has to be taken.

In Dutch law, criminal responsibility is one of four cumulative conditions for punishability (liability to punishment), the other three being: (a) having perpetrated the offence actually, (b) penalisation (this offence's having been considered a crime by a preceding statutory penal provision), and (c) culpability (which condition will be explained in this section too). The ground of diminished criminal responsibility is formed by a defective development or morbid disturbance of mental abilities (art. 39 Criminal Code). In order to result in diminished responsibility, this psychological disorder has to be of such kind, that the perpetrator suffering from it was not free to omit the criminal act. In other words, criminal responsibility relates to the voluntariness of the behaviour. The question of how the perpetrator dealt cognitively with his act, for example whether he was conscious of its consequences and intended to produce these consequences, does not pertain to criminal responsibility. In criminal law, that question is treated in the concept of culpability. This shows another 
difference with competence: as we will see, ${ }^{11}$ criteria of competence focus almost exclusively on a patient's cognitive abilities, while the voluntariness of the decision-making behaviour is hardly ever discussed under the heading of patient competence.

\subsubsection{Patient competence versus legal capacity}

Competence is also to be distinguished from the civil law concept of legal capacity. The differences between these two concepts demand a more detailed explanation. In contrast to the former, the latter concept concerns a formal legal category. Legal incapacity ${ }^{12}$ implies the inability to perform non-annullable juridical acts. The range of legal incapacity is general, relating to acts both within and outside the area of health care. Legally capable are all those persons that are not legally incapable (art. 3:32 BW). The Dutch Civil Code designates two groups of legally incapable people. The first one consists of minors acting without permission of their parents or guardian(s) (art. 1:234 BW) ${ }^{13}$ For this group, their legal incapacity follows directly from statutory provisions. The second group involves persons placed under "curatele" (art. 1:381 section $2 \mathrm{BW}) .{ }^{14}$ This measure can be pronounced by the court. It aims at the protection of adults who are not able to observe their own interests properly. In case such a court procedure is started, a judge evaluates the need for the measure. When the measure is applied, the judge appoints a legal representative, called curator, for the adult in question.

Competence is not formal in nature. Any person can be competent or incompetent, regardless of his formal legal status. As to what authority is competent to assess the competence of patients, it is the attendant health care professional who is primarily responsible for this task (Ministerie van Justitie, 1994, p. 14). For example in case of a patient suffering from cancer, his oncologist may have to judge the patient's competence. For patients with a legal representative, this representative may also be involved in competence assessment. A competence assessment is attuned to the particular decision at hand and to the moment on which this decision has to be taken. Hence, such an assessment does not cover other possible decisions or other moments. The rationale underlying this specificity is that the mental abilities required for decision-making may vary according to the nature and gravity of the decision at hand; besides, they may actually fluctuate in time, either in a positive or in a negative direction. ${ }^{15}$ If the attendant health care professional wishes so, she can consult colleagues or specialists on the matter, e.g. psychiatrists, neurologists, geriatricians, psychologists, nurses, lawyers or ethicists. However, under Dutch law there is no legal obligation to do so. Of 
course, the informal nature of incapacity does not alter the fact that the issue can be brought before the court when a dispute arises in this regard and that the assessor then has to account for the way in which she has come to her judgment (Gevers, 1987, p. 2092). In those (rare) cases, the court has the final say in judging competence.

In short, legal (in)capacity can be assessed on formal legal grounds. Thus, judicial sentences in cases of curatele are legally bound to be gazetted in the official national newspaper, to be published in two other daily newspapers, and to be recorded in public registers ex art. 1:390-391 BW. A judgment of (in)competence on the other hand, requires the ad hoc normative taxation of the actual mental state of a person in light of the decision to be taken.

The concepts of legal capacity and competence are independent of each other. This means that from a legal point of view, persons can be classified into one of four possibilities; one can be: (1) legally capable and competent in a specific matter, (2) legally capable and incompetent in that matter, (3) legally incapable and competent etc., and (4) legally incapable and incompetent. The second and third possibilities are interesting, as they are characterised by an antithesis between the formal and informal status of the person. In the context of health care related patient decision-making, legal capacity is of less importance because of the concept's formal nature. Given the weight of the principle of respect for patient self-determination in decisions on patient health care, the concept of competence is considered to prevail over the concept of legal capacity in this context (Blankman, 1990, p. 163 ff.; Blankman, 1995, p. 86; Legemaate, 1994 , p. 331). ${ }^{16}$ In other words, a legally incapable person who is competent in a certain health care related affair, should be allowed to exercise his decisional power in that affair; a legally capable person who is incompetent, should not be allowed to exercise that power himself.

The above explanation shows that in patient decision-making legal incapacity only has relevance, once incompetence has been established. Legal incapacity implies the existence of a legal representative, so that it is known who can then act and decide for the incompetent person. The same priority of informal status over formal status (and associated conditioning of the representative's authority) also applies to mentorship, a judicial protective measure for adults which is comparable to guardianship and curatele, though less far-reaching in its consequences and intended for non-financial affairs only, notably matters of medical treatment, nursing, health care and support (art. 1:450 $\mathrm{j}^{\circ} 453$ section 1 $\mathrm{BW}) .{ }^{17,18}$ Application of this measure entails the assignment of a legal representative as well, called the mentor. 


\subsection{The Basics of the Dutch Model}

Now that we know how to distinguish patient competence from related legal concepts, particularly legal capacity, in this section the basics of the Dutch model in relation to competence will be presented. First, the general legal framework for patient competence will be discussed. This framework is constituted by the Contract of medical treatment Act. Then it will be outlined who can act as a representative for the incompetent patient. The section concludes with a more detailed explanation of the legal consequences of competence versus incompetence.

\subsubsection{Explanation of the legal framework}

We restrict our explanation of the legal framework mainly to the area of voluntary care, where the interests of the patient are the paramount consideration. The area of voluntary care falls under the provisions of the Contract of medical treatment Act. ${ }^{19}$ This statute provides a legal basis for the care of somatic patients, as well as for the care of psychiatric patients receiving care voluntarily. Also, the Act pertains to the somatic care of involuntarily committed patients and to the care of the latter's mental disorders other than those on account of which they have been involuntarily committed. The Contract of medical treatment Act can be regarded as an elaboration of the articles 10 (privacy) and 11 (physical integrity) from the Dutch Constitution, with a view to the context of health care. It conceptualises the relationship between patient and health care professional as a contractual one, as suggested by the name of the regulation. Among other things, the statute explicates the rights and duties connected with the informed consent doctrine. In Dutch law a contract does not have the connotation of a written agreement form. The patient (or someone acting in his place) and the professional are free to enter into their contract in whatever form they want, e.g. in writing, verbally, or even implicitly (art. 3:37 section $1 \mathrm{BW}$ ). Tacit or implicit contracts between patient and health care professional are the most common in The Netherlands.

\subsubsection{Representatives for the incompetent patient}

In section 7.2 (Introduction) we noted that the Dutch model is an example of a representational model. It is characterised by substitute decisionmaking for incompetent patients through representation. The primary 
legal consequence of incompetence is that the patient in question should be represented. This characteristic raises the question who can act as a representative for an incompetent patient. A representative is usually someone from the patient system, i.e. the network of persons with whom the patient regularly interacts in his daily life (e.g. life partner, family members, friends), and not someone from the health care system (cf. art. 1:452 section 6 introduction sub c, $d$ and e BW). As such the representative can counterbalance possible tendencies inherent in the practice of health care, on the basis of knowledge of the patient's personal perspective. Said tendencies amount to the inclination to be guided by purely medical considerations and by what is possible from a medical technical viewpoint, instead of by what is desirable in light of the individual patient's needs and preferences. Now what persons can actually act as a representative for the patient? Dutch law has a large number of different regulations of representation (van Wijmen, 1990). Specifically for the field of health care, the Contract of medical treatment Act contains a hierarchically ordered enumeration of four categories of possible representatives (art. 7:465 BW). This hierarchical order means that the health care professional of an incompetent patient should first address a representative from the first category for providing information and for obtaining a substitute decision. If a representative from this category is not available, the health care professional turns to the second category, and so on. The first category is made up by legal representatives. We have already seen that in this context it concerns the curator or the mentor. ${ }^{20}$ The law provides for some mechanisms of control of the legal representatives (art. 1:385 $\mathrm{j}^{\mathrm{o}} 250,459$ and $461 \mathrm{BW}$ ). Thus, the court may appoint a special ad hoc curator, if there is a conflict of interests between the regular curator and the one he is representing. A mentor can always be summoned by the court to report on his activities and to appear in person to that end. Finally, both a mentor and a curator can be dismissed by the court. Attorneys-in-fact constitute the second category. An attorney-in-fact is a proxy, who has been authorised in writing by the patient himself - when he was still competent - to represent him in case of incompetence with a view to health care decisions. The third category consists of spouses or other life partners. Close kinsmen, i.e. parents, children and brothers or sisters, form the fourth category. The above-mentioned categories can actually overlap. For example a partner will often be appointed as legal representative (art. 1:383 section $3 \mathrm{BW}$ ), or a patient might authorise his daughter as an attorney-in-fact. Representatives are not qualified to take just any health care related decision for the patient. Thus, substitute decision-making in relation to admission into a mental institution or psychiatric hospital for incompetent patients who are not prepared to be hospitalised, does not 


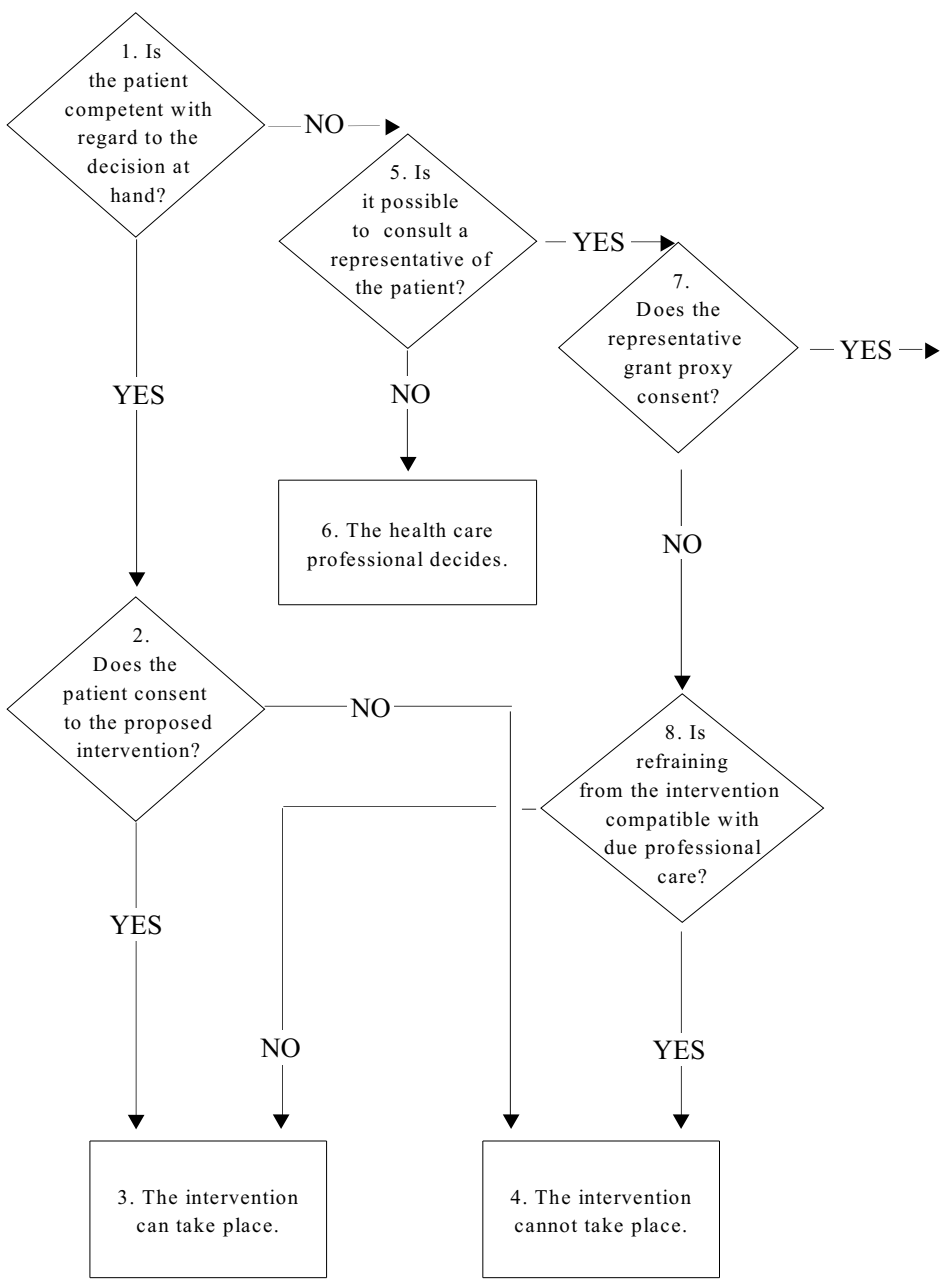

Figure K. Decision tree regarding the legal consequences of patient competence vs. incompetence (art. 7:465 Dutch Civil Code) 


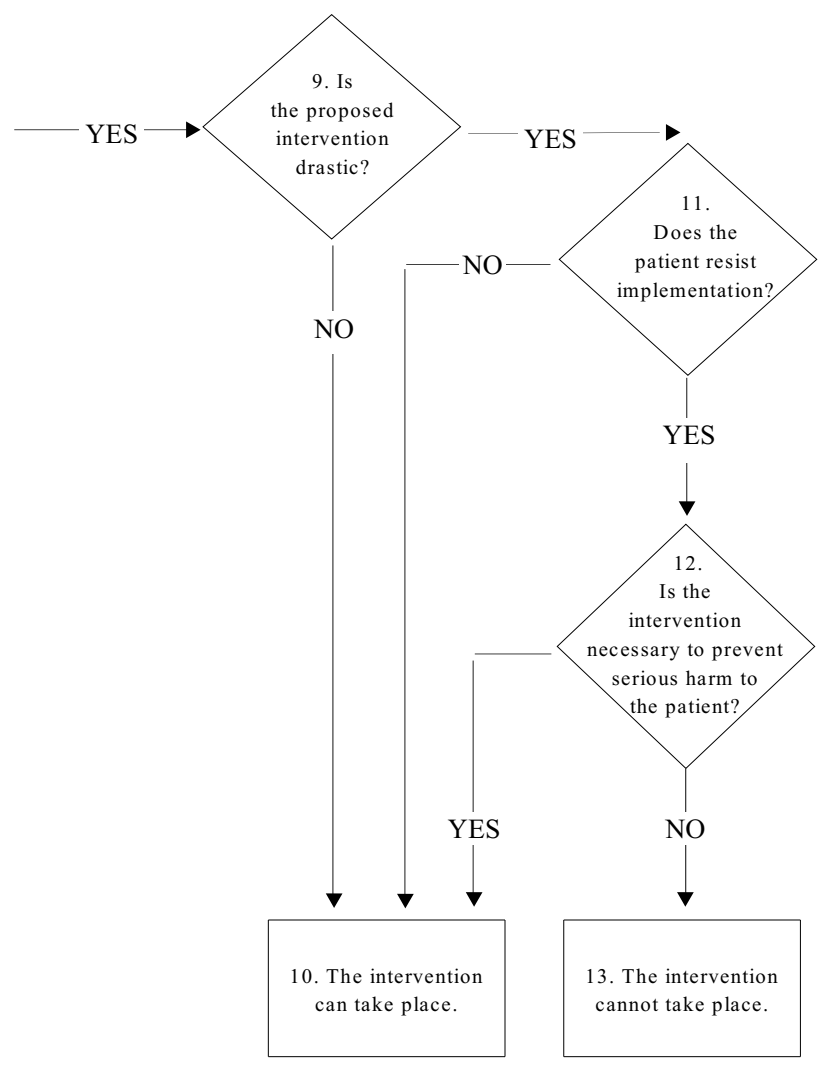


take place through representation. Such decisions are considered too personal and too drastic to be taken by a representative (Blankman, 1988,p. 214; Blankman, 1995, p. 87; van Wijmen, 1990, p. 72). It is the judge (or, in cases of time emergency, the mayor) who has to decide on that matter, according to the procedures described in the Special Admissions into Psychiatric Hospitals Act. Other examples of issues not covered - or at least not fully covered - by the authority of a representative are decisions on marriage, sterilisation, abortion, acknowledging or adopting a child, voting at the elections, will (law of inheritance) or euthanasia (Blankman, 1995, p. 85; Jansen S, 1999, p. 29; Koninklijke Nederlandsche Maatschappij tot bevordering der Geneeskunst, 2004, p. 94; Leenen \& Gevers, 2000, p. 209, 316; van Wijmen, 1990, p. 32, 46, 68, 77-78, 79).

\subsubsection{Legal consequences of competence versus incompetence}

The fact that incompetent patients have to be represented, does not mean that the patients themselves do not play any role at all in the decisionmaking process. In the first place, the representative is obliged to involve the patient as much as possible in his activities (art. 7:465 section $5 \mathrm{BW}$ ). In addition, resistance by the incompetent patient may be a ground for abandoning certain interventions. What then, are the further legal consequences of competence and incompetence according to Dutch law? To answer these questions we will have a closer look at the Contract of medical treatment Act. ${ }^{21}$ Imagine the situation in which a health care professional has proposed a certain intervention for a patient, has supplied sufficient and clear information and has not exercised undue influence. This intervention can be diagnostic, preventive, therapeutic, rehabilitative, palliative or symptomatic in nature. The question is whether the patient will eventually have to undergo or forgo this intervention. The answer to this question depends on several variables. The legal consequences can be outlined by recounting what the law prescribes, according to the values these variables adopt. In such a way, they are summarised in a decision tree (see Fig. K on p. 184-185). Patient competence is the first decision node. If the patient is competent, he decides the matter. His consent legitimises performance of the intervention. His refusal makes that it should be omitted. That goes for life-saving treatment too: the choice of the competent patient must be respected, even if it will result in consequences that are harmful to the patient in the opinion of other people. Naturally, the fact that the ultimate decisional power rests with the competent patient, does not mean that the health care professional should accept any choice by that patient 
unthinkingly. When the health care professional does not understand the patient's choice or thinks the patient is making a wrong choice, she may want to call into question that choice, seek clarification why the patient decides as he does, argue what is the best thing to do, reconsider her proposal, try to find alternatives that satisfy the patient's wishes, or perhaps make the patient change his mind - as long as she abides by his decision in the end. In case the patient is incompetent, other circumstances become relevant. The first of these concerns the substitute decision-making by the patient's representative. If such a representative withholds consent, then in principle the intervention cannot take place. ${ }^{22}$ However, if consent is provided by the representative, the incompetent patient will not automatically be subjected to the intervention. Additional circumstances come into play then. Before a health care professional can carry out a drastic intervention to an incompetent patient for whom substituted consent has been provided, she has to make sure that the patient is not resisting to the intervention. If the patient does not resist, the health care professional can indeed continue the intervention. If the patient does resist, one last circumstance determines whether the intervention can legitimately be accomplished. This circumstance is the necessity of the intervention in order to avoid serious harm to the patient. Only if the intervention is necessary in that sense, it may proceed. In that case we are dealing with permissible compulsory treatment under the Contract of all other drastic interventions, the health care professional should give way to the expression of resistance by the incompetent patient and cease the intervention. Not only verbal utterances, but also non-verbal behaviour can constitute resistance (Koninklijke Nederlandsche Maatschappij tot bevordering der Geneeskunst, 2004). The delineation of what counts as resistance is complicated, as resistance usually presumes an intention to prevent an impending action or incident, whereas the patient's incompetence can make the presence of such an intention doubtful or at least make it difficult to interpret his behaviour. A short word needs to be said about the legal position of persons (e.g. psychiatric patients) who have been involuntarily committed under the Special Admissions into Psychiatric Hospitals Act. Once committed, their legal position in relation to treatment interventions is generally comparable to the position under the Contract of medical treatment Act, which was outlined above. A main difference is that for involuntarily committed patients, the threat of serious harm resulting from the patient's mental disorder - danger, in terms of the Special Admissions into Psychiatric Hospitals Act - is not only a justification for overruling an incompetent patient's resistance, but also for passing over refusal by the representative and even for ignoring refusal by a competent patient (art. 38 section 5). Insofar as the impending harm only concerns the patient's 
own interests (and not the interests of other people in the institution: other patients, health care professionals), it is manifestly contrary to the principle of patient self-determination that the Special Admissions into Psychiatric Hospitals Act allows for compulsory treatment of competent patients (Blankman, 2003; Dijkers \& Widdershoven TP, 2002; Frederiks, 2004; van de Klippe, 1997). By the way, as noted above, ${ }^{23}$ treatment for somatic conditions of involuntarily committed patients does not fall under the provisions of the Special Admissions into Psychiatric Hospitals Act. Therefore, such treatment is allowable only if the conditions stipulated by the Contract of medical treatment Act are met (cf. Fig. K).

\subsection{CRITERIA OF COMPETENCE}

Criteria of competence have not been regulated extensively by statutory law. Neither has the assessment of competence resulted in much case law (Biesaart et al., 1997, p. 36; Hubben, 2000; van de Klippe, 1997; Chapter 6 (section 6.5) in this volume - first published as Welie SPK, 2002). Therefore those involved in judging competence have to rely mostly on the doctrine or on their own personal intuitions. The chances that competence assessments are firmly based in the doctrine are small, since this doctrine belongs to the legal discipline, whereas competence is usually judged by the attendant health care professional of the patient. What is more, we will see that there is no consensus in the literature about criteria of competence. Hence, competence can be regarded as the "catch" of the legal model: on the one hand, in that model, decisionmaking revolves on the concept of competence and this concept shows the promise of being the key to resolve decisional dilemmas; on the other hand, clear and agreed upon criteria for this concept are lacking. In this section attention will be paid to criteria of competence. First we will review statutory criteria. Then several criteria proposed in the literature will pass in review. In this context the so-called sliding scale approach will be brought up briefly. The final subsection discusses the enterprise of developing tests for competence assessment.

\subsubsection{Statutory criteria of competence}

How does statutory law define competence? The first version of the Dutch Civil Code (dating from 1838 and replaced by now) defined an incompetent person as someone that finds himself in a state of silliness, insanity or rage (art. 487) (see Blankman, 1994, p. 311). Use of the term "insanity" in the definition resulted in the inclusion of all the difficulties 
of psychiatric diagnosis in the definition of incompetence. Another dated definition was provided in the original text of the Special Admissions into Psychiatric Hospitals Act. This text defined competence as the ability to form one's will. In the current statutory definition reference to the notion of will is omitted. It defines competence as follows: a person is competent if he is considered to be able to judge his interests at hand reasonably (art. 7:465 BW; art. 38 section 2 Special Admissions into Psychiatric Hospitals Act). The core elements of the definition, reasonableness and interests at hand, are open norms. These norms have to be operationalised in more concrete terms in order to assess an individual patient's competence. Therefore, in the literature attempts are made at formulating operational criteria.

\subsubsection{Literature on criteria of patient competence}

The topic of criteria for competence has been much discussed in other countries. The Dutch discussion is based mainly on some American publications (Appelbaum, Lidz, \& Meisel, 1987; Appelbaum \& Roth, 1981, 1982; Roth et al., 1977). These publications have been summarised in an article by van de Klippe (1990). She distinguishes six different ways of assessing competence. Each approach has its own advantages and disadvantages (Beauchamp, 1991, p. 64 ff.). The six approaches can be classified into one of three categories (Berghmans, 1992, p. 299-302; Buchanan \& Brock, 1990, p. 48-51; President's Commission for the Study of Ethical Problems in Medicine and Biomedical and Behavioral Research, 1982, p. 60-62). These categories are: (1) minimal (or preferential) standards, (2) outcome (or consequential) standards, and (3) process (or evaluative) standards.

Minimal standards amount to regarding as competent anybody who is able to make and express a preference, regardless of what this preference implies. Van de Klippe's first approach falls under this standard.

Accepting a minimal standard would result in the duty of the health care professional eventually to honour any preference that is expressed by the patient about the proposed interventions. After all, expressing a preference means being competent; and being competent means that one's choice ought to be respected. The first advantage of this standard is that it places very low demands on patient competence and therefore will not often result in competent patients' being wrongly deemed incompetent. This advantage is important from the perspective of patient self-determination. Another advantage is that the expression of a preference is an overt behaviour. Therefore, the assessment of competence according to this standard does not require an interpretation 
of mental processes and complies with the principle of certainty of law. Its disadvantage, obviously, is the risk for incompetent patients of being left to fend for themselves. In practice, one of the reasons for doubting someone's competence is the health care professional's suspicion that the patient is harming himself through his choice, whereas, according to this minimal standard, the fact that the patient has made a choice as such implies that he is competent.

In outcome standards, the assessment of competence is based upon the consequences of the patient's decision. Van de Klippe's second approach falls under this standard. If the consequences of the patient's decision are rational or acceptable in the assessor's view, the patient is deemed competent. Otherwise, he is deemed incompetent. Outcome standards are characterised by the fact that they hinge upon a substantive evaluation of the outcome of the decision. ${ }^{24}$ Because of this, they are easily susceptible to contamination by the assessor's norms and values or by prevailing normative opinions, and to paternalism with that. Ideally, a patient's competence should not be judged in light of other people's value systems, but in light of the patient's personal convictions, interests and lifestyle (Beauchamp, 1991, p. 58-59; White, 1994, p. 14-18).

Process standards try to achieve that goal by focusing upon the quality of the process that leads the patient to his choice. The leading question in process standards is whether this process is such that its result (the patient's choice) can be expected to reflect what the patient really wants. Different criteria bring into prominence different aspects of this process. In the respective criteria, these aspects are the patient's reasons for taking a certain decision (van de Klippe's third approach), the patient's ability to understand relevant information (van de Klippe's fourth approach), the extent to which the patient has actually understood this information (van de Klippe's fifth approach) and the patient's appreciation of his condition and health situation (van de Klippe's sixth approach). The difference between the two last criteria is that according to the latter (i.e. appreciation) the patient not only has to understand intellectually the objective information provided by the health care professional, but also has to realise that this information applies to himself and be able to translate the information in terms of his personal norms and values.

In 1994 a governmental committee, instituted by the Minister of Justice and the Secretary of State for Public Health, issued a report with guidelines on competence assessment (Ministerie van Justitie, 1994). It gives an elaboration of the process standard of competence. According to the report, a patient can be considered as competent, "if he shows understanding of the information which is attuned to his comprehension, to such an extent as is necessary in light of the nature and scope of the 
decision at hand." The report further states that "[t]he information concerns the intended diagnostic interventions and the proposed treatment, but also the developments in examination, treatment and health state of the patient, and the consequences to be expected if examination or treatment are refrained from." The definition given in the report corresponds with the core notion of the informed consent doctrine, i.e. that patient decisions ought to be based on the information provided by the health care professional.

According to van de Klippe, there is not one ideal approach. This leaves the assessor of competence with the task of determining what approach is most appropriate in a given case. The assessor has plenty of latitude in selecting the applicable criteria, as the approaches outlined above range from very restrictive to very permissive. This state of affairs holds the risk that the assessor may instrumentally choose that criterion which helps realising the objectives set by the assessor. The sliding scale (or variable criterion) approach purports to deal with this problem by making the applicable criterion dependent upon the risk involved in the decision to be taken (Drane, 1984, 1985; Gezondheidsraad, 2002, p. 106). The sliding scale approach states that high risk decisions (e.g. refusing life-saving treatment or consenting to a risky experimental procedure) ask for restrictive criteria, whereas permissive criteria suit low risk decisions. Thus, the sliding scale prescribes which criterion should be used in what situation. The sliding scale may be defensible with a view to policy consequences. However, as criterion of patient competence it is problematic, in that it treats the choice in favour of accepted interventions (e.g. life-saving treatment) and the choice against these interventions as different decisions (Culver \& Gert, 1990; Freedman B, 1981); similarly, it regards refusal of unusual experimental procedures as a decision different from acceptance of those procedures. As a consequence of that asymmetry, the outcome of a patient's decision (i.e. assent or refusal) is eventually decisive for his competence. In the next section, we will see that because of this, the sliding scale approach is at odds with one of the preconditions of competence assessment (i.e. the third one).

\subsubsection{On tests for competence assessment}

Following the work of foreign scholars, the tendency has emerged among Dutch researchers to construct tests or test-like instruments for “measuring" patient competence (Fitten et al., 1990; Glass, 1997; Grisso et al., 1997; Kitamura et al., 1998; Marson et al., 1995; Tomoda et al., 1997; Vellinga et al., 2004). Examples of instruments that have been developed so far, are the Amsterdam vignette method and the method for 
assessing incompetence of mentally retarded patients (Biesaart et al., 2000; Gouwenberg et al., 1997; Schmand et al., 1999; Vellinga et al., 2002; Vellinga, Smit, van Leeuwen, van Tilburg, \& Jonker, 2004). This tendency is understandable, as people working in the practice of health care express the need for concrete, workable criteria for competence assessment.

One of us has argued that the psychometric requirements of tests are incompatible with the conditions of valid competence assessment (Chapters $5 \& 6$ in this volume - first published as Welie SPK, 2001a, 2002). Other authors have been critical about the use of tests as part of competence assessment as well (Kapp \& Mossman, 1996; Berghmans, 2000, p. 73 ff.; Widdershoven GAM \& Berghmans, 2002, p. 203-204). Therefore, we should not have unrealistic expectations in regard to testlike instruments. Test scores can at best provide additional information in competence assessment, e.g. about the patient's cognitive functioning, ${ }^{25}$ they can never substitute an individual judgment of competence.

\subsection{PreConditions of COMPETENCE ASSESSMENT}

The above discussion shows that the quest for criteria of competence proceeds very laboriously. Twenty-five years after the seminal article by Roth et al., an evaluative study of the Special Admissions into Psychiatric Hospitals Act still ends with the conclusion that useful guidelines for the assessment of competence are hardly available and with the recommendation that the government should stimulate research aiming at clarification of the concept (Begeleidingscommissie evaluatie Wet Bopz, 2002, p. 45; Kabinetsstandpunt, 2004; Roth et al., 1977). This fact raises the question whether it is not more advisable now to investigate why finding criteria of competence is so problematic, rather than to just persist in trying to formulate concrete criteria. However, there seems to be consensus about some preconditions of competence assessment. Four preconditions can be inferred from the literature (Biesaart et al., 1997, p. 24 ff.; van Delden, 1991, p. 30 ff.; van Delden, 1993, p. 85 ff.; Gezondheidsraad, 2002, p. 104-106; van de Klippe, 1990; Leenen \& Gevers, 2000, p. 37 \& 216 ff.; Legemaate, 1992, 1994; Ministerie van Justitie, 1994, p. 8-10; van Veen, 1991, p. 484; van Wijmen, 1996a, p. 8).

Firstly, authors agree that the assumption of competence should be the starting point in a discussion on patient decision-making. This assumption means several things. In the first place incompetence should never be assumed, but always be proved in each individual case on the basis of concrete facts. If incompetence cannot be demonstrated in a 
convincing way, the patient should be deemed to be competent "by default".

In the second place there must be a legitimate trigger before a patient's competence may be called into question. Again, if such a trigger is not present, the patient should be regarded as competent. The requirement of a legitimate trigger results in keeping down the disadvantages inherent in any competence assessment, to a minimum. Generally questions about a patient's competence may arise when the choice of the patient differs significantly from what is in the best interests of the patient according to the viewpoint of the health care professional. Competence assessment will thus often take place in regard to refusals of treatment and care by the patient. From a legal perspective, competence assessment may also be indicated in case the patient complies with the health care professional's proposals. If the patient acquiesces without realising what the proposals amount to, representation by somebody who knows the patient well, may be necessary.

In the third place, the assumption of competence means that a judgment of incompetence may only be pronounced if the advantages of this "verdict" outweigh its disadvantages (principle of proportionality), and if the goals of such a verdict cannot be reached by other, less drastic means (principle of subsidiarity) (Jansen S, 1999, p. 24; van de Klippe, 1990, p. 131, 135; Leenen \& Gevers, 2000, p. 216; Legemaate, 1994, p. 328329). When a competence assessment would not comply with these two principles, the patient should remain being regarded as competent.

A second precondition concerns the character of the concept of competence. There is consensus that competence ought to be conceptualised as task-specific and decision-relative. A patient's incompetence to perform a certain task, does not automatically disqualify him for other tasks. On the level of decisions, a patient who is not able to take decision $x$, may be very well able to take decision $y$. The reason for this is that different decisions may appeal to different cognitive functions and abilities. A psychological disorder that leads to incompetence with regard to decision $x$, may leave intact the abilities needed for taking decision $y$. For example, a patient not able to grasp all relevant matters in a complex decision, may be competent to decide on a simpler - but therefore not necessarily less consequential - affair. Or, to give one more example, it is possible that the delusions a patient is suffering from, may cause incompetence in relation to decisions concerning treatment of these delusions indeed, yet that these delusions in no way impede competent decision-making regarding somatic conditions. The decision-relative character of competence is reflected in the words "at hand" in the statutory definition of competence. Hence, status (or category) standards, 
in which whole categories of persons - e.g. psychiatric patients, mentally retarded or demented persons - are deemed incompetent because of their mental status, are rejected in The Netherlands (Berghmans, 1992, p. 300; de Jong \& van Wijmen, 1999/2000, p. 13; Legemaate, 1994, p. 328). ${ }^{26}$ For health care professionals this means that their assessment of patient competence should be accommodated to the specific decision that must actually be taken. The conclusion of the assessment cannot be generalised to other decisions, unless these decisions are logically related to each other. Earlier, we noted that a conclusion regarding one and the same decision, cannot even be projected to other moments than the one on which the patient's competence has been assessed, as the mental conditions underlying competence may fluctuate in time. ${ }^{27}$

Conceptualising competence as task-specific and decision-relative results in an optimal degree of respect for patient self-determination in patients who cannot take a certain decision themselves, but who are able to take other decisions. The price to pay for this, is giving up certainty of law. The need for constant re-evaluation of a patient's competence means that a patient's legal position is not easily recorded, neither for the health care professionals, nor for the patient system.

Thirdly, an assessment of competence should focus on the quality of the decision-making process. The eventual outcome of the decision must not be the deciding factor in assessing a patient's competence. This precondition is directly connected with the principle of patient selfdetermination. Patients are free to pursue in their lives whatever goals, norms and values they want to. The outcome of the decision is usually determined by the individual patient's norms and values. Assessing competence on the basis of the outcome of a decision would lead up to promoting certain norms and values and opposing other ones. This is contrary to the maxim that a competent patient must be allowed to make any decision he wants regarding the proposed interventions.

Lastly, the threshold of competence varies with the gravity of the decision. The more drastic the decision is, the higher the threshold should be. And, vice versa, as the decision is less drastic, lower demands should be made upon the competence to decide. It should be noted that the gravity of a decision is independent of the complexity of a decision. Furthermore, from a logical viewpoint, the decision to consent to a certain intervention (e.g. routine life-saving treatment of pneumonia by means of antibiotic medication) is equally drastic as the decision to refuse that intervention, because exactly the same issue is at stake. This means that the aforementioned sliding scale approach cannot be justified by an 
appeal to this fourth precondition, but only by a substantive bias in favour of certain health related ends.

\subsection{BEYOND THE PROCEDURAL ROLE OF THE HEALTH CARE PROFESSIONAL}

The role of the health care professional in decision-making seems to be procedural: determining from a medical technical viewpoint what options are available and suitable for the patient given his diagnosis; informing the patient and/or his representative about these options and the patient's condition; awaiting either the patient's (in case of competence) or the representative's (in case of incompetence) decision; and abiding by that decision. However, on further consideration various exceptions showing the "power" of the health care professional, are revealed: in several instances Dutch law, specifically the Contract of medical treatment Act, prescribes the health care professional to exceed her procedural role and to engage in a material evaluation of the patient's interests and behaviour. Let us go into this by checking the chronology of decision-making for patients. For reasons of convenience, we divide the decision-making process into three phases: (1) preparation of the decision by the health care professional, (2) decision-making on behalf of the patient, and (3) implementation of the decision. ${ }^{28}$

\subsubsection{Preparation of the decision by the health care professional}

During the preparatory phase, the health care professional influences the decision-making for patients in advance by selecting the (alternative) interventions that will be proposed and from which the patient or his representative will have to make their choice. Only interventions that make "medical" sense with a view to the individual patient at hand, are eligible for selection. In selecting the interventions, the health care professional will be guided by her professional standard. This standard has a medical aspect: proposed interventions must be in accordance with up-to-date medical scientific knowledge and experience, they must be indicated on medical grounds given the diagnosis of the patient, and they must be proportional in relation to their goal (Leenen \& Gevers, 2000, p. 187, 358; Leenen et al., 2002, p. 31 ff., p. 40 ff.). It also has a nonmedical aspect: proposed interventions must comply with patient rights and "other societal norms" as well (Leenen \& Gevers, 2000, p. 187; Leenen et al., 2002, p. 33). Among other things, this means that the health care professional "should always weigh the pros and cons of medical 
intervention and attempt to achieve the goal with as minimal risk as possible" (Leenen et al., 2002, p. 41). Neither the medical professional standard, nor the concept of medical sense are strictly objective (Leenen et al., 2002, p. 41; Leenen \& Gevers, 2000, p. 359 - respectively). In both, factors that are related to the individual patient and his situation, play a role (Leenen \& Gevers, 2000, p. 360; Leenen et al., 2002, p. 41). The late Dutch health lawyer Leenen remarks that a judgment on medical sense does not pertain to the meaning of the patient's life, but to the meaning of medical intervention (Leenen et al., 2002, p. 40). However, now that the notion of medical sense does not so much relate to the technical question whether an intervention takes any effect, as it does to the question whether a certain effect is desirable in light of the burdens, we are left wondering how these two "senses of meaning" could be distinguished. After all, the aim of medical intervention is to improve the patient's life. It seems evident that in assessing medical sense, considerations about the patient's quality of life - as far as that quality is related to the disease from which the patient is suffering - inevitably matter (Leenen \& Gevers, 2000, p. 359; Legemaate, 1994, p. 336).

Leenen tries to save the alleged medical nature of the concept by stating that judgments about medical sense or about the proportionality of medical interventions in relation to their goal, should be "bound to medical expertise" or that these judgments should "fit into a medical frame of reference" (Leenen et al., 2002, p. 41; Leenen \& Gevers, 2000, p. 360, 359). It is not explained what these qualifications mean. From a material viewpoint, the dividing line between what the health care professional does here on the one hand and what is usually the patient's responsibility on the other, is clearly paperthin, if not absent: quality of life judgments concern the subjective factors in decision-making. In this context, use of the term "medical" mainly has the procedural, policyrelated meaning of leaving the interpretation of the concept to the medical profession (Leenen et al., 2002, p. 33). That is exactly the proposition which is under discussion in this section: the health care professional is - in her capacity as member of the professional group - authorised to judge patient's interests substantively to some extent.

In sum, at least part of the considerations that go under the heading of the professional standard and that are therefore formally in the health care professionals' domain, actually involve judgment of patient interests from a substantive viewpoint. This implies that the health care professional may already have interpreted and evaluated the patient's interests the moment she proposes an intervention (or the moment she decides not to propose any intervention). 


\subsubsection{Decision-making on behalf of the patient}

During the phase of patient decision-making, it has to be decided whether or not the intervention proposed by the health care professional will be undergone by the patient. In this phase too, there are several instances in which the health care professional is expected to interpret the patient's interests and values.

In the first place, most importantly, it has to be determined whether a patient's consent or refusal is legally valid by judging - among other things - the patient's competence. ${ }^{29}$ Besides factual considerations, such a judgment is always characterised by normative considerations (van Delden, 1991, p. 27; van Delden, 1993, p. 88; van de Klippe, 1990, p. 131; Leenen \& Gevers, 2000, p. 216; Legemaate, 1992, p. 192; Vansweevelt et al., 1998, p. 542). Since the health care professional is usually in charge of the competence judgment, her normative views about the concept of competence and about related values and interests of the patient come into play. ${ }^{30}$ On an abstract level, the central norm underlying any judgment of competence is the principle of individual selfdetermination. The health care professional has the task of interpreting what this norm amounts to in regard to each concrete patient. This task can be illustrated by giving some examples, that revert to what we discussed above in relation to criteria of competence and preconditions of competence assessment. The health care professional may attempt operationalising the statutory formulation "able to judge his interests at hand reasonably". Therefore, she must know which patient interests are at stake and what is reasonable for this patient in the first place. The professional may select the criterion from the literature that is right under the circumstances. In order to do that, she must weigh the advantages and disadvantages of the different criteria for the patient in question. The professional may evaluate the quality of the decisionmaking process in the patient. Ideally, the background of such an evaluation is phrased in terms of the patient's values and interests. The professional may want to accept patient assent - maybe with an appeal to the assumption of competence or to the sliding scale - when she thinks that the intervention is beneficial for the patient. The professional may have to judge the proportionality of a verdict of incompetence. That implies assessing whether the benefits expected for the patient from such a verdict, justify the costs attending such a verdict for the patient. All these examples show that the health care professional - as the assessor of competence - will engage in an interpretation of the patient's interests and values. 
Secondly, we saw that some decisions are considered too personal or too drastic to be taken by a representative. Assuming that a patient is incompetent, this raises the question who is going to decide then, now that not doing anything implies a decision as well (Jansen I, 1990, p. 49). It is noted in the literature that the health care professional has a special responsibility in relation to drastic medical interventions, such as sterilisation and abortion (Blankman, 1988, p. 214). This point of view means that in some cases the health care professional is apparently supposed to be able to do what the representative is not allowed to do.

Lastly, a problem may occur in decision-making for incompetent patients when there are several representatives of equal hierarchical status, who have conflicting opinions about the optimal course of treatment for the patient. This possibility could arise if more than one person from the category of close kinsmen presents himself to the health care professional as caretaker of the patient's health care related affairs. The health care professional then has to decide whom of these she will regard as the patient's representative. She might try to solve the problem by asking these persons to designate one of themselves as the main representative. There is a chance that they will not succeed in doing this. In that case the health care professional could attempt a formal solution by getting the persons who are entitled to do so, to start court proceedings with a view to the appointment of a legal representative (art. 1:379 and 1:451 sections 1 and 2 BW for curator and mentor, respectively). She could also resolve the matter herself by selecting one of the patient's family members as the one to consult in decision-making. In doing so, the health care professional would either choose the person supporting the decision that is most favourable to the patient in the professional's mind; or she would choose the person seeming to her to be most committed to promoting the patient's well-being (Koninklijke Nederlandsche Maatschappij tot bevordering der Geneeskunst, 2004, p. 102). In order to come to a selection in such away, the health care professional has to have some idea of the patient's interests that are involved.

A comparable problem comes up if a representative refuses to act on behalf of the patient (cf. art. 7:465 section $3 \mathrm{BW}$ ). In the absence of a substitute decision by somebody else, the health care professional again has to decide herself for the patient. Belgian law makes this aspect of the health care professional's role more explicit by employing the best interests model as a last resort. For that country, the problem is dealt with in art. $14 \S 2$ of the Act concerning the Rights of the patient, relating to the situation in which there is no representative or in which different representatives mutually disagree about what is best for the patient. In 
these circumstances it is the health care professional who has to act as a substitute decision-maker for the patient.

\subsubsection{Implementation of the decision}

During the phase of implementation, that is after the patient or his representative has made his choice, the health care professional has to determine how this choice is to be acted upon. In this phase, the health care professional has both the possibility of disregarding a living will of the patient and the possibility of overruling the incompetent patient's representative. ${ }^{31}$

The ground for doing the latter is given in art. 7:465 section $4 \mathrm{BW}$. This provision states that the health care professional abides by the representative's decision, unless this is incompatible with due professional care (cf. art. 7:453 BW). The health care professional might want to appeal to this provision if there is a conflict between her and the patient's representative, e.g. in that the professional thinks that some intervention is necessary whereas the representative withholds his consent. In the literature, there are differing opinions about how the representative's responsibility and the professional's responsibility relate to each other in that case. One author contends that the representative indeed has the authority to refuse on behalf of the incompetent patient in these matters, as long as he can clearly justify his decision in reference to the views of the patient (van Veen, 1998, p. 51). Another author (one of us) has stated that under these circumstances, the representative does generally not have the authority to refuse giving consent for interventions that would improve the patient's condition or that would prevent a deterioration thereof (van Wijmen, 1990, p. 76).

Whatever the exact interpretation given to this statutory ground (i.e., incompatibility with due professional care), it implies that the standard of due professional care enables the health care professional to judge whether the representative is doing a good job. It is generally recognised that representatives ought to have the values and interests of the patient in mind as their paramount consideration when making substitute decisions (Leenen \& Gevers, 2000, p. 212-213; van Veen, 1998, p. 50; van Wijmen, 1990, p. 46, 63). ${ }^{32}$ Hence, the standard of due professional care also covers an assessment of the patient's values and interests, even if it is only marginal. The interpretation that the standard of due professional care is made up only of the medical professional standard (Leenen \& Gevers, 2000, p. 187), is untenable, unless we acknowledge that this standard covers an evaluation of subjective patient interests as well. This can be shown by distinguishing between two possible situations in which 
the health care professional may want to overrule the patient's representative: either the representative accepts the intervention suggested by the health care professional, or he refuses it. To start with the first situation, saying that performance of the intervention is objectively in conflict with the medical professional standard here, would mean that the health care professional has proposed an option that she should not have proposed in the first place. ${ }^{33}$ In that case, it is the health care professional who is not doing a good job, and not the representative. As to the second possibility, usually, compatibility of an intervention with the medical professional standard means that it is permissible for the health care professional to propose this intervention. Maintaining the opinion that the health care professional can overrule the dissenting representative on the basis of her medical professional standard, would require us to reinterpret this standard as meaning that patients are obliged to undergo the interventions that are in accordance with it. Such a reinterpretation clearly defies the principle of individual self-determination. The conclusion is that for the standard of due professional care to function as a ground for overruling representatives, this standard must include some evaluation of the patient's subjective interests.

Another exception, which has already come up (see Fig. K), can be situated in the phase of implementation. It involves the resisting incompetent patient. We saw that according to Dutch law the health care professional should honour the incompetent patient's resistance against a drastic intervention that is not necessary to prevent serious harm to the patient, even if the patient's representative consented in applying the intervention. All relevant variables in this instance, i.e. drasticalness of the intervention, patient resistance and harm, should be judged from the perspective of the patient. In other words, their judgment requires an interpretation of the patient's interests and behaviour (Koninklijke Nederlandsche Maatschappij tot bevordering der Geneeskunst, 2004, p. 111-112, 121). And it is again the health care professional who is in charge of these judgments. Apparently, the health care professional must weigh what best suits the patient's interests in the end, or rather - negatively - what is less unacceptable in light of these interests: either honouring the patient's resistance and giving up the expected positive consequences of the intervention; or having the intervention occur and throwing coercion into the bargain. One could object that the health care professional is not entirely free in her assessment, since she is only entitled to a limited review of the patient's interests: in all cases where honouring the patient's resistance does not result in a deterioration of the patient's condition below a certain minimum level, the health care professional is obliged to honour the resistance. But even then, 
establishing what this minimum level is for this particular patient, still requires a substantive evaluation of the patient's condition. Thus, the health care professional can bring about - on substantive grounds relating to the interests of the patient - that the incompetent patient is given priority over his representative.

The fact that health care professionals sometimes have the duty and/or the right to overrule representatives, proves that there is an overlap between the domain of the health care professional and the domain of the representative. Once more it turns out that health care professionals may have to take it upon themselves to pass judgment on what is in the personal interest of the individual patient and what is not.

\subsection{DisCUSSION AND CONCLUSIONS}

The above analysis of the Dutch model has shown that in more than one way, the health care professional is expected to be concerned with looking after the patient's substantive health related interests. That is not to say that the health care professional is allowed to make substitute decisions on behalf of the incompetent patient, fully on her own professional authority. But it does mean that the health care professional has to engage in judging the patient's personal interests, even if Dutch law does not use the word representation in relation to this activity. The fact that the health care professional is in the position to judge the patient's competence, in addition to her having the right to shape the decision-making process going from her own (professional) conception of the patient's interests, really makes her the master of the game. What are the practical consequences of this result?

In the first place, this result puts into perspective the difference between representational models (like the Dutch one) on the one hand and best interests models on the other: in both models health care professionals enjoy wide powers in relation to decision-making for incompetent patients. In determining what is good care for an incompetent patient, the Dutch health care professional is not at the mercy of the representative. Rather, she is entitled to put the representative in his place on the basis of her own judgment of the patient's interests. The difference between both kinds of models may really be quite insignificant, presuming that health care professionals operating in jurisdictions characterised by a best interests model, will have to consult family members, friends or other close relatives of the patient too, if need be in order to form an idea of the patient's best interests (Grubb, 1998). It would be interesting to 
investigate what differences between the above-mentioned models really stand up on a functional level, using systematic comparative law analysis of several European models in light of prototypical cases.

Secondly, insofar as the health care professional has the right to make substitute decisions on behalf of a patient, there is no compelling reason to consult a representative for a patient that complies with the health care professional's proposal: had the representative consented, the professional would have followed the representative's decision and performed the proposed intervention; had he not consented, she would have overruled it and performed the proposed intervention anyway. And with that, there is no reason to evaluate a patient's competence: if the patient is competent, his consent is a valid ground for applying the intervention; ${ }^{34}$ if the patient is incompetent, the health care professional's substitute decision legitimises the intervention. In other words, the role of the representative and the relevance of the concept of competence are limited. Although the representative's decisional power is demarcated by that of the health care professional, the latter can all the same profit from the presence of a potential representative by involving this person as a conversation partner in the decision-making process and thus improving the quality thereof. This could justify an obligation for the health care professional of an incompetent patient to hear a representative of the patient, without this obligation implying for the representative a right to decide. By the way, for this course of action, patient incompetence is not a necessary condition. Competent patients often rely on the support of a partner or close family member too in their contacts with health care professionals.

The fact that competence has only limited legal relevance, is not bad news. Acknowledging that the question of competence really matters in specific cases only, increases the chances that clear and consistent criteria can be found for operationalising the concept. Besides, it is in agreement with the assumption of competence, which states that a judgment of a patient's competence should be limited to exceptional cases. Moreover, in such a way the disadvantages that inhere to any criteria of competence, can be restricted to a minimum.

Finally, we should ask ourselves what is the health care professional's basis for judging the patient's personal interests. ${ }^{35}$ From the viewpoint of their disciplinary education or working activities, it is not obvious that just any health care professional has expertise in either assessing or evaluating her patient's beliefs, values, goals, preferences, identity, life story, etc., especially not in these times where super-specialisation is the rule rather than the exception. Our analysis suggests that these judgments 
go under the heading of the professional standard. Are there any professional norms containing guidelines on what is generally in the benefit of patients? If that is the case, these norms ought to be made explicit by the professional group. After all, in a pluralist society, the possibility of general substantive norms is open to discussion; such a discussion can only take place, if we know what norms we are talking about. Leenen says that if it is not sufficiently known what the views of the patient are, patient decision-making should be informed by "what reasonable patients would want in similar circumstances, and what is common practice to do in similar cases" (Leenen \& Gevers, 2000, p. 215). Making explicit professional norms could provide this decisionmaking standard.

It is also possible that the sought-after basis is constituted by the health care professional's knowledge of the individual patient, gained through her interaction with him in the context of the professional relationship (van Veen, 1998, p. 51). If that is the case, this aspect of the relationship deserves more attention both in the legal and ethical debate, and in professional education (Pellegrino, 1978). ${ }^{36}$ A practical instrument that may be helpful here is the so-called values history (Beijk-Damen, 1997; Lambert, Gibson, \& Nathanson, 1990; Widdershoven GAM \& Berghmans, 2004). This is a form with several areas of interest, subdivided into specific questions. It can assist representatives and health care professionals alike in substitute decision-making for the patient. Ideally, the form is filled in by the patient as he is still competent; otherwise, an intimate of the patient has to do it, after the latter has become incompetent. Various versions of values history forms differ as to the concreteness of the items they contain. But they all aim at reconstructing and/or reflecting the person's values and preferences. The questions mostly pertain to non-medical issues, e.g. the patient's trust in medicine, unfinished business from the past in personal relationships, enjoyable activities, achievements in life, fears, attitudes toward dying and death, and religious background and beliefs. It is also possible to utilise these forms as guidance in consultations amongst the health care professional and the patient himself - and possibly a close family member of the patient - with a view to exploring the patient's values that are important in light of a decision to be made. ${ }^{37}$ The values history is reported to be "an effective initiator of conversation about subjects that are difficult to contemplate even when a person is healthy", and it "should aid in promoting an honest and informed physician-patient dialogue" (Lambert et al., 1990). Such use of the form is in line with interpretive and deliberative models of the relationship between patient and health care professional (Emanuel EJ \& Emanuel LL, 1992). 
To conclude, our analysis suggests that critical research into the concept of competence must address not only the issue of criteria for competence, but also the question of health care professionals' substantive values and norms and their legal and ethical justification. These values and norms play a role both in competence assessment and in medical substitute decision-making.

\subsection{NoTES}

1. Wet Bijzondere opnemingen in psychiatrische ziekenhuizen; Wet van 29 oktober 1992, Stb. 1992, 669 (changed several times since). This statute pertains to involuntary commitment of psychiatric patients, mentally retarded and demented persons. It replaces the Lunatics Act, which dated from 1884. Its provisions relate both to the conditions and procedures for involuntarily admission (so-called external legal position) and to the legal position of the involuntarily committed patient once he stays in the hospital (internal legal position). See http://www.minvws.nl/en/folders/gvm/psychiatric-hospitals-compulsor $\mathrm{y}$-admissions-act.asp for more information about this statute.

2. Wet op de Geneeskundige-behandelingsovereenkomst; Wet van 17 November 1994, Stb. 1994, $837 \mathrm{j}^{\circ}$ 838. It takes up the articles 446-468 of book $7 \mathrm{BW}$. For an (unofficial) full text translation in English see http://www.healthlaw.nl/index $2 . h t m l$ under "Provisions concerning the contract to provide medical treatment".

3. Wet op de Orgaandonatie; Wet van 24 mei 1996, Stb. 1996, 370.

4. Wet Medisch-wetenschappelijk onderzoek met mensen;W et van 26 februari 1998, Stb. 1998, 161.

5. Its official title is Termination of life on request and assisted suicide (review procedures) Act. Wet Toetsing levensbeëindiging op verzoek en hulp bij zelfdoding; Wet van 12 April 2001, Stb. 2001, 194. For an official full text translation in English see http://www.minbuza.nl/english/ under "Ethical Issues", "Ethical Issues", "Euthanasia Policy".

6. Numerous examples from outside the area of health law can be found in the law on persons and family (competence to get married), juvenile law (competence to have the legal custody of a child), patrimonial law (competence to perform non-annullable juridical acts), law of 
succession (competence to make a will), and law of property and obligations (competence to manage and dispose of property).

7. In order to enhance the readability of this chapter, masculine pronouns will be systematically used to refer to patients or their representatives, and feminine pronouns to refer to health care professionals.

8. See note 7 .

9. Cf. the Belgian Act concerning the Rights of the patient (Wet betreffende de Rechten van de patiënt) of 22 August 2002 (Publication: 26 September 2002).

10. The terms involved are not used in a uniform way by different authors or in different jurisdictions. Sometimes the term "competence" relates to a formal legal label. Other authors may prefer the terms "mental capacity" or "decisional capacity" for what we call competence. It is a question of definition which term is used for which meaning.

11. See sub-section 7.5.2 of this chapter.

12. Persons not having legal capacity will be referred to as "legally incapable"; persons having such capacity will be referred to as "legally capable".

13. An exception which is relevant here, is made in art. 7:447 $\mathrm{BW}$. This provision declares minors aged 16 or older to have legal capacity regarding contracts of medical treatment for themselves.

14. The rule that persons placed under curatele do not have legal capacity, has exceptions as well (see e.g. art. 1:381 sections 3 and 6 and $382 \mathrm{j}^{\circ}$ 1:37 BW). These exceptions will not be discussed.

15. See section 7.6.

16. See also principles 3.2, 6 and 22 from Recommendation No. R (99) 4 of the Committee of Ministers of the Council of Europe to Member States on Principles Concerning the Legal protection of incapable adults.

17. The Mentorship for majors Act (1994) (Wet op het Mentorschap; Wet van 29 September 1994, Stb. 1994, 757) is, like the Contract of medical treatment Act, part of the Dutch Civil Code. It takes up the articles 450-462 of book $1 \mathrm{BW}$. Because of possible differences with guardianship, the transliteration mentorship is used. 
18. There is a third judicial measure, namely placement under administration ("onderbewindstelling"). This measure is the financial variant of mentorship: it pertains exclusively to financial matters (art. 1:431 BW). Placement under administration does not play any role in the present exposition.

19. In the other statutes mentioned in section 7.2, several concrete thirdparty interests explicitly come into play and may compete with the interests of the patient. These third-party interests concern danger to other persons or to the general safety of persons and property (Special Admissions into Psychiatric Hospitals Act), the need of organs for other patients in a health care system where the available organs are scarce (Organ donation Act), progress in scientific knowledge (Medicalscientific research on human subjects Act), and the importance of civil order and a careful administration of criminal justice (Euthanasia Act). Therefore, these statutes contain all kinds of nuances and qualifications, like notification and other obligatory procedures, restrictions of the circle of possible representatives, necessary formalities, and further material standards of what interventions can and cannot legitimately take place.

20. See sub-section 7.3.2. By the way, for minors, it concerns their parents or guardians.

21. At this point, no attention will be paid to complicating factors, such as the situation of time emergency, the presence of a preceding living will of the patient, or the health care professional's own professional responsibility toward the patient.

22. An exception to this rule occurs when following the representative's decision would bring the health care professional in conflict with the standard of "due professional care". This exception - and its implications - will be further investigated later, in sub-section 7.7.3.

23. See sub-section 7.4.1.

24. In section 7.6 we will see that this is in conflict with one of the preconditions of competence assessment, namely the third one.

25. The term "cognitive" is used as an umbrella concept here, including both intellectual and emotional aspects.

26. Cf. also Wong, Clare, Holland, Watson, \& Gunn (2000); Wong, Clare, Gunn, \& Holland (1999). 
27. See sub-section 7.3.2.

28. The construction of three phases may be a bit artificial. Its purpose is not describing the actual decisional processes, but clarifying the presentation of exceptions.

29. These other things being the adequacy of the provided information and the voluntariness of the patient's choice (cf. sub-section 7.4.3).

30. It is interesting to question whose judgment ought to cut the knot, when the health care professional and the (legal) representative have conflicting judgments on the patient's competence.

31. According to the law, the health care professional may deviate from the patient's living will "if [s] he deems that there are good reasons for so doing" (art. 7:450 section $3 \mathrm{BW}$ ). We will not go into the question what reasons are eligible for concretising this open norm. Art. 7:466 section $1 \mathrm{BW}$ states that in cases of time emergency where there is no time for consulting a representative, the health care professional is entitled to apply without consent interventions to the incompetent patient that are urgently necessary to prevent serious harm to the patient. By stating that interventions can take place "without consent", the law strangely suggests that no consent is needed at all. But if consent is not required, withholding consent is not relevant either. That would wrongly mean that a living will has no significance in such a situation. Therefore, from a systematic legal point of view, a preferable formulation would be that in those cases the health care professional is entitled to assume consent for the necessary interventions, as assumptions are open to refutation. Then it would immediately be clear that a negative living will can be a valid reason for not starting treatment in an emergency situation.

32. Cf. art. 7:465 section $5 \mathrm{BW}$, which contains the legal duty for representatives to act as "a good representative".

33. See sub-section 7.7.1.

34. Again, provided that the health care professional has supplied sufficient and clear information and that no undue influence has been exercised upon the patient (cf. note 29).

35. Cf. Engberts (1997, p. 329-331). 
36. Cf. Strategy 6.4 in Recommendation No. Rec(2006)18 of the Committee of Ministers of the Council of Europe (Committee of Ministers of the Council of Europe, 2006).

37. Hermans' self-confrontation method (Hermans, 1983; Hermans, 1990), Garland and Garland's Life review (Garland \& Garland, 2001), and Wilson and Groom's Valued Living Questionnaire (Wilson, 2006; Wilson \& Groom, 2002) might also be of interest in this regard. 


\section{BIBLIOGRAPHY}

Abernethy, V. (1984). Compassion, control, and decisions about competency. American Journal of Psychiatry, 141(1), 53-58.

Additional Protocol to the Convention for the Protection of Human Rights and Dignity of the Human Being with regard to the Application of Biology and Medicine, on Biomedical Research (Adopted by the Committee of Ministers on 30 June 2004 at the 890th meeting of the Ministers' Deputies). (2004). URL http://www.coe.int/T/E/Legal_Affairs/Legal_cooperation/Bioethics/Activities/Biomedical_research/Protocol_Biome dical_research.pdf.

Advisory Committee on Human Radiation Experiments. (1995). ACHRE Report - Executive Summary: URL

http://tis.eh.doe.gov/ohre/roadmap/achre/summary.html (consulted on June $\left.17^{\text {th }} 2004\right)$.

Agich, G. J. (1990). Reassessing autonomy in long-term care. Hastings Center Report, 20(6), 12-17.

Alexander, M. P. (1988). Clinical determination of mental competence: A theory and a retrospective study. Archives of Neurology, 45(1), 2326.

Algra, N. E., Gokkel, H. R. W., \& Klijn, C. A. W. (2001). Fockema Andreae's Verwijzend en Verklarend Juridisch Woordenboek (twaalfde druk). Groningen: Martinus Nijhoff.

American Medical Association. (1978). Code of Ethics. In W. T. Reich (Ed.), Encyclopedia of Bioethics (Vol. 4, Appendix, pp. 1738-1746). New York/London: The Free Press/Collier Macmillan Publishers. American Psychiatric Association. (1994). Diagnostic and Statistical Manual of Mental Disorders IV $V^{T M}$ (Fourth Edition). Washington, D.C.: American Psychiatric Association.

American Psychological Association. (2002a). Ethical Principles of Psychologists and Code Of Conduct: URL http://www.apa.org/ethics/code2002.pdf (consulted on May $30^{\text {th }}$ 2007).

American Psychological Association. (2002b). Guidelines on Multicultural Education, Training, Research, Practice, and Organizational Change for Psychologists: URL http://www.apa.org/pi/multiculturalguidelines.pdf (consulted on May $\left.27^{\text {th }} 2007\right)$. 
Annas, G. J., \& Grodin, M. A. (Eds.). (1992). The Nazi doctors and the Nuremberg Code: Human rights in human experimentation. New York/Oxford: Oxford University Press.

Appelbaum, P. S. (1998). Ought we to require emotional capacity as part of decisional competence? Kennedy Institute of Ethics Journal, 8(4), 377-387.

Appelbaum, P. S., \& Grisso, T. (1988). Assessing patients' capacities to consent to treatment. New England Journal of Medicine, 319(25), 1635-1638. [published erratum appears in New England Journal of Medicine, 1989;320(11):748]

Appelbaum, P. S., \& Grisso, T. (1995). The MacArthur Treatment Competence Study. I: Mental illness and competence to consent to treatment. Law and Human Behavior, 19(2), 105-126.

Appelbaum, P. S., \& Grisso, T. (1997). Capacities of hospitalized, medically ill patients to consent to treatment. Psychosomatics, 38(2), 119-125.

Appelbaum, P. S., \& Grisso, T. (2001). MacArthur competence assessment tool for clinical research (MacCAT-CR). Sarasota, FL: Professional Resource Press/Professional Resource Exchange. Appelbaum, P. S., Lidz, C. W., \& Meisel, A. M. (1987). Informed Consent: Legal Theory and Clinical Practice. New York: Oxford University Press.

Appelbaum, P. S., Mirkin, S. A., \& Bateman, A. L. (1981). Empirical assessment of competency to consent to psychiatric hospitalization. American Journal of Psychiatry, 138(9), 1170-1176.

Appelbaum, P. S., \& Roth, L. H. (1981). Clinical issues in the assessment of competency. American Journal of Psychiatry, 138(11), 14621467.

Appelbaum, P. S., \& Roth, L. H. (1982). Competency to consent to research: A psychiatric overview. Archives of General Psychiatry, 39(8), 951-958.

Appelbaum, P. S., Roth, L. H., \& Lidz, C. W. (1982). The therapeutic misconception: informed consent in psychiatric research. International Journal of Law and Psychiatry, 5, 319-329.

Appelbaum, P. S., Roth, L. H., Lidz, C. W., Benson, P., \& Winslade, W. (1987). False hopes and best data: consent to research and the therapeutic misconception. Hastings Center Report, 17(2), 20-24.

Armstrong, A. H. (1957/1977/1989). An Introduction to Ancient Philosophy (third edition): Littlefield Adams Quality Paperbacks.

Ashworth Underwood, E. (1991). Hippocrates: Encyclopædia Britannica. Retrieved June 9, 2005, from Encyclopædia Britannica Online. URL http://www.search.eb.com/eb/article?tocId=3220. 
Atkinson, R. L., Hilgard, E., \& Smith, C. D. (2000). Hilgard's Introduction to Psychology (Thirteenth Edition). Fort Worth, Tex: Harcourt College Publishers.

Backlar, P. (1998). Anticipatory planning for research participants with psychotic disorders like schizophrenia. Psychology, Public Policy, and Law, 4(3), 829-853.

Ballard-Reisch, D. S. (1990). A model of participative decision making for physician-patient interaction. Health Communication, 2(2), 91104.

Bean, G., Nishisato, S., Rector, N. A., \& Glancy, G. (1996). The assessment of competence to make a treatment decision: an empirical approach. Can J Psychiatry, 41(2), 85-92.

Beauchamp, T. L. (1991). Competence. In M. A. G. Cutter \& E. E. Shelp (Eds.), Competency: a study of informal competency determinations in primary care (Vol. 39, pp. 49-77). Dordrecht/Boston/London: Kluwer Academic Publishers.

Beauchamp, T. L., \& Childress, J. F. (1994). Principles of Biomedical Ethics (Fourth Edition). New York/Oxford: Oxford University Press.

Bechara, A., Damasio, H., Tranel, D., \& Damasio, A. R. (1997). Deciding advantageously before knowing the advantageous strategy. Science, 275(5304), 1293-1295.

Beecher, H. K. (1966). Ethics and clinical research: special article. New England Journal of Medicine, 274(24), 1354-1360.

Begeleidingscommissie evaluatie Wet Bopz. (2002). Evaluatie Wet bijzondere opnemingen in psychiatrische ziekenhuizen 10: Conclusies en aanbevelingen van de begeleidingscommissie. Den Haag: ZonMw.

Beijk-Damen, T. (1997). Het levensverhaal van mensen met een verstandelijke handicap: Hoe krijgen we het op schrift? Hoe laten we het verder leven? Dwingeloo: Kavanah.

Bensing, J. M. (1998). De arts-patiënt relatie: bron van genezing en frustratie. In C. W. Aakster \& J. W. Groothoff (Eds.), Medische Sociologie: sociologische perspectieven op ziekte en zorg (vijfde geheel herziene druk, pp. 122-129). Groningen: Wolters-Noordhoff.

Berghmans, R., Welie, S., \& Widdershoven, G. (2004). Nieuwe ethische benaderingen in de geestelijke gezondheidszorg. In F. Boersma \& A. Vellinga (Eds.), Oud en dement: wilsonbekwaam? (Symposiumverslag 2003) (pp. 37-48). Amsterdam: Leo Cahn stichting/Lundbeck.

Berghmans, R. L. P. (1992). Om Bestwil, Paternalisme in de Psychiatrie: een gezondheidsethische studie. Amsterdam: Thesis Publishers.

Berghmans, R. L. P. (1995). The double standard: comparison of ethical problems and standards in research and practice with demented 
patients. In M. Bergener, J. C. Brocklehurst \& S. I. Finkel (Eds.), Aging, health, and healing (pp. 511-521). New York: Springer Publishing Company.

Berghmans, R. L. P. (1998). Advance directives for non-therapeutic dementia research: some ethical and policy considerations. Journal of Medical Ethics, 24(1), 32-37.

Berghmans, R. L. P. (1999). Informed consent for psychiatric research: the case of medication-free research. Medicine and Law, 18, 515-524. Berghmans, R. L. P. (2000). Bekwaam genoeg? Wils(on)bekwaamheid in geneeskunde, gezondheidsrecht en gezondheidsethiek (Preadvies uitgebracht ten behoeve van de jaarvergadering van de Nederlandse Vereniging voor Bio-ethiek, op 23 juni 2000). Utrecht: Nederlandse Vereniging voor Bio-ethiek.

Berghmans, R. L. P. (2001). Capacity and consent. Current Opinion in Psychiatry, 14, 491-499.

Bergkamp, L. (1988). Het proefdier mens: de normering en regulering van medische experimenten met mensen [The human guinea pig: the standardisation and regulation of medical experiments with humans]. Alphen aan den Rijn: Samsom.

Berlin, I. (1969). Four Essays on Liberty. Oxford/New York: Oxford University Press.

Bernstein, D. A., Clarke-Stewart, A., Roy, E. J., \& Wickens, C. D. (1997). Psychology (4th ed.). Boston: Houghton Mifflin.

Bielby, P. (2005). The conflation of competence and capacity in English medical law: A philosophical critique. Medicine, Health Care and Philosophy, 8(3), 357-369.

Biesaart, M. C., \& Hubben, J. H. (1999). Incompetence in practice in health care in the Netherlands: report of a study. Journal of Intellectual Disability Research, 43(Pt 6), 454-460.

Biesaart, M. C. I. H., Hubben, J. H., \& Gemert, G. H. van (2000). Methodiek voor de vaststelling van wilsonbekwaamheid bij mensen met een verstandelijke handicap: verslag van een onderzoek verricht met steun van Stichting Philadelphia Zorg en Vereniging Gehandicaptenzorg Nederland. Nunspeet/Utrecht: Stichting Philadelphia Zorg/Vereniging Gehandicaptenzorg Nederland.

Biesaart, M. C. I. H., Hubben, J. H., Gemert, G. H. van, \& Oostra, J. J. (1997). Beoordeling van wilsonbekwaamheid bij mensen met een verstandelijke handicap. Nijmegen/Nunspeet/Lelystad: Faculteit der Rechtsgeleerdheid - Katholieke Universiteit Nijmegen/Stichting Philadelphia Zorg/Koninklijke Vermande (ISBN 90-75585-07-1).

Bijma, M. W., \& Hutschemaekers, G. J. M. (2007). Samenwerken voor minder dwang: een onderzoek naar de bijdrage van familie-en 
systeemleden aan het verminderen van dwangtoepassing. Maandblad Geestelijke volksgezondheid, 62(9), 734-743.

Black, H. C., Nolan, J. R., \& Nolan-Haley, J. M. (1990). Black's Law Dictionary: Definitions of the Terms and Phrases of American and English Jurisprudence, Ancient and Modern (sixth edition). St. Paul, Minn.: West Publishing Co.

Blankman, K. (1988). Mentorschap; een omstreden wetsvoorstel. Tijdschrift voor Gezondheidsrecht, 12(4), 202-222.

Blankman, K. (1990). De behandelingsovereenkomst en de onbekwame meerderjarige. Familie- en Jeugdrecht(7), 162-164.

Blankman, K. (1994). Curatele voor personen met een geestelijke stoornis en bescherming op maat. Zwolle: W.E.J. Tjeenk Willink.

Blankman, K. (1995). Mentorschap en vertegenwoordiging van wilsonbekwamen in niet-vermogensrechtelijke aangelegenheden. Tijdschrift voor Familie- en Jeugdrecht(3/4), 84-87.

Blankman, K. (2003). Psychiatrie en Recht: Rechtsbescherming bij vrijheidsbeneming in de sectoren verstandelijk gehandicaptenzorg en psychogeriatrie (Preadvies uitgebracht ten behoeve van de jaarvergadering van de Vereniging voor Gezondheidsrecht op 11 april 2003): Vereniging voor Gezondheidsrecht.

Bloom, S. W. (1995). Professional-patient relationship II. Sociological perspectives. In W. T. Reich (Ed.), Encyclopedia of Bioethics (revised edition, Vol. 4, pp. 2084-2094). New York/London: MacMillan.

Boer, T. d. (1980). Grondslagen van een kritische psychologie. Baarn: Ambo.

Boer, T. d. (1983). Foundations of a Critical Psychology. Pittsburgh, PA: Duquesne University Press.

Brahn, O. K., \& Reehuis, W. H. M. (1993). Zwaartepunten van het vermogensrecht: een introductie (Vijfde herziene druk). Arnhem: S. Gouda Quint -D. Brouwer en Zoon.

Bravo, G., Dubois, M.-F., \& Pâquet, M. (2003). Advance directives for health care and research. Alzheimer Disease and Associated Disorders, 17(4), 215-222.

British Medical Association, \& Law Society. (2004). Assessment of mental capacity: guidance for doctors and lawyers (2nd ed.). London: BMJ Books.

Brown, R. (1986). Social Psychology (The Second Edition). New York/London: Free Press/Macmillan.

Bruggink, J. J. H. (1993). De rechtsvrije ruimte. In A. R. J. Groot \& H. J. L. M. v. d. Luytgaarden (Eds.), Zonder meer recht (pp. 263-290). Zwolle: W.E.J. Tjeenk Willink. 
Buchanan, A. E., \& Brock, D. W. (1989). Deciding for Others: The Ethics of Surrogate Decision Making. Cambridge/New York: Cambridge University Press.

Buchanan, A. E., \& Brock, D. W. (1990). Deciding for Others: The Ethics of Surrogate Decision Making: Cambridge University Press.

Burg, W. v. d., \& Oevermans, H. (1994). Grondrechten in het gezondheidsrecht: beperkingen van de gangbare grondslagenbenadering. In W. v. d. Burg \& P. Ippel (Eds.), De Siamese Tweeling: recht en moraal in de biomedische praktijk (pp. 187-202). Assen: Van Gorcum.

Bürgerliches Gesetzbuch [German Civil Code]. URL http://bundesrecht.juris.de/bundesrecht/bgb/.

Bursztajn, H. J., Harding, H. P., Jr., Gutheil, T. G., \& Brodsky, A. (1991). Beyond cognition: the role of disordered affective states in impairing competence to consent to treatment. Bull Am Acad Psychiatry Law, 19(4), 383-388.

Burt, R. A. (1996). The suppressed legacy of Nuremberg. Hastings Center Report, 26(5), 30-33.

Callahan, S. (1988). The role of emotion in ethical decision making. Hastings Center Report, 18(June/July), 9-14.

Capron, A. M. (1999). Ethical and human rights issues in research on mental disorders that may affect decision-making capacity. New England Journal of Medicine, 18, 1430-1434.

Carlson, N. R., Buskist, W., \& Martin, G. N. (2000). Psychology: The Science of Behaviour (European Adaptation). Harlow: Pearson Education Limited.

Carpenter, W. T., Gold, J. M., Lahti, A. C., Queern, C. A., Conley, R. R., Bartko, J. J., et al. (2000). Decisional capacity for informed consent in schizophrenia research. Archives of General Psychiatry, 57(6), 533-538.

Carpenter, W. T., Jr., Appelbaum, P. S., \& Levine, R. J. (2003). The Declaration of Helsinki and clinical trials: a focus on placebocontrolled trials in schizophrenia. American Journal of Psychiatry, 160(2), 356-362.

Carpenter, W. T., Jr., Schooler, N. R., \& Kane, J. M. (1997). The rationale and ethics of medication-free research in schizophrenia. Archives of General Psychiatry, 54(5), 401-407.

Charland, L. C. (1998a). Appreciation and emotion: theoretical reflections on the MacArthur Treatment Competence study. Kennedy Institute of Ethics Journal, 8(4), 359-376.

Charland, L. C. (1998b). Is Mr. Spock mentally competent? Competence to consent and emotion. Philosophy, Psychiatry, \& Psychology, 5(1), 67-81. 
Charland, L. C. (1998c). Response to the commentaries on "Is Mr. Spock mentally competent? Competence to consent and emotion".

Philosophy, Psychiatry, \& Psychology, 5(1), 93-95.

Charney, D. S., Nemeroff, C. B., Lewis, L., et al.. (2002). National

Depressive and Manic-Depressive Association Consensus Statement on the use of placebo in clinical trials of mood disorders. Archives of General Psychiatry, 59, 262-270.

Charter of fundamental rights of the European Union (Nice, 7 December 2000). (2000). Official Journal of the European Communities (of 18 December 2000), 2000/C 364 (Volume 43); URL http://eurlex.europa.eu/en/index.htm.

Charter of fundamental rights of the European Union (Strasbourg, 12 December 2007). (2007). Official Journal of the European Communities (of 14 December 2007), 2007/C 303 (Volume 50); URL http://eur-lex.europa.eu/en/index.htm.

Checkland, D., \& Silberfeld, M. (1995). Reflections on segregating and assessing areas of competence. Theoretical Medicine, 16(4), 375388.

Checkland, D., \& Silberfeld, M. (1996). Mental competence and the question of beneficent intervention. Theoretical Medicine, 17, 121134.

Cohen, L. M., McCue, J. D., \& Green, G. M. (1993). Do clinical and formal assessments of the capacity of patients in the intensive care unit to make decisions agree? Arch Intern Med, 153(21), 2481-2485.

Combrink-Kuiters, L. (2000). Is recht meetbaar en voorspelbaar? Jurimetrie. Nederlands Juristenblad, 75(3), 151-155.

Comité Consultatif National d'Ethique pour les sciences de la vie et de la santé [French National Consultative Bioethics Committee for health and life sciences]. (1998). Avis $\mathrm{N}^{\circ} 58$ daté du 12 juin 1998 "Consentement éclairé et information des personnes qui se prêtent à des actes de soin ou de recherche" [Opinion number 58 dated June $12^{\text {th }}, 1998$ "Informed consent of and information to persons accepting care or research procedures"]: URL http://www.ccne-ethique.fr/.

Committee of Ministers of the Council of Europe. (1999a). Explanatory Memorandum to Recommendation No. R (99) 4 of the Committee of Ministers to Member States on Principles concerning the Legal Protection of Incapable Adults: URL http://www.coe.int/T/CM/adoptedTexts_en.asp.

Committee of Ministers of the Council of Europe. (1999b).

Recommendation No. R (99) 4 of the Committee of Ministers to Member States on Principles concerning the Legal Protection of Incapable Adults: URL http://www.coe.int/T/CM/adoptedTexts_en.asp. 
Committee of Ministers of the Council of Europe. (2004).

Recommendation No. Rec(2004)10 of the Committee of Ministers to member States concerning the protection of the human rights and dignity of persons with mental disorder: URL http://www.coe.int/T/E/Legal_affairs/Legal_cooperation/Bioethics/News/Rec(2004)10\%20e.pdf.

Committee of Ministers of the Council of Europe. (2006).

Recommendation No. Rec(2006)18 of the Committee of Ministers to member states on health services in a multicultural society: URL https://wcd.coe.int/ViewDoc.jsp?id=1062769\&BackColorInternet $=9$ 999CC\&BackColorIntranet=FFBB55\&BackColorLogged=FFAC75 (consulted on May $27^{\text {th }} 2007$ ).

Contract of medical treatment Act ("Wet op de geneeskundigebehandelingsovereenkomst") - addition to the Dutch Civil Code $=$ Burgerlijk Wetboek $=\mathrm{BW}$, taking up the articles 446-468 of book 7 BW (Wet van 17 November 1994, Stb. 1994, 837 jo 838). (1994).

Convention for the protection of Human Rights and dignity of the human being with regard to the application of Biology and Medicine (Convention on Human Rights and Biomedicine) - treaty in the framework of the Council of Europe. (1997). CETS No.: 164; URLhttp://conventions.coe.int/Treaty/en/Treaties/Html/164.htm.

Convention of 13 January 2000 on the International Protection of Adults treaty in the framework of the Hague Conference on Private International Law. (2000). Conventions HCCH No.: 35; URL http://www.hcch.net/index_en.php.

Council for International Organizations of Medical Sciences. (2002). International Ethical Guidelines for Biomedical Research Involving Human Subjects. Geneva: URL http://www.cioms.ch/guidelines_nov_2002_blurb.htm.

Cournos, F. (1993). Do psychiatric patients need greater protection than medical patients when they consent to treatment? Psychiatric Quarterly, 64(4), 319-329.

Creswell, J. W. (2003). Research Design: Qualitative, Quantitative, and Mixed Methods Approaches (2nd ed.). Thousand Oaks/London/New Delhi: Sage.

Crombag, H. F. M. (1981). Mens Rea. Zwolle: W.E.J. Tjeenk Willink. Crombag, H. F. M. (2002). Over opzet en schuld. In P. J. van Koppen, D. J. Hessing, H. L. G. J. Merckelbach \& H. F. M. Crombag (Eds.), Het Recht van Binnen: psychologie van het recht (pp. 737-760). Deventer: Kluwer.

Crombag, H. F. M., Koppen, P. J. van, \& Wagenaar, W. A. (1994). Dubieuze Zaken: De psychologie van strafrechtelijk bewijs. Amsterdam/Antwerpen: Uitgeverij Contact. 
Crombag, H. F. M., Wijkerslooth, J. L. de, \& Cohen, M. J. (1977). Een theorie over rechterlijke beslissingen. Groningen: H.D. Tjeenk Willink.

Culver, C. M., \& Gert, B. (1990). The inadequacy of incompetence. Milbank Quarterly, 68(4), 619-643.

Cuneiform Law. (2004). In Encyclopcedia Britannica Online: http://www.search.eb.com/eb/article?eu=28660 (retrieved on September $\left.13^{\text {th }} 2004\right)$.

Damasio, A. R. (1994). Descartes' error and the future of human life. Scientific American, 271(4), 144.

Damasio, A. R. (1995). Descartes' error: emotion, reason and the human brain. New York: Avon books.

Daugherty, C., Ratain, M. J., Grochowski, E., Stocking, C., Kodish, E., Mick, R., et al. (1995). Perceptions of cancer patients and their physicians involved in phase I trials. Journal of Clinical Oncology, 13(5), 1062-1072.

Davison, G. C., \& Neale, J. M. (1990). Abnormal psychology (Fifth Edition). New York/Chichester/Brisbane/Toronto/Singapore: John Wiley \& Sons.

Dawes, R. M., Faust, D., \& Meehl, P. E. (1989). Clinical versus actuarial judgment. Science, 243, 1668-1674.

Delden, J. J. M. van (1991). Het nalaten van medische behandelingen bij meerderjarige wilsonbekwame mensen (no. A91/4). Den Haag: Gezondheidsraad.

Delden, J. J. M. van (1993). Beslissen om niet te reanimeren: een medisch en ethisch vraagstuk. Assen: van Gorcum.

DeMarco, J. P. (2002). Competence and paternalism. Bioethics, 16(3), 231-245.

Department for Constitutional Affairs. (2003). Draft Mental Incapacity Bill: http://www.lcd.gov.uk/menincap/legis.htm (consulted on August 1st 2003).

Department for Constitutional Affairs. (2004 (June)). Mental Capacity Bill - English bill: URL http://www.dca.gov.uk/menincap/legis.htm (consulted on December 30th 2004).

Derde evaluatiecommissie van de Wet Bopz. (2007). Evaluatierapport: Voortschrijdende inzichten... (Deel 1). Den Haag: Ministerie van Volksgezondheid, Welzijn en Sport.

DeRenzo, E. G., Conley, R. R., \& Love, R. (1998). Assessment of capacity to give consent to research participation: state-of-the-art and beyond. Journal of Health Care Law and Policy, 1(1), 66-87.

Diamond, E. L., Jernigan, J. A., Moseley, R. A., Messina, V., \& McKeown, R. A. (1989). Decision-making ability and advance directive preferences in nursing home patients and proxies. $21 \mathrm{st}$ 
Annual Spring Conference of the Society of Teachers of Family Medicine (1988, Baltimore, Maryland). Gerontologist, 29(5), 622626.

Dijkers, W., \& Widdershoven, T. P. (Eds.). (2002). De Wet Bopz: Artikelsgewijs commentaar (losbladig). Den Haag: Koninklijke Vermande.

Dillmann, R., \& Legemaate, J. (1992). Ethiek, recht en dementie. Maandblad voor de Geestelijke volksgezondheid, 47(7/8), 827-846.

Donker, M. C. H. (1992). Gestoord burgerschap: Een beschouwing over het burgerschap van psychiatrische patiënten. In H. R. v. Gunsteren \& P. d. Hoed (Eds.), Burgerschap in Praktijken (Vol. V77, pp. 159193). Den Haag: SDU Uitgevers.

Drane, J. F. (1984). Competency to give an informed consent. A model for making clinical assessments. Journal of the American Medical Association, 252(7), 925-927.

Drane, J. F. (1985). The many faces of competency. Hastings Center Report, 15(2), 17-21.

Drenth, P. J. D., \& Sijtsma, K. (1990). Testtheorie : inleiding in de theorie van de psychologische test en zijn toepassingen. Houten [etc.]: Van Loghum Slaterus.

Dresser, R. (2000). Advance research directives: implementation issues. Journal of the American Geriatrics Society, 48(7), 859-860.

Dresser, R. S. (1999). Research involving persons with mental disabilities: a review of policy issues and proposals. In National Bioethics Advisory Commission (Ed.), Research involving persons with mental disorders that may affect decision making capacity. Commissioned papers (pp. 5-28). Rockville, Maryland: NBAC.

Dupuis, H., M. (1994). Wel of niet behandelen? Baat het niet, dan schaadt het wél. Baarn: Ambo.

Dupuis, H. M., \& Beaufort, I. D. de (1988). Informed consent. In I. D. de Beaufort \& H. M. Dupuis (Eds.), Handboek Gezondheidsethiek (pp. 217-226). Assen/Maastricht: Van Gorcum.

Dute, J. C. J. (2000). Hoofdlijnen van de regulering van de gezondheidszorg. In J. C. J. Dute \& H. E. G. M. Hermans (Eds.), Regulering van de gezondheidszorg: leerboek voor universitair en hoger beroepsonderwijs en managementopleidingen (pp. 15-38). Maarssen:

Elsevier Gezondheidszorg.

Dute, J. C. J., Friele, R. D., Gevers, J. K. M., Hubben, J. H., Legemaate, J., Roscam Abbing, H. D. C., et al. (Eds.). (2000). Evaluatie Wet op de geneeskundige behandelingsovereenkomst (Vol. 3). Den Haag: ZorgOnderzoek Nederland.

Dworkin, G. (1982). G: Autonomy and Informed Consent. In President's Commission for the Study of Ethical Problems in Medicine and 
Biomedical and Behavioral Research (Ed.), Making Health Care Decisions: A Report on the Ethical and Legal Implications of Informed Consent in the Patient-Practitioner Relationship (Volume Three: Appendices - Studies on the Foundations of Informed Consent, pp. 63-81). Washington, DC: U.S. Government Printing Office.

Dworkin, G. (1988). The Theory and Practice of Autonomy. Cambridge/New York/New Rochelle: Cambridge University Press.

Eckstein, S. (2003). Research involving vulnerable participants: some ethical issues. In S. Eckstein, B. Farsides, J. Glover, J. Lamberty, O. O'Neill \& D. Wikler (Eds.), Manual for Research Ethics Committees (6th ed., pp. 105-109): Cambridge University Press.

Elliott, C. (1991). Competence as accountability. The Journal of Clinical Ethics, 2(3), 167-171.

Elliott, C. (1998). Commentary on "Is Mr. Spock mentally competent?" Philosophy, Psychiatry, \& Psychology, 5(1), 87-88.

Emanuel, E. J., \& Emanuel, L. L. (1992). Four models of the physicianpatient relationship. Journal of the American Medical Association, 267(16), 2221-2226.

Emanuel, E. J., \& Emanuel, L. L. (1996). What is accountability in health care? Annals of Internal Medicine, 124(2), 229-239.

Engberts, D. P. (1997). Met permissie: morele argumentaties inzake het toestemmingsbeginsel bij de totstandkoming van de Wet Geneeskundige Behandelings-Overeenkomst. Deventer: Kluwer.

Engelhardt, H. T. (1986). The foundations of bioethics (1 ed.). New York: Oxford University Press.

Erde, E. L. (1991). Breaking up the shell game of consequentialism: incompetence - concept and ethics. In M. A. G. Cutter \& E. E. Shelp (Eds.), Competency: a study of informal competency determinations in primary care (Vol. 39, pp. 237-252). Dordrecht/Boston/London: Kluwer Academic Publishers.

European Commission. (2004). National ethics committees: List of national ethics committees specialising in the ethical aspects of the life sciences, biotechnology, agriculture, food safety and health: URL http://europa.eu.int/comm/research/biosociety/bioethics/bioethics_eth ics_en.htm.

European Union. (2001). Directive 2001/20/EC of the European Parliament and of the Council of 4 April 2001 on the approximation of the laws, regulations and administrative provisions of the Member States relating to the implementation of good clinical practice in the conduct of clinical trials on medicinal products for human use (European Union directive Good Clinical Practice): OJEC $2001 \mathrm{~L}$ 121; URL http://www.europa.eu.int/eur-lex/lex/en/index.htm. 
Evaluatiecommissie Wet Bijzondere Opnemingen in Psychiatrische Ziekenhuizen. (1995). BOPZ Activiteitenprogramma 1994-1996: Evaluatie Wet Bijzondere Opnemingen in Psychiatrische Ziekenhuizen. Rijswijk: Ministerie van Volksgezondheid, Welzijn en Sport.

Evaluatiecommissie Wet Bijzondere opnemingen in psychiatrische ziekenhuizen. (1996). Wet Bopz Evaluatierapport: Evaluatie Wet Bijzondere opnemingen in psychiatrische ziekenhuizen - Tussen invoering en praktijk. Rijswijk: Ministerie van Volksgezondheid, Welzijn en Sport.

Evans, D., \& Evans, M. (1996). A decent proposal: Ethical review of clinical research. Chichester: John Wiley \& Sons.

Evers, A., Caminada, H., Koning, R., Laak, J. ten, Maesen de Sombreff, P. van der, \& Starren, J. (1988). Richtlijnen voor ontwikkeling en gebruik van psychologische tests en studietoetsen. Amsterdam: Nederlands Instituut van Psychologen.

Evers, A., Vliet-Mulder, J. C. van, \& Laak, J. ten (1996). Documentatie van Tests en Testresearch in Nederland ( $6^{\mathrm{e}}$ geheel herziene uitgave). Assen/Maastricht/Amsterdam: Van Gorcum/Nederlands Instituut van Psychologen.

Faden, R. R., Beauchamp, T. L., \& King, N. M. P. (1986). A History and Theory of Informed Consent. New York/Oxford: Oxford University Press.

Federatie van Medisch Wetenschappelijke Verenigingen [Federation of Biomedical Scientific Societies in the Netherlands]. (2001/2002). Goed Gebruik: Gedragscode gezondheidsonderzoek met lichaamsmateriaal [Proper Use: Code for proper secondary use of human tissue]. Rotterdam: URL http://www.fmwv.nl.

Federatie van Medisch Wetenschappelijke Verenigingen [Federation of Biomedical Scientific Societies in the Netherlands], \& Raad voor Gezondheidsonderzoek [Dutch Advisory Council on Health Research]. (2003/2004). Goed Gedrag: Gedragscode gezondheidsonderzoek met gegevens (goedgekeurd door het College Bescherming Persoonsgegevens) [Code of Conduct for medical research: Code for adequate secondary use of data (approved by the Dutch Data Protection Authority)]: URL http://www.fmwv.nl.

Feinberg, J. (1986). Harm to Self (Volume Three). New York/Oxford: Oxford University Press.

Fiselier, J. A., Waal, A. E. van der, \& Spijker, J. (2006). Psychiater, patiënt en religie: meer dan coping alleen? Tijdschrift voor Psychiatrie, 48(5), 383-386.

Fitten, L. J., Lusky, R., \& Hamann, C. (1990). Assessing treatment decision-making capacity in elderly nursing home residents. Journal of the American Geriatrics Society, 38(10), 1097-1104. 
Fitten, L. J., \& Waite, M. S. (1990). Impact of medical hospitalization on treatment decision-making capacity in the elderly. Arch Intern Med, 150(8), 1717-1721.

Flory, J., \& Emanuel, E. (2004). Interventions to improve research participants' understanding in informed consent for research: a systematic review. JAMA, 292(13), 1593-1601.

Folstein, M. F., Folstein, S. E., \& McHugh, P. R. (1975). Mini-mental state: A practical method for grading the cognitive state of patients for the clinician. Journal of Psychiatric Research, 12(3), 189-198.

Fraenkel, J. M. (1919). Aristoteles' Zielkunde. Groningen, Den Haag: J.B. Wolters' U.M.

Franken, H. e. a. (1995). InLeiden tot de rechtswetenschap (Zevende druk). Arnhem: Gouda Quint bv.

Frankfurt, H. G. (1971). Freedom of the will and the concept of a person. Journal of Philosophy, 68(1), 5-20.

Franx, G., Stalmeier, P., \& Timmermans, D. (2006). Keuzehulp in de zorg: de integratie van kennis en waarden. Maandblad Geestelijke volksgezondheid, 61(7/8), 638-646.

Frederiks, B. J. M. (2004). De rechtspositie van mensen met een verstandelijke handicap: van beperking naar ontplooiing (Vol. 23): Sdu.

Freedman, B. (1981). Competence, marginal and otherwise: concepts and ethics. International Journal of Law and Psychiatry, 4(1-2), 53-72.

Freedman, M., Stuss, D. T., \& Gordon, M. (1991). Assessment of competency: the role of neurobehavioral deficits. Annals of Internal Medicine, 115(3), 203-208.

Freud, S. (1917). Inleiding tot de studie der psycho-analyse (Achttiende druk). Amsterdam: Wereldbibliotheek.

Frijda, N. (1993). De psychologie heeft zin. Amsterdam: Prometheus.

Frijda, N. H. (2002). Wilsbekwaamheid: de psychologie van het nemen van een weloverwogen beslissing. Tijdschrift voor Gerontologie en Geriatrie, 33(november), 196-200.

Garland, J., \& Garland, C. (2001). Life review in health and social care: A practitioner's guide. Hove (U.K.)/Philadelphia, PA: BrunnerRoutledge.

General Assembly of the United Nations. (1948). Universal Declaration of Human Rights: URL http://www.un.org/Overview/rights.html.

General Conference of UNESCO. (2005). Universal Declaration on Bioethics and Human Rights.

General Medical Council. (1995). Good medical practice. London.

Gert, B., Culver, C. M., \& Clouser, K. D. (1997). Bioethics: a return to fundamentals. New York: Oxford University Press. 
Gevers, J. K. M. (1987). De onbekwame meerderjarige patiënt. Nederlands Tijdschrift voor Geneeskunde, 131(46), 2092-2095.

Gevers, J. K. M. (2004). The European Court of Human Rights and the incompetent patient: Editorial. European Journal of Health Law, 11(3), 225-229.

Gevers, S. (2002). Advance directives in psychiatry. European Journal of Health Law, 9(1), 19-29.

Gezondheidsraad. (2002). Dementie (no. 2002/04). Den Haag: Gezondheidsraad.

Glass, K. C. (1997). Refining definitions and devising instruments: two decades of assessing mental competence. International Journal of Law and Psychiatry, 20(1), 5-33.

Gleitman, H., Fridlund, A. J., \& Reisberg, D. (1999). Psychology (5th ed.). New York: Norton.

Golinger, R. C., \& Fedoroff, J. P. (1989). Characteristics of patients referred to psychiatrists for competency evaluations. Psychosomatics, 30(3), 296-299.

Gouwenberg, B. M., Jonker, C., Smit, J. H., \& Schmand, B. (1997). Beoordeling van wilsbekwaamheid bij ouderen met dementie: ontwikkeling van een methode. Amsterdam: Vrije Universiteit.

Grisso, T., \& Appelbaum, P. S. (1995). The MacArthur Treatment Competence Study. III: Abilities of patients to consent to psychiatric and medical treatments. Law and Human Behavior, 19(2), 149-174.

Grisso, T., \& Appelbaum, P. S. (1998). Assessing Competence to Consent to Treatment: A Guide for Physicians and Other Health Professionals. New York/Oxford: Oxford University Press Inc.

Grisso, T., Appelbaum, P. S., \& Hill-Fotouhi, C. (1997). The MacCAT-T: A clinical tool to assess patients' capacities to make treatment decisions. Psychiatric Services, 48(11), 1415-1419.

Grisso, T., Appelbaum, P. S., Mulvey, E. P., \& Fletcher, K. (1995). The MacArthur Treatment Competence Study. II: Measures of abilities related to competence to consent to treatment. Law and Human Behavior, 19(2), 127-148.

Groth-Marnat, G. (1990). Handbook of Psychological Assessment (Second Edition). New York/Chichester/Brisbane/Toronto/Singapore: Wiley.

Grubb, A. (1998). Who Decides? Legislating for the Incapacitated Adult; editorial. European Journal of Health Law, 5(3), 231-240.

Gunn, M. J., Wong, J. G., Clare, I. C., \& Holland, A. J. (2000). Medical research and incompetent patients. Journal of Mental Health Law, 3, 60-72.

Gunn, M. J., Wong, J. G., Clare, I. C. H., \& Holland, A. J. (1999). Decision-Making Capacity. Medical Law Review, 7(3), 269-306. 
Gutheil, T. G., \& Bursztajn, H. (1986). Clinicians' guidelines for assessing and presenting subtle forms of patient incompetence in legal settings. Am J Psychiatry, 143(8), 1020-1023.

Haanappel, P. P. C., \& Mackaay, E. (1990). New Netherlands Civil Code: Patrimonial Law (Property, Obligations and Special Contracts). Deventer/Boston: Kluwer.

Haekens, A. (1998). Beslissingsbekwaamheid in de gerontopsychiatrische context. Leuven: Leuven University Press.

Hanson, L. C., Danis, M., Mutran, E., \& Keenan, N. L. (1994). Impact of patient incompetence on decisions to use or withhold life-sustaining treatment. Am J Med, 97(3), 235-241.

Harré, R., \& Lamb, R. (Eds.). (1983). The Encyclopedic Dictionary of Psychology. Oxford: Blackwell.

Hassin, R. R., Uleman, J. S., \& Bargh, J. A. (Eds.). (2005). The new unconscious. Oxford: Oxford University Press.

Have, H. A. M. J. ten, Meulen, R. H. J. ter, \& Leeuwen, E. van (1998). Medische ethiek. Houten/Diegem: Bohn Stafleu Van Loghum.

Have, H. A. M. J. ten, Meulen, R. H. J. ter, \& Leeuwen, E. van (2003). Medische ethiek (2e, herz. dr.). Houten: Bohn Stafleu Van Loghum.

Helmchen, H. (2000). Research Involving Incompetent Patients. A Current problem in Light of German History. In A. Okasha, J. Arboleda-Flórez \& N. Sartorius (Eds.), Ethics, Culture and Psychiatry (pp. 147-166). Washington: American Psychiatric Association.

Hendriks, A. C. (2000). Evaluatie van gezondheidswetgeving: enkele impressies. Tijdschrift voor Gezondheidsrecht, 24(2), 87-100.

Hendriks, A. C. (2006). In beginsel: de gezondheidsrechtelijke beginselen uitgediept. Leiden: Stichting NJCM-Boekerij.

Hengeveld, M. W. (2001). Het psychiatrisch onderzoek anno 1931: psychiatertaal. De Psychiater, 8(7), 23.

Hengeveld, M. W. (2002). De trias psychica: psychiatertaal. De Psychiater, 9(8), 21.

Hermans, H. J. (1983). De zelfkonfrontatiemethode: diagnostiek en procesbevordering van het menselijk waarderingsleven / The selfconfrontation method: the diagnosis and development of a personal value system. Tijdschrift voor Psychotherapie, 9(6), 295-308.

Hermans, H. J. M. (1990). Het verdeelde gemoed: over de grondmotieven in ons dagelijks leven (2e druk). Baarn: Nelissen.

Hermans, H. J. M., \& Kempen, H. J. G. (2002). Lichaam, geest en cultuur: de dialogische aard van bemiddeld handelen. In J. v. d. Lans, F. Derks \& G. v. d. Berg (Eds.), Naar een universele psychologie van het Zelf: nagelaten geschriften van Harry Kempen, cultuur- 
psycholoog (pp. 121-134). Nijmegen: sectie cultuur-en godsdienstpsychologie van de Katholieke Universiteit Nijmegen.

Hipshman, L. (1987). Assessing a patient's competence to make treatment decisions. Psychiatric Annals, 17(4), 279-283.

Hofstee, W. K. B. (1996). Overtredingen van de maximumsnelheid: meettechnische overwegingen bij arresten van de Hoge Raad. Nederlands Juristenblad, 71(13), 494-495.

Hondius, A., Zuijderhoudt, R., \& Honig, A. (2005). Wilsonbekwaamheid vaststellen: Een casus en een stappenplan. Maandblad Geestelijke volksgezondheid, 60(6), 597-607.

Hubben, J. H. (2000). De meerderjarige wilsonbekwame patiënt in de WGBO. In J. C. J. Dute, R. D. Friele, J. K. M. Gevers, J. H. Hubben, J. Legemaate, H. D. C. Roscam Abbing, B. Sluijters, G. A. M. Widdershoven \& F. C. B. van Wijmen (Eds.), Evaluatie Wet op de geneeskundige behandelingsovereenkomst (Vol. 3, pp. 131-181). Den Haag: ZorgOnderzoek Nederland.

Hughes, J. C. (2008). Assessment of competency and advance directives. In G. Stoppe \& European Dementia Consensus Network (Eds.), Competence assessment in dementia (pp. 77-84). Wien/New York: Springer.

International Committee of Medical Journal Editors. (2004 (October)). Uniform Requirements for Manuscripts Submitted to Biomedical Journals: Writing and Editing for Biomedical Publication: URL http://www.icmje.org/.

International Conference on Harmonisation of technical requirements for registration of pharmaceuticals for human use. (1996). ICH Harmonised Tripartite Consolidated Guideline for Good Clinical Practice: E6; URL http://www.ich.org.

International Covenant on Civil and Political Rights - treaty in the framework of the United Nations. (1966). URL http://untreaty.un.org/English/access.asp.

Ippel, P. (1994). Gezondheidsrecht en gezondheidsethiek: de geboorte van een Siamese tweeling. In W. v. d. Burg \& P. Ippel (Eds.), De Siamese Tweeling: recht en moraal in de biomedische praktijk (pp. 33-48). Assen: Van Gorcum.

Janofsky, J. S., McCarthy, R. J., \& Folstein, M. F. (1992). The Hopkins Competency Assessment Test: A brief method for evaluating patients' capacity to give informed consent. Hospital and Community Psychiatry, 43(2), 132-136.

Jansen, I. (1990). Grenzen aan vertegenwoordiging in immateriële aangelegenheden? Familie \& Jeugdrecht, 12(3), 49.

Jansen, S. (1999). Het Nederlandse recht inzake bescherming van meerderjarigen en aanbeveling No. R (99) 4 van het Comité van 
Ministers van de Raad van Europa aan de Lidstaten omtrent wilsonbekwame volwassen personen. In K. Boele-Woelki \& E. Mostermans (Eds.), Volwassen maar onzelfstandig: meerderjarigenbescherming in Europees en internationaal privaatrechtelijk perspectief (pp. 19-33). Antwerpen/Groningen: Intersentia.

Jansen, S. (2000). Recommendation No. R (99) 4 of the Committee of Ministers to Member States on Principles Concerning the Legal protection of incapable adults, an introduction in particular to part $\mathrm{V}$ Interventions in the health field. European Journal of Health Law, 7(3), 333-347.

Jonas, H. (1989). Philosophical reflections on experimenting with human subjects. In T. L. Beauchamp \& L. R. Walters (Eds.), Contemporary issues in bioethics (3rd ed., pp. 432-440). Belmont, Cal.: Wadsworth Publishing Company.

Jones, J. H. (1993). Bad blood: The Tuskegee syphilis experiment. New York: The Free Press.

Jong, I. A. W. d., \& Wijmen, F. C. B. van (1999/2000). Handreiking voor medische beslissingen in de laatste levensfase. Maastricht: Universiteit Maastricht/Academisch Ziekenhuis Maastricht - Commissie Medisch-Ethische Aangelegenheden.

Jörg, N., \& Kelk, C. (1988). Strafrecht met mate (5e druk). Alphen aan den Rijn: Samson H.D. Tjeenk Willink.

Kabinetsstandpunt. (2004). Kabinetsstandpunt op de tweede evaluatie van de Wet Bijzondere opnemingen in psychiatrische ziekenhuizen. Den Haag.

Kabinetsstandpunt. (2008). Kabinetsstandpunt eindrapport derde evaluatiecommissie Wet bijzondere opnemingen in psychiatrische ziekenhuizen. Den Haag: Kamerstukken II 2007/2008, 25 763, nr. 9 (http://www.overheid.nl/op/).

Kapp, M. B., \& Mossman, D. (1996). Measuring decisional capacity: Cautions on the construction of a "capacimeter". Psychology, Public Policy and Law, 2(1), 73-95.

Katz, J. (1993). Human experimentation and human rights. Saint Louis University Law Journal, 38(1), 7-54.

Katz, S., Ford, A., Moskowitz, R. W., Jackson, B. A., \& Jaffe, M. W. (1963). Studies of illness in the aged: the index of ADL; a standardized measure of biological and psychosocial function. Journal of the American Medical Association, 185(12), 94-99.

Keller, J. (1997). Autonomy, Relationality, and Feminist Ethics. Hypatia, 12(2), 152-164.

Keyserlingk, E. W., Glass, K., Kogan, S., \& Gauthier, S. (1995).

Proposed guidelines for the participation of persons with dementia as 
research subjects. Perspectives in Biology and Medicine, 38(2), 319-361.

Kihlstrom, J. F. (1987). The cognitive unconscious. Science, 237(4821), 1445-1452.

Kim, S. Y. H., Appelbaum, P. S., Jeste, D. V., \& Olin, J. T. (2004). Proxy and surrogate consent in geriatric neuropsychiatric research: update and recommendations. American Journal of Psychiatry, 161(5), 797806.

Kitamura, F., Tomoda, A., Tsukada, K., Tanaka, M., Kawakami, I., Mishima, S., et al. (1998). Method for assessment of competency to consent in the mentally ill: rationale, development, and comparison with the medically ill. International Journal of Law and Psychiatry, 21(3), 223-244.

Klippe, H. v. d. (1990). Wilsonbekwaamheid in de psychiatrie: zes benaderingen. Maandblad voor de Geestelijke volksgezondheid, 45(2), 123-138.

Klippe, H. v. d. (1997). Dwangtoepassing na onvrijwillige psychiatrische opname: een juridische beschouwing. Nijmegen: Ars Aequi Libri.

Knuiman, R. B. J., Tholen, A. J., \& Wijmen, F. C. B. van (2006). Medische behandeling van meerderjarige wilsonbekwame patiënten: Een modelrichtlijn bij de WGBO. Maandblad Geestelijke volksgezondheid, 61(7/8), 628-637.

Komen, A. (1988). Algemene inleiding. In A. Komen \& A. Rutten-Roos (Eds.), Nederlands recht in kort bestek (zevende druk, pp. 1-57). Deventer: Kluwer.

Koninklijke Nederlandsche Maatschappij tot bevordering der Geneeskunst. (2004). Implementatie van de Wgbo: van wet naar praktijk (deel 2 informatie en toestemming). Utrecht: http://www.knmg.nl/wgbo (consulted on February $12^{\text {th }} 2005$ ).

Koninklijke Notariële Beroepsorganisatie. (2006). Stappenplan Beoordeling Wilsbekwaamheid ten behoeve van notariële dienstverlening. Den Haag: URL http://www.notaris.nl/page.asp?id=878 (consulted on September $27^{\text {th }}$ 2006).

Kunst-Wilson, W. R., \& Zajonc, R. B. (1980). Affective discrimination of stimuli that cannot be recognized. Science, 207, 557-558.

Laak, J. J. F. ten, \& Bergsma, A. (1995). Psychologische diagnostiek: inhoudelijke en methodologische grondslagen. Lisse: Swets \& Zeitlinger.

Laín Entralgo, P. (1995). Professional-patient relationship I. Historical perspectives. In W. T. Reich (Ed.), Encyclopedia of Bioethics (revised edition, Vol. 4, pp. 2076-2084). New York/London: MacMillan. 
Lambert, P., Gibson, J. M., \& Nathanson, P. (1990). The values history: an innovation in surrogate medical decision-making. Law, Medicine and Health Care, 18(3), 202-212.

Lavori, P. W., \& Sugarman, J. (2000). Placebo revisited. Acta Psychiatrica Scandinavica, 101, 173-175.

Law Commission, T. (1991). Mentally Incapacitated Adults and Decision-Making: An Overview; Consultation Paper No. 119. London: HMSO.

Law Commission, T. (1993a). Mentally Incapacitated Adults and Decision-Making: A New Jurisdiction; Consultation Paper No. 128.

Law Commission, T. (1993b). Mentally Incapacitated Adults and Decision-Making: Medical Treatment and Research; Consultation Paper No. 129.

Law Commission, T. (1993c). Mentally Incapacitated and Other Vulnerable Adults: Public Law Protection; Consultation Paper No. 130.

Law Commission, T. (1995). Mental Incapacity: Report No 231. London: HMSO.

Lawton, M. P., \& Brody, E. M. (1969). Assessment of older people: selfmaintaining and instrumental activities of daily living. The Gerontologist, 9(3), 179-186.

Leenen, H. J. J., \& Gevers, J. K. M. (2000). Handboek Gezondheidsrecht, deel 1: Rechten van mensen in de gezondheidszorg (vierde, geheel herziene druk). Houten/Diegem: Bohn Stafleu Van Loghum.

Leenen, H. J. J., Gevers, J. K. M., \& Biesaart, M. C. I. H. (2002). Handboek Gezondheidsrecht, deel 2: Gezondheidszorg en recht (Vierde druk). Houten/Diegem: Bohn Stafleu Van Loghum.

Legemaate, J. (1992). Criteria voor wilsonbekwaamheid. Nederlands Juristenblad, 67(6), 190-193.

Legemaate, J. (1994). De rechtspositie van wilsonbekwame patiënten: stand van zaken. Tijdschrift voor Gezondheidsrecht, 18(6), 327-340.

Legemaate, J. (2004). Het zelfbeschikkingsrecht: een oud debat in nieuw licht. Tijdschrift voor Gezondheidsrecht, 28(1), 18-20.

Lersch, P. (1938). Der Aufbau des Charakters. Leipzig: Johann Ambrosius Barth.

Lersch, P. (1956). Aufbau der Person (Siebente, durchgesehene Auflage). München: Johann Ambrosius Barth.

Levine, R. (1986). Ethics and regulation of clinical research (2nd ed.). New Haven, Conn.: Yale University Press.

Lezak, M. D. (1995). Neuropsychological Assessment ( $3^{\text {rd }}$ edition). New York/Oxford: Oxford University Press.

Lidz, C. W., \& Appelbaum, P. S. (2002). The therapeutic misconception: problems and solutions. Medical Care, 40(9), suppl., V55-V63. 
Lidz, C. W., Appelbaum, P. S., Grisso, T., \& Renaud, M. (2004).

Therapeutic misconception and the appreciation of risks in clinical trials. Social Science and Medicine, 58, 1689-1697.

Lidz, C. W., Appelbaum, P. S., \& Meisel, A. (1988). Two models of implementing informed consent. Archives of Internal Medicine, 148, 1385-1389.

Lidz, C. W., Meisel, A., Osterweis, M., Holden, J. L., Marx, J. H., \& Munetz, M. R. (1983). Barriers to informed consent. Ann Intern Med, 99(4), 539-543.

Loenen, T. (1996). Recht en het onvervulbare verlangen naar individuele gerechtigheid: over verfijning van regelgeving, vage of open normen, en concrete toetsing aan grondrechten. RM Themis(4), 123-136.

Lord Chancellor's Department. (1997). Who Decides? Making decisions on behalf of mentally incapacitated adults; a consultation paper: Internet URL http://www.open.gov.uk/lcd/menincap/index.htm (consulted on December $16^{\text {th }} 1999$ ).

Lord Chancellor's Department. (1999). Making Decisions: the government's proposals for making decisions on behalf of mentally incapacitated adults; a report issued in the light of responses to the consultation paper "Who Decides?" Internet URL http://www.open.gov.uk/lcd/family/mdecisions/indbod.htm (consulted on December 16 ${ }^{\text {th }} 1999$ ).

Lötjönen, S. (2003). Regulation of clinical medical research on the decisionally impaired adults in Europe. Yearbook of the Finnish Lawyers' Association, XXXVI, 351-420.

Maas, P. J. van der, Delden, J. J. M. van, \& Pijnenborg, L. (1991). Medische beslissingen rond het levenseinde: het onderzoek voor de Commissie Onderzoek Medische Praktijk inzake Euthanasie. 'sGravenhage: Sdu Uitgeverij Plantijnstraat.

Mackie, J. L. (1967). Fallacies. In P. Edwards (Ed.), The Encyclopedia of Philosophy (Vol. 3, pp. 169-179). New York/London: Macmillan.

MacNabb, D. G. C. (1967). Hume, David. In P. Edwards (Ed.), The Encyclopedia of Philosophy (Vol. 4, pp. 74-90). New York/London: Macmillan.

Madigan, K. V., Checkland, D., \& Silberfeld, M. (1994). Presumptions respecting mental competence. Canadian Journal of Psychiatry, 39(3), 147-152.

Mangone, C. A., Sanguinetti, R. M., Baumann, P. D., Gonzalez, R. C., Pereyra, S., Bozzola, F. G., et al. (1993). Influence of feelings of burden on the caregiver's perception of the patient's functional status. Dementia, 4(5), 287-293.

Marson, D. C., Chatterjee, A., Ingram, K. K., \& Harrell, L. E. (1996). Toward a neurologic model of competency: cognitive predictors of 
capacity to consent in Alzheimer's disease using three different legal standards. Neurology, 46(3), 666-672.

Marson, D. C., Hawkins, L., McInturff, B., \& Harrell, L. E. (1997). Cognitive models that predict physician judgments of capacity to consent in mild Alzheimer's disease. Journal of the American Geriatrics Society, 45(4), 458-464.

Marson, D. C., Ingram, K. K., Cody, H. A., \& Harrell, L. E. (1995). Assessing the competency of patients with Alzheimer's disease under different legal standards: a prototype instrument. Archives of Neurology, 52(10), 949-954.

Marson, D. C., McInturff, B., Hawkins, L., Bartolucci, A., \& Harrell, L. E. (1997). Consistency of physician judgments of capacity to consent in mild Alzheimer's disease. Journal of the American Geriatrics Society, 45(4), 453-457.

Marta, J. (1998). Whose consent is it anyway? A poststructuralist framing of the person in medical decision-making. Theoretical Medicine and Bioethics, 19(4), 353-370.

Mastroianni, A., \& Kahn, J. (1996). Remedies for human subjects of cold war research: recommendations of the Advisory Committee. Journal of Law, Medicine and Ethics, 24, 118-126.

May, T. (1998). Assessing competency without judging merit. The Journal of Clinical Ethics, 9(3), 247-257.

McKegney, F. P., Schwartz, B. J., \& O'Dowd, M. A. (1992). Reducing unnecessary psychiatric consultations for informed consent by liaison with administration. Gen Hosp Psychiatry, 14(1), 15-19.

McNeill, P. M. (1993). The ethics and politics of human experimentation. Cambridge: Cambridge University Press.

Medical Research Council. (1991 (reprinted 1993)). The Ethical Conduct of Research on the Mentally Incapacitated: report: URL http://www.mrc.ac.uk/pdf-ethics-mental.pdf.

Medical-Scientific Research on Human Subjects Act ("Wet Medischwetenschappelijk Onderzoek met mensen") - Dutch statute (Wet van 26 februari 1998, Stb. 1998, 161, laatstelijk gewijzigd bij wet van 17 december 2003, Stb. 2004, 32; currently being amended with a view to the implementation of European Union directive Good Clinical Practice.). (1998). URL http://www.overheid.nl/op/index.html.

The Medicines for Human Use (Clinical Trials) Regulations 2004 English Statutory Instrument 2004 No. 1031. (2004). URL http://www.legislation.hmso.gov.uk/si/si2004/20041031.htm.

Meisel, A., Roth, L. H., \& Lidz, C. W. (1977). Toward a model of the legal doctrine of informed consent. American Journal of Psychiatry, 134(3), 285-289. 
Melamed, Y., Kimchi, R., Shnit, D., Moldavski, D., \& Elizur, A. (1999). Clinical assessment of competency to consent to psychiatric hospitalization. International Journal of Law and Psychiatry, 22(1), 55-64.

Mendelson, D. (2007). Roman concept of mental capacity to make endof-life decisions. International Journal of Law and Psychiatry, 30(3), 201-212.

Michels, R. (2004). Research on persons with impaired decision making and the public trust. American Journal of Psychiatry, 161(5), 777779 .

Miller, B. L. (1981). Autonomy \& the Refusal of Lifesaving Treatment: four cases, four senses of autonomy. The Hastings Center Report, 11(August), 22-28.

Ministerie van Justitie. (1994). Handreiking voor de beoordeling van wilsbekwaamheid. Den Haag: Ministerie van Justitie.

Ministerie van Volksgezondheid, Welzijn en Sport [Dutch Ministry of Health, Welfare and Sports]. (2002). Vaststelling van de begroting van de uitgaven en de ontvangsten van het Ministerie van Volksgezondheid, Welzijn en Sport (XVI) voor het jaar 2002: Kamerstukken II 2001/2002, 28000 XVI, nr. 119, p. 3 \& 4; URL http://www.overheid.nl/op/index.html.

Moody, H. R. (1988). From informed consent to negotiated consent. The Gerontologist, 28(Suppl.; Special Issue: Autonomy and long term care), 64-70.

Morgan, M. (1997). The Doctor-Patient Relationship. In G. Scambler (Ed.), Sociology as applied to medicine (4th edition, pp. 47-62). London: Saunders.

Morimura, S., \& Shimozato, M. (1983). The Devil's Gluttony. New York. Muijlwijk, R. (1996). Wettelijke grenzen en meetonzekerheid. Nederlands Juristenblad, 71(3), 95-96.

Murphy, G. H., \& Clare, I. C. H. (1995). Adults' capacity to make decisions affecting the person: psychologists' contribution (Chapter 2.5). In R. Bull \& D. Carson (Eds.), Handbook of psychology in legal contexts (pp. 97-128). Chichester [etc.]: John Wiley \& Sons.

Musschenga, A. W. (1987). Kwaliteit van leven: criterium voor medisch handelen? (Vol. 1). Baarn: Ambo.

National Bioethics Advisory Commission. (1998). Research involving persons with mental disorders that may affect decisionmaking capacity, Volume I: Report and recommendations of the National Bioethics Advisory Commission. Rockville, Maryland.

Nationale Raad van de Orde van Geneesheren [Belgian National Council of the Order of Physicians]. (2003). Code van geneeskundige 
plichtenleer [Code of medical deontology]: URL http://www.ordomedic.be/.

Nelson, A., Fogel, B. S., \& Faust, D. (1986). Bedside cognitive screening instruments: a critical assessment. The Journal of Nervous and Mental Disease, 174(2), 73-83.

Nicholson, R. H. (2003). The regulation of medical research: a historical overview. In S. Eckstein, B. Farsides, J. Glover, J. Lamberty, O. O'Neill \& D. Wikler (Eds.), Manual for Research Ethics Committees (6th ed., pp. 18-21): Cambridge University Press.

Nisbett, R. E., \& Ross, L. (1980). Human inference: Strategies and shortcomings of social judgment. Englewood Cliffs, NJ: PrenticeHall.

Nuremberg Military Tribunals. (1947). Nuremberg Code.

NVVA beroepsvereniging van verpleeghuisartsen en sociaal geriaters. (2008). Beginselen en vuistregels bij wilsonbekwaamheid bij oudere cliënten met een complexe zorgvraag: een handreiking voor verpleeghuisartsen en sociaal geriaters. Utrecht: NVVA.

Nys, H. (2000). Patiënt in Europa: op zoek naar een Europees geneeskundig dienstverleningsrecht. Maastricht: Universitaire Pers Maastricht.

Nys, H., Welie, S., Garanis-Papadatos, T., \& Ploumpidis, D. (2004). Patient capacity in mental health care: Legal overview. Health Care Analysis, 12(4), 329-337.

Office of the Public Guardian and Trustee - Ontario Ministry of the Attorney General. (1996). Guidelines for Conducting Assessments of Capacity. Toronto: Queen's Printer for Ontario.

Ogletree, T. W. (1995). Responsibility. In W. T. Reich (Ed.), Encyclopedia of Bioethics (revised edition, Vol. 4, pp. 2300-2305). New York [etc.]: Macmillan Library Reference.

Olde Rikkert, M. G. M., Bercken, J. H. L. v. d., Have, H. A. M. J. ten, \& Hoefnagels, W. H. L. (1997). Experienced consent in geriatric research: A new method to optimize the capacity to consent in frail elderly subjects. Journal of Medical Ethics, 23, 271-276.

Olde Rikkert, M. G. M., Verweij, M. F., \& Hoefnagels, W. H. L. (1995). Informed consent en beslisvaardigheid van ouderen bij medischwetenschappelijk onderzoek [Informed consent and decisional capacity of elderly in medical-scientific research]. Tijdschrift voor Gerontologie en Geriatrie, 26, 152-162.

Olsthoorn-Heim, E. T. M. (2003). Vijf jaar evaluatie regelgeving via ZonMw. Den Haag: ZonMw.

Oomens, H. C. D. M., Zutphen, Y. L. L. v., Blankman, K., \& Beijers, W. M. E. H. (1998). Evaluatie Wet Mentorschap: een onderzoek naar de 
toepassing van het mentorschap ten behoeve van meerderjarigen over de jaren 1995-1998. Amsterdam: Vrije Universiteit.

Oxford English Dictionary Online. (1989). (second ed.). Oxford: Oxford University Press; URL http://dictionary.oed.com (consulted on February 12th 2006).

Pappworth, M. H. (1967). Human Guinea Pigs. London: Routledge \& Kegan Paul.

Pascal, B. (1924). Pensées: édition nouvelle revue sur les manuscrits et les meilleurs textes avec une introduction, des notes et un index analytique (annotée par Victor Giraud). Paris: Crès Cam.

Pellegrino, E. D. (1978). Medical education. In W. T. Reich (Ed.), Encyclopedia of Bioethics (Vol. 2, pp. 863-870). New York: Free Press.

Pellegrino, E. D., \& Thomasma, D. C. (1988). For the patient's good: the restoration of beneficence in health care. New York: Oxford University Press.

Pepper-Smith, R., Harvey, W. R., \& Silberfeld, M. (1996). Competency and practical judgment. Theoretical Medicine, 17(2), 135-150.

Percival, T. (1849). Medical Ethics; or a code of institutes and precepts, adapted to the professional conduct of physicians and surgeons (3 ed.). Oxford: John Parker.

Personal Data Protection Act ("Wet Bescherming Persoonsgegevens") Dutch statute (Wet van 6 juli 2000, Stb. 2000, 302, laatstelijk gewijzigd bij wet van 30 juni 2004, Stb. 2004, 315). (2000). URL http://www.overheid.nl/op/index.html.

Peters, R. S., \& Mace, C. A. (1967). Psychology. In P. Edwards (Ed.), The Encyclopedia of Philosophy (Vol. 7, pp. 1-27). New York/London: Macmillan.

Pfeiffer, E. (1975). A short portable mental status questionnaire for the assessment of organic brain deficit in elderly patients. Journal of the American Geriatrics Society, 23(10), 433-441.

Piaget, J. (1973). The affective unconscious and the cognitive unconscious. Journal of the American Psychoanalytic Association, 21(2), 249-261.

Pincoffs, E. L. (1991). Judgments of incompetence and their moral presuppositions. In M. A. G. Cutter \& E. E. Shelp (Eds.), Competency: a study of informal competency determinations in primary care (Vol. 39, pp. 79-89). Dordrecht/Boston/London: Kluwer Academic Publishers.

Plato. (1962). Verzameld Werk - deel II (X. d. Win, Trans.). Haarlem: Tjeenk Willink. 
Pomerantz, A. S., \& de-Nesnera, A. (1991). Informed consent, competency, and the illusion of rationality. Gen Hosp Psychiatry, 13(2), 138-142.

Pontifical Council for Pastoral Assistance to Health Care Workers. (1995). The Charter for Health Care Workers. Vatican City.

President's Commission for the Study of Ethical Problems in Medicine and Biomedical and Behavioral Research. (1982). Making Health Care Decisions: A Report on the Ethical and Legal Implications of Informed Consent in the Patient-Practitioner Relationship (Volume One: Report). Washington, DC: U.S. Government Printing Office.

Purtilo, R. B. (1995). Professional-patient relationship III. Ethical issues. In W. T. Reich (Ed.), Encyclopedia of Bioethics (revised edition, Vol. 4, pp. 2094-2103). New York/London: MacMillan.

Raadgevend Comité voor Bio-Ethiek [Belgian Consultative Committee on Bioethics]. (2001a). Advies nr 13 van 9 juli 2001 betreffende experimenten met mensen [Advice number 13 dated July $9^{\text {th }}, 2001$ concerning experiments with human beings]: URL http://www.health.fgov.be/bioeth/nl/advies/advies-13.pdf.

Raadgevend Comité voor Bio-Ethiek [Belgian Consultative Committee on Bioethics]. (2001b). Advies nr 14 van 10 december 2001 betreffende "de ethische regels ten aanzien van dementerende personen" [Advice number 14 dated December $10^{\text {th }}, 2001$ concerning "the ethical rules regarding persons who grow demented"]: URL http://www.health.fgov.be/bioeth/nl/advies/advies14.pdf.

Reber, A. S. (1993). Implicit learning and tacit knowledge: an essay on the cognitive unconscious. New York: Oxford University Press.

Reber, A. S. (1995). The Penguin Dictionary of Psychology (second edition). London/New York: Penguin Books.

Ree, F. van (2004). Horen vragen over levensbeschouwing thuis in een intake? Forum. PsychoPraxis, 6(3), 86-88.

Roberts, L. W., \& Roberts, B. (1999). Psychiatric research ethics: an overview of evolving guidelines and current ethical dilemmas in the study of mental illness. Biological Psychiatry, 46(8), 1025-1038.

Roscam Abbing, H. D. C. (1994). Beslissen door de patiënt. Houten/Zaventem: Bohn Stafleu Van Loghum.

Rosenfeld, B. D., \& Turkheimer, E. N. (1995). Modeling psychiatric patients' treatment decision making. Law and Human Behavior, 19(4), 389-405.

Rosenhan, D. L. (1973). On being sane in insane places. Science, 179, 250-258.

Roth, L. H., Meisel, A., \& Lidz, C. W. (1977). Tests of competency to consent to treatment. American Journal of Psychiatry, 134(3), 279284. 
Ruskin, P. E. (1985). Geropsychiatric consultation in a university hospital: a report on 67 referrals. Am J Psychiatry, 142(3), 333-336.

Rutman, D., \& Silberfeld, M. (1992). A preliminary report on the discrepancy between clinical and test evaluations of competence. Canadian Journal of Psychiatry, 37(9), 634-639.

Schacter, D. L. (1992). Implicit knowledge: new perspectives on unconscious processes. Proceedings of the National Academy of Sciences of the United States of America, 89(23), 11113-11117.

Scheltens, D. F. (1981). Mens en Mensenrechten. Alphen aan den Rijn/Brussel: Samson.

Scheltens, D. F. (1983/1988). Inleiding tot de wijsbegeerte van het recht. Alphen aan den Rijn/Brussel?: Samson.

Schermer, M. H. N. (2001). The different faces of autonomy: a study on patient autonomy in ethical theory and hospital practice.

Amsterdam: Universiteit van Amsterdam.

Schmand, B., Gouwenberg, B., Smit, J. H., \& Jonker, C. (1999). Assessment of mental competency in community-dwelling elderly. Alzheimer Disease and Associated Disorders, 13(2), 80-87.

Scholten, P., \& Scholten, G. J. (1974). Mr. C. Asser's Handleiding tot de Beoefening van het Nederlands Burgerlijk Recht: Algemeen Deel (1) (derde druk). Zwolle: W.E.J. Tjeenk Willink.

Schwartz, H., \& Jacobs, J. (1979). Qualitative sociology: a method to the madness. New York/London: Free Press/Collier Macmillan.

Scottish Executive. (2001). Adults with Incapacity: leaflet. Internetwebsite. URL

http://www.scotland.gov.uk/justice/incapacity/AWI/awil-00.asp (consulted on August $22^{\text {nd }}$ 2001).

Shamoo, A. E., \& Keay, T. J. (1996). Ethical concerns about relapse studies. Cambridge Quarterly of Healthcare Ethics, 5, 373-386.

Silverman, H. (1997). The role of emotions in decisional competence: standards of competency and altruistic acts. Journal of Clinical Ethics, 8(2), 171-175.

Simon, H. A. (1983). Reason in human affairs. Oxford: Basil Blackwell.

Singer, P. (1991). Ethics. In Encyclopaedia Britannica (Vol. 18, pp. 492521).

Slabbers, S. (2006). Wie is de baas? Taakafbakening tussen psychiaters en psychologen. De Psycholoog, 41(3), 145-151.

Sluijters, B. (1985). Geknipt verband (rede). Deventer: Kluwer.

Sluijters, B., \& Biesaart, M. C. I. H. (2005). De geneeskundige behandelingsovereenkomst (2e druk). Deventer: Kluwer.

Sociaal-Wetenschappelijke Raad (SWR) [Social Sciences Council]. (2003). Gedragscode voor gebruik van persoonsgegevens in wetenschappelijk onderzoek: Advies van de Sociaal-Wetenschap- 
pelijke Raad [Code of conduct for use of personal data in scientific research: Advice of the Social Sciences Council]. Amsterdam:

Koninklijke Nederlandse Akademie van Wetenschappen [Royal

Netherlands Academy of Arts and Sciences]; URL

http://www.knaw.nl/swr/.

Spanjaard, M. (2006). Wie beslist? (wilsonbekwaamheid en

vertegenwoordiging) (3e ongewijzigde druk, Vol. 10). Utrecht:

Nederlandse Patiënten Consumenten Federatie.

Spicer, C. M. (1995). Codes, oaths, and directives related to bioethics:

oath of Hippocrates. In W. T. Reich (Ed.), Encyclopedia of Bioethics

(revised ed., Vol. 5, Appendix, pp. 2632). New York/London:

Macmillan/Simon \& Schuster and Prentice Hall International.

Sprung, C. L., \& Winick, B. J. (1989). Informed consent in theory and

practice: legal and medical perspectives on the informed consent

doctrine and a proposed reconceptualization [see comments]. Critical

Care Medicine, 17(12), 1346-1354.

Staatssecretaris van Volksgezondheid, Welzijn en Sport [Dutch State

Secretary of Health, Welfare and Sports]. (2004). Vaststelling van de begrotingsstaat van het Ministerie van Volksgezondheid, Welzijn en

Sport (XVI) voor het jaar 2004: Kamerstukken II 2003/2004, 29200 XVI, nr. 230; URL http://www.overheid.nl/op/index.html.

Stanley, B., Guido, J., Stanley, M., \& Shortell, D. (1984). The elderly patient and informed consent. Empirical findings. Jama, 252(10), 1302-1306.

Stichting Patiëntenvertrouwenspersoon Geestelijke gezondheidszorg. (2003). PVP jaarkrant (bevat jaarverslag 2002) (13e jaargang). Utrecht.

Stichting Patiëntenvertrouwenspersoon Geestelijke gezondheidszorg. (2004a). Jaarcijfers: vragen en klachten: Internet-Homepage Stichting PVP URL http://www.pvp.nl/teksten/subcategorie.htm (consulted on July $1^{\text {st }} 2004$ ).

Stichting Patiëntenvertrouwenspersoon Geestelijke gezondheidszorg. (2004b). PVP jaarkrant (bevat jaarverslag 2003) (14e jaargang). Utrecht.

Stocking, C. B., Hougham, G. W., Baron, A. R., \& Sachs, G. A. (2004). Ethics reporting in publications about research with Alzheimer's disease patients. Journal of the American Geriatrics Society, 52(2), 305-310.

Stoppe, G., \& European Dementia Consensus Network (Eds.). (2008). Competence assessment in dementia. Wien/New York: Springer.

Störig, H.-J. (1986). Geschiedenis van de filosofie 1 (Negentiende druk). Utrecht/Wijnegem: Aula/Het Spectrum (821). 
Sunderland, T., \& Dukoff, R. (1999). Surrogate decision making and advance directives with cognitively impaired research subjects. In $\mathrm{H}$. A. Pincus, J. A. Lieberman \& S. Ferris (Eds.), Ethics in Psychiatric Research: A Resource Manual for Human Subjects Protection (pp. 107-119). Washington, DC: American Psychiatric Association.

Szasz, T. S., \& Hollender, M. H. (1956). A contribution to the philosophy of medicine: the basic models of the doctor-patient relationship. A.M.A. Archives of Internal Medicine, 97, 585-592.

Thiel, G. J. M. W. van, \& Delden, J. J. M. van (1998). Respect in de verpleeghuiszorg: een normatief-ethisch en empirisch onderzoek naar respect voor autonomie van bewoners van verpleeghuizen. Utrecht: Cenrum voor Bio-Ethiek en Gezondheidsrecht, Universiteit Utrecht.

Tijmstra, T. (1987). Het imperatieve karakter van medische technologie en de betekenis van "geanticipeerde beslissingsspijt". Nederlands Tijdschrift voor Geneeskunde, 131(26), 1128-1131.

Tomoda, A., Yasumiya, R., Sumiyama, T., Tsukada, K., Hayakawa, T., Matsubara, K., et al. (1997). Validity and reliability of Structured Interview for Competency Incompetency Assessment Testing and Ranking Inventory. Journal of Clinical Psychology, 53(5), 443-450.

Tongeren, P. J. M. van (1991). Moraal, recht, ervaring: Katholieke Universiteit Nijmgegen.

Touwen, D. P. (2008). Voor een ander: beslissingsverantwoordelijkheden in de verpleeghuisgeneeskunde. Amsterdam: Aksant.

Treaty establishing a Constitution for Europe (Rome, 29 October 2004). (2004). Official Journal of the European Union (of 16 December 2004), 2004 C 310 (Volume 47); URL http://www.europa.eu.int/eurlex/lex/en/index.htm.

Treaty of Lisbon amending the Treaty on European Union and the Treaty establishing the European Community (Lisbon, 13 December 2007). (2007). Official Journal of the European Union (of 17 December 2007), 2007 C 306 (Volume 50); URL http://eurlex.europa.eu/en/index.htm.

Tronto, J. C. (1993). Moral Boundaries: A Political Argument for an Ethic of Care. New York/London: Routledge.

Tversky, A., \& Kahneman, D. (1981). The framing of decisions and the psychology of choice. Science, 211(4481), 453-458.

Tweede Kamer der Staten-Generaal. (1993/94). Kamerstukken II 1993/94, 21 561, nr. 28 (Toelichting bij amendement van het lid Kohnstamm).

Tymchuk, A. J., Ouslander, J. G., Rahbar, B., \& Fitten, J. (1988). Medical decision-making among elderly people in long term care. The 
Gerontologist, 28(Suppl.; Special Issue: Autonomy and long term care), 59-63.

UNESCO. (2004). Standard-setting action with a view to a Declaration on Universal Norms on Bioethics: URL http://portal.unesco.org/ (see under Themes "Social Sciences" > "Ethics" > "Bioethics" > "Declarations and other Instruments").

UNESCO. (2005). Universal Draft Declaration on Bioethics and Human Rights. Paris: URL

http://portal.unesco.org/shs/en/file_download.php/11445d5a75d2306 d7437f0626f35e1c1Draft_EN.pdf (consulted on October $\left.8^{\text {th }} 2005\right)$.

Vanderpool, H. Y. (1991). The competency of definitions of competency. In M. A. G. Cutter \& E. E. Shelp (Eds.), Competency: a study of informal competency determinations in primary care (Vol. 39, pp. 197-210). Dordrecht/Boston/London: Kluwer Academic Publishers.

Vandersteen, W. (1977). Suske en Wiske 165: de Sputterende Spuiter. Antwerpen/Amsterdam: Standaard Uitgeverij/N.V. Scriptoria.

Vandersteen, W. (1979). De avonturen van Suske en Wiske 130: de Steensnoepers. Antwerpen/Amsterdam: Standaard Uitgeverij.

Vansweevelt, T., Swennen, F., Heerdt, J. T., Weyts, B., \& Jeger, N. (1998). Het voorontwerp van wet "patiëntenrechten": een kritische analyse. Tijdschrift voor Gezondheidsrecht/Revue de Droit de la Santé, 3(5), 534-554.

Veen, E. B. van (1991). Mensenrechten en meerderjarige onbekwamen: rode draad "De positie van onbekwamen in het recht". Ars Aequi, 40(6), 484-493.

Veen, E.-B. van. (1998). De meerderjarige wilsonbekwame patiënt. In J. Legemaate (Ed.), De Wgbo: van tekst naar toepassing (derde druk, pp. 42-58). Houten/Diegem: Bohn, Stafleu Van Loghum.

Veldhuijsen, P. van (2001). Over het goede leven en het menselijk geluk: een klassieke beschouwing. In A. Denker (Ed.), Mensbeelden uit de geschiedenis van de filosofie (pp. 9-20). Budel: Damon.

Vellinga, A. (2006). To know or not to be: Development of an instrument to assess decision-making capacity of cognitively impaired elderly patients.

Vellinga, A., Smit, J. H., Leeuwen, E. van, Tilburg, W. van, \& Jonker, C. (2002). De beoordeling van wilsbekwaamheid bij ouderen met en zonder cognitieve stoornissen: de vignetmethode nader bekeken. Tijdschrift voor Gerontologie en Geriatrie, 33(november), 207-211. Vellinga, A., Smit, J. H., Leeuwen, E. van, Tilburg, W. van, \& Jonker, C. (2004). Competence to consent to treatment of geriatric patients: judgements of physicians, family members and the vignette method. International Journal of Geriatric Psychiatry, 19(7), 645-654. 
Vellinga, A., Smit, J. H., Leeuwen, E. van, Tilburg, W. van, \& Jonker, C. (2004). Instruments to assess decision-making capacity: An overview. International Psychogeriatrics, 16(4), 397-419.

Vollmann, J. (2002). Country Report: Germany. Country Report EPICC:

URL http://www.globalethics.bham.ac.uk/ResearchProjects/ EPICCIntro.htm.

Vollmann, J., \& Winau, R. (1996). The Prussian regulation of 1900: early ethical standards for human experimentation in Germany. IRB: $A$ Review of Human Subjects Research, 18(4), 9-11.

Vranken, J. B. M. (1995). Mr. C. Asser's Handleiding tot de Beoefening van het Nederlands Burgerlijk Recht: Algemeen Deel (2). Zwolle: W.E.J. Tjeenk Willink.

Wagenaar, W. A., \& Crombag, H. F. M. (2002). Ook rechters maken menselijke fouten. In P. J. van Koppen, D. J. Hessing, H. L. G. J. Merckelbach \& H. F. M. Crombag (Eds.), Het Recht van Binnen: psychologie van het recht (pp. 835-853). Deventer: Kluwer.

Walker, D. (1980). The Oxford Companion to Law. Oxford: Clarendon Press.

Warner, T. D., Roberts, L. W., \& Nguyen, K. (2003). Do psychiatrists understand research-related experiences, attitudes, and motivations of schizophrenia study participants? Comprehensive Psychiatry, 44(3), 227-233.

Warren, S. D., \& Brandeis, L. D. (1890). The right to privacy. Harvard Law Review, 4(5), 193-220.

Wason, P. C. (1966). Reasoning. In B. M. Foss (Ed.), New Horizons in Psychology (Vol. 1, pp. 135-151). Harmondsworth, England: Penguin Books.

Wegner, D. M. (2002). The Illusion of Conscious Will. Cambridge, Massachusetts/London, England: Bradford Books the MIT Press.

Weinfurt, K. P., Sulmasy, D. P., Schulman, K. A., \& Meropol, N. J. (2003). Patient expectations of benefit from phase I clinical trials: linguistic considerations in diagnosing a therapeutic misconception. Theoretical Medicine and Bioethics, 24, 329-344.

Weisstub, D. N. (1990). Mental Competency: final report. Toronto: Queen's printer for Ontario.

Welie, J. V. M. (1998). In the Face of Suffering: The PhilosophicalAnthropological Foundations of Clinical Ethics. Omaha, NE: Creighton University Press.

Welie, J. V. M. (1999). Do you have a healthy smile? Ugliness as a medical indication for dental and surgical treatment. Medicine, Health Care and Philosophy, 2(2), 169-180. 
Welie, J. V. M., \& Welie, S. P. K. (2001a). Editorial: Is incompetence the exception or the rule? Medicine, Health Care and Philosophy, 4(2), 125-126.

Welie, J. V. M., \& Welie, S. P. K. (2001b). Patient decision making competence: Outlines of a conceptual analysis. Medicine, Health Care and Philosophy, 4(2), 127-138. [reproduced in this volume as Chapter 4]

Welie, S. P. K. (2001a). Criteria for patient decision making (in)competence: A review of and commentary on some empirical approaches. Medicine, Health Care and Philosophy, 4(2), 139-151. [reproduced in this volume as Chapter 5]

Welie, S. P. K. (2001b). The Welie diagram. In M. Parker \& D. Dickenson (Eds.), The Cambridge medical ethics workbook: Case studies, commentaries and activities (pp. 174): Cambridge University Press.

Welie, S. P. K. (2002). Wilsbekwaamheid in de gezondheidszorg. In P. J. van Koppen, D. J. Hessing, H. L. G. J. Merckelbach \& H. F. M. Crombag (Eds.), Het Recht van Binnen: psychologie van het recht (pp. 85-106). Deventer: Kluwer. [reproduced in translation in this volume as Chapter 6]

Welie, S. P. K. (2005). Annotatie bij Rb. Arnhem 20 juli 2005, BJ 2005, 40. Bopz Jurisprudentie, 11(4), 252-256.

Welie, S. P. K., Blomert, L., Merckelbach, H., \& Vries, R. de (2004). De WMO en het wetenschappelijk onderzoek in de psychologie. De Psycholoog, 39(5), 268-274.

Welie, S. P. K., Dute, J., Nys, H., \& Wijmen, F. C. B. van (2005). Patient incompetence and substitute decision-making: An analysis of the role of the health care professional in Dutch law. Health Policy, 73(1), 21-40. [reproduced in this volume as Chapter 7]

Wendler, D. (2004). Can we ensure that all research subjects give valid consent? Archives of Internal Medicine, 164(20), 2201-2204.

Wenger, N. S., \& Halpern, J. (1994). Can a patient refuse a psychiatric consultation to evaluate decision-making capacity? Case and discussion. The Journal of Clinical Ethics, 5(3), 230-234.

Wenger, N. S., Oye, R. K., Bellamy, P. E., Lynn, J., Phillips, R. S., Desbiens, N. A., et al. (1994). Prior capacity of patients lacking decision making ability early in hospitalization: implications for advance directive administration. The SUPPORT Investigators.

Study to Understand Prognoses and Preferences for Outcomes and Risks of Treatments. J Gen Intern Med, 9(10), 539-543.

Wettstein, R. M. (1995). Competence. In W. T. Reich (Ed.), Encyclopedia of Bioethics (revised edition, Vol. 1, pp. 445-451). New York [etc.]: Macmillan Library Reference. 
Weyers, W. (2003). The abuse of man: An illustrated history of dubious medical experimentation. New York: Ardor Scribendi, Ltd.

White, B. C. (1994). Competence to Consent. Washington, D.C.: Georgetown University Press.

Whymant, R. (1983). The butchers of Harbin: experimentation on POWsJapan, World War II. Connecticut Medicine, 47(3), 163-165.

Wiarda, G. J. (1988). Drie typen van rechtsvinding (derde druk). Zwolle: W.E.J. Tjeenk Willink.

Widdershoven, G. (1987). Handelen en rationaliteit: een systematisch overzicht van het denken van Wittgenstein, Merleau-Ponty, Gadamer en Habermas. Meppel: Boom.

Widdershoven, G. (2000). Ethiek in de kliniek: hedendaagse benaderingen in de gezondheidsethiek: Boom.

Widdershoven, G., \& Berghmans, R. (2002). Wilsbekwaamheid in de ouderenzorg. Tijdschrift voor Gerontologie en Geriatrie, 33(november), 201-206.

Widdershoven, G. A. M., \& Berghmans, R. L. P. (2004). Wilsbekwaamheid in de zorg voor mensen met een verstandelijke beperking. Nederlands Tijdschrift voor de Zorg aan mensen met verstandelijke beperkingen, 30(3), 166-180.

Widdershoven, T. P. (2003). Psychiatrie en Recht: De Wet Bopz en de psychiatrie - Kanttekeningen bij een regeling (Preadvies uitgebracht ten behoeve van de jaarvergadering van de Vereniging voor Gezondheidsrecht op 11 april 2003): Vereniging voor Gezondheidsrecht.

Widdershoven, T. P. (2006). Na de Wet Bopz: Aandachtspunten voor een regeling van psychiatrische dwang. Tijdschrift voor Gezondheidsrecht, 30(7), 488-503.

Wijmen, F. C. B. van (1990). Driehoeksverhoudingen: gezondheidsrechtelijke beschouwingen over vertegenwoordiging van meerderjarige onbekwamen (Preadvies uitgebracht ten behoeve van de jaarvergadering van de Vereniging voor Gezondheidsrecht op 27 april 1990): Vereniging voor Gezondheidsrecht.

Wijmen, F. C. B. van (1996a). Goed patiëntschap als spiegelbeeld van verantwoorde zorg. Deventer: Kluwer.

Wijmen, F. C. B. van (1996b). Onbekwaamheid en onbekwamen. In P. J. H. Laurs, W. J. A. M. Dijkers \& T. P. J. C. Widdershoven (Eds.), Handboek Opneming en Verblijf (pp. A3.1 - 1-32). Arnhem: Gouda Quint.

Wijmen, F. van (2006). Een kleine mooie ritselende revolutie: over de effectiviteit van 35 jaar patiëntenrechten in Nederland. Maastricht.

Wilson, K. G. (2006). Valued Living Questionnaire: Working Manual V. 6-3-06: URL 
http://www.onelifellc.com/VLQ\%20working\%20manual\%20v6-306.pdf (consulted on May $26^{\text {th }} 2008$ ).

Wilson, K. G., \& Groom, J. M. (2002). Valued Living Questionnaire:

URL http://www.onelifellc.com/VLQ\%205-22-02.pdf (consulted on May $\left.26^{\text {th }} 2008\right)$.

Winograd, C. H. (1984). Mental status tests and the capacity for self-care. Journal of the American Geriatrics Society, 32(1), 49-55.

Winter, H. B. (1997). Evaluatie van het gezondheidsrecht: de Wet Bopz als casus. Tijdschrift voor Gezondheidsrecht, 21(7), 382-393.

Wong, J. G., Clare, C. H., Holland, A. J., Watson, P. C., \& Gunn, M. (2000). The capacity of people with a 'mental disability' to make a health care decision. Psychological Medicine, 30(2), 295-306.

Wong, J. G., Clare, I. C., Gunn, M. J., \& Holland, A. J. (1999). Capacity to make health care decisions: its importance in clinical practice. Psychological Medicine, 29(2), 437-446.

World Health Organization: European Region. (2005). Mental Health Declaration for Europe: Facing the Challenges, Building Solutions: URL http://www.euro.who.int/document/mnh/edoc06.pdf.

World Health Organization: Regional Office for Europe. (1994). Declaration on the Promotion of Patients' Rights in Europe: URL http://www.who.int/genomics/public/eu_declaration1994.pdf.

World Medical Association. (1964 (as most recently amended in 2000)). Declaration of Helsinki/Ethical principles for medical research involving human subjects: URL http://www.wma.net/e/policy/b3.htm.

Yeide, H., Jr. (1992). The many faces of autonomy. Journal of Clinical Ethics, 3(4), 269-274.

Zajonc, R. B. (1980). Feeling and thinking: Preferences need no inferences. American Psychologist, 35(2), 151-175.

Zajonc, R. B. (1984). On the primacy of affect. American Psychologist, $39(2), 117-123$.

Zeeuw, J. d. (1995). Algemene psychodiagnostiek I: Testmethoden (7e geheel herziene druk). Lisse: Swets \& Zeitlinger.

Zeeuw, J. d. (1996). Inleiding in de psychodiagnostiek: het psychologische testonderzoek (derde geheel herziene druk). Lisse: Swets \& Zeitlinger.

Zentrale Ethikkommission bei der Bundesärztekammer [Central Ethics Commission at the German Federal Chamber of Physicians]. (1997). Stellungnahme zum Schutz nicht-einwilligungsfähiger Personen in der medizinischen Forschung [Statement on the protection of mentally incapable patients in medical research]. Köln: URL http://www.zentrale-ethikkommission.de/10/70Schutz.html. 
ZorgOnderzoek Nederland. (2001). Evaluatie regelgeving: programmatekst. Den Haag.

Zwart, H. A. E. (1993). Ethische consensus in een pluralistische samenleving: de gezondheidsethiek als casus. Amsterdam: Thesis Publishers. 


\section{AUTHOR INDEX}

Abernethy 144, 209

Advisory Committee on Human

Radiation Experiments 58, 209

Agich 13, 43, 209

Alexander 121, 209

Algra 167, 209

American Medical Association 12, 209, 218, 219, 225

American Psychiatric Association 126, 161, 209, 223, 236

American Psychological Association 22, 42, 209

Annas 57, 210

Appelbaum 6, 7, 14, 20, 27, 31, 32, $36,59,63,69,70,72,76,85,97$, $120,121,124,125,135,154,189$, $210,214,222,226-228$

Armstrong 11, 210

Ashworth Underwood 11, 210

Atkinson 151, 211

Backlar 64, 211

Ballard-Reisch 43, 211

Bargh 35, 223

Baron 61, 235

Bartko 214

Bartolucci 229

Bateman 6, 210

Baumann 228

Bean 121, 211

Beauchamp 5, 11-14, 20, 85, 97, 108, 120, 144, 166, 177, 189, 190, 211, 220, 225

de Beaufort 13, 14, 144, 218

Bechara 155, 156, 211

Beecher 58, 211

Begeleidingscommissie evaluatie

Wet Bopz 81, 148, 192, 211

Beijers 148, 231

Beijk-Damen 203, 211

Bellamy 239

Bensing 43, 211

Benson 69, 210 van den Bercken 74, 231

Berghmans v, 6, 7, 11, 18, 20-22, 29, $31,38,43,55,57,63,64,70,74$, 134, 160, 189, 192, 194, 203, 211 , 212, 240, 261

Bergkamp 58, 212

Bergsma 164, 226

Berlin 13, 212

Bernstein 151, 212

Bielby 6, 212

Biesaart 7, 10, 91, 121, 154, 188, 192, 212, 227, 234

Bijma 24, 212

Black 1, 82, 135, 161, 213

Blankman 6, 17, 148, 181, 186, 188, 198, 213, 231

Blomert 11, 239

Bloom 43, 213

de Boer 38, 213

Bozzola 228

Brahn 144, 213

Brandeis 13, 238

Bravo 63, 213

British Medical Association 6, 68, 69, 213

Brock 7, 20, 27, 73, 85, 96, 107, 166, $167,189,214$

Brodsky 7, 214

Brody 227

Brown 149, 213, 262

Bruggink 22, 213

Buchanan 7, 20, 27, 73, 85, 96, 107, 166, 167, 189, 214

van der Burg 12, 214, 224

Bursztajn 6, 7, 214, 223

Burt 57, 214

Buskist 151, 214

Callahan 135, 214

Caminada 220

Capron 56, 214

Carlson 151, 214

Carpenter 57, 59, 60, 63, 65, 214 
Charland 7, 135, 160, 214, 215

Charney 58, 215

Chatterjee 228

Checkland 5, 6, 20, 98, 166, 215, 228

Childress 11-13, 120, 144, 177, 211

Clare 7, 70, 127, 194, 222, 230, 241

Clarke-Stewart 151, 212

Clouser 96, 109, 110, 154, 221

Cody 162, 229

Cohen MJ 4, 121

Combrink-Kuiters 80, 215

Comité Consultatif National d'Ethique pour les sciences de la vie et de la santé 67,215

Committee of Ministers of the Council of Europe 22, 42, 60, 66, 88, 161, 176, 181, 203, 215, 216

Conley 70, 214, 217

Council for International Organizations of Medical Sciences 60, 73, 216

Cournos 121, 216

Creswell 86, 216

Crombag vi, 4, 22, 150, 151, 156, 159, 216, 217, 238, 239, 261

Culver 6, 16, 74, 96, 100, 109, 110 , 130, 154, 167, 169, 191, 217, 221, 262

Cuneiform Law 93, 217

Damasio AR 155, 156, 160, 161

Damasio H 155

Danis 223

Daugherty 70, 217

Davison 161, 217

Dawes 154, 217

van Delden 20, 21, 192, 197, 217, 228, 236

DeMarco 19, 217

Department for Constitutional Affairs 68, 176, 217

Derde evaluatiecommissie van de Wet Bopz 17, 81, 217

DeRenzo 70, 74, 217

Desbiens 239

de-Nesnera 233

Diamond 128, 217
Dijkers 17, 188, 218, 240

Dillmann 152, 153, 218

Donker 29, 218

Drane 6, 19, 90, 124, 168, 191, 218

Drenth 164, 218

Dresser 56, 64, 218

Dubois 63, 213

Dukoff 63, 236

Dupuis 13, 14, 144, 145, 218

Dute vi, 12, 80, 155, 175, 218, 224, 239

Dworkin 21, 218, 219

Eckstein 56, 63, 219, 231

Elizur 230

Elliott 5, 7, 219

Emanuel EJ 43, 74, 203

Emanuel LL 43, 203

Engberts 12, 202, 219

Engelhardt 13, 219

Erde 32, 156, 219

European Commission 65, 219

European Dementia Consensus Network 6, 224, 235

European Union 39, 60, 61, 68, 91, 215, 219, 229, 236

Evaluatiecommissie Wet Bijzondere opnemingen in psychiatrische ziekenhuizen $81,87,220,225$

Evans D 60

Evans M 60

Evers 164, 220

Faden 5, 11-14, 20, 21, 43, 59, 108, 168,220

Faust 154, 166, 217, 231

Federatie van Medisch Wetenschappelijke Verenigingen 62, 220

Fedoroff 120, 222

Feinberg 177, 220

Fiselier 22, 220

Fitten 121, 128, 129, 162, 191, 220, 221,236

Fletcher 222

Flory 74, 221

Fogel 166, 231

Ford 225

Fraenkel 151, 221

Franken 11, 82, 221 
Frankfurt 21, 221

Franx 21, 221

Frederiks 188, 221

Freedman B 6, 32, 130, 156, 167, 191

Freedman M 121

Freud 35, 155, 221

Fridlund 151, 222

Friele 218, 224

Frijda 7, 135, 160, 161, 169, 221

Garanis-Papadatos 27, 231

Gauthier 64, 225

van Gemert 7, 212

General Assembly of the United Nations 60, 221

General Conference of UNESCO 22, 60,221

General Medical Council 68, 221

Gert 6, 16, 74, 85, 96, 100, 109, 110, $130,154,167,169,191,217,221$

Gevers 6, 7, 10, 12, 13, 16, 20, 29, $35,40,90,144,153,159,167$, 181, 186, 192, 193, 195-197, 199, 203, 218, 222, 224, 227

Gezondheidsraad 29, 191, 192, 217, 222

Gibson 203, 227

Glancy 211

Glass 7, 64, 71, 127, 191, 222, 225

Gleitman 151, 222

Gokkel 167, 209

Gold 214

Golinger 120, 222

Gonzalez 228

Gordon 221

Gouwenberg 7, 121, 148, 154, 162, $163,192,222,234$

Green 215

Grisso 7, 14, 27, 31, 32, 36, 69, 70, $72,85,97,120,121,154,191$, $210,222,228$

Grochowski 217

Grodin 57, 210

Groom 203, 241

Groth-Marnat 121, 154, 162, 164, 166,222

Grubb 177, 201, 222
Guido 235, 261

Gunn 70, 194, 222, 241

Gutheil 6, 7, 214, 223

Haanappel 151, 223

Haekens 6, 21, 223

Halpern 127, 239

Hamann 162, 220

Hanson 122, 223

Harding 7, 214

Harré 164, 223

Harrell 162, 228, 229

Harvey 6, 96, 232

Hassin 35, 223

ten Have 11-14, 20, 21, 74, 120

Hawkins 229

Hayakawa 236

Heerdt 20, 237

Helmchen 68, 223

Hendriks 12, 80, 223

Hengeveld 151, 223

Hermans 35, 203, 218, 223

Hilgard 151, 211

Hill-Fotouhi 7, 222

Hipshman 89, 224

Hoefnagels 13, 74, 231

Hofstee 80, 224

Holden 228

Holland 70, 194, 222, 241

Hollender 43, 236

Hondius 6, 224

Honig 6, 224

Hougham 61, 235

Hubben 7, 85, 154, 188, 212, 218 , 224

Hughes 6, 224

Hutschemaekers 24, 212

Ingram 162, 228, 229

International Conference on Harmonisation of technical requirements for registration of pharmaceuticals for human use 60,224

International Committee of Medical Journal Editors 61, 224

Ippel 4, 12, 214, 224, 261

Jackson 225

Jacobs 87, 234

Jaffe 225 
Janofsky 130, 224

Jansen I 198

Jansen S 66, 147, 186, 193

Jeger 20, 237

Jernigan 217

Jeste 63,226

Jonas 74,225

Jones 57,225

de Jong 194, 225

Jonker 7, 72, 154, 192, 222, 234, 237,238

Jörg 1, 225

Kabinetsstandpunt 17, 148, 192, 225

Kahn 58, 229

Kahneman 158, 159, 236

Kane 63, 214

Kapp 7, 127, 162, 192, 225

Katz J 57

Kawakami 226

Keay 63, 234

Keenan 223

Kelk 1, 225

Keller 21, 225

Kempen 35, 223

Keyserlingk 64, 225

Kihlstrom 35, 226

Kim 63, 226

Kimchi 230

King 5, 14, 220

Kitamura 127, 154, 191, 226

Klijn 167, 209

van de Klippe 6, 17, 20, 89, 90, 97, 152, 188, 189, 191-193, 197, 226

Knuiman 6, 226

Kodish 217

Kogan 64, 225

Komen 82, 226

Koning 220

Koninklijke Nederlandsche Maatschappij tot bevordering der Geneeskunst 6, 8, 20, 90, 153, 186, 187, 198, 200, 226

Koninklijke Notariële Beroepsorganisatie 8, 16, 226

van Koppen vi, 150, 216, 238, 239

Kunst-Wilson 156, 226

ten Laak 164, 220, 226
Lahti 214

Laín Entralgo 43, 226

Lamb 164, 223

Lambert 203, 227

Lavori 65, 227

Law Commission 5, 68, 89, 91, 176, 227

Law Society 6, 68, 69, 213

Lawton 127, 227

Leenen $6,7,10,12,13,20,29,35$, 40, 90, 144, 153, 159, 167, 186, 192, 193, 195-197, 199, 203, 227

van Leeuwen 11, 72, 154, 192, 223, 237, 238

Legemaate 4, 6, 12, 20, 27, 40, 85, $89,90,97,152-154,164-167,181$, 192-194, 196, 197, 218, 224, 227. 237,261

Lersch 151, 227

Levine 59, 64, 214, 227

Lewis 58,215

Lezak 127, 164, 227

Lidz 1, 7, 14, 38, 43, 69, 76, 189, 210, 227-229, 233

Loenen 22, 152, 228

Lord Chancellor's Department 68, 176,228

Lötjönen 63, 67, 68, 228

Love 70, 101, 217

Lusky 162, 220

Lynn 239

van der Maas 106, 228

Mace 151, 232

Mackaay 151, 223

Mackie 82, 228

MacNabb 82, 228

Madigan 5, 89, 136, 228

van der Maesen de Sombreff 220

Mangone 121, 228

Marson 121, 162, 191, 228, 229

Marta 100, 111, 229

Martin 151, 214

Marx 228

Mastroianni 58, 229

Matsubara 236

May 96, 100

McCarthy 224 
McCue 215

McHugh 221

McInturff 229

McKegney 120, 229

McKeown 217

McNeill 57, 59, 229

Medical Research Council 68, 229

Meehl 154, 217

Meisel 1, 7, 14, 189, 210, 228, 229, 233

Melamed 121, 230

Mendelson 22, 230

Merckelbach vi, 11, 216, 238, 239

Meropol 70, 238

Messina 217

ter Meulen 11, 223, 261

Michels 73, 230

Mick 217

Miller 20, 21, 230

Ministerie van Justitie 6, 8, 28, 85, $89,90,152-154,164,180,190$, 192,230

Ministerie van Volksgezondheid, Welzijn en Sport 63, 217, 220, 230,235

Mirkin 6, 210

Mishima 226

Moldavski 230

Moody 43, 230

Morgan 43, 230

Morimura 58, 230

Moseley 217

Moskowitz 225

Mossman 7, 127, 162, 192, 225

Muijlwijk 80, 230

Mulvey 222

Munetz 228

Murphy 7, 127, 230

Musschenga 13, 230

Mutran 223

Nathanson 203, 227

National Bioethics Advisory Commission 58, 64, 218, 230

Nationale Raad van de Orde van Geneesheren 65, 230

Neale 161, 217

Nelson 166, 231
Nemeroff 58, 215

Nguyen 76, 238

Nicholson 61, 231

Nisbett 159, 231

Nishisato 211

Nolan 161, 213

Nolan-Haley 161, 213

Nuremberg Military Tribunals 57, 59, 231

NVVA beroepsvereniging van verpleeghuisartsen en sociaal geriaters 6,231

Nys vi, 27, 68, 175, 176, 231, 239, 261

O'Dowd 229

Oevermans 12, 214

Office of the Public Guardian and Trustee - Ontario Ministry of the Attorney General 6, 176, 231

Ogletree 5, 231

Olde Rikkert 13, 70, 74, 231

Olin 63, 226

Olsthoorn-Heim 81, 231

Oomens 148, 231

Oostra 7, 212

Osterweis 228

Ouslander 236

Oxford English Dictionary Online 84,232

Oye 239

Pappworth 57, 232

Pâquet 63, 213

Pascal 143, 156, 232

Pellegrino 96, 203, 232

Pepper-Smith 6, 96, 107, 232

Percival 12, 232

Pereyra 228

Peters 151, 232

Pfeiffer 232

Phillips 239

Piaget 35, 232

Pijnenborg 228

Pincoffs 6, 33, 135, 168, 232

Plato $11,151,232$

Ploumpidis 27, 231

Pomerantz 111, 233 
Pontifical Council for Pastoral

Assistance to Health Care

Workers 13, 233

President's Commission for the

Study of Ethical Problems in

Medicine and Biomedical and

Behavioral Research 5, 7, 14, 18, 29, 70, 176, 189, 218, 233

Purtilo 43, 233

Queern 214

Raad voor Gezondheidsonderzoek 62,220

Raadgevend Comité voor Bio-Ethiek 66, 233

Rahbar 236

Ratain 217

Reber 35, 156, 164, 233

Rector 3, 211

van Ree 21, 233

Reehuis 144, 213

Reisberg 151, 222

Renaud 69, 228

Roberts B 56

Roberts LW 56, 76

Roscam Abbing 144, 218, 224, 233

Rosenfeld 121, 233

Rosenhan 150, 233

Ross 159, 231

Roth 1, 6, 7, 20, 69, 97, 124, 125, $148,189,192,210,229,233$

Roy 151,212

Ruskin 120, 234

Rutman 121, 234

Sachs 61, 235

Sanguinetti 228

Schacter 35, 234

Scheltens 21, 234

Schermer 6, 8, 18, 21, 28, 40, 91, 234

Schmand 7, 154, 192, 222, 234

Scholten GJ 11

Schooler 63, 214

Schulman 70, 238

Schwartz H 87

Scottish Executive 176, 234

Shamoo 63, 234

Shimozato 58, 230
Shnit 230

Shortell 235

Sijtsma 164, 218

Silberfeld 5, 6, 20, 96, 98, 121, 166, 215, 228, 232, 234

Silverman 7, 234

Simon 159, 234, 235

Singer 21, 82, 234

Slabbers 4, 234

Sluijters 12, 91, 144, 224, 234

Smit 7, 72, 154, 192, 222, 234, 237, 238

Smith 6, 96, 107, 151, 211, 232

Sociaal-Wetenschappelijke Raad 62, 234,235

Spanjaard 6, 235

Spicer 12, 235

Spijker 22, 220

Sprung 168, 235

Staatssecretaris van Volksgezondheid, Welzijn en Sport 63, 235

Stalmeier 21, 221

Stanley B 120

Starren 220

Stichting Patiëntenvertrouwenspersoon Geestelijke gezondheidszorg 147, 235

Stocking 61, 217, 235

Stoppe 6, 224, 235

Störig 151, 235

Stuss 221

Sugarman 65, 227

Sulmasy 70, 238

Sumiyama 236

Sunderland 63, 236

Swennen 20, 237

Szasz 43, 236

Tanaka 226

van Thiel 20, 21, 236

Tholen 6, 226

Thomasma 96, 232

Tijmstra 145, 236

van Tilburg 72, 154, 192, 237, 238

Timmermans 21, 221

Tomoda 121, 154, 191, 226, 236

van Tongeren 19, 38, 39, 236

Touwen 40, 236 
Tranel 155, 211

Tronto 21, 236

Tsukada 226, 236

Turkheimer 121, 233

Tversky 158, 159, 236

Tweede Kamer der Staten-Generaal 91,236

Tymchuk 121, 236

Uleman 35, 223

UNESCO 22, 60, 221, 237, 263

Vanderpool 169, 237

Vandersteen 2, 237, 259, 260

Vansweevelt 20, 197, 237

van Veen 6, 177, 192, 199, 203, 237

van Veldhuijsen 151, 237

Vellinga 7, 72, 154, 191, 192, 211, 237, 238

Verweij 13, 231

van Vliet-Mulder 164, 220

Vollmann 59, 67, 238

Vranken 11, 238

de Vries 11, 239

van der Waal 22, 220

Wagenaar 150, 159, 216, 238

Waite 121, 221

Walker 82, 161, 238

Warner 76, 238

Warren 13, 238

Wason 157, 169, 238

Watson 194, 241

Wegner 35, 238

Weinfurt 70, 238

Weisstub 7, 21, 28, 70, 85, 89, 176, 238

Welie JVM 21, 22, 30, 38, 85, 99, $100,122,153$

Wendler 74, 239

Wenger 121, 127, 239

Wettstein 5, 18, 20, 85, 96, 239

Weyers 57-59, 240

Weyts 20, 237

White 1, 6, 12, 21, 32, 85, 89, 124, $153,154,190,240$

Whymant 58,240

Wiarda 11, 22, 240

Wickens 151, 212
Widdershoven GAM 12, 35, 38, 84, 144, 192, 203

Widdershoven TP 17, 188

de Wijkerslooth 4, 217

van Wijmen 4, 6, 12, 89, 153, 164, $175,177,183,186,192,194,199$, 224-226, 239, 240

Wilson 156, 203, 226, 240, 241

Winau 59, 238

Winick 168, 235

Winograd 128, 129, 241

Winslade 69,210

Winter 80, 241

Wong 70, 194, 222, 241

World Health Organization: European Region 60, 241

World Health Organization:

Regional Office for Europe 60, 241

World Medical Association 59, 241

Yasumiya 236

Yeide 13, 21, 241

Zajonc 156, 226, 241

de Zeeuw 164, 241

Zentrale Ethikkommission bei der Bundesärztekammer 67, 241

ZorgOnderzoek Nederland 80, 218, 224, 242

Zuijderhoudt 6, 224

van Zutphen 148, 231

Zwart 12-14, 242 


\section{FIGURE INDEX}

Figure A.

Two relevant dimensions in relation to patients' values ...... p. 23

Figure B.

Normative and descriptive aspects of patient competence and its

assessment ............................ 34

Figure C.

Decision tree regarding the assessment of patient competence according to the recognisable reasons approach in combination with the notion of a supportive situation $\ldots \ldots \ldots \ldots \ldots \ldots$ p. 37

Figure D.

The situations in which a patient must be treated as competent . . p. 39

Figure E.

Decision tree regarding legitimate triggers for competence assessment ............................ 41

Figure F.

Definitions of competence $\ldots \ldots \ldots \ldots \ldots \ldots \ldots \ldots \ldots$ p. 96

Figure G.

Psychiatric conditions obstructing cognitive content ....... p. 125

Figure $\mathrm{H}$.

Psychiatric conditions obstructing manipulation of cognitive

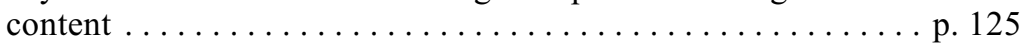

Figure I.

Psychiatric conditions obstructing freedom of will ........ p. 126

Figure J.

Psychiatric conditions obstructing ability to express one-self . . p. 126

Figure K.

Decision tree regarding the legal consequences of patient

competence vs. incompetence (art. 7:465 Dutch Civil Code) ... p. 184 


\section{SUMMARY}

Patient competence is the subject of the present dissertation, which reflects its author's quest for criteria of the said concept. The leading research question in this quest is: how ought patient competence to be assessed? This main question is divided into sub-questions relating to the rationale of patient competence, the relevance of patient competence, legal consequences in competence assessment, criteria for assessing patient competence, problems in competence assessment, the underlying norm in competence assessment, preconditions of competence assessment, the conformity of available criteria with these preconditions, test-like instruments for assessing competence, the psychological validity of criteria in the light of everyday decision-making, the role of emotionality in patient competence, possible support during competence assessment, and indications for such assessment.

With the exception of the overview, which forms the first chapter (see below), this dissertation's chapters are papers that have been published elsewhere, and three of them have one or more co-authors (see the Preface for bibliographic data).

The second chapter of this dissertation gives a legal-ethical outline of the research context, treating competence in relation to clinical trials using patients with severe mental illness as subjects. It enumerates several (international) legal and ethical documents pertaining to human experimentation. These documents have in common that they establish valid consent on behalf of the participant as a necessary condition for legitimate subjection of the participant to research interventions. One of the necessary conditions for the validity of consent is the consenting person's competence. Also, the chapter gives a brief comparison with four other European countries and a discussion of normative aspects of competence to consent to participation in research, which aspects relate to the tension between the goal of protecting vulnerable patients and the goal of favouring scientific progress. It ends with a sketch of the decision-making procedure called "experienced consent".

Chapter Three reports on a qualitative empirical research study into assessment of patient competence in a (psycho-)geriatric care setting. During this study, health care professionals were observed in the daily course of their activities and later interviewed about the observed results. The original aim of the study was to make an inventory of criteria used by health care professionals in their assessment of patient competence. 
Unexpectedly, the study revealed that patient competence is not a topic of discussion at all in the observed practice, although the setting had expressly been selected so as to increase the chances of encountering patients with questionable ability to decide for themselves. Apparently, there is a discrepancy between the pivotal place competence occupies in theoretical models of decision-making, and the actual attention this concept receives in daily health care practice. This result has been confirmed in numerous informal contacts with other health care professionals and academic researchers.

In the chapter, the significance of these factual research data for the law is explored. It is argued that these data must not be taken as signalling a shortcoming in health care practice, but that they can methodically serve as an occasion to critically re-examine the legal model, notably the concept of competence (see Chapter 4), available empirical approaches for assessing competence (see Chapter 5), psychological considerations on competence assessment (see Chapter 6), and the legal role of the health care professional with respect to patient competence (see Chapter 7).

In the fourth chapter, the critical examination of the concept of competence is taken up. After a brief introduction to different approaches used in relation to patient decision-making competence and to the literal meaning of the term "competence", an outline of four necessary conditions for competence assessment is given, starting from a task-specific definition of the concept. These conditions are (1) that the kind of task be known, (2) that it be known what constitutes sufficient fulfilment of the task at hand, (3) that the required abilities and qualities be known, and (4) that it be ascertainable whether or not the person in question actually has the required abilities and qualities. Application of these conditions to the field of health care makes us substitute health care decision-making for the task at hand in the first condition. Since health care decision-making may involve vital interests, such as a persons's life, somatic and mental health, functional ability and well-being, of a vulnerable group, i.e. patients, this task entails an important responsibility. From the second condition, it is immediately clear that competence assessment includes a normative dimension: a threshold is needed to distinguish sufficient from insufficient fulfilment. It is suggested that decision-making fostering beneficial health care tailored to the personal needs and values of the individual patient ought to comprise the necessary threshold. The chapter underlines the necessity of patient involvement in decision-making on the assumption that health related 
interests are too individual to be expressed in commonly applicable terms and too personal to be wholly knowable for health care professionals. As to the third condition, such decision-making requires adequate judgment of the patient's own health related interests. The qualities and abilities presupposed for that sort of judgment fall into the following four elements, implying four cumulative criteria of patient decision-making competence, namely cognitive content (knowledge of facts and personal values), manipulation of cognitive content (analysing, reasoning, prioritising, integrating etc.), freedom of will, and means of expression. The reader should note that possession of these qualities enables the patient to decide in favour of beneficial health care, but does not compel him to do so.

The fourth condition relates to the testability of patient incompetence. Testability of the abilities and qualities required for patient competence, provides the assessor of competence with an empirical basis for deviating from the assumption of competence, as the occasion arises.

The fifth chapter embroiders on this notion of testability by reviewing some empirical approaches for assessing patient competence or incompetence. It distinguishes between a negative approach, which focuses on identifying psychopathologic conditions that impair sound decision-making, and a positive approach, which attempts to assess whether a patient actually has the required abilities and qualities. The chapter shows that none of the reviewed approaches offers a reliable and valid method for competence assessment. Typical of the negative approach is that it practically includes the whole range of psychiatry. This is unsatisfactory, because it unsettles the principle of autonomy with respect to psychiatric patients. In other words, the negative approach may be very sensitive; but it lacks specificity. The insufficiency of the positive approach can be attributed to the fact that the abilities and qualities measured by the tests in question have limited relevance in the context of patient competence.

Among other things, the chapter's commentary addresses situational influences in patient competence and competence assessment, of which a weighty one is the health care professional herself. After all, she shapes the decision-making task for the patient and judges whether he is able to perform it. Patient behaviour associated with incompetence might be reducible to mental incapacity indeed, but it may just as well be the consequence of a lack of situational support. Such support is possible with a view to all four qualities and abilities mentioned in the previous chapter. In this regard, the assessor of patient competence has the duty of structuring the situation so as to optimise the chances that the person under investigation meets the criteria of competence. In other words, the 
assessor should not simply attempt to establish the patient's incompetence, but rather try to get the person to competently decide himself.

Sixthly, after the empirical review of Chapter 5, the next chapter embarks upon a psychological analysis of the concept of patient competence. It concentrates on two elements that are part of common models for patient competence, namely conscious motivation of decision-making in the first place and consistency of information-processing in the second. By means of some illustrative psychological theory and several research examples, it is argued that in general, the aforesaid models aim too high: application of these two elements as standards for competence would easily exceed the way in which persons usually make decisions, certainly when we are talking about patients who are not quite their normal selves after they have been overcome with sudden disease.

An investigation of the potential significance of emotionality as criterion of competence, leads to the conclusion that a patient's emotions do have relevance to competence assessment in that they may be indicative of this patient's interests and values, but also to the conclusion that the emotions' relevance in the context of patient competence is limited in that they do not decide the matter just like that. Furthermore, the inherent impossibility of psychometric tests for measuring patient competence is demonstrated -at least for those cases which raise the need for tests- by employing psychometric theory and relating that theory to the rationale of the concept of competence and the underlying principle of respect for patient autonomy. At the end, this chapter points to the necessity of obtaining an explicit normative framework for passing judgments on patient competence.

In the previous chapters it was noticed that clear, concrete, fair criteria of patient competence which can be reliably and validly assessed at that, are lacking. In view of this lack, it is not surprising that health care professionals only rarely venture upon such an assessment in their daily practice. The seventh chapter, lastly, inquires into the question whether any grounds can be found in the law for the health care professional to get round judging patient competence. It does so by critically re-examining the role of the health care professional in the legal model.

The result of this is that the health care professional is indeed shown to have reasons justifiably to steer clear of explicit competence assessment: generally speaking, the professional may want to appeal to the assumption of patient competence, when she thinks that there is no legitimate trigger for calling it into question. The deeper cause of this is the fact that the health care professional is expected to evaluate to a 
certain extent herself the personal interests of her patient, and to incorporate this evaluation in her "medical" decision-making concerning the patient. If under these circumstances the health care professional succeeds in persuading the patient and any other persons involved (e.g. family members or other potential representatives) to assent to the interventions proposed by her, she is permitted to act on the assumption that the decision is representative for the interests of the patient. Insofar as the health care professional rightly takes care of judging her patient's interests -and properly so-, there is no -or, at any rate, less of aneed for the patient to do this; and insofar as the patient has no task in judging his interests, it directly follows from the task-specific character of the concept that competence does not matter in this regard, and hence does not have to be assessed. And that demonstrates that from a legal point of view, the health care professional can often refrain from assessing competence, or even that she has to refrain from such assessment. Finally, attention is drawn to the question how professionals could be able to judge their patients' interests, and to the possible use of the so-called values history in this respect.

The Overview chapter (Chapter 1), preceding the publications summarised above, explicates the interrelationship between these publications. In this overview, it is argued that in organising and implementing patient care, health care professionals should try to create circumstances under which it is justified to appeal to the assumption of competence conceived as a presumption of law. The obligation in question amounts to doing everything possible to take seriously the subject of the patient and his wishes, experiences, questions and hesitancies, and to doing their utmost to shape professional care interventions in such a way that they are adapted to the patient's values, interests, needs and lifestyle.

The incidence of cases in which an assessment of patient competence is nevertheless necessary, with transfer of the decisional power to someone other than the patient as a possible consequence, cannot be totally ruled out. The exposition in hand proposes that they be limited to those situations where one or both of two strictly defined legitimate triggers present themselves. On the premise that a test of competence is about testing the quality of the decision-making process, the author defends as criterion for those -ideally- exceptional cases a recognisable reasons approach, which requires the patient to demonstrate to the assessor of competence, usually the health care professional in charge of treatment, that -and why- his choice is accountable in light of his personal values and perspective on life and death. 
As to its practical implications, the combination of the discussed legitimate triggers and the recognisable reasons approach, as visualised in Figures $\mathrm{E}, \mathrm{C}$ and $\mathrm{K}$, resembles the sliding scale for competence assessment. However, in comparison with the sliding scale, the model defended by the author has the triple advantage -firstly- of being more consistent, in that it does not pretend to be a test of competence when such a test is actually not the matter, -secondly- of being more protective, in that it includes an additional professional safeguard in cases where the sliding scale would make no demands on patient competence worthy of mention, and -thirdly- of being more instructive, in that it supplies the assessor with further guidance if a test of competence must indeed take place. 


\section{ABSTRACT}

Where there's a will there's a way!

But where's the way of the will?

Lambik in Vandersteen (1979, p. 12)

Criteria for assessment of patient competence: a conceptual analysis from the legal, psychological and ethical perspectives

Patient competence is a pivotal element of the informed consent doctrine, where it helps to balance the principles of autonomy and beneficence; with that, it potentially plays an important role in health care practice too. Therefore patient competence forms the subject of this multi-disciplinary study. Starting from a task-specific conception of the concept, we attempt to formulate criteria for assessing it and for determining whether one ought to have a representative decide in the patient's stead. Now that neither the relevant literature, nor the health care professionals involved apparently succeed in handing unambiguous and valid criteria, the dissertation tries an analysis of the problematic nature of the concept. After the explicit pointing out of the patient's subject and values as underlying norms and after a brief sketch of the epistemological and ontological dimensions that can be distinguished in relation to these values, a systematic argument is put forward on both positive legal and philosophical grounds. This argument implies that competence assessment with a view to taking away decisional power from the patient, should be reserved for specific exceptional cases and that the best way to assess competence in those cases is provided by the so-called recognisable reasons approach. In other cases, the efforts should not be directed at answering the procedural question Who decides?, but at answering the substantial question What is good care?. 


\section{UITTREKSEL}

Waar een wil is, is een weg!

Maar waar is de weg van de wil?

Lambik in Vandersteen (1979, p. 12)

Criteria voor de beoordeling van wilsbekwaamheid: een begripsmatige uiteenzetting vanuit juridisch, psychologisch en ethisch perspectief

Wilsbekwaamheid is een centraal element in de informed-consentdoctrine. Het zorgt voor een evenwicht tussen het beginsel van zelfbeschikking en dat van weldoen, waardoor het ook in de praktijk van de gezondheidszorg mogelijk een belangrijke rol speelt. Daarom vormt wilsbekwaamheid het onderwerp van dit multidisciplinaire onderzoek. Uitgaand van een taakspecifieke opvatting van het begrip, trachten we criteria op te stellen voor de beoordeling van wilsbekwaamheid, op grond waarvan bepaald kan worden of een vertegenwoordiger in plaats van de patiënt moet beslissen. Nu noch de relevante literatuur, noch de betrokken hulpverleners heldere en geldige criteria lijken aan te reiken, wordt in dit proefschrift de problematische aard van het begrip aan een analyse onderworpen. Nadat uitdrukkelijk het subject en de waarden van de patiënt als onderliggende normen zijn geïdentificeerd, en nadat de epistemologische en ontologische dimensies die in verband met deze waarden onderscheiden kunnen worden, kort geschetst zijn, geeft de auteur een redenering op zowel positiefrechtelijke als filosofische gronden. Deze redenering behelst dat de beoordeling van wilsbekwaamheid met de bedoeling beslissingsbevoegdheid aan de patiënt te ontnemen, beperkt moet blijven tot specifieke uitzonderlijke gevallen, en dat de beste manier om wilsbekwaamheid in die gevallen te beoordelen wordt geleverd door de zogeheten "recognisable reasons"-benadering. In andere gevallen moet men de inspanningen niet richten op het beantwoorden van de procedurele vraag Wie beslist?, maar op het beantwoorden van de inhoudelijke vraag Wat is goede zorg?. 


\section{DANKWOORD}

Naast de in de Preface (p. v) genoemde instanties en haar medewerkers wil ik hier graag in het bijzonder de volgende mensen persoonlijk bedanken:

promotor Frans, voor de verwerving van het OIO-project "Wils(on)bekwaamheid: criteria, procedures, consequenties", voor mijn aanstelling daarop, voor de vervolgens gekregen vrijheid om het onderzoek volledig naar eigen inzicht in te vullen, en voor je finishing touch;

promotor Jos, voor de lezing van teksten, voor je openhartige kritiek en nuttige tekstuele commentaar, en voor je praktische adviezen;

promotor Guy,

voor je belangstelling voor de richting waarin mijn onderzoek zich heeft ontwikkeld, voor de zijden draad aan mijn academische loopbaan na afloop van de aanstelling bij de sectie gezondheidsrecht, en voor de zo geboden ruimte -niet alleen figuurlijk, maar ook letterlijk- om het proefschrift af te schrijven;

voorzitter en overige leden van de beoordelingscommissie

Guido de Wert, Hans Crombag,

Pieter Ippel,

Johan Legemaate en

Frans Verhey,

voor uw bereidheid om deel uit te maken van de beoordelingscommissie en om mijn niet altijd even toegankelijke manuscript door te nemen;

medeauteurs Ron Berghmans \& Herman Nys,

voor de prettige samenwerking en voor jullie informele steun;

Ruud ter Meulen, voor de financiering van de eerder genoemde zijden draad; Rein Vos,

voor het toelaten van een vreemde eend in de afdeling; 
Arnold van Alphen, voor het onderhouden van m'n e-mailaccount en werkplek;

Halime Çelik \& Angelique Heijnen, voor het verschaffen van toegang tot het universiteitsgebouw buiten kantooruren;

Bart Penders, voor je tips met betrekking tot soft-\& hardware en voor het delen van je inzicht in de politiek van proefschrift-stellingen;

Hellen Heutz, voor de vlotte en doeltreffende afhandeling van correspondentie met de beoordelingscommissie;

Ingrid Lathouwer, voor het beroep dat ik altijd kon doen op je copieerkaart;

Rob Houtepen, Clint Eastwood, Diogenes van Sinope \& Sokrates, voor jullie voorbeeldige eigenwijsheid;

Johann Sebastian Bach, Thelonious Monk, James Brown, Ralf Hütter und Florian Schneider, Bernard Sumner, Peter Hook, Ian Kevin Curtis \& Stephen Morris, voor jullie heilzame klanken;

mijn moeder en mijn vader zaliger, voor jullie stimulerende opvoeding gericht op waarheid, goedheid en schoonheid;

Jos,

voor te veel om op te noemen, onder andere de inleiding in de wijsbegeerte halverwege de jaren ' 80 van de vorige eeuw, het attenderen op de vacature voor het OIO-project, de vliegende start hiervan samen op weg naar Madrid in december 1994, het diner met Chuck Culver in Fort Lauderdale, en je onmisbare hulp in Fort Calhoun bij het drukklaar maken van dit boekje; Linda,

for your Texan hospitality in Nebraska;

Lodewiek en Père, voor de frequente opvang van de kinderen, waardoor ik meer tijd had om te schrijven;

Isabelle \& Frédérique, voor jullie begrip dat ik 's avonds minder vaak heb kunnen voorlezen dan gewenst; en

Bien,

voor het geduldig verdragen van het lange promotietraject en voor jouw goede zorg (vgl. 1 Kor 13, 7). 


\section{CURRICULUM VITAE}

Sander Welie was born in Cadier en Keer, The Netherlands, on the $10^{\text {th }}$ of April 1969. He attended gymnasium B at Jeanne d'Arc school in Maastricht (1980-1986; final exam summa cum laude, kleine Karlspreis Stadt Aachen). Then he studied law (J.D.) at the University of Maastricht (1986-1990; thesis prize Stichting Wetenschapsbeoefening), and psychology (M.Psy.) and philosophy at the Catholic Radboud University Nijmegen (1989-1995; propaedeutic exam cum laude, master's exam with distinction).

In 1995 Welie started working as a researcher at the University of Maastricht (first at the department of health law, later at the department of health care ethics and philosophy), where he has taught in the Faculty of Health Sciences, the Faculty of Law and the Faculty of Medicine.

Through the years, he has participated in several European research projects (DMIC, EBEPE, EPICC), acted as a guest reviewer for "Medicine, Health care and Philosophy - a European Journal", served as a member of two Ethics Committees, and chaired two Statutory Complaint Committees. He has also taken care of various post-academic courses in law and/or ethics (PAOG, HAIO, HOVO, RINO, AVG, NOMET), lectured in The Netherlands and abroad, and published in international and Dutch journals. Furthermore, he has advised Atrium Medical Centre (Heerlen), the Ministry of Health, Welfare and Sports (The Hague), the National UNESCO Commission (The Hague), the Faculty of Psychology (Maastricht), the Central Committee on Research involving Human Subjects (The Hague), the Netherlands' Society of Physicians for People with Intellectual Disabilities (Rotterdam), and the Dutch Professional Association of Psychologists (Amsterdam) in specific matters.

As of 2005, Welie is legal counsel at the National Foundation of Patient Advocates in Mental Health Care, in Utrecht. He is currently a member of the editorial staff of "Maandblad Geestelijke volksgezondheid". He takes a scholarly interest in issues at the intersection of law, psychology and philosophy, such as epistemology, research methods \& philosophy of science, ethics \& anthropology, the therapeutic relationship, clinical \& legal decision-making, dispute resolution, juridification, legal theory, responsibility and human rights. His personal interests concern music and architecture. 


\section{STELLINGEN}

Stellingen behorend bij het proefschrift "Criteria for assessment of patient competence: a conceptual analysis from the legal, psychological and ethical perspectives"

1. De centrale opdracht aan de hulpverlener is zich erin te verdiepen welke zorg de patiënt echt wil (dit proefschrift).

2. Het gangbare gezondheidsrechtelijke discours over wilsbekwaamheid impliceert ten onrechte een zelfbeschikkingsplicht in plaats van een zelfbeschikkingsrecht (dit proefschrift).

3. Naast criteria om de vraag te kunnen beantwoorden of een patiënt wilsbekwaam is, zijn er criteria nodig om deze vraag überhaupt te mogen stellen (dit proefschrift).

4. De vele bevoegdheden die de wet toekent aan de hulpverlener ten opzichte van patiënt en mogelijke vertegenwoordiger, maken van de hulpverlener feitelijk een "supervertegenwoordiger" (dit proefschrift).

5. Minstens zo belangrijk als kennis van het geldend recht is voor de rechtswetenschappelijke competentie het vermogen kritisch te reflecteren op strekking en werking daarvan.

6. De onevenredige nadruk op statistiek en kwantificerende onderzoeksmethodologie in de hedendaagse onderwijscurricula van mens-en maatschappijwetenschappen duidt op een collectieve onderwaardering van het menselijk zielsleven als bron van relevante informatie.

7. Hoger-onderwijsbeleid gericht op het opleiden van een beperkt aantal gediplomeerden die veel van de stof begrijpen, dient leerling -en op de lange termijn ook samenleving- beter dan beleid gericht op het opleiden van veel gediplomeerden die de stof slechts in beperkte mate begrijpen. 
8. "Het toevoegen van stellingen die over het onderwerp van het proefschrift gaan, ${ }^{1}$ bevordert academisch grasduinen in plaats van diepgraven" (Anonymus, 2008). ${ }^{2}$

9. Mensen die stellen dat de waarheid niet bestaat, verdienen evenveel wantrouwen als mensen die haar in pacht denken te hebben.

10.In het land der éénogen zit twééoog in het gekkenhuis.

Sander P.K. Welie, 2008

${ }^{1}$ Artikel 22 lid 4 tweede volzin Promotiereglement Universiteit Maastricht (versie d.d. 12 mei 2003):

"Vier stellingen dienen betrekking te hebben op het onderwerp van het proefschrift."

${ }^{2}$ Vergelijk: "Een promotieplechtigheid moet, zolang ze nog onvermijdelijk blijft, door alle betrokkenen met gepaste ernst worden verdragen" (Jos Kunst, 1978 zie http://www.joskunst.net). 